\title{
USE OF GIS MODELLING IN ASSESSMENT OF FORESTRY LAND'S POTENTIAL IN THUA THIEN HUE PROVINCE OF CENTRAL VIETNAM
}

\author{
Dissertation \\ zur Erlangung des Doktorgrades \\ der Mathematisch-Naturwissenschaftlichen Fakultäten \\ der Georg-August-Universität zu Göttingen
}

\author{
vorgelegt von \\ Nguyen Van Loi
}

Aus Namdinh, Vietnam

Göttingen 2008 
Referent: Prof. Dr. Martin Kappas

Korreferent: Prof. Dr. Gerhard Gerold

Tag der mündlichen Prüfung: Juni 2008

Author:

Nguyen Van Loi

Remote Sensing and GIS, M.Sc. 


\section{Abstract: Use of GIS Modelling in Assessment of Forestry Land's Potential in Thua Thien Hue Province of Central Vietnam.}

Land suitability assessment is a prerequisite for sustainable forestry production. It involves simultaneous consideration of geo-morphological and ecological factors and environmental and socio-economic aspects in order to produce land potential maps for development of forestry production. These factors and remotely sensed data have been integrated through GIS modelling to define potential areas and identify better and more suitable places for predetermined forest trees.

Three sets of Landsat ETM+ data acquired on 31 January and 24 April 2003 and 7 April 2004 were used in this research. An ISODATA unsupervised classification was performed based on fusion data from a composite image of the bands ETM3, ETM4 and ETM5 with panchromatic band. Using this output, available secondary data together with field data in order to perform a Maximum Likelihood supervised classification. Six classes of forestland were classified, namely dense forest, degraded forest, forest plantation, grass, shrub and barren land. The overall accuracy for this classification is $84.6 \%$ and Kappa index of Agreement is $82 \%$. The individual forest classes show a producer's accuracy above 73 \% and a user’s accuracy above $75 \%$.

The suitability assessment for forestry use and each tree species was conducted using the method described in FAO guidelines for land evaluation for forestry (FAO, 1984). The assessment process was partly modified for fitting particular tree conditions inside Vietnam. All derived data were integrated into GIS and a Weighted Linear Combination Method was used, to combine factors consisting of climate, soil property, topography, vegetation and their impacts to express land suitability for the land potential. The result is a comprehensible map that shows an area of 365,891 ha suitable for forestry production. Furthermore, the entire area was divided into high potential, medium potential, low potential and very low potential. Besides, an assessment of land suitability related to special tree requirements and determination of possible areas for new forest plantation also were developed under forestland management practices in Vietnam. 


\section{Abstract: Use of GIS Modelling in Assessment of Forestry Land's Potential in Thua Thien Hue Province of Central Vietnam.}

Die Bewertung der Eignung von Landoberflächen ist eine Voraussetzung für die nachhaltige Forstwirtschaft. Dieser Prozess umfasst die gleichzeitige Betrachtung von geomorphologischen, ökologischen und sozio-ökonomischen Aspekten um Karten der potenziellen Landnutzung für die Planung in der Forstwirtschaft zu erstellen. Die genannten Faktoren wurden auf räumlichexpliziter Ebene zusammen mit Fernerkundungsdaten in einem Geographischen Informationssystem (GIS) verarbeitet um potenzielle und besser geeignete Flächen für bestimmte Baumarten im Waldbau auszuweisen.

Die Datenbasis der Fernerkundungsdaten besteht aus drei Aufnahmen des Sensors Landsat ETM+ vom 31 Januar 2003, 24 April 2003 und vom 7 April 2004. Die Kartierung der Landbedeckung wurde aus diesem Datensatz mit Hilfe eines kombinierten Ansatzes der digitalen Klassifikation durchgeführt. Zunächst wurde eine unüberwachte Cluster-Bildung (ISODATA Klassifikation) durchgeführt. Das Resultat der Cluster-Bildung diente Felddaten und Sekundärdaten als Eingangsdatensatz für die überwachte Klassifikation (Maximum Likelihood). Insgesamt wurden sechs Landbedeckungsklassen ausgewiesen (dichter Wald, degradierter Wald, Forstflächen, Grassland, Buschland, Ödland). Die Genauigkeit der Kartierung beträgt 84,6 \% (overall accuracy) bzw. 82 \% (Kappa Index). Die einzelnen Waldklassen weisen Genauigkeiten von jeweils über 73 \% (producers’ accuracy) bzw. über 75 \% (users’ accuracy) auf.

Die Landbewertung für forstliche Nutzung allgemein und den Anbau bestimmter Baumarten im Speziellen wurde auf Basis der FAO Richtlinien für die Landevaluierung in der Forstwirtschaft (FAO, 1984) durchgeführt. Der Bewertungsprozess wurde angepasst auf spezifische Baumarten und Standortansprüche für Vietnam. Alle erstellten Datenebenen wurden im GIS mit einer linearen Gewichtung kombiniert. Das Resultat waren räumlich explizite Informationsebenen der Umweltfaktoren Klima, Boden, Topographie und Vegetation und deren Einfluß auf die Eignung von Land für die Forstwirtschaft. Das Gesamtergebnis der Untersuchung ist dargestellt in Form einer umfangreichen Karte und weist ein Gebiet von 365,891 ha Größe für die potentielle Bewirtschaftung aus. Darüber hinaus wurde das gesamte Untersuchungsgebiet in Flächen hoher, mittlerer geringer und sehr geringer Eignung unterteilt. Außerdem wurde eine Landbewertung für bestimmte, im kommerziellen Waldbau in Vietnam vorherrschende Baumarten durchgeführt. 


\section{Acknowledgements}

During my PhD study at department of Cartography, GIS and Remote Sensing of Geographical institute of Goettingen University. I received support from the many people. This thesis is the most important product of my $\mathrm{PhD}$ research work. It would not have been finished without the helps and cooperation of many individuals and organizations. I wish to express here my sincere thanks to them all.

First of all, I would like to express my deep appreciation to my supervisor, Professor. Dr. Martin Kappas, who guided me in my research work by providing intellectual advices. His valuable comments have been most helpful in improvement of this thesis.

I would like to express my sincere gratitude to Dr. Stefan for discussions, suggestions and occasional technical support at various stages of this study. I am very much thankful to all departments who provided my knowledge. My thanks are expressed to Catrin Collatschny for helping me with the proof reading of the thesis script.

I would like to express my wholeheartedly acknowledge to the Government of Vietnam for providing full financial support, together with research subsidy support by the DAAD (German Academic Exchange Service).

Field work have been impossible without the supports of district forest officers in Thua Thien Hue province, several staff members and students of forestry faculty helped me to collect field data and soil science department of Hue University of Agriculture and Forestry for providing soil property information as well as valuable ideas of land potential assessment.

I am very much indebted to the University of Maryland, USA, Department of Rural and Agricultural Development, Department of Science and Environment and Institute of Forest Inventory and Planning, Thua Thien Hue province and Institute of Geography, Vietnam for providing satellite images, the relevant maps and information.

Finally, I expressed my deepest gratitude to my parents. I would also like to thank my wife, brother and sister for giving all the moral support love and best wishes. 


\section{Contents}

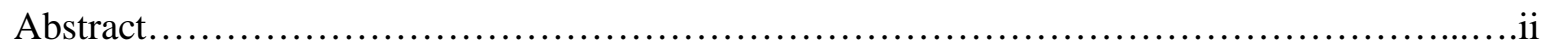

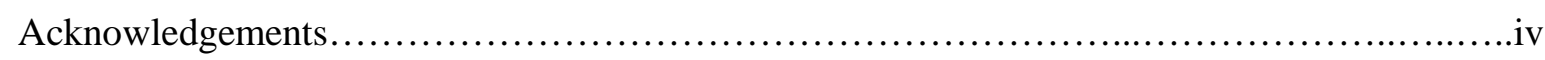

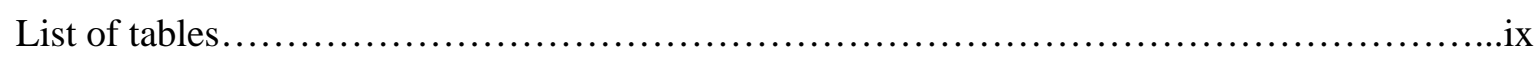

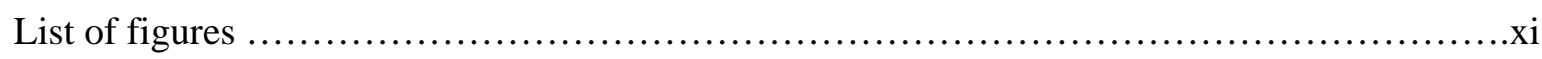

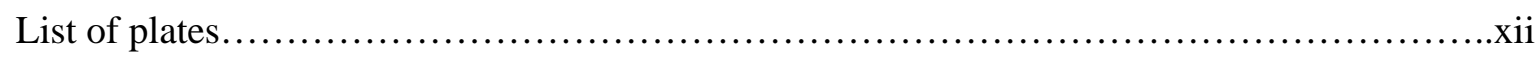

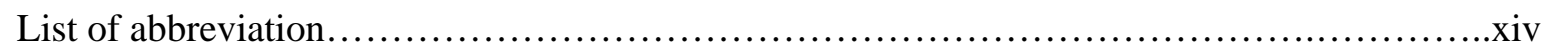

\section{Chapter 1. Introduction}

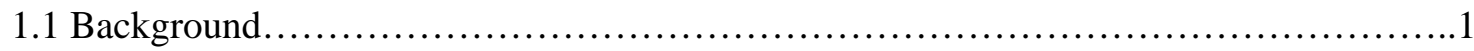

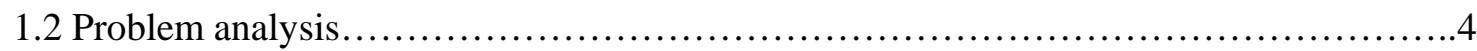

1.3 Aim and objectives of the research..............................................

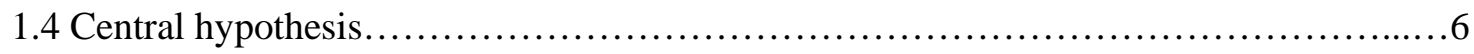

1.5 Structure of the thesis..........................................................

\section{Chapter 2. Methodical Background}

2.1 Definitions of land evaluation for forestry.....................................

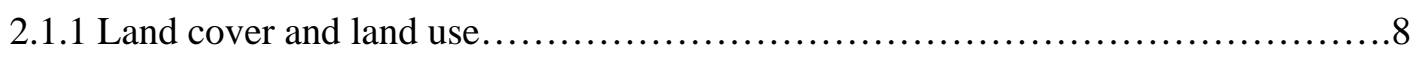

2.1.2 Land evaluation and FAO framework for evaluation..........................9

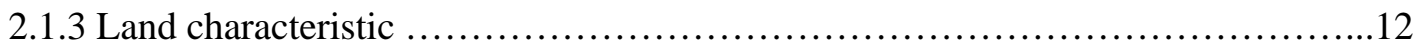

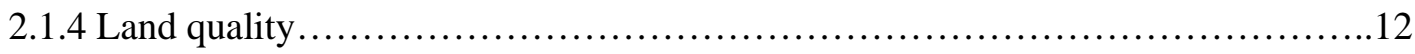

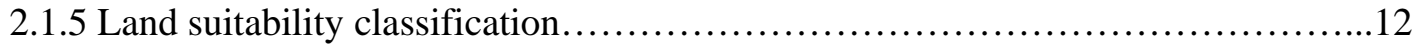

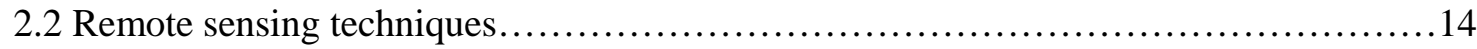

2.2.1 Remote sensing technique for forest and land cover mapping...................14

2.2.2 Classification issues...................................................17

2.2.3 Consideration for classification accuracy assessment...........................18

2.2.3.1 Considerations about Kappa Statistics or K (KHAT).....................20

2.2.3.2 Sampling design considerations.....................................20

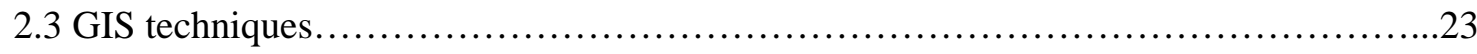

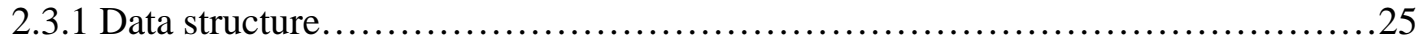

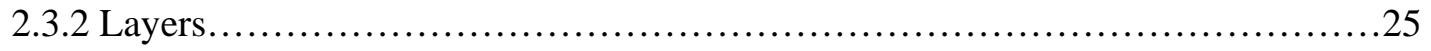

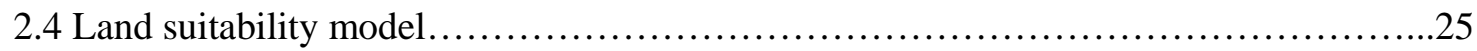




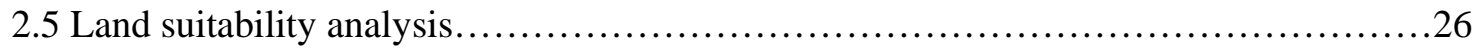

2.6 Integration of remote sensing and GIS for land resources analysis....................28

\section{Chapter 3. Characteristics of Study Area}

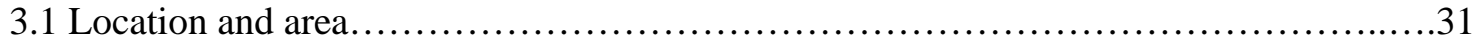

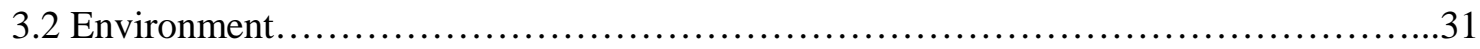

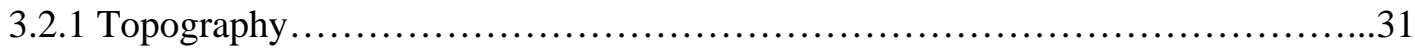

3.2.2 Geology ........................................................... 34

3.2.3 Climate........................................................... 34

3.2.3.1 The weather and climate...........................................34

3.2.3.2 Climatic zones in Thua Thien Hue province.............................39

3.2.4 Forest soil.............................................................. 42

3.2.4.1 Main features of soil types found on forestlands............................42

3.2.4.2 Current status of forest soils and their potentials for forest development........50

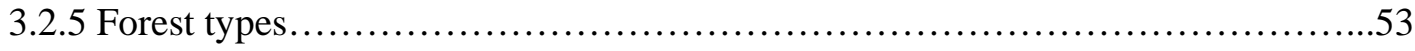

3.2.5.1 Forest types based on the major purpose of utilization......................53

3.2.5.2 Forest types based on the forest origin..................................54

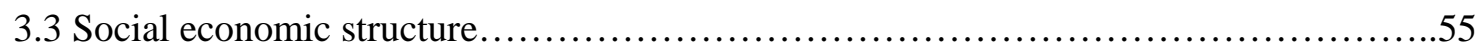

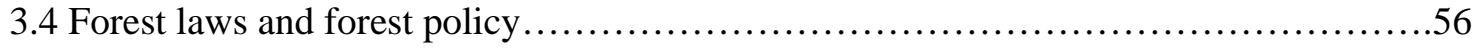

\section{Chapter 4. Data, Tools and Fieldtrip}

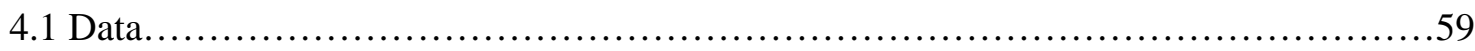

4.1.1 Satellite data............................................................ 59

4.1.2 Arial photographs......................................................64

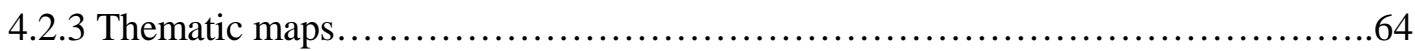

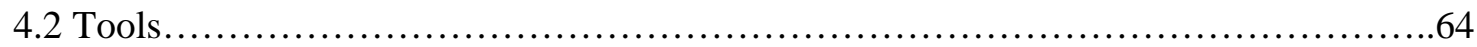

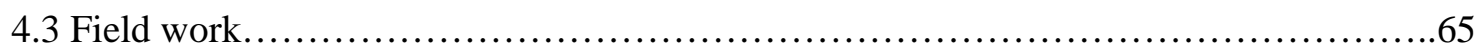

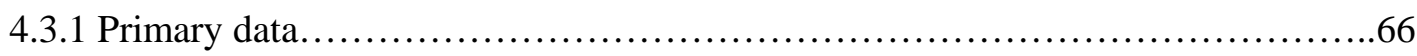

4.3.2 Secondary data.......................................................67

\section{Chapter 5. Landsat ETM + Processing}

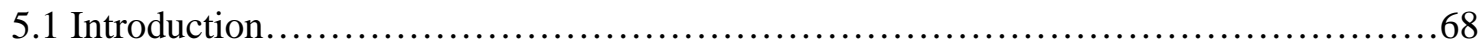

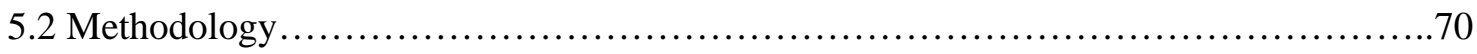

5.2.1 Data acquisition and collection........................................ 72

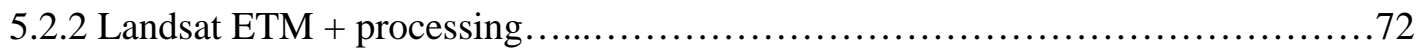




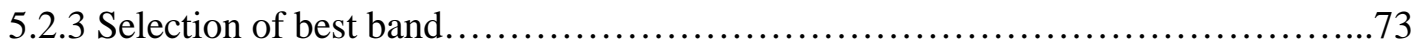

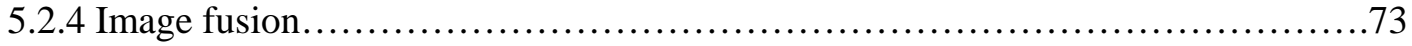

5.2.5 Landsat ETM + classification...........................................74

5.2.5.1 Unsupervised classification............................................ 74

5.2.5.2 Supervised classification......................................... 75

5.2.5.2.1 Selection of training samples for image classification ...................75

5.2.5.2.2 Maximum likelihood classification................................80

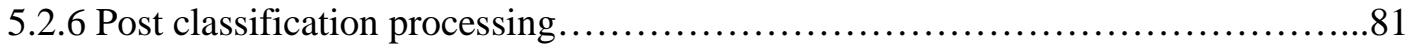

5.2 .7 Accuracy assessment................................................... 81

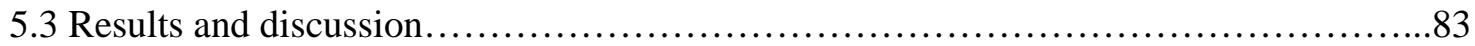

5.3.1 Selection of best band................................................... 84

5.3.2 Maximum Likelihood supervised classification...............................84

5.3.2.1 Visual interpretation and training sample................................ 84

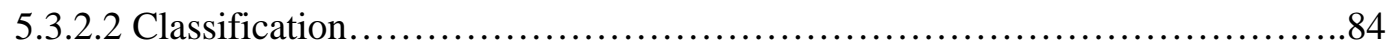

5.3 .3 Land cover classification map......................................... 85

5.3.3.1 Dense forest................................................... 90

5.3.3.2 Degraded forest.................................................92

5.3.3.3 Forest plantation.................................................... 93

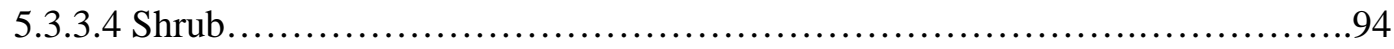

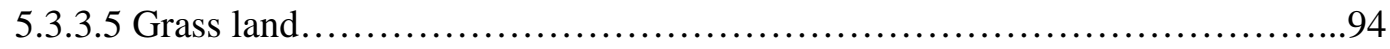

5.3.3.5 Barren land ........................................................ 95

5.3.3.6 Other land..................................................... 95

5.3.3.7 Accuracy assessment...........................................95

5.4 Conclusion..............................................................97

\section{Chapter 6. Land Potential Productivity Assessment for Forestry Use}

6.1 Introduction.............................................................. 99

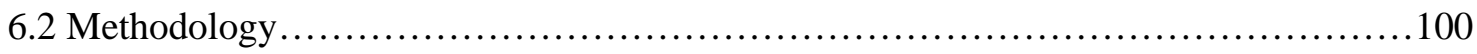

6.2.1 Determination of factors and variables and database development...............100

6.2.1.1 Soil property factor................................................ 100

6.2.1.2 Topographic factor...................................................

6.2.1.3 Climatic factor..................................................... 104

6.2.1.4 Vegetation factor................................................. 105

6.2.2 Determination of weights of factor and variables........................... 105 


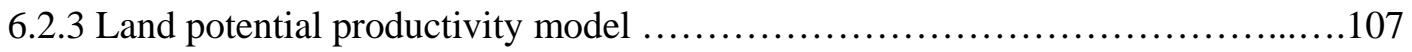

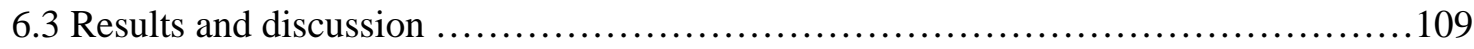

6.3.1 Provisional land potential productivity assessment ..........................109

6.3.1.1 Assessment of soil property factor......................................109

6.3.1.2 Assessment of climatic factor ..........................................115

6.3.1.3 Assessment of topographic factor ...................................117

6.3.1.4 Assessment of vegetation factor..................................... 120

6.3.2 Final land potential productivity assessment................................120

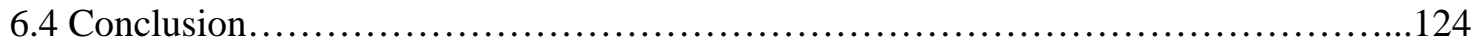

\section{Chapter 7. Land Potential Suitability Assessment for Forest plantation}

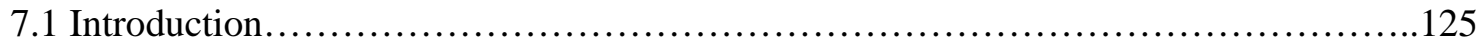

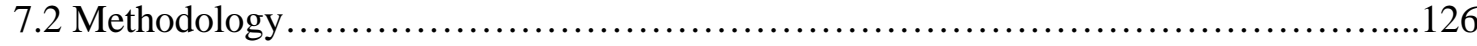

7.2.1 Selection of the forest tree species.......................................126

7.2.2 Determination of ecological parameters.......................................129

7.2.3 Determination of classes for each ecological parameter........................133

7.2.4 Procedure of weight and score of land suitability for selected tree species..........135

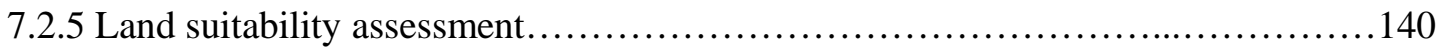

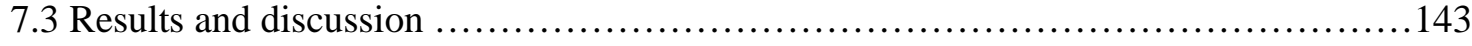

7.3.1 Provisional land suitability assessment...................................... 143

7.3.1.1 Physical land suitability assessment.....................................143

7.3.1.1.1 Assessment of land suitability for two Pine species.......................143

7.3.1.1.2 Assessment of land suitability for four Acacia species....................147

7.3.1.1.3 Assessment of land suitability for Casuarinas species.....................152

7.3.1.2 Assessment of land suitability for economic forestry (production forest)........154

7.3.1.3 Assessment of land suitability for environmental forestry (protection forest)...157

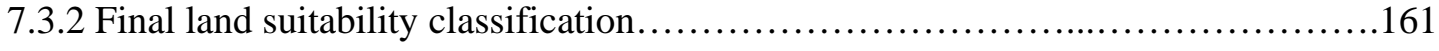

7.3.3 Selection of possible land areas for new forest plantation.......................163

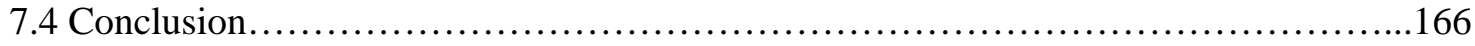

\section{Chapter 8. General conclusions and recommendation}

8.1 Conclusions...................................................................... 167

8.2 Recommendation for further research.......................................... 
References.

Appendix 1: Plates- The forest and land cover types of the study area.....................190

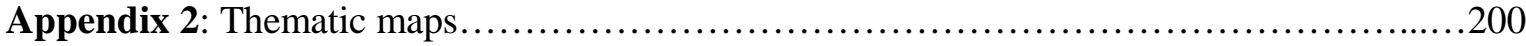

Appendix 3: Pair-wise comparison matrix of all parameters over complete hierarchy.........203

\section{List of tables}

Table 1.1: Vietnam's forest cover throughout different period 4

Table 3.1: Climate at different elevations in Thua Thien Hue province (1996 - 2006) 36

Table 3.2: Temperature $\left({ }^{0} \mathrm{C}\right)$ in months at different elevations in Thua Thien Hue province (1996 -2006)

Table 3.3: Annual rainfall (mm) in months at different elevations 37

Table 3.4: The chemical properties of yellowish brown soils on old alluvia 43

Table 3.5: The chemical properties of yellowish red soil on acid magma rock 44

Table 3.6: The chemical properties of yellowish red soils on sandstone 45

Table 3.7: The chemical properties of yellowish red soil on metamorphic rock 45

Table 3.8: The chemical properties of thin layer soil 46

Table 3.9: The chemical properties of alluvial soils on river areas 46

Table 3.10: Chemical properties of inland sandy soil group 48

Table 3.11: Current status of forest soils in the study area 50

Table 3.12: Forest types in Vietnam 53

Table 3.13: Distribution of population for eight districts and Hue city 56

Table 3.14: National policies impacting forestry activities in Thua Thien Hue province 57 (1991-2006)

Table 4.1: Landsat ETM + wavelength and its applications 60

Table 5.1: Characteristic of Landsat ETM+ data 72

Table 5.2: Identification and description of training samples for forest and land cover type $\begin{array}{ll}\text { in Thua Thien Hue province (visual interpretation). } & 78\end{array}$

Table 5.3: Correlation matrix of Landat ETM+ for the study area 84

Table 5.4: Forest and land cover areas and percentage area of Thua Thien Hue province based on the classified image

Table 5.5: Error (or confusion) matrix of the Maximum Likelihood clustering method of land cover classification

Table 6.1: Weight for factors and variables 106

Table 6.2: Score of each variable category for land potential productivity assessment 
Table 6.3: The level of land potential productivity

Table 6.4: Distribution of forestland with different depth classes

Table 6.5: Distribution of forest land with different soil texture

Table 6.6: Distribution of forest land with different organic matter

Table 6.7: Distribution of forest land with different soil $\mathrm{pH}$

Table 6.8: Potential productivity level of soil fertility condition for forestry use

Table 6.9: Potential productivity level of soil property factor for forestry use

Table 6.10: Potential productivity level of climatic factor for forestry use

Table 6.11: Distribution of forest land with different elevation

Table 6.12: Distribution of forest land with different slope

Table 6.13: Potential productivity level of topographic factor for forestry use

Table 6.14: Land potential productivity level for forestry use

Table 7.1: Attributes of tree species for economic forestry (production forest)

Table 7.2: Attributes of tree species for environmental forestry (protection forest)

Table 7.3: List of selected tree species function for assessment of forest plantation potential

Table 7.4: Weights of ecological parameters in land suitability assessment

Table 7.5: Parameters for determination of suitable classes for growing selected tree species

Table 7.6: Land suitability classes

Table 7.7: Scenarios for the land suitability classification

Table 7.8: Conversion of the land suitability classes

Table 7.9: Land suitability class for two selected pine species

Table 7.10: Land suitability class for four selected Acacia species

Table 7.11: Land suitability class for Casuarinas species

Table 7.12: Land suitability for economic forestry (production forest)

Table 7.13: Land suitability for environmental forestry (protection forest)

Table 7.14: Land suitability for selected tree species

Table 7.15: The possible area for establishment of new forest plantation 


\section{List of figures}

Figure 2.1: Illustrates the steps necessary for performing a land suitability model 27

Figure 3.1: Location of the study area 32

Figure 3.2: The boundaries of districts and Hue city, Thua Thien Hue province 33

Figure 3.3: Geological map of the study area 35

Figure 3.4: Climatic diagram of Hue city (10 metres) showing monthly temperature and rainfall (1996-2006) 38

Figure 3.5: Climatic diagram of Namdong (60 metres) showing monthly temperature and rainfall (1996-2006) 38

Figure3.6: Climatic diagram of Aluoi (572 metres) showing monthly temperature and rainfall (1996-2006)

Figure 3.7: Sub-climate zones of the study area $\quad 40$

Figure 4.1: Landsat ETM + image subset of 31 January 2003, RGB 345

Figure 4.2: Landsat ETM + image subset of 24 April 2003, 28.5 m (band 3,4,5) fused with $14.5 \mathrm{~m}$ Panchromatic data 62

Figure 4.3: Landsat ETM + image subset of 7 April 2004, RGB 345

Figure 4.4: The flowchart of data collection during field survey 66

$\begin{array}{ll}\text { Figure 5.1: The flowchart of Landsat ETM + image processing } & 71\end{array}$

$\begin{array}{ll}\text { Figure } 5.2 \text { a: PAN image } & 74\end{array}$

$\begin{array}{ll}\text { Figure } 5.2 \text { b: Colour composite image }(4,5,3) & 74\end{array}$

Figure 5.2 c: 28.5 meter ETM+ data (bands 4, 5, 3) fused with 14.5 meter PAN data $\quad 74$

$\begin{array}{ll}\text { Figure 5.3: ISODATA unsupervised classification } & 76\end{array}$

Figure 5.4: Three different False Colour Composite (FCC) combinations 77

Figure 5.5: Maximum likelihood classification of Thua Thien Hue province 86

Figure 5.6: Land cover map of different forest types of Thua Thien Hue Province 87

Figure 5.7: Comparison between the 1998 map and the Landsat ETM+ classification 90

Figure 5.8 a: The montane closed evergreen sub-tropical monsoon forest, 1,250 m a.s.l 91

Figure 5.8 b: The closed evergreen tropical monsoon forest, $750 \mathrm{~m}$ a.s.l 91

Figure 5.9 a: The secondary forest, $350 \mathrm{~m}$ a.s.l 92

Figure 5.9 b: The young secondary forest, $300 \mathrm{~m}$ a.s.l 92

Figure 5.10: Different kinds of forest plantation 93

$\begin{array}{ll}\text { Figure 5.11: Shrub land } & 94\end{array}$

Figure 5.12: Grass land $\quad 95$ 
Figure 6.1: The general flow of the land potential productivity assessment for forestry use 108

Figure 6.2: Potential productivity classification for soil property factor 114

Figure 6.3: Potential productivity classification for climatic factor 116

Figure 6.4: Potential productivity classification for topographic factor 119

Figure 6.5: Potential productivity classification for vegetation factor 122

Figure 6.6: Land potential productivity classification for forestry use 123

Figure 7.1: Hierarchical organization of the parameter considered for assessing physical $\begin{array}{ll}\text { land potential suitability for selected tree species } & 136\end{array}$

Figure 7.2: Process steps of land suitability analysis for forest plantation 142

Figure 7.3: Physical land suitability for growing Pinus merkussi 145

Figure 7.4: Physical land suitability for growing Pinus caribaea 146

Figure 7.5: Physical land suitability for growing Acacia auriculiformis 148

Figure 7.6: Physical land suitability for growing Acacia mangium 149

Figure 7.7: Physical land suitability for growing Acacia hybrid $\quad 150$

Figure 7.8: Physical land suitability for growing Acacia crassicarpa 151

Figure 7.9: Physical land suitability for growing Casuarina equisetifolia 153

Figure 7.10: Land suitability for economic forestry (production forest) 156

Figure 7.11: Land suitability for environmental forestry (protection forest) 160

Figure 7.12: Final land suitability for forest plantation 162

Figure 7.13: Possible potential land suitability for new forest plantation 165

\section{List of plates}

Plate 1: Montane closed evergreen sub-tropical monsoon forest with Podocarpus imbricatus species, 1,250 m a.s.l., Phuloc district

Plate 2: Montain closed evergreen sub-tropical monsoon forest, 1115 m a.s.l., Nam dong district

Plate 3: Closed evergreen tropical monsoon forest, $600 \mathrm{~m}$ a.s.l., Aluoi district

Plate 4: Closed evergreen tropical monsoon forest, $750 \mathrm{~m}$ a.s.l., Phuloc district 189

Plate 5: Closed evergreen tropical monsoon forest, $400 \mathrm{~m}$ a.s.l., Phongdien district 189

Plate 6: Closed evergreen tropical monsoon forest, $430 \mathrm{~m}$ a.s.l., Huongthuy district 189

Plate 7:Young secondary forest, 1,350 m a.s.l., Phuloc district 190

Plate 8: Secondary forest, $300 \mathrm{~m}$ a.s.l., Aluoi district 190

Plate 9: Secondary forest, 400 m a.s.l., Namdong district 190 
Plate 10: Secondary forest, 300 - $400 \mathrm{~m}$ a.s.l., Huongthuy district

190

Plate 11: Young secondary forest, $200 \mathrm{~m}$ a.s.l., Namdong district

Plate 12: Young secondary forest with older stands in the background, $300 \mathrm{~m}$ a.s.l., Phongdien district

Plate 13: Secondary forest bordered by grass and shrub, $250 \mathrm{~m}$ a.s.l., Phong dien district

Plate 14: Secondary forest bordered Acacia mangium plantation, 250 m a.s.l., Aluoi district

Plate 15: Two views of transition from grass land to short shrub

Plate 16: Two views of short shrub (Rhodomyrtus tomentosa and Melastoma spp.)

Plate 17: Two views of grass land (Sacch spontaneum and Imperata cylindrical)

Plate 18: Two views of land cover mix of grass land and (sparse) Acacia auriculiformis plantation between 100 and $250 \mathrm{~m}$ a.s.l., Huongtra district

Plate 19: Rocky land with short shrub, Aluoi district

192

Plate 20: Eucalyptus camaldulensis plantation, Huongtra district

Plate 21:Young Acacia mangium plantation, Huong Thuy district

Plate 22: Acacia mangium plantation, Huong Tra district

Plate 23: Acacia hybrid plantation, Huongthuy district

Plate 24: Acacia crassicarpa plantation, Huongtra district

Plate 25: Acacia auriculiformis plantation, Aluoi district

Plate 26: Acacia auriculiformis plantation grows in inland sandy soil, Quang dien district

Plate 28: Pinus caribaea plantation, Phuloc district

Plate 29: Casuarina equisetifolia plantation grows in coastal sandy soil, Phuvang district

Plate 30: Young Casuarina equisetifolia plantation grows in low hills, Huongtra district

Plate 32: Maize field

Plate 32: Peanut field

Plate 34: Google earth view of dense forest in forest surroundings, Nom cavern (Dong Nom), 1,186 m a.s.l., Namdong district

Plate 35: Google earth view of dense forest in forest surroundings, Truoi cavern (Dong truoi), 1,154 m a.s.l., Phuloc district

Plate 36: Google earth view of barren land and shrub in surroundings of Nhut cavern (Dong Nhut), Phuloc district

Plate 37: Google earth view of degraded forest in forest surroundings, Mang mount (Nui Mang), 1,712 m a.s.l., Namdong district

Plate 38: Google earth view of Pinus merkussi plantation, 80 m a.s.l., Huongtra district 


\section{List of Abbreviation}

AHP: Analytic Hierarchy Process

a.s.l.: above sea level

AVHRR: Advanced Very High Resolution Radiometer

C: Celsius

FCC: False Colour Composite

DBH: Diameter Beast Height

DEM: Digital Elevation Model

e.g.: for example

ETM+: Enhanced Thematic Mapper Plus

FAO: Food and Agriculture Organisation of the United Nations

GCP: Ground Control Point

GIS: Geographic Information System

GPS: Global Position System

ha: Hectare

HUAF: Hue University of Agriculture and Forestry

IFOV: Instantaneous Field

ISODATA: Iterative Self - Organization Data Analysis

5MHRP: Five million hectare reforestation project.

LAI: Leaf Area Index

LQ: Land Quality

LUR: Land Use Requirement

LUT: Land Utilization Type

MAI: Mean annual increment

MARD: Ministry of Agriculture and Rural Development

MODIS: Moderate Resolution Imaging Spectroradiometer

MSS: Multi-spectral Scanner

NOAA: National Oceanic and Atmospheric Administration

NPK: Nitrogen, Phosphorous, and Potassium

NTFP: Non-Timber Forest Product

OM: Organic matter

PAN: Panchromatic

ppm: Part per million 
RGB: Red, Green, Blue (display colour channels)

RMSE: Root Mean Square Error

RS: Remote Sensing.

SAR: Synthetic Aperture Radar

Spot HRV: SPOT High Resolution Visible Multispectral

TM: Thematic Mapper

UNEP: United Nation Environment Program

UNESCO: United Nations Educational, Scientific and Cultural Organization

UTM: Universal Transverse Mercator

WLC: Weighted Linear Combination 


\section{Chapter 1. Introduction}

\subsection{Background}

Forestry has traditionally been an important industry in Vietnam, and a mainstay to the livelihood of some rural communities. Based on available documents, in 1943, $43 \%$ of the total land area of the country was covered by forests, since that time, especially between 1975 to 1990 forest cover has decreased dramatically from $34 \%$ to $27.2 \%$, but from 1990 to the present, the forest area has been increased gradually, due to reforestation and rehabilitation of natural forest. Based on the official statement in decision No 1970/QD/BNN-KN-LN dated July 6, 2006, the total national forest area is 12.61 million hectares (Table 1.1), with $37 \%$ forest cover. The unused land of the entire country is 6.6 million hectares, of which barren land on hilly and mountainous areas is 6.76 hectares or $18.59 \%$ of the total national area. This barren land will be a potential, but also a challenge for development of forest production in the future, because most of the land is distributed on the slope, degraded and scattered land. The Vietnamese government is attempting to restore forest cover with huge reforestation programs such as program 327 and the five million hectare plantation program. The aim is to reach a forest cover of $43 \%$ in the year 2010 as it was prevailing before 1943 and to increase the ratio of land with forest up to $47 \%$ by 2020.

Table 1.1: Vietnam's forest cover throughout different period (1000 ha)

\begin{tabular}{|l|r|r|r|r|r|r|r|r|r|}
\hline $\begin{array}{l}\text { Forest } \\
\text { type }\end{array}$ & 1943 & 1976 & 1980 & 1985 & 1990 & 1995 & 2000 & 2004 & 2006 \\
\hline $\begin{array}{l}\text { Natural } \\
\text { forest }\end{array}$ & - & $11,076.7$ & $10,016.0$ & $9,308.3$ & $8,430.7$ & $8,252.5$ & $9,444.1$ & 10,088 & 10,280 \\
\hline $\begin{array}{l}\text { Forest } \\
\text { plantation }\end{array}$ & - & 92.6 & 422.3 & 583.3 & 7.444 .9 & $1,047.7$ & $1,471.3$ & $2,218.5$ & 2,330 \\
\hline $\begin{array}{l}\text { Total } \\
\text { area }\end{array}$ & 14,300 & $11,169.3$ & $10,608.3$ & 9891.9 & $9,175,6$ & $9,302.2$ & $10,915.5$ & $12,306.7$ & 12,610 \\
\hline
\end{tabular}

Source: MARD, 2006

Population increased from 27 to 81 million between 1945 and 2003.Vietnam's population is estimated to grow to 100 million by 2020, according to official statistics (GoV, 2005). About 25 million Vietnamese people are living in or near forest and depend for some part of their subsistence on forest resources and Vietnam's forests. These people depend on forest resources for an average $20 \%$ of their total income. The fast growing population with population densities among the highest in Southeast Asia, and the demand for timber and the supply of raw material 
for wood pulp export and paper industry is the key defining factor in forest plantation planning. The wood for export and industry recently come from both forest plantations and natural forests, but increasingly is shifting to forest plantation when the government promulgated the "close the natural forest gate" policy to restrict over-exploitation. These put high pressure on land use stemming from need to expand and intensify forestry production.

Forestry of Thua Thien Hue not only creates forest products as commodities and services contributing to the province economy, but also plays an important role in environmental protection, such as watershed protection, soil and water conservation, and climate regulation, and makes vital contributions to livelihood improvement and poverty reduction for people in the hilly and mountainous areas. Therefore, forestry is a specific technical economic sector, including all activities connected with commodity production and services from the forest, such as reforestation / afforestation, harvesting, transportation, production and processing of forest products, and providing environmental services related to forests; the forestry sector plays a very important role in the protection of the environment, biodiversity conservation, and poverty reduction, particularly for the ethnic minority people in the mountainous, remote and isolated areas (GoV, 2006).

The province has a natural area of 505,339 ha, the forestland area is distributed mainly in the hilly and mountainous area of the entire province. During the two wars against the France and the United States of America, the forests of Thua Thien Hue have degraded heavily to 147,299 thousand ha of natural forest today, containing mostly of poor and medium forest, not sufficient for environmental protection and not providing enough products for consumer needs. The unused land of the entire forest area occupies about $35 \%$ of total natural area of the province. This kind of land will be a potential, but also a challenge for development of forestry production in Thua Thien Hue in the future. Increasing population, wood export and paper pulp create a growing demand for forestry and agricultural land. In addition inappropriate land use leads to a degradation of forest quality and forestland. These can have direct adverse impacts on the forest soil properties, the hydrological system, the entire ecosystem and on the local and regional climate as well as other social problems.

Many provinces of Vietnam like Thua Thien Hue are trying to improve their provincial economies by paper pulp for export. However, there is very little expert knowledge about the best forestry land use, which could lead to undue pressure on the forestland. 
In order to ensure that forestland is not degraded it should be used according to its capacity to satisfy human needs for present and future generations, and also maintain the earth's ecosystems. Part of the solution to the land-use problem is land evaluation in support of rational land-use planning and appropriate and sustainable use of natural and human resources (Rossiter 1996). Land evaluation is process of predicting land performance of over time according to specific land use types (Van Diepen et al., 1991). Land evaluation is concerned with the assessment of land performance for specific land utilization purposes and provides a rational basis for taking land-use decisions, based on the analysis of relations between the land use and land, giving estimates of required inputs and predicted outputs (FAO, 1985; Sys et al., 1991). So, one would expect that land use planners and other decision makers who influence rural land use would be eager to use the results of land evaluation (Bacic et al., 2003).

Geographic Information System (GIS) can be used for input, management and analysis both of biophysical and socio-economic data. GIS can be used for information analysis and spatial modelling incorporating both environmental and socio-economic variables to assess land potential productivity for forestry use. In this regard the GIS based on GIS modelling can play a crucial.

Assessment of land potential is one of many appropriate remote sensing and GIS application. Remote sensing is a tool for survey and inventory of resources, which provides a primary source of up to date geographic data. The existing forest and land cover was derived by multi-date Landsat ETM+ data analysis. The present forest cover is an important information for local foresters and policy makers in land use planning. GIS can be used to facilitate resource management and planning activities within the Thua Thien Hue province. It provides a synthetic and a comprehensive analysis of information in effective land use planning. Furthermore, the spatial data handling capacity of Geographic Information System (GIS) can simplify the preparation and will also be used to develop new approaches to identify best sites for the location of tree species in the province. The final results of land potential assessment are maps, which partitions the landscapes into suitable and not suitable areas for forestry land use. The land suitability could be better expressed by land suitability maps.

With such a background, it becomes very clear that the forestland and its suitability for forestry use is a very important aspect in forestry production. One of the most important aspects of this research is to assess land potential productivity for forestry use and land suitability for development of forest plantation. 


\subsection{Problem analysis}

In many developing countries like Vietnam, especially in Thua Thien Hue province, the population and the pressure on land are ever increasing and current land use systems are not sustainable as they contribute to the problems of land degradation. Considering the ever increasing population in the developing countries, there is an increasing urgent need to match land types and land use in the most rational way possible, so as to maximize sustainable production and to satisfy the diverse needs of society while conserving fragile ecosystem (FAO, 1993).

At present, the forestry production in Thua Thien Hue is facing the problem of encroachment for firewood supply and conversion of forestland to agricultural land. The boundary of different forest resources, forestry land, and agricultural land are not clear.

Development of forestry production means that it has a high potential for poverty Alleviation, rural development and environmental improvement. However, industrialisation, misuse and overexploitation and inappropriate forestry land use have intensified degradation of land resources. The degradation of forestland resource is a major threat that affects the existence and livelihood of the community. The land itself and its soils are an important precondition for forest and down streamed wood production. The soil is a natural resource and at the same time, an important environment contributing to the growth and development of forests and their vegetation. The expansion of forest plantation in unsuitable land has increasingly grown in most parts of uplands and has negative impacts on forestland resources of the province. On the other hand, there is a lack of detailed information about forestry, especially regarding forest and forestland potential for appropriate forestry use. Moreover, assessment of land potential for all kinds of use has done very little, and assessment concerning land potential has not incorporated current forestry land use practices.

From these problems, it is obvious that forestry land use planning has to be adapted. A thorough analysis of land potential and constraints for forestry alternatives is needed before rational decisions can be made. In order to minimize forestry production risks and utilize the forestry land resources in a sustainable way, it is necessary to set up a database and update information, especially to assess land potential productivity and its suitability for forest production. The assessment of forest land potential productivity is also necessary to help the planner in planning land use effectively. Rational land use on forest land will not only provide knowledge for re- 
greening barren lands and environmental protection, but also for economic development in order to enhance forest land's potential. Moreover, knowledge about the earning potential is an urgent condition for proper land use and land protection in the future. Land suitability assessment is concerned with the process of estimating the potential of land for alternative kinds of land use (Dent and Young, 1981). Land suitability has been evaluated from soil, topography, land cover and the interrelationship between soil, landform and vegetation (Allen et al., 1995). However, the multiple variables integrated by one assessment cannot produce accurate and efficient results unless a GIS is used. Geographic Information Systems (GIS) is a powerful tool for collecting, storing, retrieving, transforming and displaying spatial data from the real world (Burrough, 1986). GIS systems have been widely recognized as the most promising tool capable of providing reliable information for both planning and decision-making tasks (Michalak, 1993). Thus GIS has found wide application in assessment of land potential.

Remote sensing is a methodological approach to obtain information about an object, area, or phenomena through the analysis of data acquired by a device that is not in contact with the object, area, or phenomena under investigation. Remote sensing can be used as a tool to gather data sets for use in a GIS context (Wilkinson, 1996).

In this research, environmental data (climate, topography and soil properties), socio-economic data and remotely sensed data were integrated in GIS in order to provide an assessment of land potential productivity for forestry use and the land suitability of the study area for forest tree species. The potential productivity sites and their suitability were derived from GIS modelling based on the stand requirements of single tree species with regard to particular conditions of soil, climate and relief (slope, elevation). These results could also be used as a basic soil-database and play an important role for the use of suitable soil resources and sustainable land management. In addition, assessment of land potential productivity can be produced by a combination between the techniques of remote sensing and field survey in GIS modelling as a new approach in Thua Thien Hue province of Vietnam.

\subsection{Aim and objectives of the research}

The aim of this research is to assess forestland for its productive potential and suitability for forestry interventions, natural regeneration and expansion of forest plantation using remote sensing and GIS through GIS modelling, thereby to contribute to effective land use and land use planning for forestry use. In order to achieve this aim, the following specific objectives are proposed: 
- To map forest and land cover distribution and identify suitable areas for forestry production using Landsat ETM + data, thus contributing to the process of improvement of existing forest resource map and assessment of the forestry land potential in Thua Thien Hue (Chapter 5).

- To develop databases and GIS modelling to assess land potential productivity for forestry use using Weighted Linear Combination Method of environmental factors (Chapter 6).

- To develop a GIS based modelling for land potential suitability assessment for selected forest tree species (Chapter 7).

- To make suggestions for management and rational land use on forestland in Thua Thien Hue province (Chapter 8).

\subsection{Central hypothesis.}

- Remote sensing data analysis is indispensable to map tropical mountain forests. Digital image classification of Landsat ETM+ data can contribute to improve the existing forest and forest map. It can avoid the laborious and meticulous work compared to conventional methods.

- Digital image classification accuracy for mapping the forest and land cover can be improved through image fusion of high resolution panchromatic with medium resolution data of Landsat ETM+.

- Remote sensing and GIS tools provide a suitable set of techniques for assessment of land potential productivity for forestry use and assessment of land suitability for forest tree species within the study area.

- Forest soils in the study area differ significantly in their properties and suitability. There are specific land qualities that differentiate lands into classes of different productivity for forestry land use types.

- It is possible to assess land potential productivity for forestry production that can be predicted through GIS modelling based on socio-economic and environmental factors.

\subsection{Structure of the thesis.}

There are eight chapters in this dissertation. This first chapter provides an overview of the study. It presents the research background and the research problem analysis. It further outlines the aim and objectives of the research. Finally, it gives an overview of the thesis structure. Some of the 
methodical backgrounds are considered in Chapter 2. In chapter 3 an introduction to the study area, item of location, topography, geography, climate, soil, forest types, social economic structure and forest laws and forest policy is given. Chapter 4 specifies the data and tools used. Chapter 5 demonstrates the use of Landsat ETM+ data for mapping forest and land cover. Chapter 6 describes the modelling results for land potential productivity assessment for forestry production, using Weighted Linear Combination Method. Chapter 7 deals with the physical land suitability analysis, the environmental and economic analysis for seven selected forest tree species and selection of possible land areas for the establishment of new forest plantation. And the last chapter, chapter 8 gives the conclusions of the research and makes recommendations for future research. 


\section{Chapter 2. Methodical Background}

\subsection{Definitions of land evaluation for forestry}

\subsubsection{Land cover and land use}

The terms "land cover" and "land use" are often confusing. Land cover is the observed physical and biological cover of the earth's land, as vegetation or man-made feature. In contrast, land use is the total of arrangement, activities, and inputs that people undertake in a certain land cover types (FAO, 1997a, FAO/UNEP, 1999). Therefore, land use and land cover are closely related. Land cover refers to all the natural and human-made features that cover the earth's surface, whereas land use refers to the human activities associated with a specific land unit in terms of use and management practices and impacts (FAO, 1997a).

Land cover is the observed biophysical cover on the earth's surface (FAO, 2000). Land cover in forestry defines a forest in terms of vegetative land cover. An example follows:” An ecosystem characterized by more or less dense and extensive tree cover”. Typically, the cover is assessed as percent crown cover. A distinction may be made between open-and closed canopy forests (FAO, 1999).

Land use is characterized by the arrangements, activities and inputs people undertake in a certain land cover type to produce, change or maintain it (FAO, 1997a).

Land use in forestry defines forests in terms of land use. A typical example follows: "An area managed for the production of timber and other forest products or managed as woody vegetation for such indirect benefits as protection of catchment areas or recreation. Therefore, according to land evaluation for forestry (FAO, 1984), land use is a description of the land forms the most distinctive feature of land suitability evaluation as compared to other approaches. It is the basis for the principle that land suitability can only be assessed with respect to specified kinds of use. Only by describing the potential uses their requirement can be determined as the basis of comparison with the land qualities.

The definition of land use establishes a direct link between land cover and the activities of people in their environment. Generally speaking, land cover does not coincide with land use. A land use class is composed of several land covers.

In this study the emphasis is put on using remote sensing data to provide land cover information for assessment of the forestry land potential. 


\subsubsection{Land evaluation and FAO Framework for land evaluation}

Land evaluation is the process of the assessment of land performance when the land is used for specified purposes involving the execution and interpretation of surveys and studies of landforms, soils, climate, vegetation and other aspects of land in order to identify and compare of promising kinds of land use in terms applicable to the objectives of the evaluation (FAO, 1976).

According to land evaluation for forestry (FAO, 1984), land evaluation is the process of assessment of land performance under specified kinds of land use. It basically consists of the comparison between land and land use, where land refers to all features of the natural environment which can exert a significant influence on the use of land by man. More specifically, land evaluation involves the comparison of the requirements of land use with the qualities possessed by land. This comparison is the basis for predicting the consequences of applying the different land utilization types to each of the mapped land units.

The primary objective of land evaluation is the improved and sustainable management of land for the benefit of the people and the aim of land evaluation is to determine the suitability of land for alternative, actual or potential, land uses which are relevant to the area under consideration. The suitability assessment is based on the productivity, stability and sustainability of land use systems (Huizing et al., 1995). Land evaluation is primarily the analysis of data about the land its soils, climate, vegetation, etc. in terms of realistic alternatives for improving the use of that land. It is focused upon the land itself, its properties, functions and potential (FAO, 2007). However, a lot of land use decisions are made on the basis of socio-economic aspects, hence the principle objective of land evaluation is to collect the optimum land use for each land use type of land, taking into account both physical and socio-economic considerations and the conservation of environmental resources for future use (Rossiter, 2001). Therefore, land evaluation supports many other disciplines. It may be used for many purposes, ranging from land use planning to explore the potential for specific land uses, especially forestry land use or the need for improved forestry land management or forestry land degradation control.

The principles and general approach adopted for land evaluation start with the publication of the FAO Framework for Land Evaluation (1976) and subsequent guidelines for land evaluation of general kinds of land use such as in dry land agriculture (FAO, 1983), forestry (FAO, 1984), irrigated agriculture (FAO, 1985), extensive grazing (FAO, 1991) and steep lands or the hill and mountain areas (Siderius, 1986). The Framework for land evaluation (FAO, 1976) has proved to be one of the most durable and widely used FAO methodologies in evaluation of land resources. 
It has been implemented in a lot of developing countries, including Nigeria (Hill, 1979), Malaysia (Biot et al., 1984), Sri Lanka (Dent and Ridgway, 1986), Bangladesh (Brammer et al., 1988), Jamaica (FAO/UNEP, 1994), Kenya (Fischer and Antoine, 1994), and Thailand (Shrestha et al., 1995).

Based on the objectives of the evaluation, the framework uniformly defines concepts related to land evaluation such as land, land mapping unit, major kind of land use, land utilization type, multiple and compound land use, land characteristics, land qualities, diagnostic criteria, land use requirements, imitations, land suitability, land suitability order, class, subclass, unit and potential suitability classification. Most of principles and concepts of the 1976 framework remain valid. The existing framework is extended with socio-economic procedures developed in the diagnosis and design framework (FAO, 2007).

Land evaluation originated from the need for a comprehensive assessment of land performance when used for different specified purposes. The Framework for Land Evaluation sets out basic concepts, principles and procedures for a systematic biophysical and socio-economic assessment of the potentials for specific land uses likely to be relevant to the area. It provided detail on which factors or land qualities should be considered in the evaluation for different kinds of land uses and how to evaluate these qualities. For purposes of supra-national classification of potential productivity, climate and land resources were combined into agro-ecological zones (FAO 1978a, 1978b, 1980, 1981). FAO (1980) stated that the art of land evaluation is to predict the most important changes, to decide whether these are desirable or acceptable, and thus to categorize the proposed as a wise or unwise use of land. Socio-economic aspects were also dealt with in subsequent guidelines on land evaluation for forestry (FAO, 1984), for agriculture (FAO, 1983, 1985) and for the special conditions of steep lands (Siderius, 1986).

The framework allows to compare or match the requirements of each potential land use with the characteristics of each kind of land (FAO, 1983). Overall land suitability of a specific land area for a specific land use is evaluated from a set of more-or-less independent land qualities, which may each limit the land-use potential (Rossiter and van Wambeke, 1997)

Land evaluation can be done physically and economically. Physical land evaluation is based on physical factors whether a land utilization type can be implemented on an area, the nature and severity of physical limitations or hazards. Economic land evaluation is based on the economic measures of benefits of a specific land utilization. Therefore, land evaluation may be conducted in either physical or economic terms. In physical evaluation, the boundaries between suitability 
classes are defined in terms of land qualities or characteristics. In the original framework, physical evaluations are referred to as qualitative evaluations. Quantified methods require moreor-less detailed models of land performance, and these models usually have high data requirements. Recently, there has been some work comparing quantitative and qualitative assessments of land qualities, using the qualitative models to identify which land areas are worth further investigation with quantitative models, and which areas can be rejected as unsuitable without detailed study (van Lanen et al., 1992a; 1992b). Van Diepen et al., (1991) provided a good review of the historical and current state of land evaluation practice (Rossiter, 1996).

According to Bronsveld et al., (1994), the process of land evaluation could be improved in several ways. Firstly, by involving local users in the plan formulation, so that their preferences and constraints are taken into account. This would include both the assessment of the impact of interventions by market as well as the economic, social and environmental outputs of the implementation of the land use plans. Secondly, using existing data but changing the methods of data processing by the use of more flexible data processing methods. Thirdly, by the optimal use and better integration of the existing data like remote sensed data and field data. Finally, by a clear presentation of land evaluation and land use plans in non-technical terms.

Evaluation of land for forest plantation is not conceptually different from evaluating for agriculture though there is the important practical difference that it is possible to measure productivity without the crop. The natural forest evaluation only serves a practical purpose if the intention is to manage it in some ways. Special feature of land evaluation for natural forests are therefore that the land use types may be related to conservation rather than production, that land use is commonly use, including wood production, conservation, recreation, grazing etc. Land evaluation for forestry without consideration of economical and social aspects is not valuable. Forestland use has the function of bringing benefits to people. It provided directly benefits, such as output of wood products, none forest products, grazing use, water, etc., and intangible benefits such as biological conservation and recreation. Forest land also plays a part in community social life, in patterns of work and leisure. Hence socio-economic analysis in land evaluation clearly has a considerable influence upon the types of land use and management that are most suited to an area (FAO, 1984).

The framework, especially the principles and approach to be adopted for evaluation of forestry were set out land evaluation for forestry (FAO, 1984) and have begun to be used widely in assessment of land potential suitability, establishment of forest plantation or selection of sites for different forest tree species. 


\subsubsection{Land characteristic}

Land characteristic is an attribute of the land that can be measured or estimated and that can be used to distinguish between land units of differing suitabilities for use and employed as a means of describing land qualities. Examples are mean annual rainfall, $\mathrm{pH}$ and soil nitrogen percentage (FAO, 1983).

According to land evaluation for forestry, FAO (1984), land characteristic is defined as the property of the land which can be measured and estimated, and which is employed as a means of assessing land. Examples are mean annual rainfall, slope angle, soil texture, biomass of vegetation, and volume of standing timber. These land attributes can be directly measured or estimated in routine survey, including remote sensing and census as well as natural resource inventory.

\subsubsection{Land quality}

Land quality is an attribute of land which acts in a distinct manner in its influence on the suitability of the land for a specific kind of use. Examples of land qualities widely applicable in forestry are temperature regime, moisture availability, soil drainage, rooting conditions, potential for mechanization, and erosion hazard (FAO, 1984). The land ability has to fulfil specific requirements for a land utilization type (LUT). Usually it cannot be measured or estimated in routine survey, and so must be inferred from a set of diagnostic land characteristics. The land quality (LQ) expresses the 'supply' side of the land use and land area matching procedure. If the land utilization type is defined as a set of land use requirements (LUR), land suitability is based on the set of severity levels of the land qualities corresponding to the land use requirements. The value of a LQ may vary over time, resulting in a time-series of severity levels of land quality (Rossiter, 1996).

\subsubsection{Land suitability classification}

The process of land suitability classification is the appraisal and grouping of specific land in terms of their suitability for defined uses. Suitability can be scored based on factor rating or the degree of limitation of land use requirements when matched with the land qualities. In other words land suitability evaluation is a comparison and matching of land utilization type requirements with land unit's characteristics. Land suitability classes reflect degrees of suitability. Land suitability assessment was founded in 1976 by FAO and afterwards, many researches were done and are being done in land suitability evaluation for land utilization types (LUT) in different countries (FAO, 1984). 
According to land evaluation for forestry, (FAO, 1984), the suitability is the fitness of a given type of land for a defined use. The land may be considered in its present condition or after improvements. The process of land suitability classification is the appraisal and grouping of specific areas of land in terms of their suitability for defined uses. There are four categories recognized for land suitability classification:

a) Land Suitability Orders: Reflecting kinds of suitability, land suitability orders indicate whether given types of land are suitable or not suitable, for the land utilization type concerned. Where as $\mathrm{S}=$ Suitable, $\mathrm{N}=$ Not suitable for the land use.

b) Land Suitability Classes: Reflecting degrees of suitability within suitable orders, three classes are normally recognized: Highly suitable, moderately suitable and marginally suitable, indicated by symbols S1, S2 and S3 respectively.

- S1 (Highly suitable): Land having no significant limitations to sustained application of a given land utilization type, or only minor limitations that will not significantly reduce productivity or benefits and will not raise inputs above an acceptable level.

- S2 (Moderately suitable): Land having limitations which in aggregate are moderately severe for a sustained application of a given land utilization type. The limitations will reduce productivity or benefits and increase required inputs to the extent that the overall advantage to be gained from the use will be appreciably inferior to that expected on class S1 land.

- S3 (Marginally suitable): Land having limitations which in aggregate are severe for sustained application of a given land utilization type and will so reduce productivity or benefits, or increase required inputs, that this expenditure will only be marginally justified.

- $\quad \mathrm{N} 1$ (Currently not suitable): Land having limitations which may be surmountable in time but which cannot be corrected with existing knowledge at currently acceptable cost. The limitations are so severe as to preclude successful sustained application of the given land utilization type.

- N2 (Permanently not suitable): Land having limitations which appear as severe as to preclude any possibilities of successful sustained application of a given land utilization type. 
c) Land Suitability sub-classes: Subclasses reflect kinds of limitations or required improvements measures within classes.

d) Land Suitability Units: indicating differences in required management within subclasses.

\subsection{Remote sensing techniques}

\subsubsection{Remote sensing techniques for forest and land cover mapping}

Remote sensing is a powerful tool that could be used to address the problem of thematic maps which are out of date and have to be updated. The capabilities of remote sensing to map and extract information about earth resources for various applications are well documented. Among those prominently used is land cover mapping, considered as one of the most important, most direct and well established applications of remote sensing (Campbell, 1987).

Forest resource mapping by remote sensing began in the first part of the twentieth century with local-scale forest mapping from aerial photography. Land cover mapping is a product of the development of remote sensing, initially through aerial photography (Colwell, 1960). This is because 'viewing' large areas repeatedly is necessary for acquiring information about land cover. For the same reason, land cover mapping has been perhaps the most widely studied problem employing satellite data, beginning with Landsat 1 since July, 1972, with the launch of the first satellite sensor for monitoring Earth resources. There have been significant advances in remote sensing technology that have allowed forest resources mapping over much larger areas through the use of spaceborne sensors. Landsat 2 through 5 has provided more data about forest resource than can ever be analysed. The program is so successful that it continues even today with Landsat 7 being planned.

Remote sensing has been used in research of vegetation for many years with different perspectives such as mapping forest fires, vegetation cover and detecting changes in vegetation through different periods (Janssen et al., 1990, Dorren et al., 2003). Use of remote sensing for mapping vegetation is a widely used technique in ecological research since it can quickly determine the formation, distribution, and change of vegetation for very large areas. Moreover, it offers the possibility of extrapolating results of mapping to a regional extent, especially in large inaccessible areas (Hoersch et al., 2002).

Despite the different types of remote sensing data that have applied in forest and land cover map since 1972, however no kind of satellite remote sensing currently fully meets the requirements of a comprehensive forest resource assessment system (Malingreau et al., 1992). Numerous studies have been carried out regarding the relationship of forest structure and species composition to 
geological and topographic features (Pinder et al., 1997, Fahsi et al., 2000, Takyu et al., 2002). Correlations of tree species with environmental variables are used to obtain information about the vegetation distributions in different scales. Furthermore it is important to incorporate the terrain attributes (e.g. slope, elevation, local relief) into the statistical decision rules to classify ecological units using remotely sensed data (Moore et al., 1991). According to Boyd, D.S and F.M. Danson, 2005 “ Satellite remote sensing may be used to provide three levels of forest resource information:

1) The spatial extent of forest cover, which can be used to assess the spatial dynamics of forest cover.

2) The forest type.

3) The biophysical and biochemical properties of forests.

Low resolution satellite data like NOAA (National Oceanic and Atmospheric Administration), AVHRR (Advanced Very High Resolution Radiometer) images are often used for large area forest map on a regional and global scale. This is widely used for environmental applications at regional to global scales (Goward et al., 1985 and Ehrlich et al., 1994). The first satellite-based global land cover maps have been produced (DeFries and Townshend, 1994, DeFries et al., 1998, Hansen et al., 2000, Loveland et al., 2000). AVHRR imagery has also been used widely to estimate the extent and biophysical properties of forests (Foody \& Curran 1994; Malingreau et al., 1989). Therefore the coarse spatial resolution remotely sensed data are the most useful for forest cover delineation for large area (Grainger, 1993; Downton, 1995; Archard et al., 2001). However, there is one major problem that small areas may be not detected, which leads to incorrect estimation of remaining forest, this makes it difficult to observe local details.

Medium spatial resolution imagery such as the Spot HRV and Landsat MSS/TM have been used successfully to map and monitor forests (Franklin, 1993, Green \& Sussman, 1990). Pioneering studies illustrated the potential of these optical satellite data for the delineation of forest cover from non forest cover such as those carried on the Landsat and Spot data for estimation of forest cover at the local and national levels (Green and Sussman, 1990; Houghton et al., 2000). The medium optical imageries of Spot and Landsat are also used in estimation of tropical forest biological and biochemical properties like leaf area index (LAI), biomass or canopy cover (Curran, 1983, Boyd, 2001 and Foody et al., 2003).

Optical remote sensing is used extensively to map forest extent, and the temporal and spatial dynamics of deforestation, re-growth, and fire (Mayaux and Lambin, 1995; DeFries et al., 1995, Li and Cihlar, 1997; Ahern et al., 1998 and 1999). The advantages of using Landsat and Spot 
data in their Panchromatic tropical remote sensing survey as mentioned in the FAO's Forest resources assessment in 2000. However, the use of these optical imaging systems is that these technologies cannot penetrate clouds, which persist over many parts of the tropics during the wet season and, indeed, throughout the year in many tropical upland and montane environments. This effectively reduces the number of Landsat passes that researchers may use to map and monitor tropical forest as months or years may transpire before cloud-free Landsat imagery becomes available for certain cloudy locations (Trigg et al., 2006).

Another application for low and medium optical satellite data is the mapping of burned areas resulting from tropical forest fires (Fuller and Fulk, 2001). Therefore, remotely sensed data may be used to provide information on biomass burning, which can indicate the magnitude and temporal dynamics of forest cover change through deforestation by burning events (Eva and Lambin, 2000).

High resolution satellite data like IKONOS and Quickbird represent a new generation of remote sensing satellites, the IKONOS has a spatial resolution of $1 \mathrm{~m}$ for panchromatic imagery and $4 \mathrm{~m}$ for multi-spectral imagery, and its future successors are reported to generate images with a spatial resolution of approximately $50 \mathrm{~cm}$ (Richard and Jia, 1999). The Quickbird satellite, launched in October 2001, leads the quality list of optical remote sensing with panchromatic imagery of $70 \mathrm{~cm}$ spatial resolution. In most aspect, the IKONOS satellite and imagery captured is similar to the Quickbird satellite. Both these satellites with its spatial resolution promise to increase the accuracy of forest resources inventories. These imageries have been used for the validation of products derived from lower resolution data (Wang et al., 2003, Morisette et al., 2003). They have also been tested for forest land use and land cover classifications as well as for the estimation of forest biomass and the detection of selective logging (Clark et al., 2004, Thenkabail et al., 2004, Hurtt et al., 2003). However, IKONOS and Quickbird have limitations of spectral and spatial resolution. They do not have bands in the mid and thermal infrared region of the electromagnetic spectrum and IKONOS and Quickbird data also have less bands available than Landsat which do not allow a breadth of multi-spectral analysis. This is a disadvantage for the spectral discrimination of vegetation types (Mumby and Edwards, 2002). Despite the differences, all data sources can be used together to create a variety of solutions.

To overcome some of the problems of frequently cloud cover in tropical areas which renders much of the optical satellite unusable and SAR data have been used. Radar remote sensing could be a better alternative for tropical region due to its ability of cloud free imaging (Hussin and Shake, 1996). SAR imagery is used to produce forest cover, particularly, through the acquisition 
of multi-temporal datasets (Suzuki and Shimada, 1992; de Groof et al., 1992; Quegan et al., 2000; Balzter et al., 2002). In addition, the use of SAR data for mapping forest stand properties such as the classification of forest cover types from SAR imagery exploits difference in the macro structure between stands of different species, age or density (Ranson and Sun, 1994; Castel et al., 2002). However, despite the potential of SAR shown for provision of forest and land cover information, currently it is the optical remote sensing approach that is more useful (Hyppä et al., 2000) as SAR data are not available in tropical regions and are a relatively expensive option.

The importance of remote sensing to generate information for effective forest protection and management has been widely recognized as mentioned above. It is the only way to acquire repetitive biophysical data for large geographic area at reasonable cost, accuracy and effort (Flanklin, 2001). Different remote sensing data have been successfully used to map different forest types and land cover. Therefore, there is good possibility of using remote sensing to provide forest and non-forest, which would be needed for assessment of forestry's land potential, for sustainable forest management.

On the whole, in many tropical developing countries like Vietnam, the application of high spatial resolution satellite data so far has rarely been used for forest types and land cover mapping. Among various satellite images used in studies of tropical forest, Landsat TM (Thematic Mapper) and ETM+ (Enhanced Thematic Mapper Plus) are the sensors most commonly used in tropical forest applications and remain the standard to which other optical satellite data are usually compared. The spatial resolution of Landsat TM and ETM+ (30 m for 6 optical bands and $15 \mathrm{~m}$ for Panchromatic band) appropriate for the detection of change in canopy condition, extent as well as land use around forested areas. On the other hand, Landsat TM and ETM+ generally provide a clear delineation forest and non-forest cover types and allow both manual (Townshend et al., 1995) and semi-automated interpretation (Achard et al., 2002). In addition Landsat scene covers approximately $170 \mathrm{~m}$ x $170 \mathrm{~m} \mathrm{~km}$ is suitable for the study area.

\subsubsection{Classification issues}

Digital image classification is the process of assigning pixels to class. Usually each pixel is treated as an individual unit composed of values in several spectral bands (Campbell, J. B, 2002). Unsupervised classification method is used to identify natural groups, or structure, within multispectral data. Only afterwards information labels are assigned to the resulting groups. The disadvantage and limitation of these methods primarily arise from a reliance upon "natural” 
grouping and difficulties in matching these groups to the informational categories that are of interest to the interpreter. In addition, the interpreter limit controls over the menu of classes and their specific identities.

By contrast, supervised classification method is the process of using samples of known identity (training area or training field) and extends it to the entire image. Each primitive image is characterized by $n$ observations (the values in $n$ data channels). The training samples are vectors in an $n$-dimensional space (the feature space). A supervised classifier uses the distribution of the training samples for each class to estimate density functions in the feature space and to divide the space into class regions (Fukunaga, 1990). This method has many disadvantages. First, the analyst, in effect, imposes a classification structure upon the data. Second, training data are often primarily defined with the reference to informational categories and only secondarily with reference to spectral properties. A training area that is "100 \% forest" may be accurate with respect to the "forest" designation, but may still be very diverse with respect to density, age, shadowing, and the like, and therefore form a poor training area. Third, the training area selected by the analyst may not be representative of conditions encountered throughout the image. Fourth, conscientious selection of training data can be a time consuming, expensive, and tedious undertaking, even if ample resource are at hand. Finally, supervised classification may not be able to recognize and present special or unique categories not represented in the training data (Campbell, J. B, 2002). Therefore, the use of these methods in separate classification may be unsatisfactory.

\subsubsection{Considerations for classification accuracy assessment}

Accuracy assessment is an important step in the process of analyzing remote sensing data. There are a number of reasons why this assessment is so important including:

(1) To let the end user need to know how good the data is and to learn from the mistakes.

(2) The ability to use the information resulting from the spatial data analysis in some decisionmaking process.

Thematic maps derived from remotely sensed data are used in a lot of applications, but especially applied in forestry, these maps should be accompanied by information about their accuracy. Meaningful and consistent measures of thematic map reliability are necessary for the map user to assess the appropriateness of the map data for forestry application; additionally, the accuracy of the thematic map may significantly affect the outcome of forestry application. 
Aronoff (1982) stated that "users with a variety of applications should be able to evaluate whether the accuracy of the map suits their objectives or not”.

Map accuracy measures are equally important for the producer of a thematic map to analyze sources of error and weaknesses of a particular classification strategy. Yet, documenting map accuracy is not a straightforward task. While individual measures of map accuracy are well established in the literature (Congalton, 1991; Congalton and Green, 1999), considerable ambiguity remains concerning the implementation and interpretation of thematic map accuracy assessment. Uncertainties include the selection of which accuracy measures to report, how to interpret them, and the nature and quality of reference samples. As a result, map quality remains “a difficult variable to consider objectively” (Foody et al., 2002).

Accuracy assessment determines the quality of the information derived from remotely sensed data. Accuracy assessment can be qualitative or quantitative, expensive or inexpensive, quick or time-consuming, well-designed and efficient or haphazard. The purpose of quantitative accuracy assessment is the identification and measurement of map errors (Congalton and Green, 1999). Therefore, quantitative accuracy measures are necessary to compare the relative accuracies resulting from different data processing methods.

Typically, most quantitative methods to assess classification accuracy involve an error matrix built from the two data sets (i.e., remotely sensed map classification and the reference data). The error matrices represent the number of correctly mapped pixels by comparing information from reference sites to information of a map for a number of samples areas. The overriding assumption in the entire accuracy assessment procedure is that the error matrix must be representative for the entire area mapped from the remotely sensed data (Congalton, 1988a). Overall map accuracy is calculated by dividing the correctly classified pixels/samples (sum of the value in the major diagonal) by the total number of pixels/samples checked. When the total number of correct pixels in a category is divided by the total number of pixels of that as derived from the reference data, the result is an accuracy measure called "Producer's accuracy". On the other hand, when the total number of correct pixels in a category is divided by the total number of pixels that were classified in that data), this measure is called "User's accuracy." Or the reliability is indicative of the probability that a pixel classified on the map/image actually represents that category on the ground (Story and Congalton, 1986). 


\subsubsection{Considerations about Kappa Statistics or K (KHAT)}

Another discrete multivariate technique of use in accuracy assessment is called KAPPA (Cohen, 1960) and has been utilized for land cover and land use accuracy assessment derived from remotely sensed data (Congalton et al., 1983; Rosenfield and Fitzpatrick-Lins, 1986). The result of performing a KAPPA analysis is a KHAT statistic (an estimate of KAPPA), which is another measure of agreement or accuracy. The values can range from +1 to -1 . A Kappa of zero occurs when the agreement between classified data and verification data equals chance agreement (Fenstermaker, 1991). The values of Kappa greater than 0.80 (80\%) represent a strong agreement; a value between 0.40 and 0.80 (40-80\%) represents moderate agreement; and a value below 0.40 (40\%) represents poor agreement (Landis and Koch, 1977).

The Kappa coefficient was introduced to the remote sensing community in the early 1980s (Congalton et al., 1983) and has become a widely used measure for classification accuracy. It was recommended as a standard by Rosenfield and Fitzpatrick-Lins (1986). The Kappa coefficient is a powerful tool because of its ability to provide information about a single matrix and as a means to statistically compare matrices (Congalton, 1991). He also stated that the power of the Kappa analysis is that it provides two statistical tests of significance. Using this technique, it is possible to test weather an individual land cover map generated from remotely sensed data is significantly better than that of the map that had been generated by randomly assigning labels to areas. The second test allows for the comparison of any two matrices to see if they are statistically significantly different. In this way, it is possible to determine that one algorithm is different than another and, based on a chosen accuracy measure (e.g. overall accuracy), to conclude which is better (Congalton, 2001). Therefore, Kappa analysis must still be considered a vital accuracy assessment measure. Although some authors have criticized its characterization of actual map accuracy (Foody, 1992).

\subsubsection{Sampling design considerations}

The overriding assumption in the entire classification accuracy assessment procedure is that the error matrix must be representative of the entire area mapped from the remotely sensed data (Congalton, 1988a). Using the wrong sampling design can be costly and yield poor results. Richard (1993) and Congalton (1991) stated that "Designing a poor sampling scheme can easily result in significant biases being introduced into the error matrix, which will then affect the classification accuracy”. For this reason, a proper sampling approach must be chosen. Therefore, the sample design is a critical part of the accuracy assessment of image classification. 
The sampling design includes a number of considerations about the relations between study area and sampling such as: 1) the spatial distribution of samples within a study area, 2) the size of the individual sample, 3) the number of samples to be collected within a study area, 4) the choice of the appropriate sampling scheme.

\section{Spatial distribution of samples}

The spatial distribution of samples depends on the classification. The reference data need to be collected and labelled using the same classification scheme that was used to generate the map. Important considerations are the discrete nature of map information and the spatial interrelationship of that information. Therefore the distribution of map categories will affect both, how to select accuracy assessment and the outcome of analysis (Congalton and Green, 1999).

\section{Size of each sample}

Aronoff (1985) stated that a point unit is, in practice, also an area unit because a point can not be accurately verified. Sampling units should be at least the size of one pixel but, in order to take into consideration of geometric distortions also, these sampling units should be more than one pixel. Fenstermaker (1991) recommended, for a multistage approach, a 3 x 3 pixel environment as the sampling unit.

\section{Number of samples}

Depending on the goal of the accuracy assessment the number of samples can be calculated with different methods. Curran and Williamson (1985) indicate that the number of sample sites within a study area is dependent upon the size of the training data set and the number of classes in the final analysis. They conclude that a larger sample size than 30 should be collected in remote sensing studies if sampling errors are to be kept low. A balance between what is statistically sound and what is practically attainable is to be reached. Typical remote sensing analysis calls for approximately 50 samples per class as an appropriate sample size (Congalton and Green, 1999). The more the better, this is obviously a huge and money commitment. The larger the area being mapped, the more samples should be collected. Important categories can be sampled more than less important categories.

\section{Choice of the appropriate sampling scheme}

The choice of sampling scheme is a part of any accuracy assessment. The selection of the appropriate scheme is critical to generate an error matrix that is representative of the entire map. 
There are five common sampling schemes that have been applied for collecting reference data: Simple random sampling, systematic sampling, stratified random sampling, cluster sampling and stratified systematic unaligned sampling. These sampling methods are also recommended by Congalton and Green (1991 \& 1999).

Simple random sampling is a method of selecting the sample units out of the population, such that each element in the population has an equal chance of being selected (Cochran, 1977). Therefore, sampling design should be random in order to meet the statistical requirements of the Kappa analysis, among other statistical techniques that are based on the error matrix (Congalton, 1991). Simple random sampling can be appropriate if the sample size is large enough to ensure that all classes are adequately represented. The adoption of a simple sampling design is also valuable in helping to meet the requirements of a broad range of users (Stehman \& Czaplewski, 1998) although the objectives of all users cannot be anticipated (Stehman et al., 2000). However the simple random sampling yields too many samples in the large areas and too few samples in small areas (Congalton, 1988a). This can lead to classes of small extent failing to be represented in the sample.

Stratified random sampling is similar to simple random sampling, however, some prior knowledge about the study area is used to divide the area into groups or strata and then each strata is randomly sampled (Congalton and Green, 1999). The major advantage of stratified random sampling is that all strata (i.e., land cover types), no matter how small, will be included in the sample, so that stratified random sampling is frequently used in order to ensure that samples from all classes are included in the accuracy assessment (Helmer et al. 2002). On the other hand, simple random sampling may lead to problems if the resulting samples are located in inaccessible areas where the true class cannot be determined. Because of this, some authors use cluster sampling.

Cluster sampling is a technique of sampling in which units are not single pixels but groups of pixels, the cluster sampling is also frequently used in accuracy assessment of image classification, especially to collect information on many samples quickly. However, cluster sampling must be intelligent. Simply using very large clusters is not a valid method of collecting data, because each pixel is not independent of the other and adds very little information to the cluster (Congalton and Green, 1999).

Systematic sampling is a method in which the sample units are selected at some equal interval over the study area. The advantage of systematic sampling is the convenience of obtaining the 
sample and the uniform spread of the sampled observations over the entire population (Cochran, 1977). An obvious problem in systematic sampled population is the bias that exists if the population shows some kind of spatial autocorrelation. If the presence, absence, or degree of certain characteristics affects those in neighbouring units, then the phenomenon is said to exhibit spatial autocorrelation (Cliff and Ord, 1973).

The cluster sampling, and also systematic sampling do not ensure that every individual in the population has an equal chance of being included in the sample, thus violating the requirements for inferential statistics.

Stratified systematic sampling combines the advantage of randomization and stratification with the useful aspects of systematic sampling, while avoiding the possibilities of bias due to the presence of periodicity (Berry and Baker, 1968). When dealing with very large areas where cost and time are of great concern sampling from a car can be a necessary choice. Some consider this sampling technique as a mixture of random and a systematic sampling (Hellden, 1980). Nevertheless, disadvantages are limitation of the sampling to passable roads. Extensive classes that are not covered by roads, e.g. mountainous terrain, may then be under- or unsample. Land use and other human activities may also not be representative for the whole area.

The concept of randomness is a central issue when perform almost any statistical because a random sample is one in which each member of population has an equal and independent chance of being selected (Congalton and Green, 1999). For the purpose of using the Kappa coefficient in the analysis of the confusion matrix, a random sample sampling methods should be chosen.

\subsection{GIS techniques}

Geographic Information System (GIS) is a powerful tool for collecting, storing, retrieving, transforming and displaying spatial data from the real world (Burrough, 1986).

GIS can be used in concrete applications ranging from resource assessment to land evaluation and land use planning. It provides a powerful set of tools for data visualization, data analysis and evaluation of scenarios. GIS is an integrating technology that allows, encourages and expects users to bring together data from many different sources through the unifying medium of geography. The typical application of GIS is in a kind of spatial modelling which can be described simply as combining information from several different images to produce a single output image for land suitability assessment (Ramond Caldwell). One major part of a GIS is the ability to overlay various layers of spatially referenced data, this allows the user to determine graphically and analytically, how structures and objects, interact with each other. 
Land evaluation by map analysis techniques may be accomplished with any geographical information system (GIS) (Burrough, 1986; 1987). GIS technology continues to be used for making forest and land suitability maps. The use of this technology leads to the rapid generation of thematic maps and area estimates, and enables many of the analytical and visualization operations to be carried out in a spatial format, by combining different sets of information in various ways to produce overlays and interpreted maps. On the other hand, the modelling capability of the GIS is being used for the site selection (Hobbs, 1980 and Han and Kim, 1988), and for natural resources decisions, GIS can be a powerful tool base for evaluation of choice alternatives based on spatially related criteria (Carver, 1991). GIS have been recognized as the most promising tool capable of providing reliable information for both planning and decisionmaking for the sustainable management of resources (Michalak, 1993). Furthermore, GIS have been widely applied in the land suitability analysis, according to Guillermo A. Mendoza "An integrated GIS-based multi-criteria approach to land suitability analysis and allocation offers significant advantages. The GIS environment enables the spatially explicit evaluation of site suitability and the assignment of various measures of suitability to specific sites or geographic areas. The integration also allows area allocations at specific spatial or geographic locations. Hence, the integrated GIS-based model combines the spatial capabilities of GIS, with the analytical power of multi-criteria analyses. It means that the GIS-based integrated model permits both analytical planning and optimization of land use decisions at different levels, namely; 1) site suitability assessments based on different factors and specific land uses; 2) generation of suitability indices based on combinations of different factors (i.e. composite index/measure of site suitability); and 3) generation of an optimal land use plan that simultaneously considers the individual site suitabilities, and the optimal allocation to the most suitable land use i.e., mix of land uses that yields the highest overall cumulative suitability”.

GIS methods are combined with production modelling to support for land suitability assessment (Bouma et al., 1993). GIS and expert knowledge has been used for land suitability assessment for Cherimoya in southern Ecuador (Bydekerke et al., 1998). The combination of GIS technology with expert system to inform a land suitability evaluation model (Kalogirou, 2002). Therefore, GIS technology is already a prerequisite for managing the massive datasets required for spatial land evaluation application - a simple map subsystem (e.g. ArcView; ESRI, 1996). 


\subsubsection{Data structure}

There are two types of spatial data: geometric data and descriptive data. Geometric data - points, lines and polygons, express location or shape of entities. Descriptive data, on the other hand, relate to geometric entities.

\subsubsection{Layers}

A GIS has the capability to manage many layers of data for the same points in space in order to perform analyses. Layers represent different sets of geographic information. Layers can provide information on geologies, soil, land use, species distribution, vegetation, etc.

GIS applications involve everything from basic to complex functions. These applications include the analysis of spatial reference data, queries on point or polygons, data classification, map production, area calculations, the creation of buffer as well as elevation models.

\subsection{Land suitability model}

A model is a representation of an object or a phenomenon, a design to be copied, an ideal or standard situation, or a perfect thing to be imitated. In the sense in which it is used here the term model means a simplified representation of reality, where we can compute outcomes without having to perform actual experiments. The model is designed here to facilitate visualization, prediction and calculation, and which can also be expressed mathematical or computable form. In land evaluation, Ramond Caldwell notes that "models are computer programs that predict the performance of a land use on a land area, when given information on that area's land characteristics “. Therefore, many land assessment computer models were developed by Schuthink (1987), Van Diepen et al., (1988), Yizengaw and Verheye (1995) and Zuhdi (1999).

Modelling is the process of designing and using these models. Spatial modelling are the analytical procedures applied with GIS and GIS modelling is the process of creating new GIS products from existing products. There is a range of methodologies for environmental modelling. Some of these are based on an assessment of factors and combinations of factors, and others primarily on a process modeling approach (FAO, 2007). In spatial modelling there are three different classes of models, e.g. logical, empirical and conceptual (Heuvelink et al., 1993):

- A logical model simulates a new attribute by applying simple rules.

- Models that are set out principally to describe or mimic the observed relationships between variables are called empirical models. 
- A conceptual model describes essential features of a meteorological phenomenon and identifies the principal processes taking place.

The land suitability model is a set of procedures by which the suitability of a cell for a new land use is quantitatively assessed on the basis of selected environmental variables (Robert et. al). The procedure of the land suitability model for performing land suitability analysis is expressed in Fig. 2.1.

\subsection{Land suitability analysis}

As mentioned above, land suitability is fitness of a given type of land for a specified kind of land use. The land may be considered in its present condition or after improvements. The process of land suitability classification is the appraisal and grouping of specific areas of land in terms of their suitability for defined uses (FAO, 1976). The main objective of the land assessment is the prediction of the inherent capacity of a land unit to support a specific land use for a long period of time without deterioration, in order to minimize the socio-economic and environmental costs (de la Rosa, 2000). Land suitability analysis/assessment of suitability is made by comparison between land use and land quality, couple with analysis in environmental, economic and social terms (land evaluation for forestry, FAO, 1984). Roberts et al., noted "land suitability analysis incorporates human use information, such as demographic data, distance measures, and economic factors in addition to the physical data used in land capability analysis”. Therefore, land suitability analysis is an interdisciplinary approach by including the information from different domains like soil science, crop science, meteorology, social science, economics and management.

Analysis of land suitability is an evaluation problem involving several factors. The principal problem of land suitability analysis is to measure both the individual and cumulative effects of the different factors. In the other hand, analysis of land suitability generally involves determining an appropriate approach to combine these factors. Some approaches to combine these factors include:

1) The weighted linear combination method which used GIS based decision rules (Hopkins, 1977; Tomline, 1990; Carver, 1991; Berry 1993 and Eastman et al., 1995 and Malczewski, 1999). In addition, this analysis method is often applied in site selection, analysis of land suitability and problems of resources evaluation (Eastman et al., 1995; Lowry et al., 1995). 


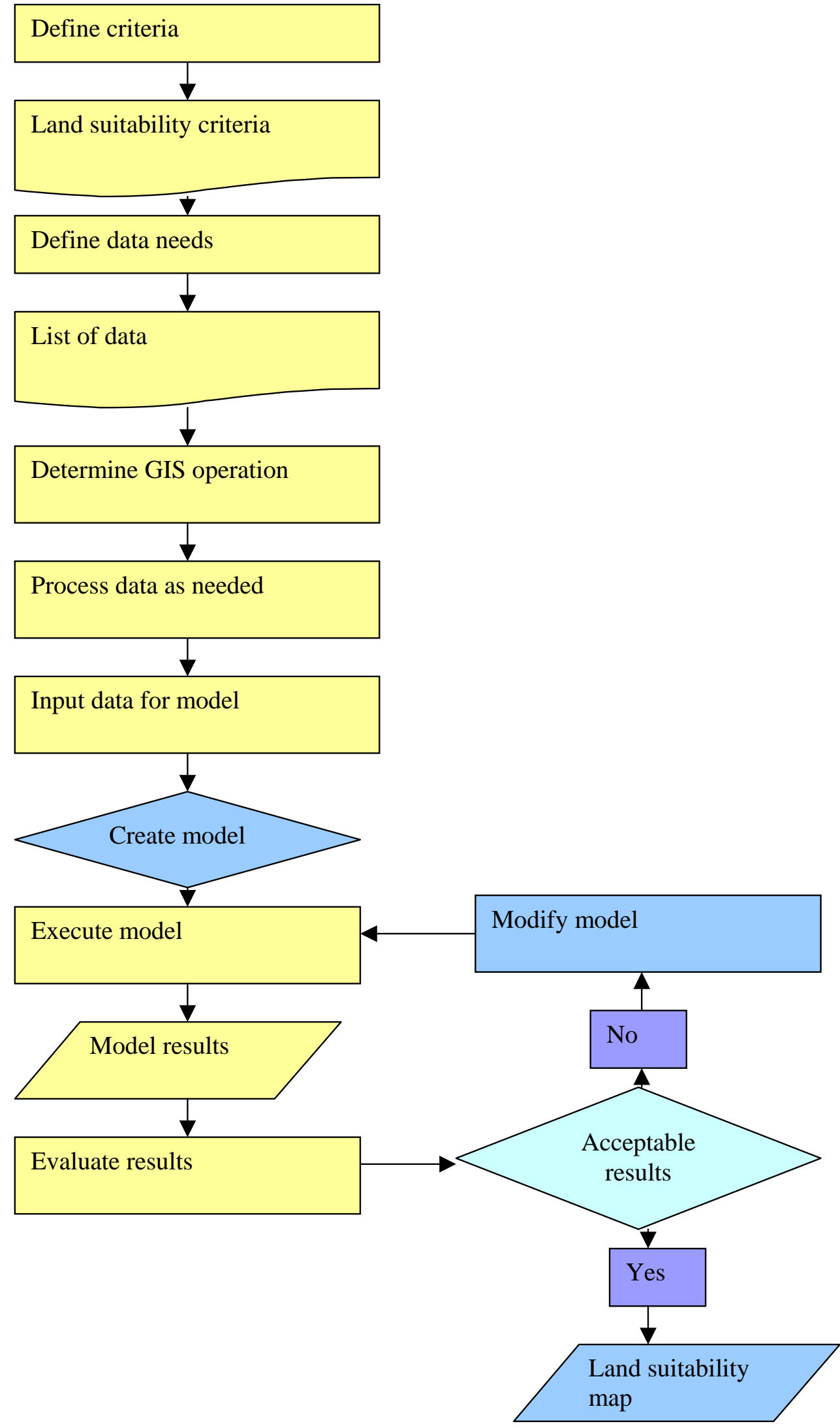

Figure 2.1: Illustrates the steps necessary for performing a land suitability model Source: User guide for Acrview 3.x and Arcview 9.x 
2) The heuristic rules of combination expressed through verbal logic rather than in numeric terms (Hopkins, 1977),

3) The various forms of multi-criteria approaches such as compromise programming (Pereira and Duckstein, 1993).

4) Composite rating consists of weighted composite rating by Anderson (1987). These approaches use a weighting scheme to combine criteria into a single measure of utility.

On the whole, the weighted linear combination method is one of the most widely used in the land suitability analysis. The reason for selecting this method is that the method is very easy to implement within the GIS environment using map algebra operations and cartographic modelling (Berry, 1993), and the method is also easy to understand and intuitively appealing to decision makers (Massam, 1998).

\subsection{Integration of Remote Sensing and GIS for land resources analysis}

Remote Sensing and GIS technology are both tolls for managing spatially distributed information in large quantities and at a variety of scale, both provide a systematic or synthetic view of spatial information, both increase the capabilities of human decision makers and planners to gap relations at larger scales and in more complex settings than has been possible before.

According to Wilkinson (1996), both Remote Sensing and GIS play an important role in assessing natural resources. They are a tool for resource survey and inventory that provides a primary source for up-to-date geographic data. These technologies are complementary to each other and it has been seen that the analysis of remotely sensed data is a complex subject to many difficulties especially with regard to classification and generalization. However, pre-existing GIS data can have impact roles both on the performance of classification and also in spatial operations in the image domain. The GIS data have reported on the use for image stratification using Boolean operations between data layer, to incorporate GIS data in natural resource network classifiers, and in evidential reasoning with geographical context.

Integration of remote sensing and GIS will be a powerful tool to interpret real word situation in most realistic and transparent way. Research by Emmanuel et al., (1999) has shown that “ integrated Remote Sensing and GIS technology can be threefold. Firstly, GIS can be used to provide image analysis algorithms with a priori information, which is used, e.g. to restrict the search space or impose constraints. Secondly, image analysis and processing methods can be used within a GIS for data analysis, especially for raster data (e.g. buffering of a corridor by 
using mathematical morphology), visualisation, content-based image retrieval etc. The third case is when image analysis and GIS fully interact, e.g. GIS information is used to guide image analysis, which extracts more complete and accurate information, which is in turn used to update the GIS database “.

GIS information can be used in image analysis for image classification purpose to produce forest and land cover map, e.g. in supervised classification to automatically select training areas, and in unsupervised ones to automatically assign detected information classes to thematic classes. In contrast, the use of remote sensing, especially image classification will provide a more rapid updating of GIS database.

Remote sensing in combination with GIS for the major forestry application addressed were the following:

Davis et al., (1990) proposed an approach to integrate existing data on species distribution and habitat characteristics in bio-diversity assessment using GIS supported by Remote Sensing inputs.

Stoms and Estates (1993) addressed in many bio-diversity related areas, comprehensive biological survey, identifying habitat preference, testing and revising diversity hypothesis and improving extinction based modelling, very limited study in individual plants and animal species of economic or conservation importance and bio-diversity and whole has been completed.

Roseberry et al., (1994) evaluated the potential impact of conservation reserves programs land on Bobwhite habitat by using remote sensing and GIS and habitat modelling. Remote sensing Global Positioning (GPS) and GIS were used to locate the habitat of Giant Sequoia Grove on the Squana natural forest.

Dees and Koch (1997) integrated image and map data in GIS for forest information system.

Newton et al., (1994) used remotely sensed images in GIS for updating of forest and forest change maps.

Walter and Fritsch (1998) used GIS for automatic training area selection and verification of the results in land cover and land use classification in agriculture and forestry.

Congalton, R.G. Kass Green and John Teply (1993) used remote sensed data integration with geographic information system for mapping old growth forests on national forest and park land in the Pacific Northwest. They incorporated the use of the remotely sensed data to produce a GIS database and map of old growth forest lands on national park lands in Oregon and Washington. 
The GIS layers include: Slope, aspect, elevation, hydrology, location of research and inventory plot, crown closure, size class/ stand structure, species, current vegetation, type polygon, suitable spotted owl habitat, suitable land for timber production, flight line maps, habitat conservation areas, forest boundaries, potential Pacific yew habitat, historical distribution of vegetation. Distribution of species can be refined from crude range maps by identification of areas of unsuitable habitat within the range boundary (Scott et al., 1991 cited in Myint, 1996).

In this study, using the interpretation of Landsat ETM+ imagery was integrated with GIS (Arcview /Info) to create model for assessment of forestry land's potential and land suitability for forest tree species in order to meet forestry production requirements. 


\section{Chapter 3. Characteristics of Study Area}

\subsection{Location and area}

Thua Thien - Hue province is located in a narrow trip of the central part of Vietnam (Fig.3.1), at latitude $16^{0}-16^{\prime} 45^{0}$ North and longitude $107^{0} 03$ - $108^{0} 08$ East. The province has an area of 505,339 ha, with the north bordering Quang Tri province, the south with Danang and Quang nam province, the east with the South China Sea, and the west with the Xekong province of Laos PDR. The border shared with Laos in Thua Thien Hue province stretches $88 \mathrm{~km}$. It has $126 \mathrm{~km}$ of beaches.

Thua Thien Hue is divided into eight administrative districts, which are Phuloc, Huongthuy, Namdong, Aluoi, Huongtra, Phuvang, Quangdien and Phongdien district and one city Hue City (Fig 3.2). Hue is the ancient capital of Vietnam, and an important cultural, educational and health care centre of Vietnam. The province is $654 \mathrm{~km}$ from Hanoi capital and 1,051 km from Ho Chi Minh City. The North-South Highway 1 and the railway linking Hanoi to Ho Chi Minh City pass through Hue and effectively bisect the province.

\subsection{Environment}

\subsubsection{Topography}

Thua Thien Hue is located in the Annamite mountains, it is characterised by ridges of low mountains and hills, which runs west-east from Laotian border to East sea at the Haivan pass. The province has a complex topography. It is made up four distinct ecological zones: a mountainous area, hills, plain, and lagoons separated from the sea by sandbank. The mountains which cover more than half of the total area of the province, are located along the west and southwest border of the provinces, their height varies from 500 to 1774 metres. This zone is known locally for its one breathtaking pass of Haivan and harmoniously beauty of Bachma national park. The topography is generally steep and rugged. Forest and forestland areas are dominated by mountainous ridges with several peaks above 1,000 m such as Phu loc district has Truoi cavern (1,154 m) and Bachma mount (1,448 m). Phong Dien district has Coctonbai (1,408 m), Cocmuen (1,298 m), Covaladut (1,438 m), and Copung (1,615) m. Namdong district has Nom cavern (1,186 m), Mang mount (1,712 m) and Rap cavern (1,184 m). Aluoi district has Ano cavern (1,485 m); Tatrach cavern (1,242 m), Tahung (1,600 m) Narumcalung (1,402 m), Pho 
cavern $(1,065 \mathrm{~m})$, Va mount $(1,200 \mathrm{~m})$ and Tregong cavern $(1,130 \mathrm{~m})$, and the highest mount of which is Ngai cavern of Aluoi district at 1,774 m.

The hills are lower, between 20 and 200 metres, with some points at 400 metres, and occupy a third of the area of the province. The kind of this topography is situated between the mountains and the plains with lower slope.

The plain land covers about ten percent of the surface area, with a height of only up 20 metres above sea level, and are located the East and Northeast of the province.

The lagoons are situated between the hills and occupy above five percent of the surface area of the province.

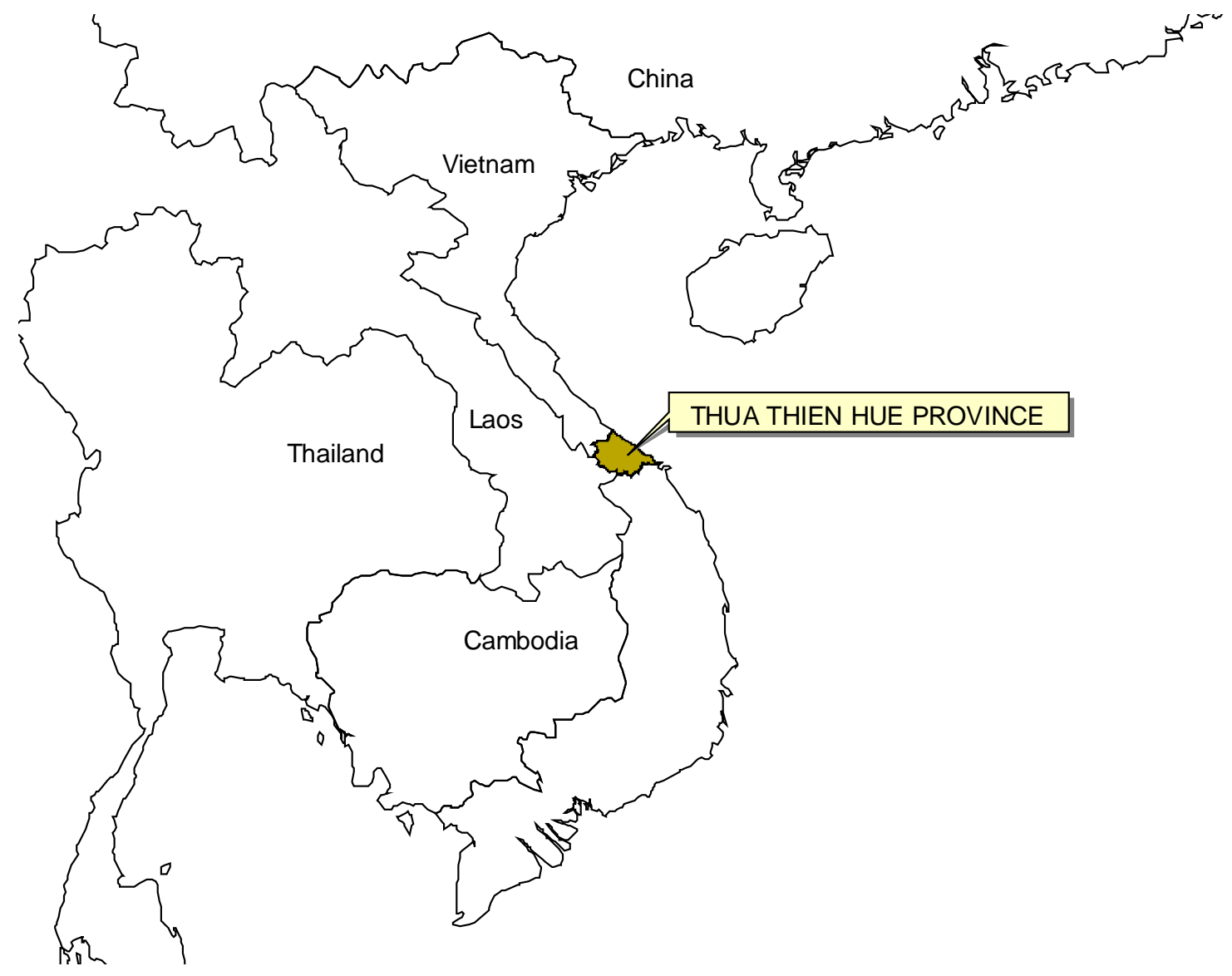

$0 \quad 300$ Kilometers

Figure 3.1: Location of the study area 


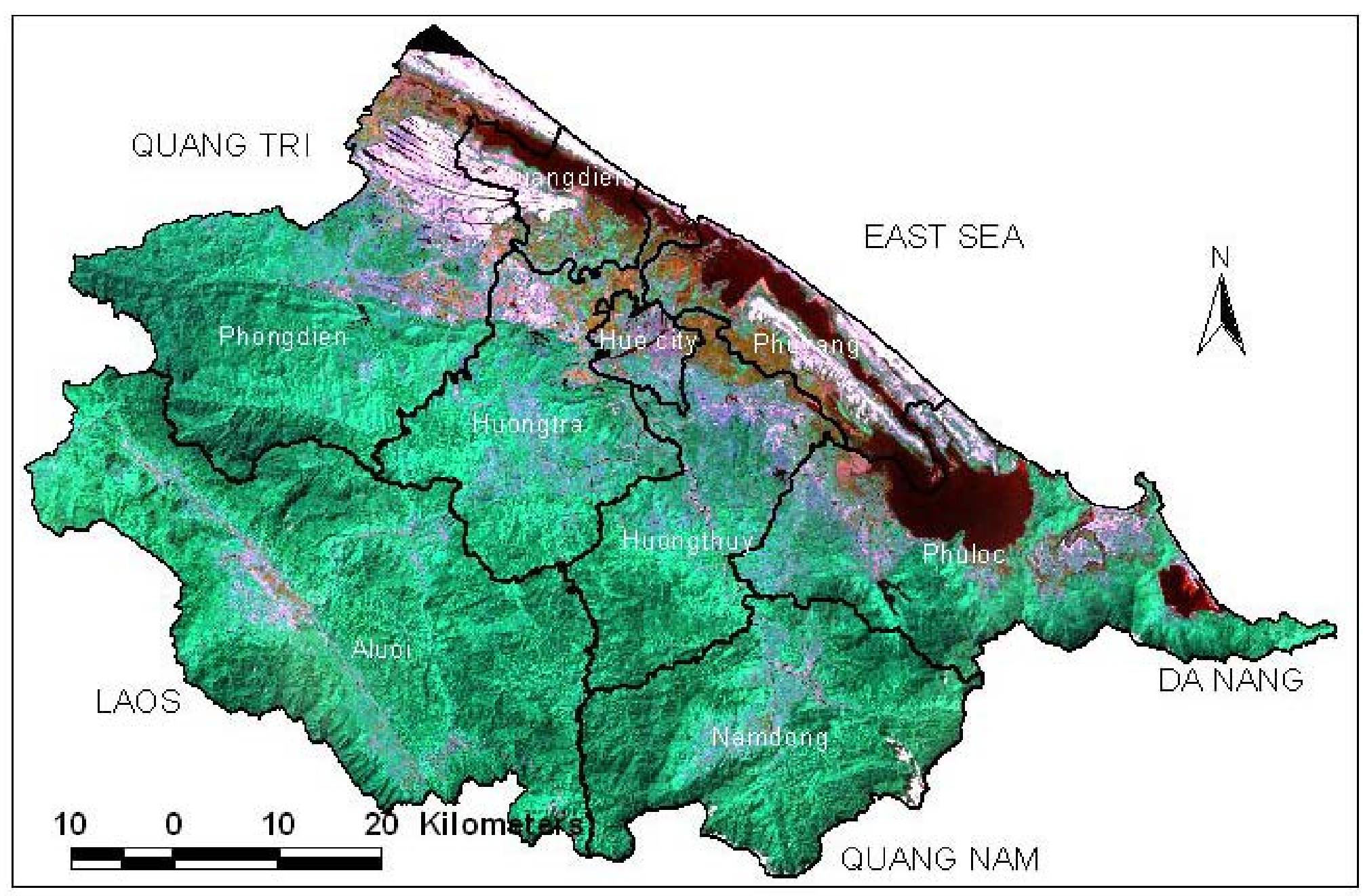

Figure 3.2: The boundaries of districts and Hue city, Thua Thien Hue province 


\subsubsection{Geology}

Thua Thien-Hue Province is located in central Vietnam within the Viet-Lao Caledon enfolded syncline. This syncline complex developed from the Cambrian Period at the beginning of the Devonian Period. The geology of the province is actually formed by series of deeply eroded plateau with higher isolated massifs. The forestlands of the study area are developed on parent materials (Fig 3.3) as follows:

- Sediment sand.

- Metamorphic rock.

- Sandstone.

- Old alluvia.

- Acid magma rock and granite.

The geology of most of forestland in the mountainous area is dominated by argillaceous and metamorphic rock, sandstone, acid magma rock and granite which are widespread in the province from the Ordovician-Silurian Age. The geology of low hills is characterized by old alluvia and coastal area is characterized by sediment sand.

\subsubsection{Climate}

\subsubsection{The weather and climate}

The climate of Thua Thien Hue is similar to central Vietnam in general, the weather is submitted to tropical monsoon climate divided into four distinct seasons: spring, summer, autumn and winter. The spring is cool and warm, the autumn is cool, the summer is hot and dry westerly winds and the winter is cold and wet. The hot dry season lasts from March to August. The hottest months of the year are usually June and July, with an average temperature of $29^{\circ} \mathrm{C}$, the highest temperatures can reach $39-40^{\circ} \mathrm{C}$. The stormy season starts in early September and continues until late November. The cold and wet season lasts from December to February with the lowest temperature can drop to $10^{\circ} \mathrm{C}$. In this time, it rains a lot, sometime it lasts all day. In the mountainous area, the weather is cool and sometime falls down to $5^{0} \mathrm{C}$. The climate in Thua Thien Hue is also under disadvantage of weather, such as typhoons, floods and droughts which are threatening the life and the forestry production.

The province is affected by the monsoon and ranges of Haivan and Truongson mountains, that's why the annual rainfall is higher than in the other regions which are located at the same elevation 


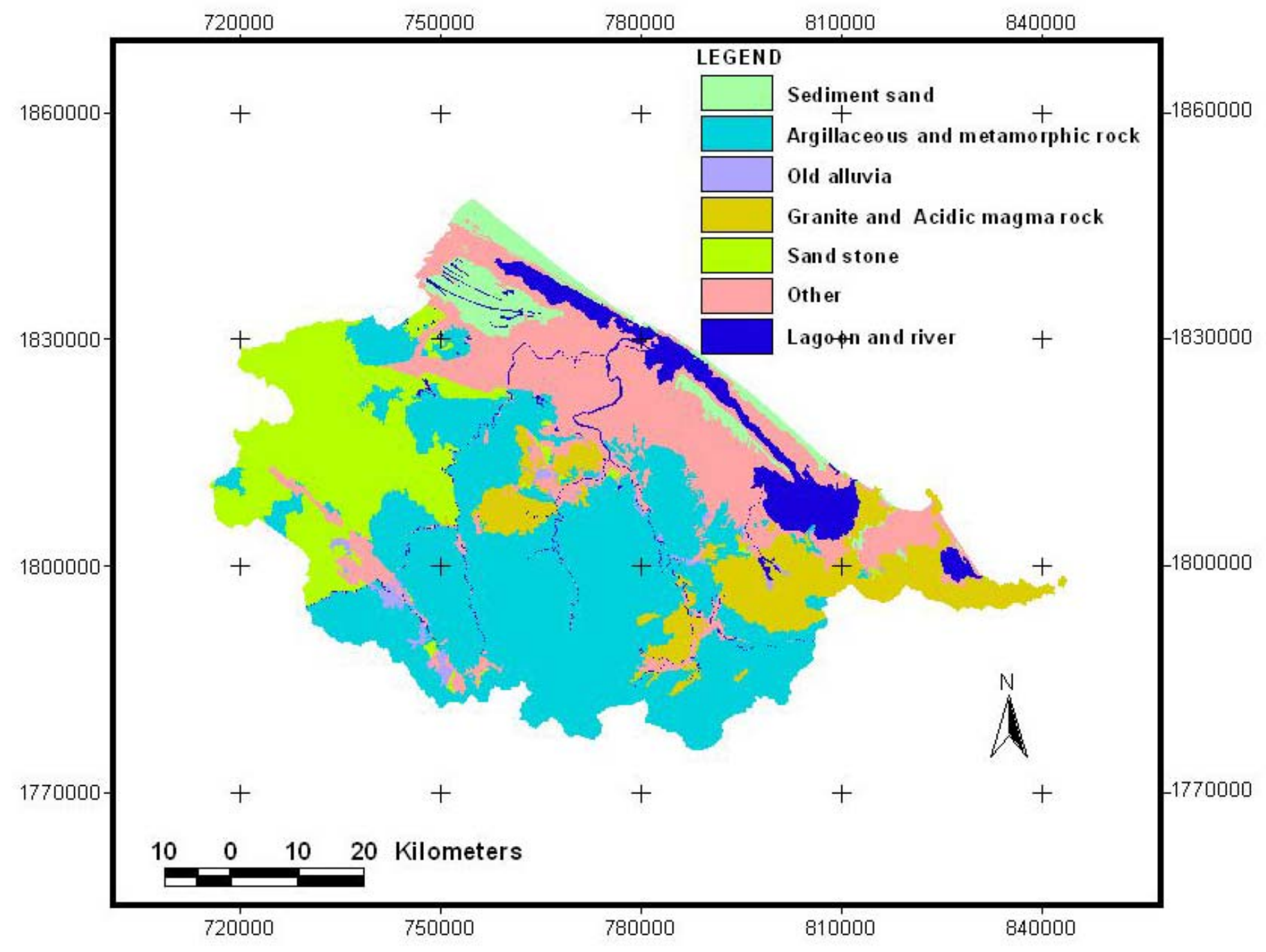

Figure 3.3: Geological map of the study area 
in Vietnam. September and October have the highest rainfall and account for up 45 percent of the total annual rainfall.

Every year there are more than 140 rainy days and a mount of sunny hours varies from 1,429 to 1,930. Depending on the year the annual rainfall may be 2,500 to 3,500, average is $2,915 \mathrm{~mm}$ in the plains and 3,000 to 4,500, average is $3,532 \mathrm{~mm}$ in the mountains. In some years the rainfall may be much higher and reach more than $5,000 \mathrm{~mm}$ in the mountains. Rainfall often occurs in short heavy bursts which can cause flooding and erosion, with serious environmental and socioeconomic consequences. The relative humidity averages between 85.6 and 88.3 percent. During the rainy season, the relative humidity is commonly 90 percent. The minimum relative humidity during the hottest months of the dry season can be below 30 percent.

The temperature in the study area is high. The average annual temperature varies between 21.3 and $25.7^{\circ} \mathrm{C}$. However, the average temperature is different in every zone. In the plains, the average annual temperature is $25^{0} \mathrm{C}$, in the hills it is $24.3^{\circ} \mathrm{C}$, but in the mountains only $21.9^{0} \mathrm{C}$. Meteorological data from three weather stations in the region are indicative of the prevailing meteorological conditions within the study area (Table 3.1).

Table 3.1: Climate at different elevations in Thua Thien Hue province (1996 - 2006)

\begin{tabular}{|l|l|l|c|c|c|}
\hline No & Elements & Unit & $\begin{array}{c}\text { Hue } \\
(10 \mathrm{~m})\end{array}$ & $\begin{array}{c}\text { Namdong } \\
(60 \mathrm{~m})\end{array}$ & $\begin{array}{c}\text { Aluoi } \\
(572 \mathrm{~m})\end{array}$ \\
\hline 1 & Average annual temperature & ${ }^{0} \mathrm{C}$ & 25.0 & 24.3 & 21.9 \\
\hline 2 & Highest air temperature & ${ }^{0} \mathrm{C}$ & 39.6 & 39.3 & 35.4 \\
\hline 3 & Lowest air temperature & ${ }^{0} \mathrm{C}$ & 12.4 & 12.5 & 10.0 \\
\hline 4 & Annual number of sunny hours & hour & $1,845.7$ & $1,777.8$ & $1,632.4$ \\
\hline 5 & Total annual rainfall & $\mathrm{mm}$ & $2,915.8$ & $3,481.5$ & $3,532.4$ \\
\hline 6 & Annual humidity & $\%$ & 84.4 & 86.6 & 87.9 \\
\hline
\end{tabular}

Source: Weather stations of Thua Thien Hue province

Under influence of monsoon, and further because of the complicated topography, the climate in the study area always changes in one year, between the years, or between the areas from lowland to highland (Table 3.2, 3.3 and Fig 3.4, 3.5 and 3.6) 
Table 3.2: Temperature $\left({ }^{0} \mathrm{C}\right)$ in months at different elevations in Thua Thien Hue province (1996 -2006)

\begin{tabular}{|c|c|c|c|c|c|c|c|c|c|}
\hline \multirow[t]{3}{*}{ Month } & \multicolumn{3}{|c|}{$\begin{array}{c}\text { Hue } \\
(10 \mathrm{~m})\end{array}$} & \multicolumn{3}{|c|}{$\begin{array}{c}\text { Namdong } \\
(60 \mathrm{~m})\end{array}$} & \multicolumn{3}{|c|}{$\begin{array}{c}\text { Aluoi } \\
(572 \mathrm{~m})\end{array}$} \\
\hline & \multicolumn{3}{|c|}{$\begin{array}{c}\text { Temperature } \\
\text { (Celsius) }\end{array}$} & \multicolumn{3}{|c|}{$\begin{array}{c}\text { Temperature } \\
\text { (Celsius) }\end{array}$} & \multicolumn{3}{|c|}{$\begin{array}{c}\text { Temperature } \\
\text { (Celsius) }\end{array}$} \\
\hline & $\begin{array}{l}\text { Average } \\
\text { monthly }\end{array}$ & $\begin{array}{l}\text { Highest } \\
\text { recorded }\end{array}$ & $\begin{array}{l}\text { Lowest } \\
\text { recorded }\end{array}$ & $\begin{array}{l}\text { Average } \\
\text { monthly }\end{array}$ & $\begin{array}{l}\text { Highest } \\
\text { recorded }\end{array}$ & $\begin{array}{l}\text { Lowest } \\
\text { recorded }\end{array}$ & $\begin{array}{l}\text { Average } \\
\text { monthly }\end{array}$ & $\begin{array}{l}\text { Highest } \\
\text { recorded }\end{array}$ & $\begin{array}{l}\text { Lowest } \\
\text { recorded }\end{array}$ \\
\hline January & 19.8 & 33.5 & 12.4 & 20.1 & 34.4 & 13.6 & 17.4 & 31.2 & 11.1 \\
\hline February & 21.4 & 35.7 & 12.9 & 21.9 & 37.1 & 12.6 & 19.2 & 33.0 & 11.0 \\
\hline March & 22.7 & 36.5 & 12.9 & 23.2 & 36.9 & 12.6 & 20.6 & 33.5 & 10.0 \\
\hline April & 26.1 & 37.7 & 17.6 & 26.6 & 38.6 & 16.8 & 22.9 & 34.6 & 15.5 \\
\hline May & 28.1 & 38.6 & 18.7 & 27.9 & 39.0 & 17.0 & 24.4 & 34.6 & 12.7 \\
\hline June & 29.3 & 39.6 & 23.4 & 26.7 & 39.3 & 22.8 & 25.7 & 35.4 & 19.4 \\
\hline July & 28.8 & 38.2 & 22.8 & 28.0 & 38.0 & 22.0 & 24.9 & 33.4 & 18.0 \\
\hline August & 28.3 & 38.9 & 23.0 & 27.5 & 37.7 & 22.2 & 24.6 & 33.6 & 19.0 \\
\hline September & 26.6 & 36.6 & 21.5 & 26.2 & 36.5 & 20.6 & 23.1 & 33.0 & 16.4 \\
\hline October & 25.0 & 33.9 & 19.0 & 24.3 & 35.2 & 17.3 & 21.6 & 32.4 & 13.2 \\
\hline November & 23.6 & 33.7 & 17.6 & 23.3 & 34.5 & 16.2 & 20.5 & 31.0 & 13.7 \\
\hline December & 20.5 & 31.1 & 13.4 & 20.5 & 33.6 & 12.5 & 17.8 & 29.2 & 10.2 \\
\hline
\end{tabular}

Source: Weather stations of Thua Thien Hue

Table 3.3: Annual rainfall (mm) in months at different elevations in Thua Thien Hue province $(1996$ - 2006)

\begin{tabular}{|l|c|c|c|}
\hline Month & $\begin{array}{c}\text { Hue } \\
(10 \mathrm{~m})\end{array}$ & $\begin{array}{c}\text { Namdong } \\
(60 \mathrm{~m})\end{array}$ & $\begin{array}{c}\text { Aluoi } \\
(572 \mathrm{~m})\end{array}$ \\
\hline January & 89.4 & 94.2 & 38.4 \\
\hline February & 61.3 & 59.1 & 54.4 \\
\hline March & 29.0 & 73.5 & 41.1 \\
\hline April & 51.7 & 107.9 & 193.2 \\
\hline May & 82.9 & 184.3 & 257.2 \\
\hline June & 114.3 & 148.0 & 127.4 \\
\hline July & 80.0 & 158.1 & 173.7 \\
\hline August & 225.3 & 281.0 & 346.2 \\
\hline September & 481.7 & 511.8 & 506.0 \\
\hline October & 764.8 & 804.9 & 756.1 \\
\hline November & 618.4 & 720.0 & 633.2 \\
\hline December & 317.0 & 338.8 & 405.4 \\
\hline Year & $\mathbf{2 , 9 1 5 . 8}$ & $\mathbf{3 , 4 8 1 . 5}$ & $\mathbf{3 , 5 3 2 . 4}$ \\
\hline
\end{tabular}

Source: Weather stations of Thua Thien Hue province 


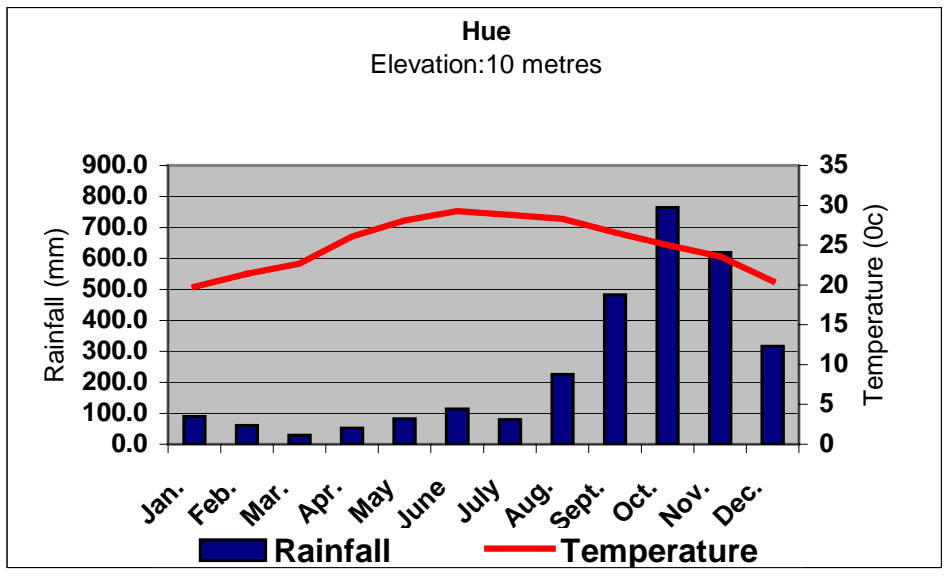

Figure 3.4: Climatic diagram of Hue city (10 metres) showing monthly temperature and rainfall (1996-2006)

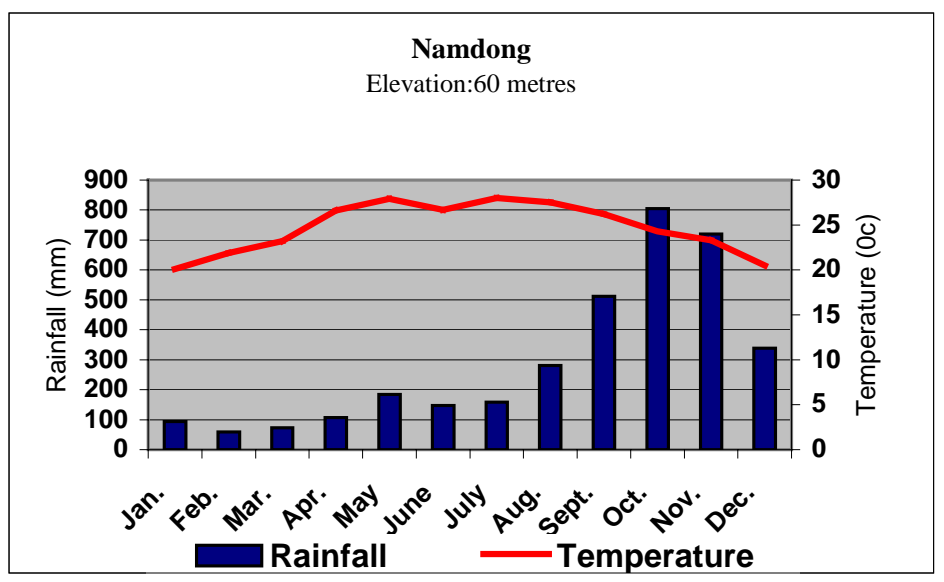

Figure 3.5: Climatic diagram of Namdong (60 metres) showing monthly temperature and rainfall (1996-2006)

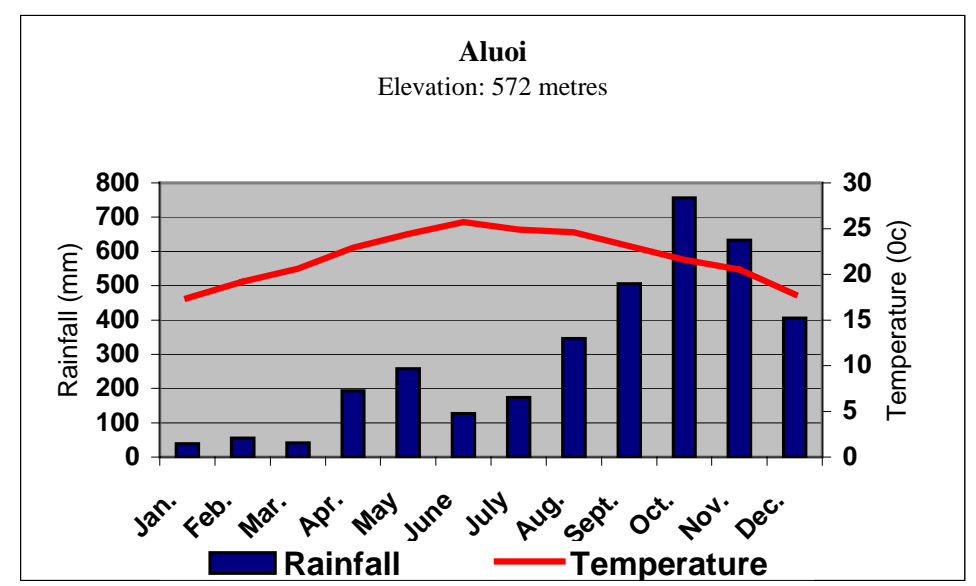

Figure3.6: Climatic diagram of Aluoi (572 metres) showing monthly temperature and rainfall (1996-2006) 


\subsubsection{Climatic zones in Thua Thien Hue province}

In the study area, under the influence of the monsoon, the Haivan pass and the Eastern Truongson mountain side, further climatic influence is based on tough topography. Therefore, we find a variation of climate from coastal plains to mountainous areas. Rainfall is abundant, with annual rainfall exceeding 2,500 mm almost everywhere, the average rainfall increases from the North to the South and the rainfall in mountainous areas is higher but the amplitude of temperature in coastal plains is the highest in the province.

Thua Thien Hue features the tropical monsoon climate. It is divided into two distinct climate regions: 1) the climate of the plain and low hill zone and the climate of the hilly and mountainous zone. The climate of the plain and low hill zone is divided into three sub- climate zones: 1a, 1b and 1c; 2) climate of hilly and mountainous zone climate is divided into five subclimate zones: 2a, 2b, 2c, 2d and 2e (Fig. 3.7)

\section{1) Climate of plain and low hill zone}

This climatic zone is located at an elevation below $100 \mathrm{~m}$ above sea level, it stretches from Phongdien, Huongtra, Huongthuy towards the southern Phuloc districts. The annual average temperature here is over $24^{\circ} \mathrm{C}$. The rainy season begins in early September and continues until late December with an average rainfall of 2,800 to 3,400 $\mathrm{mm}$ and with average humidity of 75 to $88 \%$ throughout the year.

\section{Sub- climate zone 1a}

This region is located at coastal plains of Phuvang and Quangdien district, low hills of Huongtra and Phongdien district and a northern part of Huongthuy district and Hue city. The temperature is the highest in the province, the annual average temperature ranges from $24^{0} \mathrm{C}$ to $25.2{ }^{0} \mathrm{C}$. The sunny hours are over 2,000, the lowest temperatures can drop below $10{ }^{\circ} \mathrm{C}$ in winter and the highest temperatures can reach to $40^{\circ} \mathrm{C}$ in summer. On the other hand, the rainfall here is the lowest in the province and average rainfall is 2,600 to $2,800 \mathrm{~mm}$. This zone is influenced strongly by typhoons, floods and dry-hot westerly winds.

\section{Sub- climate zone $1 b$}

Sub- climate region of $1 \mathrm{~b}$ is located at plain areas from Phubai town to Truoi mountain range. This region has climatic characteristics and is similar to sub- climate zone 1a, but differences in rainfall and humidity. The average rainfall varies between 2,800 and 3,200 $\mathrm{mm}$ and is rarely influenced by hot and dry westerly winds. 


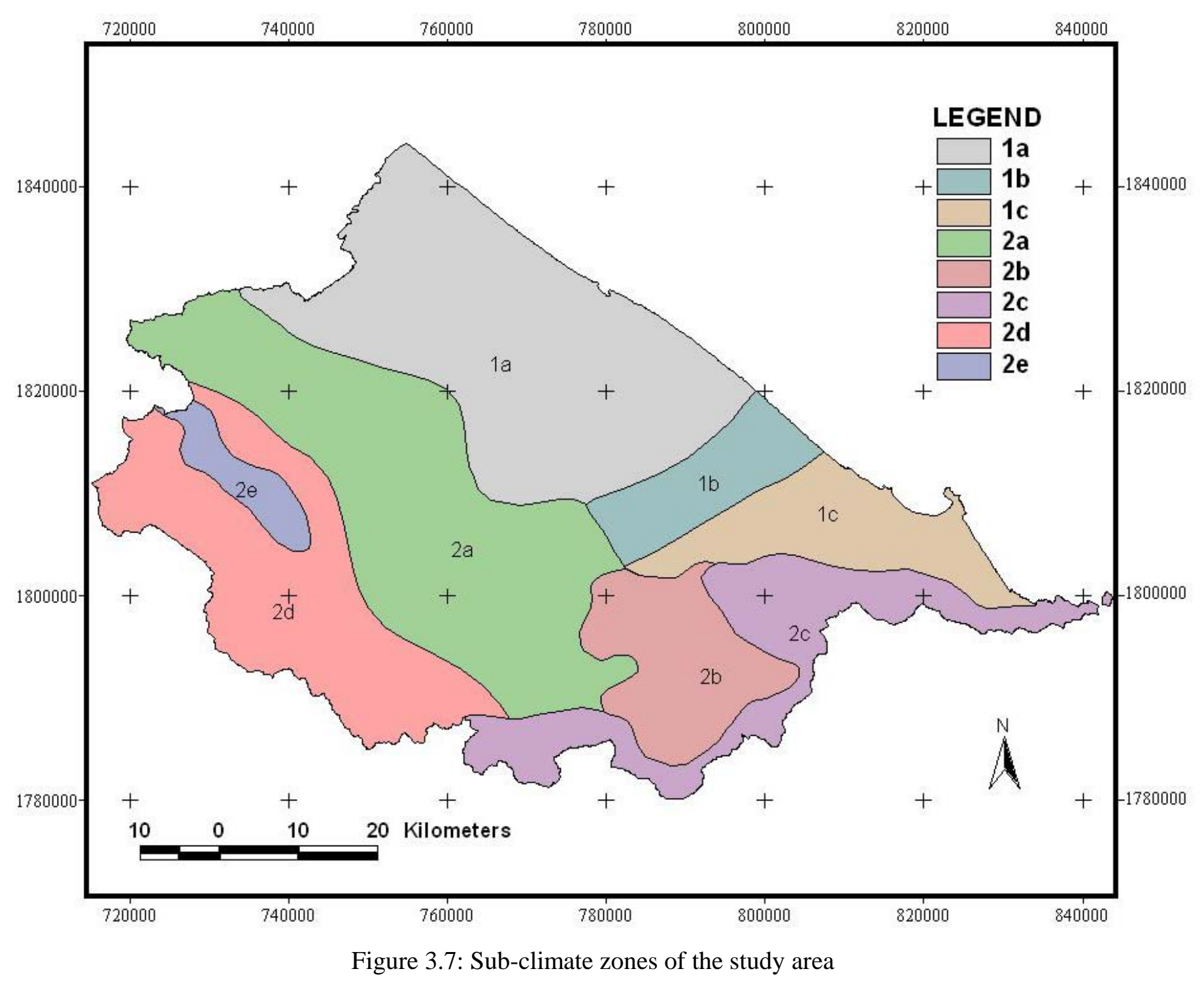




\section{Sub-climate zone $1 c$}

The kind of this climatic type includes plain areas of Phuloc district, the climate is the same subclimate zone1b, the amplitude of temperature is the lowest in the province. The average rainfall is high, from 3,200 to $3,400 \mathrm{~mm}$.

\section{2) Climate of hilly and mountainous zone}

Climate of hilly and mountainous zone is located at an elevation higher than $100 \mathrm{~m}$ above sea level. It covers the hilly and mountainous areas of Huongtra, Phongdien, Huongthuy, Phuloc, Aluoi and Namdong districts and the southwest of Hue city. This zone is divided into five subclimate zones.

Sub -climate zone $2 a$ (hilly climate)

The hilly climate zone includes hilly areas at elevation from 100 to $150 \mathrm{~m}$ above sea level at Phongdien, Huong tra, Huongthuy, Phongdien and Phuloc district and the southwest of Hue city. Total temperature in this region is lower than climatic zone 1 , total temperature varies between 8,000 and $8,760^{\circ} \mathrm{C}$, the average annual temperature ranges from 24 to $24.5^{\circ} \mathrm{C}$. The rainy season lasts from May to December with the average rainfall is 2,800 to $3,200 \mathrm{~mm}$.

Sub -climate zone $2 b$ (valley climate)

The kind of this climatic type is found at valley areas of Namdong district, the average annual temperature is similar to the hilly climate zone, but precipitation is higher and the average rainfall varies between 3,200 and 3,600 $\mathrm{mm}$. This region is influenced strongly by hot and dry westerly winds and the temperature rarely reaches $40^{\circ} \mathrm{C}$. The rainy season lasts from May to December. It is quite cold with average annual temperature below $20^{\circ} \mathrm{C}$, but sometime down to $10^{0} \mathrm{C}$.

Sub -climate zone 2c (high mountain climate)

This climatic type is situated at Bachma (white horse) mount. Comparing to the other zone, the temperature is colder in summer and average rainfall is the highest in the province and in Vietnam. The average annual temperature ranges from 18 to $22^{\circ} \mathrm{C}$ and the average rainfall is over $3,600 \mathrm{~mm}$.

\section{Sub -climate zone 2d (climate of Aluoi zone)}

The climate of Aluoi zone is located at elevation from 450 to $500 \mathrm{~m}$ above sea level. The average annual temperature is below $22^{\circ} \mathrm{C}$, the annual rainfall is over $3,400 \mathrm{~mm}$ and the sunny hours are 
1,700 to 1,800 . There are no hot and dry westerly winds, the lowest temperature can drop to $5{ }^{\circ} \mathrm{C}$ in the winter.

Sub -climate zone $2 \boldsymbol{e}$ (high mountain climate of Ngai cavern)

The mountainous climate at Ngai cavern is similar to sub -climate zone of Bachma, but precipitation is lower and the average rainfall varies between 3,400 and 3,600 $\mathrm{mm}$. The average annual temperature ranges from 18 to $22^{\circ} \mathrm{C}$.

\subsubsection{Forest soil}

Thua Thien Hue province has a high diversity of forest soil types that are located in several subclimate zones. According to FAO-UNESCO, there are seven major soil groups found in the forest soils as follows:

- Rhodic Ferrasoils

- Xanthic Ferrasoils

- Lithic Leptosoils

- Dystric Fluvisoils

- Luvic Arenosols

- Haplic Arenosols

- Glayic Arenosols

In order to exploit the potential of the forestry land resources, to enlarge the forest plantation land and to increase the tree production it is required to solve land evaluation for forestry.

For assessment of the forestry's land potential and suitability assessment of the selected forest tree species on mountainous and coastal areas, careful studies of main soil types and identification of basic and criteria for that purpose seem to be essential.

\subsubsection{Main features of soil types found on forestlands}

\section{- Distribution and basic features of main soil types on hilly and mountainous region}

The hilly and mountainous areas in Thua Thien Hue province occupy about 70 percent of total natural land, they are located in the west and a south-western part of the province. From 2000 to 2004, a group of soil scientists of Hue University of Agriculture and Forestry, Forest Inventory and Planning of Thua Thien Hue and Soil Research Station of Taynguyen had intensive land surveys and produced soil maps for mountainous districts. Based on the research results and soil surveys of these soil scientists, the forest soils of the hilly and mountainous areas in Thua Thien 
Hue are classified into four soil groups: 1) Rhodic Ferrasoils, 2) Xanthic Ferrasoils, 3) Lithic Leptosoils and 4) Dystric Fluvisoils. These are the following main soil types:

a) Yellowish brown soils on old alluvial.

b) Yellowish red soils on acidic magma rock.

c) Yellowish red soils on sandstone.

d) Yellowish red soils on argillaceous and metamorphic rock.

e) Thin layer soils, and.

f) Alluvial soils on river areas.

\section{1) Yellowish brown soil group (Rhodic Ferrasoils)}

The yellowish brown soils on old alluvia are located at elevation below $600 \mathrm{~m}$ above sea level and soil depth varies from medium to thick. This soil type covers 4,761.1 hectare, of which Aluoi district has a big area is 3,105.8 ha, Huongthuy is 187.1 ha, Huongtra is 779.2 and Phuloc is 689.3 ha. The soil is characterized by its texture ranging from loam to clay loam. The soil reaction is very strong acid with soil $\mathrm{pH}_{\mathrm{kcl}}$ values of 3.59 to 4.84 . Soil organic matter $(\mathrm{OM})$ in different places varies from 0.92 to 1.66 percent. Generally speaking, the soils are medium in available phosphorus and potassium (Table 3.4).

Table 3.4: The chemical properties of yellowish brown soils on old alluvia

\begin{tabular}{|c|c|c|c|c|c|c|}
\hline Location & Range & $\left(\mathrm{pH}_{\mathrm{kcl}}\right)$ & $\begin{array}{l}\text { OM } \\
(\%)\end{array}$ & $\begin{array}{c}\mathbf{N} \\
(\%)\end{array}$ & $\begin{array}{c}\mathbf{P}_{\mathbf{2}} \mathbf{O}_{5} \\
\text { (mg/100 g soil) }\end{array}$ & $\begin{array}{c}\mathbf{K}_{\mathbf{2}} \mathbf{O}_{5} \\
\text { (mg/100 g soil) }\end{array}$ \\
\hline \multirow[t]{3}{*}{ Huongtra } & Min & 3.59 & 0.95 & 0.07 & 0.59 & 2.32 \\
\hline & Max & 4.45 & 1.32 & 0.12 & 2.57 & 6.79 \\
\hline & Average & 4.04 & 1.18 & 0.10 & 1.68 & 5.04 \\
\hline \multirow[t]{3}{*}{ Huongthuy } & Min & 3.89 & 0.92 & 0.08 & 0.98 & 4.25 \\
\hline & Max & 4.30 & 1.21 & 0.12 & 3.52 & 4.80 \\
\hline & Average & 4.10 & 1.07 & 0.10 & 2.25 & 4.52 \\
\hline \multirow[t]{3}{*}{ Huongtra } & Min & 4.02 & 1.17 & 0.07 & 0.93 & 3.50 \\
\hline & Max & 4.55 & 1.47 & 0.11 & 5.02 & 7.85 \\
\hline & Average & 4.09 & 1.21 & 0.09 & 1.83 & 4.89 \\
\hline \multirow[t]{3}{*}{ Phuloc } & Min & 3.95 & 0.97 & 0.07 & 0.95 & 3.12 \\
\hline & Max & 4.84 & 1.66 & 0.11 & 3.00 & 7.23 \\
\hline & Average & 4.27 & 1.38 & 0.09 & 1.82 & 3.78 \\
\hline
\end{tabular}

Source: Faculty of forestry and Department of soil sciences of HUAF, Forest Inventory and Planning of Thua Thien Hue province 


\section{2) Yellowish red soil group (Xanthic Ferrasoils)}

\section{Yellowish red soils develop on acid magma}

The yellowish red soils develop on acid magma with an area of 51,140.9 hectare, of which 29,847.2 ha lies at Phuloc, 10,603.9 ha lies at Namdong, 9,851.5 ha lies at Huongtra and 729.1 ha lies at Aluoi district. The soil depth is more than $70 \mathrm{~cm}$, the soils are endowed with a strong acid ( $\mathrm{pH}$ kcl: 3.79 -5.2), the humus range from 0.32 to 2.8 percent, total nitrogen and available phosphorus are poor with total average nitrogen of 0.04 to 0.08 percent and the available phosphorus of 1.27 to 1.58 percent and the average available potassium changes from 2.90 to $6.50 \% \mathrm{mg} / 100$ gram soil (Table 3.5).

Table 3.5: The chemical properties of yellowish red soil on acid magma rock

\begin{tabular}{|l|l|c|c|c|c|c|}
\hline \multicolumn{1}{|c|}{ Location } & Range & $\left.\mathbf{( p H}_{\mathbf{k c l})}\right)$ & $\begin{array}{c}\mathbf{O M} \\
(\%)\end{array}$ & $\begin{array}{c}\mathbf{N} \\
(\%)\end{array}$ & $\begin{array}{c}\mathbf{P}_{\mathbf{2}} \mathbf{O}_{\mathbf{5}} \\
(\mathrm{mg} / 100 \text { g soil) }\end{array}$ & $\begin{array}{c}\mathbf{K}_{\mathbf{2}} \mathbf{O}_{\mathbf{5}} \\
(\mathrm{mg} / 100 \mathrm{~g} \text { soil) }\end{array}$ \\
\hline \multirow{4}{*}{ Huongtra } & Min & 3.79 & 0.32 & 0.06 & 0.39 & 4.53 \\
\cline { 2 - 7 } & Max & 4.70 & 1.49 & 0.08 & 3.57 & 13.2 \\
\cline { 2 - 7 } & Average & $\mathbf{4 . 1 9}$ & $\mathbf{1 . 3 9}$ & $\mathbf{0 . 0 8}$ & $\mathbf{1 . 3 0}$ & $\mathbf{5 . 1 8}$ \\
\hline \multirow{3}{*}{ Phuloc } & Min & 3.98 & 0.98 & 0.07 & 0.45 & 2.00 \\
\cline { 2 - 7 } & Max & 5.00 & 1.68 & 0.13 & 3.2 & 9.25 \\
\cline { 2 - 7 } & Average & $\mathbf{4 . 2 3}$ & $\mathbf{1 . 1 5}$ & $\mathbf{0 . 0 8}$ & $\mathbf{1 . 5 8}$ & 5.47 \\
\hline \multirow{3}{*}{ Namdong } & Min & 4.00 & 0.98 & 0.02 & - & - \\
\cline { 2 - 7 } & Max & 4.15 & 2.80 & 0.07 & - & - \\
\cline { 2 - 7 } & Average & $\mathbf{4 . 1 2}$ & $\mathbf{1 . 9 7}$ & $\mathbf{0 . 0 4}$ & $\mathbf{1 . 2 7}$ & $\mathbf{2 . 9 0}$ \\
\hline Aluoi & Average & $\mathbf{4 . 0 7}$ & $\mathbf{0 . 9 8}$ & $\mathbf{0 . 0 7}$ & $\mathbf{1 . 2 7}$ & $\mathbf{6 . 5 0}$ \\
\hline
\end{tabular}

\section{Yellowish red soils on sandstone}

The yellowish red soils on sandstone cover 78,443.5 hectares or 21.1 percent of the total forestry area, of which Aluoi and Phongdien occupy large areas are 32,626.5 and 43,897.9 ha respectively, Huongtra is 1,629.9 ha, and Phuloc is 289.2 ha. These soil types are distributed at elevation from 50 to $700 \mathrm{~m}$ above sea level. The soil texture is fine sand, the soil depth is more than $50 \mathrm{~cm}$, soil acidity ranges from moderately acid to strongly acid with $\mathrm{pH}_{\mathrm{kcl}}$ values of 3.92 4.86. Soil organic carbon in the surface layer varies from $0.66-1.76 \%$. Total nitrogen varies from 0.06-0.12 \%. Percentage of available $\mathrm{P}_{2} \mathrm{O}_{5}$ ranges from $0.93-5.82 \%$ while the percentage of available $\mathrm{K}_{2} \mathrm{O}_{5}$ ranges from 1.15-6.50 \% (Table 3.6). 
Table 3.6: The chemical properties of yellowish red soils on sandstone

\begin{tabular}{|c|c|c|c|c|c|c|}
\hline Location & Range & $\left(\mathrm{pH}_{\mathrm{kcl})}\right)$ & OM (\%) & $\mathrm{N}(\%)$ & $\mathbf{P}_{2} \mathbf{O}_{5}(\mathrm{mg} / 100$ g soil $)$ & $\mathbf{K}_{2} \mathbf{O}_{5}(\mathrm{mg} / 100$ g soil $)$ \\
\hline \multirow[t]{3}{*}{ Aluoi } & Min & 4.01 & 0.90 & 0.07 & 1.27 & 1.62 \\
\hline & Max & 4.23 & 1.63 & 0.09 & 4.32 & 4.15 \\
\hline & Average & 4.09 & 1.03 & 0.08 & 1.64 & 3.80 \\
\hline \multirow[t]{3}{*}{ Huongtra } & Min & 4.06 & 0.98 & 0.07 & 0.93 & 1.97 \\
\hline & Max & 4.86 & 1.76 & 0.09 & 4.43 & 6.50 \\
\hline & Average & 4.32 & 1.38 & 0.08 & 2.04 & 4.84 \\
\hline \multirow[t]{3}{*}{ Phongdien } & Min & 3.92 & 0.66 & 0.06 & 1.39 & 1.15 \\
\hline & Max & 4.54 & 1.28 & 0.12 & 5.82 & 2.09 \\
\hline & Average & 4.23 & 0.90 & 0.10 & 2.89 & 1.62 \\
\hline Phuloc & Average & 4.07 & 0.98 & 0.07 & 1.27 & 6.50 \\
\hline
\end{tabular}

\section{Yellowish red soils on metamorphic rock}

The yellowish red soil on metamorphic rock occupies the largest area among slopping lands in the province with an area of 194,843.5 hectare or 53.2 percent of the total forestry area or 38.5 percent of the total natural area of the province. This kind of soil distributes at the south and southwest of the study area and is located at elevation from 20 to $700 \mathrm{~m}$ above sea level. Most of the land areas are found at Aluoi (75,207.5 ha), Namdong (48,206.8 ha), Phongdien (16,644 ha), Huongthuy (30,678.4 ha), Huongtra (20,333.5 ha) and Phuloc district (3,862.0 ha). The soil layer varies from medium to thick, but unlike, The soil is characterized by its texture ranging from clay to loam, the soil is poor to medium in organic matter (OM: $0.90-2.80 \%$ ), the total nitrogen varies from 0.07 to $0.13 \%$, the available phosphorus in soils varies from 0.84 to $3.56 \mathrm{mg} / 100$ gram soil and the available potassium from 1.75 to $13.2 \mathrm{mg} / 100$ gram soil (Table 3.7).

Table 3.7: The chemical properties of yellowish red soil on metamorphic rock

\begin{tabular}{|c|c|c|c|c|c|c|}
\hline Location & Range & $\left(\mathrm{pH}_{\mathrm{kcl})}\right)$ & OM(\%) & $\mathbf{N}(\%)$ & $\mathbf{P}_{2} \mathbf{O}_{5}(\mathrm{mg} / 100$ g soil $)$ & $\mathbf{K}_{2} \mathbf{O}_{5}(\mathrm{mg} / 100$ g soil $)$ \\
\hline \multirow[t]{3}{*}{ Aluoi } & Min & 4.00 & 0.98 & 0.07 & 1.16 & 3.57 \\
\hline & Max & 4.12 & 1.25 & 1.11 & 2.26 & 6.50 \\
\hline & Average & 4.10 & 1.23 & 0.09 & 2.03 & 3.82 \\
\hline \multirow[t]{3}{*}{ Huongthuy } & Min & 3.84 & 0.90 & 0.07 & 1.00 & 2.06 \\
\hline & Max & 5.15 & 1.42 & 1.13 & 3.30 & 6.87 \\
\hline & Average & 4.35 & 1.21 & 0.10 & 2.02 & 4.56 \\
\hline \multirow[t]{3}{*}{ Huongtra } & Min & 4.07 & 1.02 & 0.07 & 0.84 & 1.75 \\
\hline & Max & 5.16 & 1.89 & 0.10 & 3.56 & 13.2 \\
\hline & Average & 4.31 & 1.43 & 0.09 & 1.83 & 3.70 \\
\hline \multirow[t]{3}{*}{ Phuloc } & Min & 3.92 & 1.17 & 0.07 & 0.36 & 2.10 \\
\hline & Max & 4.65 & 2.80 & 0.10 & 3.00 & 6.50 \\
\hline & Average & 4.07 & 1.32 & 0.08 & 1.33 & 3.05 \\
\hline \multirow[t]{3}{*}{ Phongdien } & Min & 4.0 & 1.04 & 0.09 & 1.25 & 2.16 \\
\hline & Max & 4.58 & 1.70 & 0.10 & 3.09 & 7.29 \\
\hline & Average & 4.17 & 1.29 & 0.09 & 1.89 & 5.09 \\
\hline \multirow[t]{3}{*}{ Namdong } & Min & 4.00 & 1.25 & 0.02 & 1.27 & 3.57 \\
\hline & Max & 4.15 & 2.8 & 0.09 & 2.16 & 6.50 \\
\hline & Average & 4.02 & 2.67 & 0.07 & 1.34 & 6.27 \\
\hline
\end{tabular}




\section{3) Thin layer soil group (Lithic Leptosoils)}

Thin layer soils are found at four districts of Phuloc, Huongthuy, Huongtra and Phong dien. They distributes at elevation below $100 \mathrm{~m}$ above sea level with an area of 7,945.2 hectare, of which Huongthuy is 1,312.7 ha, Huongtra is 1,993.2 ha, Phongdien is 1,573.9 and Phuloc is 3,065.3 ha. Most of land areas are thin layer (less than $30 \mathrm{~cm}$ ), their main features are very high soil acidity, the soils are poor in organic mater and total nitrogen, the available phosphorus varies between 0.61 and $430 \mathrm{mg} / 100$ gram soil, and the available potassium ranges from 2.10 to 6.92 mg/100 gram soil (Table 3.8)

Table 3.8: The chemical properties of thin layer soil

\begin{tabular}{|l|l|c|c|c|c|c|}
\hline $\mathbf{N o}$ & \multicolumn{1}{|c|}{ Location } & $\left.\mathbf{( p H}_{\mathbf{k c l})}\right)$ & $\begin{array}{c}\mathbf{O M} \\
(\mathbf{\%})\end{array}$ & $\begin{array}{c}\mathbf{N} \\
(\%)\end{array}$ & $\begin{array}{c}\mathbf{P}_{\mathbf{2}} \mathbf{O}_{\mathbf{5}} \\
(\mathrm{mg} / 100 \text { g soil) }\end{array}$ & $\begin{array}{c}\mathbf{K}_{\mathbf{2}} \mathbf{O}_{\mathbf{5}} \\
(\mathrm{mg} / 100 \text { g soil) }\end{array}$ \\
\hline 1 & Huongthuy & 3.99 & 1.07 & 0.06 & 1.19 & 3.93 \\
\hline 2 & Huongtra & 4.00 & 1.07 & 0.08 & 1.70 & 6.92 \\
\hline 3 & Phuloc & 3.90 & 1.13 & 0.07 & 0.61 & 3.37 \\
\hline 4 & Phongdien & 4.06 & 1.39 & 0.07 & 1.45 & 2.10 \\
\hline
\end{tabular}

\section{4) Alluvial soil group on river area (Dystric Fluvisoils)}

This kind of soil is found in all of river areas from the Northern to the southern province. Due to geographical and geological conditions, the soil is lower in organic matter and in total nutrients than other region of Vietnam (Table 3.9). This soil is mainly used for agricultural production, however, so far an area is approximately 6,930.2ha is used for forestry production, of which 2,671.2 ha lies at Aluoi, 1,288.0 ha lies at Huongthuy, 523.8 ha lies at Huongtra, 1,361.6 ha lies at Namdong, 780.9 ha lies at Phongdien and 304.7 ha lies at Phuloc district.

Table 3.9: The chemical properties of alluvial soils on river areas

\begin{tabular}{|l|l|c|c|c|c|c|}
\hline $\mathbf{N o}$ & \multicolumn{1}{|c|}{ Location } & $\left.\mathbf{( p H}_{\mathbf{k c l})}\right)$ & $\begin{array}{c}\mathbf{O M} \\
(\%)\end{array}$ & $\begin{array}{c}\mathbf{N} \\
(\%)\end{array}$ & $\begin{array}{c}\mathbf{P}_{\mathbf{2}} \mathbf{O}_{\mathbf{5}} \\
(\mathrm{mg} / 100 \text { g soil) }\end{array}$ & $\begin{array}{c}\mathbf{K}_{\mathbf{2}} \mathbf{O}_{\mathbf{5}} \\
(\mathrm{mg} / 100 \text { g soil) }\end{array}$ \\
\hline 1 & Aluoi & 5.07 & 1.39 & 0.08 & 2.88 & 6.39 \\
\hline 2 & Huongthuy & 5.50 & 1.37 & 0.13 & 1.36 & 8.70 \\
\hline 3 & Huongtra & 4.25 & 1.23 & 0.10 & 1.47 & 9.25 \\
\hline 4 & Namdong & 4.11 & 2.63 & 0.06 & 3.11 & 6.79 \\
\hline 5 & Phuloc & 4.10 & 0.97 & 0.17 & 0.86 & 2.82 \\
\hline 6 & Phongdien & 4.68 & 1.40 & 0.10 & 3.24 & 5.01 \\
\hline
\end{tabular}

\section{- Distribution and basic features of coastal sand soil types.}

The coastal sand soil is found on low and flat areas, on fixed moving sand dunes at elevations below $15 \mathrm{~m}$ above sea level along the coasts of Thua Thien Hue from North to South. These kinds of sandy soil is located in Phongdien, Quangdien, Phuvang and Phuloc district, total area 
of sandy soil covers about 48,400 ha, of which the percentage of sandy soil in interior field is 83 percent and the sandy dunes only is 17 percent.

Total area of sandy soil which is used for forestry is about 21,826.8 hectare, of which Phong dien is $12,858.8$ ha or 58.9 percent, Phuvang is $4,277.9$ ha or 19.6 percent, Quangdien is 3,359.7 ha or 15.4 percent, Phuloc is $1,036.6$ ha or 4.7 percent and Huongtra is 293.8 ha or 1.3 percent of total area of forestry land.

From 2003 to 2005, a group of soil scientists of the Institute of Geography, Ho Chi Minh city and Forest Inventory and Planning, Thua Thien Hue and Forestry faculty of HUAF also had an intensive land surveys and produced the sandy soil maps for coastal districts. Based on the results of land surveys made by soil scientists, the classification of sandy soil for forestry production was presented as follows:

O Inland sandy soil group.

o Yellow and white sandy soil group on dunes.

The main properties of sandy soil, especially coastal soil has loose structure, non-sticky plasticity and low water holding capacity. Water and wind erosion occur throughout the year. In general, the sandy soil has quite low contents of humus, total $\mathrm{N}$ and $\mathrm{P}_{2} \mathrm{O}_{5}$ and $\mathrm{K}_{2} \mathrm{O}$, and low soil $\mathrm{pH}$ values.

A soil survey in order to produce sandy soil maps was undertaken with 402 samples, of which 300 samples were collected for analysis. According to soil scientists, the sandy soils acidity ranges from strongly acid to very strongly acid, the soils are very low in Organic Matters (OM), $\mathrm{pH}$, total Nitrogen, total phosphorus and available.

\section{1) Inland sandy soil group}

There are four main sandy soil types that have been used for forestry use in inland sandy soil of the study area, these are:

a) Typical sandy soil

b) Typical acid sandy soil

c) Exhausted white sandy soil

d) Gley sandy soil

These soil types have a low percentage of clay particles but a very high percentage of fine sand. The sand content of these surface soils ranges from 95.2 to 97.7 percent. The typical acid sandy soil has the highest amount of OM (1.12 \%) compares to the gley sandy soil at the same depth (1.06 \%), the typical sandy soil (0.85 \%) and the exhausted white sandy soil (0.4 \%). The largest 
amount of total nitrogen is the similar to OM for the surface soil. Percentage of total phosphorus $\left(\mathrm{P}_{2} \mathrm{O}_{5}\right)$ ranges from 0.0042 to $0.017 \%$ and available phosphorus varies from 0.26 to $0.19 \mathrm{mg} / 100$ g soil (Table 3.10).

Table 3.10: Chemical properties of inland sandy soil group

\begin{tabular}{|l|c|c|c|c|c|}
\hline \multicolumn{1}{|c|}{ Name of soil types } & $\mathbf{p H}_{\mathbf{k c l}}$ & $\begin{array}{c}\mathbf{O M} \\
(\%)\end{array}$ & $\begin{array}{c}\mathbf{N} \\
(\%)\end{array}$ & $\begin{array}{c}\mathbf{P}_{\mathbf{2}} \mathbf{O}_{\mathbf{5}} \\
(\%)\end{array}$ & $\begin{array}{c}\mathbf{P}_{\mathbf{2}} \mathbf{O}_{\mathbf{5}} \\
(\mathrm{mg} / 100 \mathrm{~g} \text { soil })\end{array}$ \\
\hline Typical sandy soil & 3.79 & 0.850 & 0.018 & 0.0042 & 0.1900 \\
\hline Typical acid sandy soil & 3.95 & 1.120 & 0.041 & 0.005 & 0.0600 \\
\hline Exhausted white sandy soil & 3.80 & 0.404 & 0.025 & 0.0045 & 0.0036 \\
\hline Gley sandy soil & 3.56 & 1.06 & 0.029 & 0.0026 & 0.2600 \\
\hline
\end{tabular}

\section{Typical sandy soil (Haplic Arenosols)}

Typical sandy soil is located in inland sandy soil with an area of 2,864.32 ha, it is found on flat areas at elevations of 5-10 m. The kind of this soil occupies 15.82 percent of total sandy area.

The total area of this soil types for forestry production is $6,492.5$ or 29.7 percent of the total area of forestry sandy soil, of which 4,133.9 ha is at Phongdien, 1,635.4 ha is at Quangdien and 723.2 ha is at Phuvang district. Many kinds of Acacias such as Acacia auriculiformis, Acacia mangium, A.hybrid and A. crassicarpa have been grown for several sites of this sandy soil type. However, the growth of these tree species is rather low because of low soil fertility.

The soil acidity ranges from strongly acid to very strongly acid with $\mathrm{pH}_{\mathrm{kcl}}$ values of 3.79 in surface layer $(0-15 \mathrm{~cm})$ and 5.19 in lower layer $(90-120 \mathrm{~cm})$. The surface soil has a higher amount of OM (0.85 \%) compares to lower layer of 90-120 cm (0.39\%). The total nitrogen and the available phosphorus decrease from surface soil to lower layers (the total nitrogen is $0.018 \%$ for the surface soil and 0.011 for the lower layer, the available phosphorus of the surface soil is 0.19 and the lower layer is $0.14 \mathrm{mg} / 100 \mathrm{~g}$ soil).

\section{The typical acid sandy soil (Dystry Haplic Arenosols)}

Total area of the typical acid sandy soil is 700.8 ha or 3.2 percent of total area of sandy land for forestry production, it is only found at Phongdien district. At present most of this sandy soil is covered by small shrubs and a part of area still is bare soil. This kind of soil is being seriously degraded by wind and water erosion. Moreover, it is located at an elevation higher than other sandy soil, therefore the soil is very dry and poor in nutrient.

The physical property of the soil is similar to the typical sandy soil with a high percentage of sandy content (97-98\%), the clay is only found in surface soil (1.24 \%) and the silt content ranges from 1 to $1.7 \%$. 


\section{Exhausted white sandy soil (Albic Arenosols)}

The exhausted white sandy soil covers an area of 3,629.96 ha, of which forestry land occupies 3,153.5 hectare or 14.1 percent. Distribution of the land for purpose of the forestry use at Phuvang is 1,308.4 ha, Phongdien is 1,448.0 ha and Quangdien is 397.2 ha. This kind of sandy soil is being seriously degraded. The soils is very dry, and susceptible to wind and water erosion. The soil has a high percentage of sand, $97.74 \%$ is sand content and $2.26 \%$ is silt content for surface soil and $98.08 \%$ is sand content and $1.91 \%$ is silt content for lower layer $(15-35 \mathrm{~cm})$ and there is no clay content for both soil layers. The soil has a lowest amount of OM compares to other sandy soil at the same soil depth. The Organic mater of surface soil $(0-15 \mathrm{~cm})$ is $0.78 \%$, while the lower layers $(15-35 \mathrm{~cm}$ and $35 \mathrm{~m}-180 \mathrm{~cm})$ have only 0.1 and $0.03 \%$ respectively. The soil is very poor in total nitrogen, total phosphorus and available phosphorus and these nutrients decrease from surface soil to lower layers.

\section{Gley sandy soil (Gleyic Arenosols)}

The gley sandy soil is used for forestry production which is found on low and flat areas in inland sandy areas with a fair big area of 2,227.8 ha, of which 1,802.4ha is at Phongdien, and 475.3 ha is Quangdien district.

This kind of soil has a sand content of $84-96 \%$ and a low percentage of clay, but compared to other sandy soil, it has a fair percentage of clay and silt (the clay content varies from 0.72 to 3.48 $\%)$. The surface soil $(0-15 \mathrm{~cm})$ has the mount of clay and silt is $1.3 \%$ and $3.41 \%$ respectively and especially the lower layer $(100-120 \mathrm{~cm})$ has the higher mount of clay and silt (3.48 \% for clay and $10.47 \%$ for silt). The total nitrogen is very low, $0.029 \%$ for surface layer and 0.011 for lower layer (15-35). The total phosphorus is also very poor, $0.0026 \%$ for surface layer and 0.018 \% for soil layer of 15-35 cm (Nguyen Van De, et al., 2005).

\section{2) Yellow and white sandy soil group on dunes (Luvic Arenosols)}

The kind of sandy soil is located along the coasts of Thua Thien Hue with an area of 19,771 ha, of which 9,125.5 hectare is used for forestry production. Sand beaches and dunes are found here, they are greyish white in colour. Sandy particles are found in layers on beaches, while sand dunes as they are formed by prevailing sea winds are of fine sand and have no clear layers. The main properties of sandy soils have a very high percentage of loose sand, subjected to the saltation process by sea winds. The soil is very poor in total nitrogen and $\mathrm{P}_{2} \mathrm{O}_{5}$ and $\mathrm{K}_{2} \mathrm{O}$, and the soil $\mathrm{pH}$ varies from 5.10 to 5.25 


\subsubsection{Current status of forest soils and their potential for forest development}

The total natural area of Thua Thien Hue province is about 505,339 ha, including 361,891 ha of forestry land and 139,448 ha of other land. Distribution of forestry land can be classified into two land types as follows: The forested land is $180,751.9$ ha and the Non-forested land is 185,139.5 ha.

The non-forest land of the study area, occupies on hilly and mountainous areas of 344,064.2 ha, equivalent to $68.1 \%$ of the total provincial area and on coastal sand dunes and inland sandy area of 10,286.9 ha. The gradual decreased distribution of the non-forest land for different forest soil types as follows: $38.6 \%$ for yellowish red soil on argillaceous and metamorphic rock, $15.5 \%$ for yellowish red soil on sandstone, $10.1 \%$ for yellowish red soil on cid magma rock, $1.8 \%$ for yellow and white sandy soil, $1.6 \%$ for thin layer soil, $1.4 \%$ for alluvial soils on river areas, 1.3 \% for typical sandy soil, $0.9 \%$ for yellowish brown soil on old alluvia, $0.6 \%$ for exhausted white sandy soil, $0.5 \%$ for gley sandy soil and $0.1 \%$ for typical acid sandy soil (Table 3.11).

The forest soil, especially on hilly and mountainous area will be a potential but also a challenge for forestry use in the future, because most of the forest soil on the degraded, slope and scattered in distribution.

Table 3.11: Current status of forest soils in the study area

\begin{tabular}{|l|r|r|r|c|}
\hline \multicolumn{1}{|c|}{ Name of soil types } & \multicolumn{1}{c|}{$\begin{array}{c}\text { Forested } \\
\text { area }\end{array}$} & $\begin{array}{c}\text { Non-forested } \\
\text { area }\end{array}$ & \multicolumn{1}{c|}{$\begin{array}{c}\text { Total } \\
\text { area }\end{array}$} & \multicolumn{1}{c|}{$\begin{array}{c}\text { \% of total } \\
\text { area }\end{array}$} \\
\hline Alluvial soils on river areas & $5,673.5$ & $1,256.7$ & $6,930.2$ & 1.4 \\
\hline Thin layer soil & $3,206.2$ & $4,739.0$ & $7,945.2$ & 1.6 \\
\hline Yellowish brown soil on old alluvia & $3,644.3$ & $1,117.1$ & $4,761.4$ & 0.9 \\
\hline Yellowish red soil on acid magma rock & $23,413.1$ & $27,727.8$ & $51,140.9$ & 10.1 \\
\hline Yellowish red soil on sandstone & $47,269.2$ & $31,174.3$ & $78,443.5$ & 15.5 \\
\hline $\begin{array}{l}\text { Yellowish red soil on metamorphic } \\
\text { rock }\end{array}$ & & & & \\
\hline Typical sandy soil & $86,005.8$ & $108,837.7$ & $194,843.5$ & 38.6 \\
\hline Exhausted white sandy soil & $24,87.4$ & $4,005.1$ & $6,492.5$ & 1.3 \\
\hline Gley sandy soil & $3,000.1$ & 153.4 & $3,153.5$ & 0.6 \\
\hline Typical acid sandy soil & 406.7 & $1,947.9$ & $2,354.6$ & 0.5 \\
\hline Yellow and white sandy soil & 415.7 & 285.1 & 700.8 & 0.1 \\
\hline Other land & $5,229.9$ & $3,895.4$ & $9,125.3$ & 1.8 \\
\hline \multicolumn{1}{|r|r|r|}{ Total } & - & - & $139,448.0$ & 27.6 \\
\hline
\end{tabular}

\section{Yellowish red soil group}

The main characteristics of a yellowish red soil group are described by Vietnamese soil scientists as follows: 
- The soil has a low amount of organic matter and the process of decomposition is quite high resulting in a low $\mathrm{C} / \mathrm{N}$ ratio of $8-11 \%$.

- The reaction of soil is acid with low percentage of base saturation.

- High total phosphorus but low available phosphorus because the presence of $\mathrm{Fe}$ and $\mathrm{Al}$ percentage is high.

- The potassium content is low.

- The process of potassium degradation seems to be immediate after deforestation, with organic matter content and soil depth all becoming less and less.

- The soils are rich in clays, they have good structure and drainage under the forest but when the forest cover is cleared, the forest soils can get very dry and compact and both their structure and drainage severely destroyed.

The yellowish red soil group developed on a range of different parent materials has a variable productivity potential, the main points of which are:

The yellowish red soil on argillaceous and metamorphic rock has medium productivity potential, this soil type has good physical conditions and is richer in nutrients than the other yellowish red soils. It can be found easily at all districts of hilly and mountainous area and occupies a biggest area of 194,830 ha, of which the soils are the sites of forested area $(23,413.1$ ha) and non-forested area $(27,727.8 \mathrm{ha})$.

The yellowish red soil developed on sandstone has lower productivity potential than the yellowish red soil on argillaceous and metamorphic rock because of their fine sand texture, poor soil texture and low tree nutrients. This kind of soil is found at four districts of Aluoi, Phongdien, Huongtra and Phuloc ditrict with an area of 78,443.5 ha, of which 47,269.2 ha lies in forested area and 31,174.3 ha lies in non- forested area.

The yellowish red soil developed on acid magma rock has a lower productivity potential than the yellowish red soil on argillaceous and metamorphic rock but a higher one than the yellowish red soil developed on sandstone. It can be seen on mountainous sides of Phuloc, Namdong and Huongtra district with an area of 51,140.9 ha, the forested area is 23,413.1 ha and non- forested area is $27,727.8$ ha.

\section{Yellowish brown soil group}

The yellowish brown soil developed on its parent material is old alluvia, thus providing colour to soil developed on it. This kind of soil proves to be more productive than red ones because of better structure (from loam to clay loam) and richer in tree nutrients. The total area of this soil 
types is 4,761.4 ha, of which 3,644.3ha is forested area and 1,117.1ha is non- forested area. It can be found on undulating hillsides mainly at Aluoi, Huongtra, Huongthuy and Namdong district.

\section{Thin layer soil group}

This group is found on the tops and upper of the study area at four districts (Huongthuy, Huongtra, Phuloc and Phongdien). The group includes all soil types with thin and very thin layers. Generally speaking the soil is low in organic mater, total nitrogen, $\mathrm{pH}$ and N,P,K. In comparison with other soils, the thin soil group has lowest productivity potential with an area of 7,945.2 ha, of which 3,206.2 ha lies in forested area and 4,739.0 lies in non- forested area.

\section{Alluvial soil group}

The alluvial soil on the river area is well known for its high productivity potential because of loam texture, high organic mater and nitrogen content and good soil structure. The alluvial materials of different river basins have different properties, most of the alluvial soil is very fertile and highly productive and is used for farming crops such rubber, maize and banana. However, so far the soil has lower productivity potential it is used for development of forest plantation such as Acacia and Casuarinas. This kind of soil is a good producer of wood. It can be found in flat areas with a forested area of 5,673.5 ha and non- forested area of 1,256.7 ha.

\section{Sandy soil group}

Sandy soils are often considered as soils with many limitations because of weak structure or no structure, poor water retention properties, high permeability and very low in tree nutrients.

The gley sandy soil has highest productivity potential compares to other sandy soil because of thick surface layer, good physical property, fair amount of OM and good soil moisture of many months during the year. This kind of soil is said to be suitable for both framing crops, depending much on the supply of water from ground water table. Therefore, an area of 1,947.9 ha still is unused, while many kinds of Acacia have been grown for several sites with an area of 406.7 ha. However, the growths of theses species in this sandy soil are rather low.

The typical sandy soil and typical acid sandy soil have lower productivity potential than the gley sandy soil because of its limitations such as low organic mater, low tree nutrient, coarse sand texture and low soil moisture during the year. This kind of sandy soil is considered to be suitable for forestry development, however a fair big area of 4,290.2 ha still is unused, of which the typical sandy soil is 4,005.1 ha and the typical acid sandy soil is 285.1 ha. 
The exhausted white sandy soil has the lowest productivity potential compared to other sandy soils because of high percentage of sand and very low tree nutrients. This sandy soil is considered as the soil with most limitations and it is not suitable for farm crops. Most of the land area is used for development of forest plantation but the quality and efficiency of forest plantation is very low.

Yellow and white sandy soil on dunes for the development of forestry is covering an area of 9,125.3 ha, due to limitation by water drainage and poor productivity potential. Therefore, many coastal sandy soils still remain under fallow (3,895.4 ha).

\subsubsection{Forest types}

\subsubsection{Forest types based on the major purpose of utilization}

The forests are classified into three forest types: Production, protection and special use forests, as defined by the Forest Protection and Development. Vietnam had 6.2 million hectare or 49.0 percent of protection forests, 4.48 million hectare or 35.8 percent of production forests, and 1.93 million hectare or 15.2 percent of special-use forests in 2006 (Table 3.12). The main role of production forests is to supply timber and non-timber forest products (NTFP). In addition they provide environmental protection. The protection forests are maintained to protect water stream and soils, mitigate natural disasters and prevent soil erosion. The special use forest has a main purpose: natural conservation, protection historical and cultural relics, tourism, and to some extent, environmental protection.

Table 3.12: Forest types in Vietnam

\begin{tabular}{|l|c|c|}
\hline Forest classification & Area (million ha) & $\mathbf{\%}$ \\
\hline Special-use forest & 1.93 & 15.2 \\
\hline Protection forest & 6.20 & 49.0 \\
\hline Production forest & 4.48 & 35.8 \\
\hline Total area & $\mathbf{1 2 . 6 1}$ & $\mathbf{1 0 0}$ \\
\hline
\end{tabular}

Source: Vietnam forestry development strategy 2006-2020 (MARD 2006).

The government promulgated Decree 08/QD of 2001, to regulate the management of these three forest types. The Decree of special -use forest is sub-divided as follows:

1) National parks.

2) Natural reserves, further sub-divided into flora habitat reserves and natural reserves, and.

3) Historical and environmental relics or landscape-protected areas.

Related to available data of the Department of Agriculture and Rural Development, the total area of land with forest cover of Thua Thien Hue province is 214,184 hectare or 42.4 percent of the total natural area, consisting of 120,541 hectare of protection forests, 29,517 hectare of special 
use forests (Bachma National Park, Phongdien Nature Reserve and Haivan Nature Reserve) and 64,125 hectare of production forest.

\subsubsection{Forest types based on the forest origin}

The forest is classified in two categories on forestland, consisting of natural forest and plantation forest. According to the Ministry of Agriculture and Rural Development (MARD), the total national area of Vietnam is 12.61 million hectare, including 2.33 million ha of forest plantation, and 10.28 million hectare of natural forest, of which 1.8 percent of the natural forest area and 2.0 percent of the forest plantation is distributed in Thua Thien Hue province.

\section{The natural forest}

The natural forest of Thua Thien Hue covers 170,243 hectare. The kinds of this forest type were originally classified by criteria based on the standing timber volume according to forestry criteria, consisting of rich forest (more than $150 \mathrm{~m}^{3} / \mathrm{ha}$ ), medium forest (80-150 $\mathrm{m}^{3} / \mathrm{ha}$ ) and poor forest (less than $80 \mathrm{~m}^{3} / \mathrm{ha}$ ).

The area of rich, medium and poor quality natural forests in Thua Thien Hue are still declining, especially in the area surrounding the roads, rivers and villages. The medium and rich quality natural forests with a forest stock of more than $80 \mathrm{~m} 3 / \mathrm{ha}$, were recently estimated to occupy up to 24 percent of total natural forest area.

Formally, the natural forests in the province would have been classified in two types of forest: 1) dense natural forest and 2) degraded natural forest.

\section{The dense natural forest}

The dense natural forests are found mainly along the border between the province and LAOS, Thua Thien Hue with Quang Nam and Quang Tri province. Disturbance is minimal, the structure of forest is from dense to very dense and largely intact. The forest has a lot of stratification, and it is generally stratified into five layers such as: Emergent layer, canopy layer, middle layer, shrub layer and ground layer. This kind of forest type is divided into two subclasses: montane closed evergreen subtropical monsoon forest and closed evergreen tropical monsoon forest (rich forest and medium forest).

The montane closed evergreen subtropical monsoon forest is distributed at an elevation above $900 \mathrm{~m}$. The main species in this forest types are from families of Fagaceae, Diterocarpecea, and Theaceae. 
The closed evergreen tropical monsoon forest is distributed within the lowland and lower montane zone $(500-900 \mathrm{~m})$. The main species presented belong to families of Sapindaceae, Sterculiaceae, Fabceae, Lauraceae and Diterocarpecea. The most tree species of economic value (Hopea pierrei, Erythrophleum spp., Sindora siamensis, Sindora tonkinensis, Madhuca pasquieri, Parashorea stellata, Heritiera cochinchinensis and Nageia wallichiana), and rare tree species (Cassia siamea) are found in this forest type.

\section{The degraded natural forest}

This forest is found at an elevation lower than $500 \mathrm{~m}$ above sea level, the kind of this forest is classified into two sub- classes: Secondary forest/opened forest and young secondary forest.

The secondary forest/opened forest (poor forest): This forest type is distributed in easily accessible and exploitable areas, such as along rivers and streams, and close to roads. This forest type has been seriously degraded, and the forest canopy is open. Canopy cover is only about 15$60 \%$ and there is no clear stratification into forest layers. Tree species of high economic value are rare. Even trees with low economic value, such as Ormosia dasycarpa, Cratoxylon formosum, Polyalthia nemoralis and Calophyllum spp., have been heavily exploited.

The young secondary forest (regenerating forest): This forest growing back in clear-cuts is resulting either from agriculture or logging. There are two classes of young secondary forest in Thua Thua Thien Hue: 1) heavily disturbed, immature secondary growth interspersed with remnant mature trees: The forest structure and tree component of the kind of this forest is similar to dense forest and 2) pioneer communities on fallow areas previously under shifting cultivation: The vegetation is dominated by fast-growing pioneer species, such as Macaranga denticulate, Macaranga andersonii, Trema orientalis, and other desiccation-tolerant species.

\section{The forest plantation}

According to the Department of Agriculture and Rural Development, the total area of forest plantation and perennial industrial trees is more than 43,940 ha, the growth of forest plantation has contributed significantly to Thue Thien Hue's forest cover. The dominant tree species in forest plantation are acacia, pine, rubber and some indigenous species.

\subsection{Social economic structure}

Thua Thien Hue is divided into nine administrative units including the major city of Hue, two districts in the mountainous areas (Namdong and Aluoi), four districts in the plain and hilly areas (Phongdien, Huongtra, Phuloc and Huongthuy) and two districts in coastal sandy areas (Phuvang 
and Quangdien). It is consisting of major ethnic groups like Viet (Kinh), Catu, Taoi, Vankieu, Bru and H'mong. The population is about 1,101,228 people, most of whom are Buddhist. Most people live on the coastal plain, within $25 \mathrm{~km}$ of the coast. Therefore we find a difference of population density inside the districts (Table 3.13). The largest part of the interior of the province has a population density of less than 50 people per sq. $\mathrm{km}$.

Table 3.13: Distribution of population for eight districts and Hue city

\begin{tabular}{|l|l|c|}
\hline Districts & Administrative structure & Population \\
\hline Phu loc & 16 communes and two townlets & 148,985 \\
\hline Aluoi & 20 communes and one townlet & 38,258 \\
\hline Nam dong & 11 communes and one townlet & 21,044 \\
\hline Huongthuy & 11 communes and one townlet & 92,000 \\
\hline Phuvang & 19 communes and one townlet & 178,968 \\
\hline Huongtra & 15 communes and one townlet & 114,021 \\
\hline Phongdien & 15 communes and one townlet & 101,425 \\
\hline Quangdien & 10 communes and one townlet & 91,527 \\
\hline Hue city & 25 wards and communes & 315,000 \\
\hline Total & - & $\mathbf{1 , 1 0 1 , 2 2 8}$ \\
\hline
\end{tabular}

Source: Statistical offices of eight districts and Hue city, central Vietnam (2006).

The socio-economic situation in the study area is in many ways not similar to other province in Vietnam. More than 80 percent of the local people make their occupation through farming, predominately wet rice production, they are also grown upland rice but only for consumption not for trading. The forestry production has increased in recent years, the value of agriculture, aquaculture and forestry only occupies 8.7 percent of GDP, the economic growth rate is expected to reach 9.6 percent during the period 2001-2005. The average per capita income is still low at around 580 USD per year and 7.5 percent of households are classified as poor, income varies from district to district depending on environmental conditions. The province has a great potential in developing forestry, but without alternative economic incentives to forestry, many households continue to use and commercial illegal forest products, such as timber, firewood, and non-wood forest products.

\subsection{Forest laws and forest policies}

At present, the Vietnam government has given high priority to forestry, as stipulated by a series of laws and legal documents. The forest laws and forest policies and other relevant policies are main factors that influence forestry activities in Vietnam in general and Thua Thien Hue in particular. The land law and some policies related to forestry activities are summarised in the following table. 
Table 3.14: National policies impacting forestry activities in Thua Thien Hue province (19912006)

\begin{tabular}{|c|c|c|}
\hline No & Policy area & Main policies \\
\hline 1 & $\begin{array}{l}\text { Forest } \\
\text { management }\end{array}$ & $\begin{array}{l}\text { The Decision 08/2001-Regulates the management of special use forests, } \\
\text { production forests and protection forests. } \\
\text { The Forest Protection and Development Law } 1991 \text { and } 2004 \text {. }\end{array}$ \\
\hline 2 & $\begin{array}{l}\text { Land } \\
\text { policies and } \\
\text { beneficiary } \\
\text { policies }\end{array}$ & $\begin{array}{l}\text { The Decision 327/CT dated } 15 \text { September 1992: On policies the use of } \\
\text { bare land and denuded hills, coastal alluvial areas and water surfaces. } \\
\text { The } 1993 \text { Land Law. } \\
\text { The Decree No.01/CP,1994: Forest land contracts } \\
\text { The Decree No.02/CP dated } 15 \text { January 1994: Regulates forestland } \\
\text { allocation to organization, households and individuals for sustainable and } \\
\text { long-term use. } \\
\text { The Decree No 01/CP/1995 regarding land allocation for farming } \\
\text { cultivation, forest production and aquaculture by state owned enterprises. } \\
\text { The } 1998 \text { Land Law (revised). } \\
\text { The Decision 661/QD dated } 29 \text { July } 1998 \text { : On objective, duties, policies } \\
\text { and implementing organizations of the five million hectare reforestation } \\
\text { project (5MHRP). The } 5 \mathrm{MHRP} \text { which is being executed between } 1998 \\
\text { and } 2010 \text { in order to increase forest cover to } 43 \text { percent. } \\
\text { The Decree No.163/1999 dated } 16 \text { November 1999:On forestland } \\
\text { allocation, lease and landing to organizations, households and individuals } \\
\text { for sustainable and long-term use. } \\
\text { The Decision 178/2001: On the beneficiary rights and obligations of } \\
\text { households and individuals who have forests and forest land allocated, } \\
\text { leased and lent. } \\
\text { The } 2003 \text { Land Law (revised) }\end{array}$ \\
\hline
\end{tabular}

In 1991, the "Tropical Forestry Action Plan, the Forest Resources Protection and Development Act, and the first National Forest Policy" allocated forestland for households to manage and use, shifting responsibility away from State Forest Enterprises. The Ministry of Agriculture and Rural Development (2004) introduced the new Forest Protection and Development law which gives a clearer framework for the management and the use of protection forest. The intention was that this could lead to enhance management system which would better combine protection with production. Vietnam has created its own form of "community-based" resource management, in 
which the role of local people and their traditional forest management practices are considered to be important components of overall forest management.

In Vietnam, the policies on forest and forestland allocation have been implemented since 1983 through Decision No.184 from that years and strengthened and the promulgation of the 1993 Land Law. The revised Land Law of 1998 and the recent Land Law of 2003 defined local responsibilities and different authorities' spheres of administrative control over forestland. The Land Law gives local authorities influence and allocates use rights to households. Thomas Sikor and Ulrich Apel had an assessment of the forest laws in Vietnam as follows: "The 1993 Land Law gave local people extensive rights over forest land. The law stipulates that long-term usufruct rights should, for most lands be issued to non-state entities, including households, groups of households, and organizations. Therefore use rights include permission to exchange, transfer, lease, mortgage, and pass on land for inheritance. The state is restricted to specifying only the broad purpose for which an allocated plot is to be used and its ability to recover land is narrowly defined. Decree 2/CP (1994) specifies that use rights granted for forest land should extend over period of 50 years.” 


\section{Data, Tools and Fieldtrip}

\subsection{Data}

\subsubsection{Satellite data}

Landsat data support a wide range of applications including global change research, agriculture, forestry, geology, resource management, mapping, water quality, oceanography, research and outreach, and visualization and simulation. Landsat data is useful for large study areas that do not require high resolution for analysis. It is less expensive than QuickBird and Spot imagery, but may not be appropriate for all applications. Landsat data provides more bands available than QuickBird or SPOT which allows a breadth of multi-spectral analysis (USGS 17.05.2004).

Landsat 7 has a sun-synchronous with a $98.2^{0}$ inclination and an altitude of $705 \mathrm{~km}$. It has a swath width of $185 \mathrm{~km}$ and a repeat coverage interval of 16 days. Landsat 7 is the newest in this series of remote sensing satellites which was launched on 15 April 1999. Landsat 7 carries the new Enhanced Thematic Mapper Plus (ETM+) instrument. This instrument has the same 7 spectral bands as its predecessor TM (Landsat 4 and 5), but has an added panchromatic band with $15 \mathrm{~m}$ resolution and a lower resolution $60 \mathrm{~m}$ thermal band. The ETM+ product provides greater spectral variation allowing for more detailed analysis of the land cover present within the image. The wide spectral range of both the ETM+ and the TM instrument allow for the identification and isolation of various types of land cover.

The potential applications of Landsat ETM + image are useful for image interpretation for a much wider range of applications than Landsat MSS images. This is because the ETM + has both an increase in the number of spectral bands and an improvement in spatial resolution compared to MSS. With the decreased IFOV of ETM + data, these are containing mixed pixels which are smaller and interpretation accuracies are increased. ETM + 's improved spectral and radiometric resolution also aid image interpretation. The radiometric characteristics of ETM + and its application were shown in table 4.1 .

Three Landsat ETM + images (path-row 125/49) were used in this study as a source for forest and land cover mapping. The first two images were acquired on 31 January and 24 April 2003 and the most recent image was acquired on 7 April 2004. However, ETM+ data in April 2004 is bad quality and this month of image is similar to ETM+ data of 2003. Moreover two dates: 31 January and 24 April were found to be the most suitable dates for discrimination of vegetation 
types, therefore ETM + data of 7 April 2004 were used as reference data. The full scenes were not required for the achievement of this study, the subsets of the images were extracted to match approximately the same coverage with the study area (Fig. 4.1, 4.2 and 4.3).

Table 4.1: Landsat ETM + wavelength and its applications

\begin{tabular}{|c|c|c|c|}
\hline $\begin{array}{l}\text { Band } \\
\text { number }\end{array}$ & $\begin{array}{l}\text { Spectral range } \\
\text { (microns) }\end{array}$ & EM region & Generalised application details \\
\hline 1 & $0.45-0.515$ & Blue & $\begin{array}{l}\text { Designed for water body penetration making it } \\
\text { useful for coastal water mapping. Also useful for } \\
\text { soil/vegetation discrimination, forest type } \\
\text { mapping, and cultural feature. }\end{array}$ \\
\hline 2 & $0.525-0.605$ & Green & $\begin{array}{l}\text { Designed to measure green reflectance peak of } \\
\text { vegetation for vegetation discrimination and } \\
\text { vigor assessment. Also useful for cultural feature } \\
\text { identification. }\end{array}$ \\
\hline 3 & $0.63-0.690$ & Visible Red & $\begin{array}{l}\text { Designed to sense in a chlorophyll absorption } \\
\text { region aiding in plant species differentiation. } \\
\text { Also useful for cultural feature identification }\end{array}$ \\
\hline 4 & $0.75-0.90$ & Near Infrared & $\begin{array}{l}\text { Use full for determining vegetation types vigor } \\
\text { and biomass content, for delineating water } \\
\text { bodies, and for soil moisture discrimination. }\end{array}$ \\
\hline 5 & $1.55-1.75$ & Middle Infrared & $\begin{array}{l}\text { Indicative of vegetation moisture content and soil } \\
\text { moisture. Also useful for differentiation of snow } \\
\text { from clouds. }\end{array}$ \\
\hline 6 & $10.40-12.50$ & $\begin{array}{l}\text { Thermal } \\
\text { Infrared }\end{array}$ & $\begin{array}{l}\text { Thermal mapping, soil moisture studies and plant } \\
\text { heat stress measurement }\end{array}$ \\
\hline 7 & $2.09-2.35$ & Middle Infrared & $\begin{array}{l}\text { Useful for discrimination of mineral and rock } \\
\text { types. Also sensitive to vegetation moisture } \\
\text { content. }\end{array}$ \\
\hline 8 & $\begin{array}{l}0.52-0.90 \\
\text { (panchromatic) }\end{array}$ & $\begin{array}{lr}\text { Green, } & \text { Visible } \\
\text { Red, } & \text { Near } \\
\text { Infrared } & \\
\end{array}$ & Large area mapping, urban change studies. \\
\hline
\end{tabular}

Source: Australia centre for remote sensing 


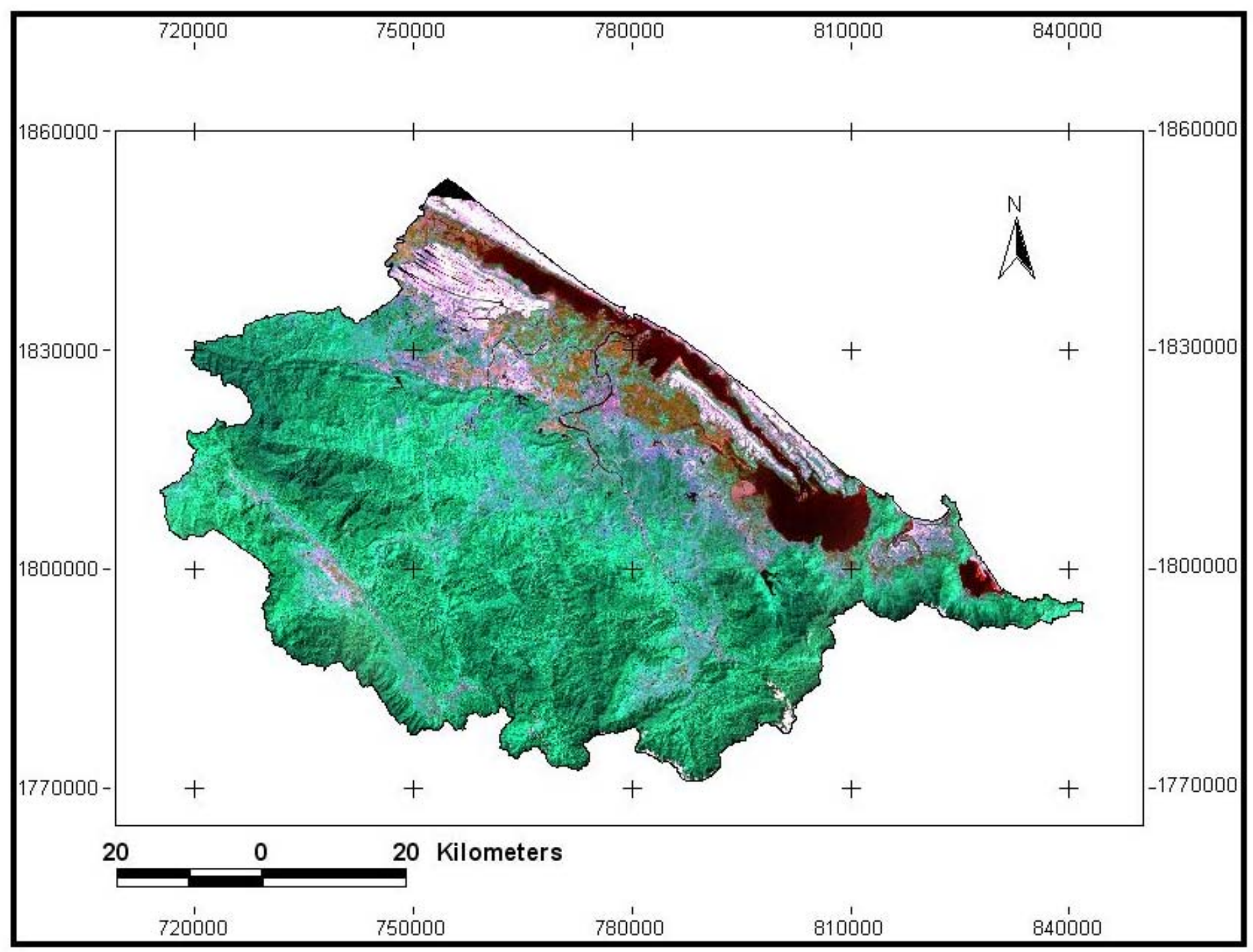

Figure 4.1: Landsat ETM + image subset of 31 January 2003 of the study area, RGB 345 


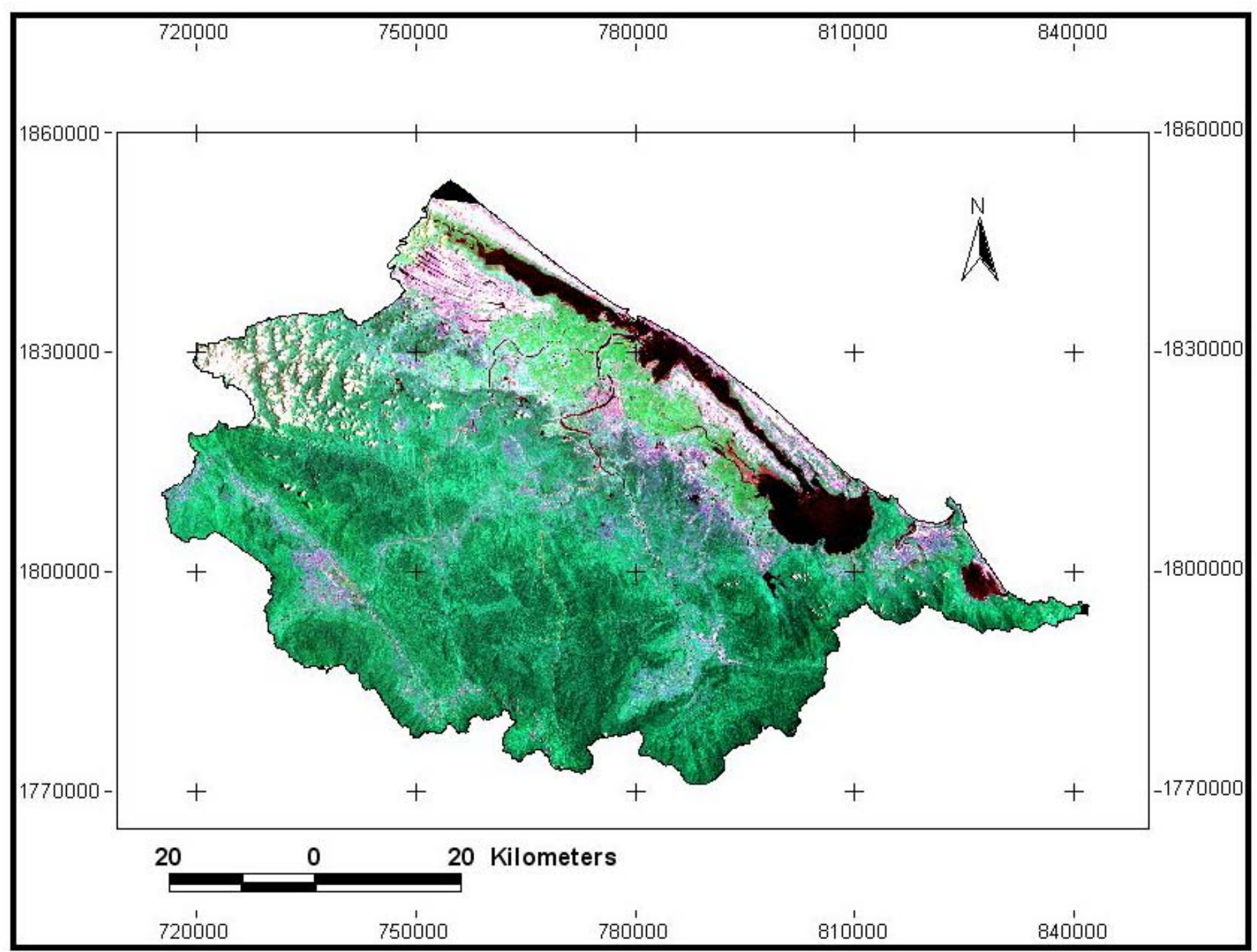

Figure 4.2: Landsat ETM + image subset of 24 April 2003 of the study area. $28.5 \mathrm{~m}$ (band 3,4,5) fused with $14.5 \mathrm{~m}$ Panchromatic data 


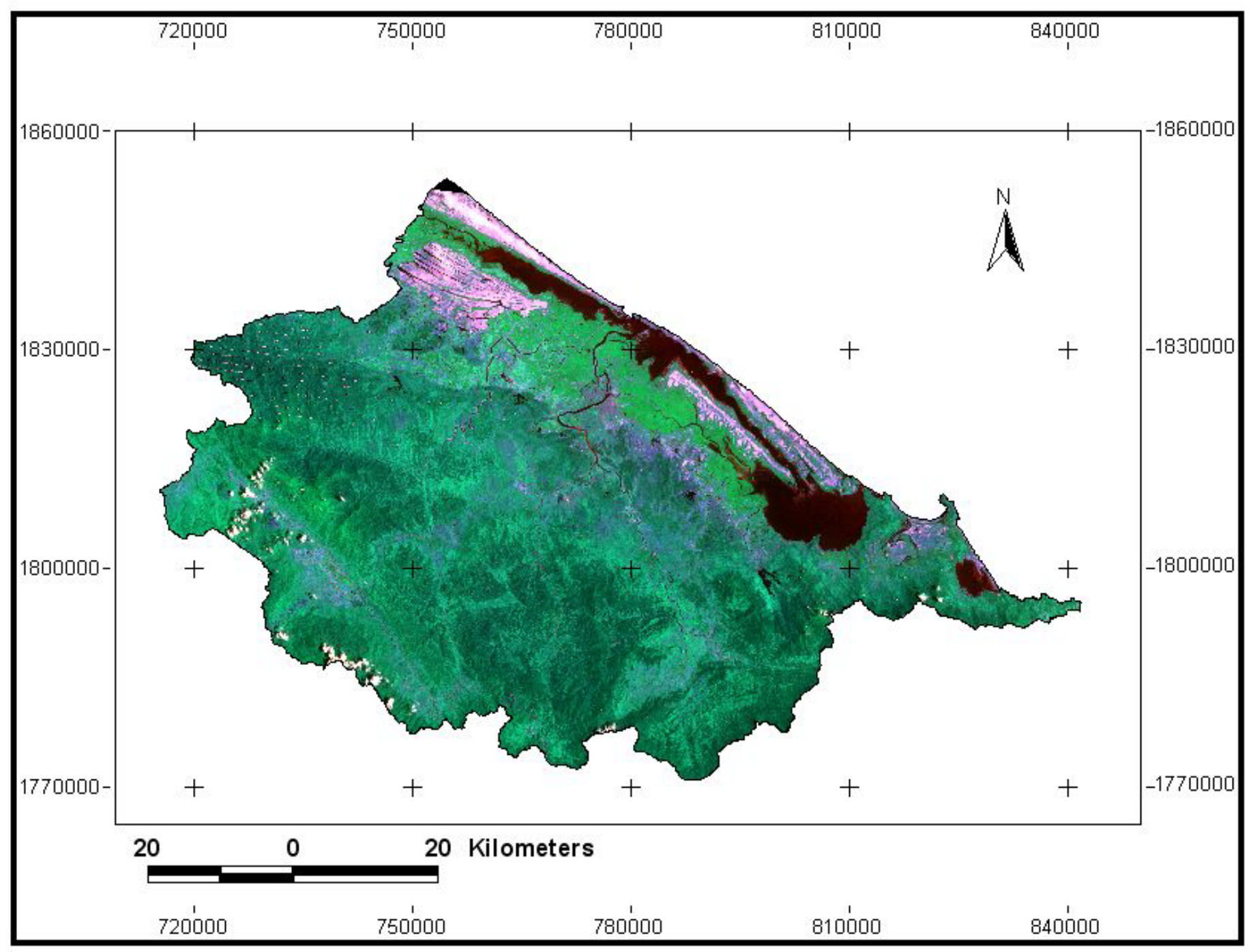

Figure 4.3: Landsat ETM + image subset of 7 April 2004 of the study area, RGB 345 


\subsubsection{Arial photographs}

Black and white vertical aerial photographs with scale 1: 33,550 from May 25, 1999 as reference use were available for the entire study area.

\subsubsection{Thematic maps}

Topographic maps covering the whole study area at the scale 1:25,000 were used in this research. These maps were originally compiled in 2000.

Soil map of Thua Thien Hue at the scale 1:100,000 (Ministry of Agriculture, 1997).

Soil maps of Phong Dien and Quangdien produced in 2003 by Geography institute of Vietnam.

Soil property maps of inland sandy area and hilly and mountainous area were prepared by department of Soil Science, Hue University of Agriculture and Forestry and Institute of Geography, Vietnam during the period of 2000 and 2004.

The existing forest and land cover map of the study area was prepared in october, 1998 by subinstitute of forest inventory and planning located in Thua Thien Hue province.

The map of climatic classification of the study area (climatic stations of Thua Thien Hue).

\subsection{Tools}

The ENVI software (version 4.2) was used for image processing and classification. The ArcView/info (version 3.2) was used for database development and spatial data analysis. The following is the list of key equipment used in this study.

- Garmin 12 XL Global positioning System (GPS)

- Compass

- $50 \mathrm{~m}$ measuring tape

- Altimeter

- Clinometer

- Soil sampling and digging tools

- Laptop

- Writing instruments

- Calculator

- Digital Camera and accessories 
The GPS receiver was selected to collect geographical location at each plot, the compass and altimeter were selected to obtain the orientation in the terrain. The digital camera was used to collect photos of the different vegetation types into the different plot.

\subsection{Field work}

Before going to the field survey, pre-field work was carried out, this was the first stage of the research work which included many activities as follows:

- Literature review related to the study topic and area.

- Examination and selection of sub area of the Landsat ETM+ images.

- Selection of best bands.

- To locate the samples on the topographic maps.

- To make geometric correction the Landsat ETM+ images.

- To locate the samples on the topographic maps and the Landsat ETM+ images

- To make a false colour composite.

- To make ISODATA unsupervised classification.

- To prepare interview forms.

- Collection of equipment required for fieldwork.

The Landsat ETM+ images of 2003 and 2004 were used for fieldwork purpose. Based on the ISODATA classification, aerial photo and image interpretation, a preliminary sampling scheme was built up. The false colour composite (453, RGB) and ISODATA classification map were later adjusted in the field.

The field survey was used for the following main purpose:

1) To determine the main types of forest and land cover in the study area, which helped to design a forest and land cover classification scheme.

2) To support image classification to produce the forest and land cover map while the other part was used as independent reference data in the accuracy assessment of the forest and land over map.

3) To collect the additional information of soil properties and check the results of GIS modelling.

4) Interview (direct and indirect) of local people and forestry experts in order to obtain information about selected tree species and other forestry information in the study area. 
In summer of 2005 and 2007, two field surveys were organized in the study area. All together 535 samples were collected. These samples were distributed over the whole study area, as far as the access and the time permitted. Additionally field data were available from the forestry faculty and the department of soil science of Hue University and team of forest inventory and planning and state forestry enterprises of Thua Thien Hue province, and from sub-institute of forest inventory and planning. These data were collected in 2003. One part of these data was used as support for the classification process while the other part was used as independent reference data in the accuracy assessment. Besides, several hundred observation points were recorded in 2005 and 2007 with different detail levels.

In order to meet the objectives of the study, the primary and secondary data were collected and the procedure of the field survey implemented, are presented in figure 4.4.

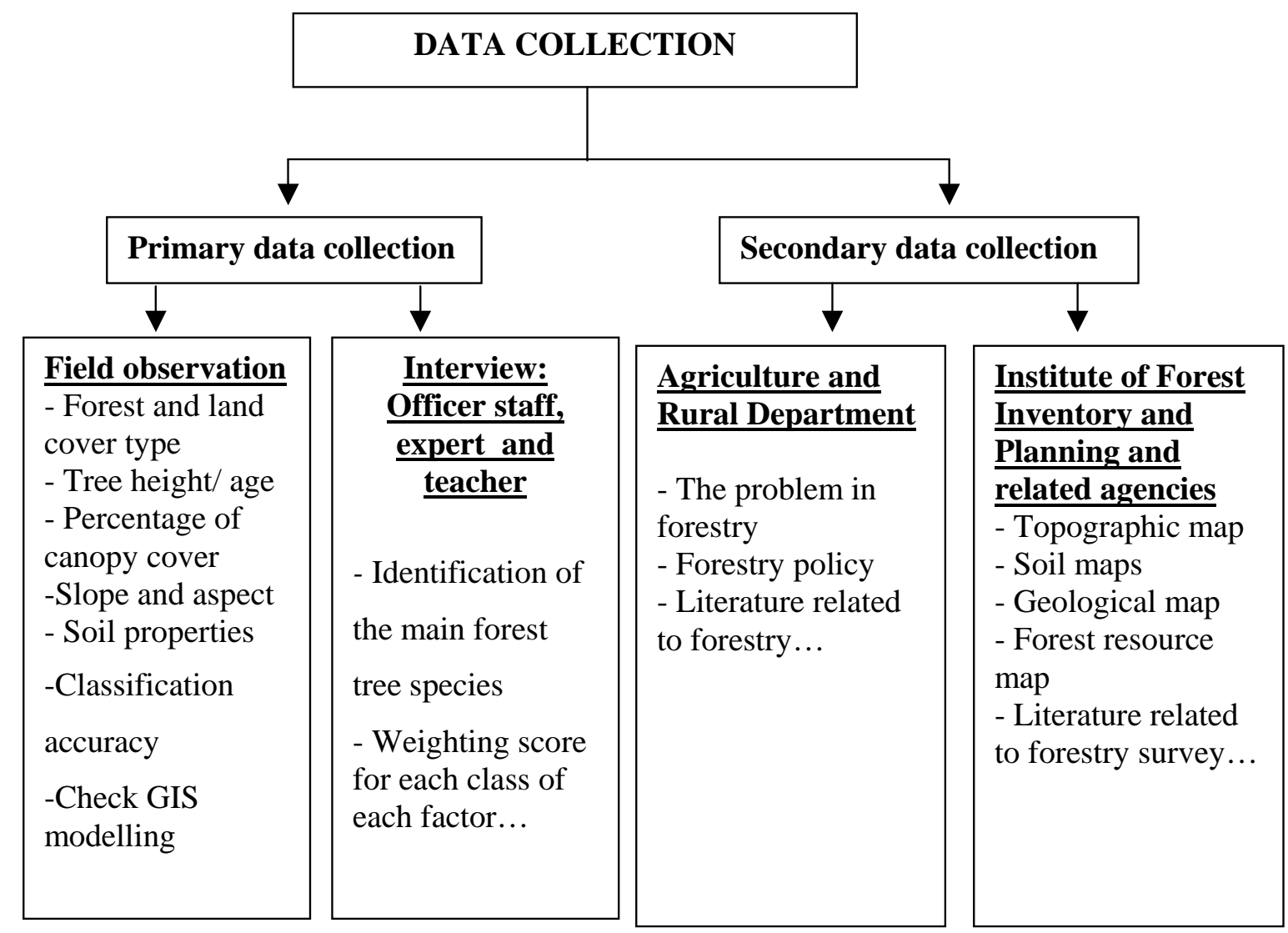

Figure 4.4: The flowchart of data collection during field survey

\subsubsection{Primary data}

The primary data on soil and vegetation were gathered using the sampling site. The sampling site was conducted to examine the actual soil types, land use and land cover pattern. The sampling site frequency depends upon the types of landscape. A number of survey points were randomly 
selected in each of the main land type or forest and land cover type that was identified in the province. To locate the points in the field, maps of the printed images, Garmin 12 XL Global Position System (GPS) receiver, measuring tape, compass, and altimeter were used. The information was collected at each sample of geographical location, soil properties (soil texture and soil depth, colour and other soil feature), forest and land cover types, tree height, diameter beast height $(\mathrm{DBH})$, canopy cover percentage, slope and aspect. The forest and land cover types were documented with ground photographs (appendix 1).

Based on the interview forms prepared during the pre-field work, interviews were made with the people concerning: Realizing that the information needed from the researcher's point of view may be different than that of local villagers and/or local staff's point of view, a questionnaire survey was conducted with management authorities, and local inhabitants to identify core datasets such as the forestry land use, requirements of forestry land use, severity levels, diagnostic factors and selected tree species in forestry production.

Pre-testing was done to accommodate necessary modification prior to the carrying out of the final survey. For this purpose, a consultation with some local experts has also been done.

\subsubsection{Secondary data}

The forest and land cover types were extracted from Landsat ETM+ received from the Institute of Forest Inventory and Planning of central Vietnam and University of Maryland, USA.

The existing forest and land cover information was derived from the department of Agriculture and Rural Development, Thua Thien Hue province.

Geological information was derived from geological map, slope, and elevation were derived from a digital topographic map (UTM-VN2000) from the Institute of Forestry Inventory and Planning.

Soil property information such as soil types, soil texture, soil $\mathrm{pH}$, soil depth and soil fertility were extracted from reconnaissance survey maps which have been prepared by the Department of Soil Science and Forestry Faculty of Hue University of Agriculture and Forestry and the Institute of Geography, Vietnam during the period of 2000 and 2004.

Climatic information was derived from weather stations of Thua Thien Hue province.

The forest policies, problems and literature related to assess forestry land use potential were obtained from the Department of Agriculture and Rural Development in Thua Thien Hue province. 


\section{Chapter 5. Landsat ETM+ Processing}

\subsection{Introduction}

Thua Thien Hue has a natural area of 505,339 ha, of which $70 \%$ of is forestry land. The forestland area is mainly situated in the hilly and mountainous areas of the entire province, where hundreds of thousand people from different ethnic groups can be found. The forest is one of the main income source for the people in this province. According to the existing regulation on classification of the provincial economic sectors, forestry is ranked as the economic sector level II, with main activities being forest protection, harvesting of forest products and reforestation or afforestation. The final products are materials supplied to processing industries, consumption and export. However, due to unsustainable management and a very high need for conversion of forestland and for forest products for socio-economic development, the population pressure on forest land is increasing, therefore the forest area and forest quality have been continuously decreased over the years. This is leading to negative effects on human livelihood and environmental protection such as soil and water conservation, watershed protection and the climate. In order to reduce poverty and to improve the livelihoods of rural mountainous people, it is necessary to sustainably establish, manage, protect, develop and use 365,891 ha of land planned for forestry use. In addition, to increase forestry's contributions to socio-economic development, environmental protection, biodiversity conservation and environmental services supply and to contribute to increase the country's forest cover from $28.1 \%$ in 1995 to $43 \%$ by the year 2010 and $47 \%$ by 2020. The provincial forestry development strategy for the period 2006-2020 has emphasized that "Existing natural forests should be well-managed, forest plantation areas should be expanded and their productivity should be improved, and bare land areas should be used effectively and properly for forestry development”.

One of the important sources to carry out by broaden the provincial forestry development strategy is information of the forest and land cover types. Under the national forest resource survey, the forest and land cover maps of the whole province were prepared in 1998 at scale 1:50,000. All maps were prepared based on conventional methods by foresters who used field and aerial survey, and the standard topographic maps are used as the background maps.

However, the existing forest cover maps which were produced by conventional method is not free from errors. First of all, the error could be originated from the inaccuracy of the topographic map. Secondly, the identification and draw of the different boundaries of the forest cover types 
on the topographic map may be difficult. Thirdly quantitative data on the extent and variation of the forest ecosystem are incomplete and sometimes inaccurate. In addition, the forest cover maps are also considered outdated for present-day planning since the pattern of land cover features, especially vegetation is highly dynamic. The forest and land cover types might have changed by themselves and through human activities such as logging, reforestation and conversion of forestland. These changes of forest cover should be taken into account in the existing land cover map. The conventional methods of map revision are so costly and highly time consuming. Often the forests are inadequately mapped due to great survey costs, which are a consequence of the large spatial extent and poor accessibility of these areas.

One of the main causes of ineffective forestry land use refers to poor spatial planning, and is due to weakness in surveys of forest and forestland resource. This is particularly true for the province because spatial data sets are often lacking. Sound decision-making during land use planning is often hampered by lack of reliable and up-to-date maps. The forest and land cover information is an important theme because it affects more of the important decisions that have to be made during forestry land use planning than do most other themes. Thus existing forest resource maps are not considered to be a reliable information as an input for decision making.

Remote sensing (RS) is a powerful tool that could be used to address the problem of out of date thematic maps. The capabilities of remote sensing to map and extract information about earth resources for various applications are well documented. Among those prominently used is land cover mapping, is considered as one of the most important, most direct and well established applications of remote sensing (Campbell, 1987). The recent availability of satellite data such as Landsat ETM + offer an interesting alternative for map producing and updating. Foody and Curran (1994) suggested that space-borne sensors have the potential for delivering reliable estimates of the extent, quality and changes of the tropical forests. Moreover, a better impression of the tropical forest environment and related ecosystem services could be achieved with greater classification detail and the full potential of remote sensing for distinguishing tropical forest types have still to be exploited (Hill and Foody, 1994).

Remote sensing technologies have been applied in forest survey in Vietnam since 1980. But remote sensing has not been used routinely for forest cover mapping so far. Therefore, remote sensing techniques are a promising alternative in mapping forest and land cover in Thua Thien Hue province. However, the land cover classification with satellite data is not a perfect process as many sites are often misclassified (Czaplewski, 1991). Additionally, there is no standard 
approach in extracting information of forest and land cover that could be applied for all situations.

With regard to the assessment of land potential for forestry use, forest and land cover information are even more necessary than usually. Information on forest and land cover is required in some of the following relevant land suitability assessment tasks:

(1) Identification and definition of potential land suitability area

(2) Forestland resource monitoring and evaluation.

(3) Forest maintenance and protection.

(4) Forestland allocation and prioritization.

(5) Identification and definition suitable areas for reforestation or silvicultural treatments and expansion of forest plantation.

In order to meet the objectives of the study, Landsat -7 Enhanced Thematic Mapper plus (ETM +) data were selected due to the spectral and spatial characteristics of the sensor, which have been documented as approximate data for mapping broad vegetative types such as deciduous and evergreen forests (Schriever and Congalton, 1993). The forest and land cover types in the study area were mapped using ETM+ data. An ISODATA unsupervised classification was performed based on data fusion between the panchromatic band and a composite image of the bands ETM4, ETM5 and ETM3. Using this output, available secondary data together with field data were chosen to perform a Maximum Likelihood supervised classification to produce the forest and land cover map. This is a part of GIS modelling in assessment of land potential for forestry production in Thua Thien Hue, Vietnam.

\subsection{Methodology}

The study methodology can be divided into the following components:

i. Data acquisition and collection.

ii. Data pre-processing.

iii. Selection of best band.

iv. Data fusion.

v. Image classification.

vi. Post classification processing, and.

vii. Accuracy assessment.

The steps of image processing from Landsat ETM+ data are expressed in figure 5.1. 


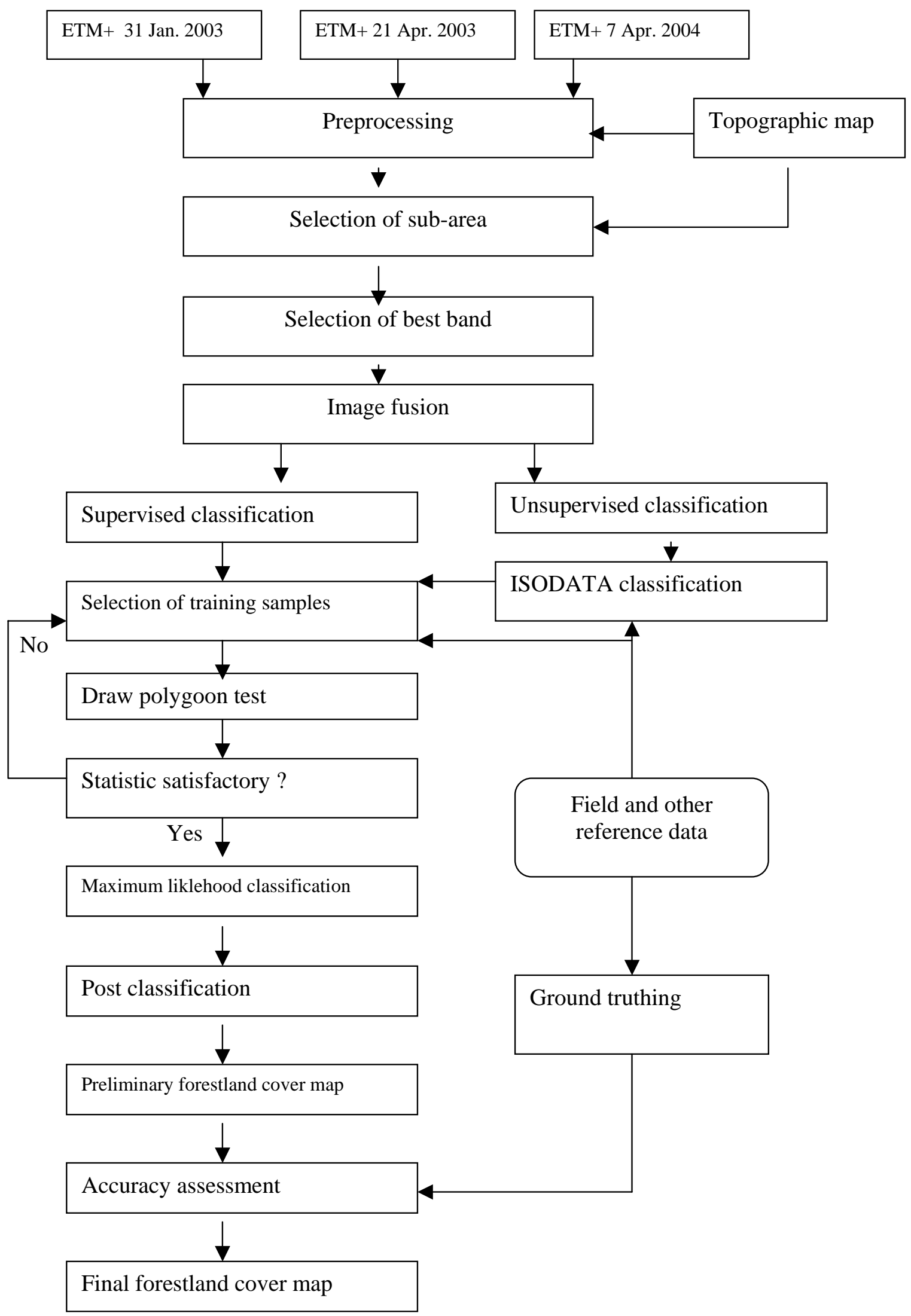

Figure 5.1: The flowchart of Landsat ETM + image processing 


\subsubsection{Data acquisition and collection}

Landsat 7 ETM + data were selected for this study due to its wider spectral coverage and availability of a high resolution band (Panchromatic band) for enhancing spatial resolution and features. Three Landsat ETM+ images of January 31, and April 21, 2003 and April 7, 2004 were selected for the analysis (Table 5.1). These dates of imageries were selected to allow an optimum discrimination of different vegetation types.

From each image, three visible bands (ETM 1, ETM 2 and ETM 3), one near band infrared band (ETM 4) and two middle infrared bands spectral bands (ETM 5 and ETM 7) having $28.5 \mathrm{~m}$ resolution and one panchromatic band (Band 8) having $14.5 \mathrm{~m}$ resolution were used for the analyses to select best bands. Since full images were not required for the achievement of this study, the subsets of the images were extracted to map forestland cover type. Subset is the part of image scene and often performs to create a new image of desirable size. It was done with the capabilities of ENVI software. The subset helps to process the image faster and reduces the data volume.

Table 5.1: Characteristic of Landsat ETM+ data

\begin{tabular}{|l|l|l|l|l|l|}
\hline No & Image & Resolution & Path & Row & Date of pass \\
\hline 1 & Landsat ETM+ & 28.5 m (band 1-5 \& 7) & 125 & 049 & January 31, 2003 \\
\cline { 1 - 2 } 2 & Landsat ETM+ & 60 m (band 6) & 125 & 049 & April 21, 2003 \\
\cline { 5 - 6 } 3 & Landsat ETM++ & 14.5 m (band 8) & 125 & 049 & April 7, 2004 \\
\hline
\end{tabular}

ETM+ data was acquired for relatively cloud free dates in 2003 (January 31, 2003 and April 21, 2003). Cloud and cloud shadows covered areas in the image of April 2003 were masked out using visual interpretation and on screen digitizing, these areas were replaced by image of January 2003 and April 2004.

\subsubsection{Landsat ETM + pre-processing}

Landsat data usually contains both systematic and unsystematic geometric errors. Before interpreting satellite image, inherent distortion needs had to be reduced. On the other hand, to integrate Landsat ETM+ images with the vector polygon boundaries, it was necessary to register both data sets to a common map coordinate system. This is very useful to the analyst either when compiling with other map information or for individual analysis. For this purpose, 35 ground control points (GCPs) were rectified the Panchromatic band of the subsets of Landsat ETM+, 2003 to a UTM (Universal Transverse Mercator) map projection (Zone 48, WGS 84) using image to map registration. Band 1-5 and 7 of January, April 2003 and April 2004 were then coregistered to the Panchromatic band using image to image registration. For all images, the root 
mean square error (RMSE) values were calculated less than 0.5 pixels in both $\mathrm{X}$ and $\mathrm{Y}$ directions.

\subsubsection{Selection of best band}

To perform selection of optimal band combination for interpretation purpose and image classification (supervised and unsupervised classification), it was necessary to specify the Landsat bands to be used for the classification. For this study, the selection of best bands was made on the basis of visual inspection and correlation matrix analysis of the images and analyzing the statistical values. This correlation matrix helps detecting the redundancy and identifies possible reduction in the number of bands. If the bands show strong correlation (value near to 1.000), this indicates that the bands usually contain similar information to each other. Therefore, the band with the lowest correlation will be selected, because this band brings information independent of the other bands. The correlation matrix was made on the subsets of images after geo-reference processing.

\subsubsection{Image fusion}

After applying error correction and geo-reference procedures and best band selection, data from different resolutions can easily be integrated. Image fusion is the next step of image preprocessing. The fusion image is the integration of different digital images in order to create a new image and obtain more information than can be separately derived from any of them (Pohl and van Genderen, 1998). In this step, 28.5m resolution Landsat ETM + of colour composite image were fused with the $14.5 \mathrm{~m}$ resolution panchromatic band. The resulting fused bands were spatially enhanced while keeping the spectral characteristics close to the original bands. Figure 5.2(a) represents the PAN image, figure 5.2 is the colour composite image ( $R=4, G=5$ and $B=$ 3) and figure 5.2(c) is the fused mage. The resulting output images were then used to perform unsupervised and supervised classification. 


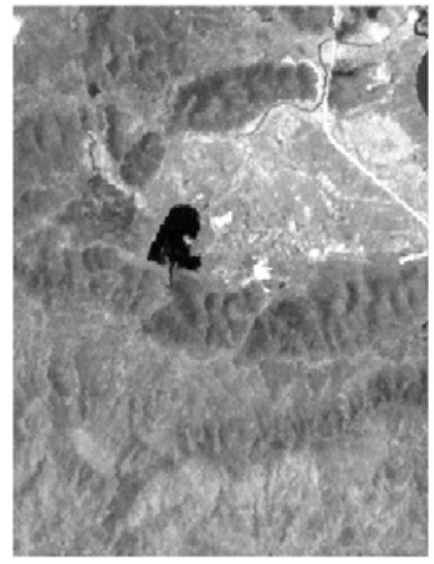

(a)

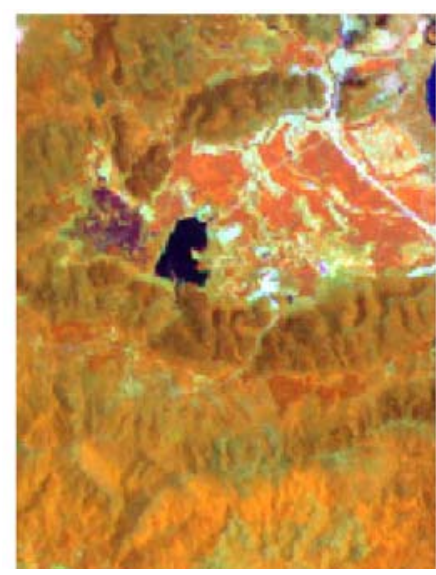

(b)

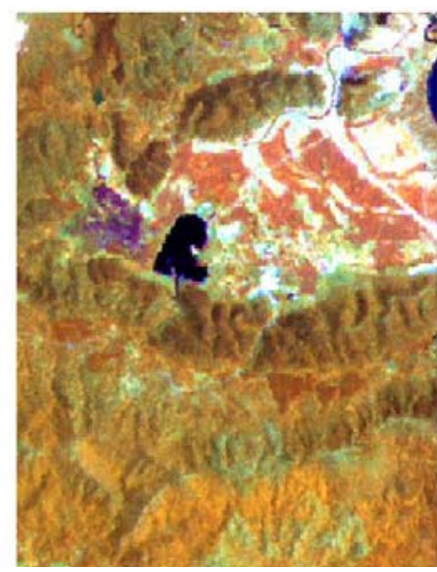

(c)

Figure 5.2: (a) PAN image, (b) Colour composite image (4,5,3), (c) 28.5 meter ETM+ data (bands 4, 5, 3) fused with 14.5 meter Panchromatic data

\subsubsection{Landsat ETM + classification}

ENVI software was used to perform all image processing functions required to complete the forestland cover classification. The forestland cover mapping from satellite imagery is normally performed using either supervised and/or unsupervised classification techniques. In a supervised classification, the image analysis is responsible for defining "training area”, which presents all of the cover types one wishes to extract from an image. However, it is often difficult to account for all the cover types in an image as well as variability within cover types. Unsupervised classification differs from supervised classification in that so far as the computer develops the signatures that will be used to classify the scene. The classification process results in a number of spectral classes, which the analyst must then assign to information classes of interest. This requires knowledge of terrain in the scene as well as its spectral characteristics (Scott G.Bourne, 2001).

In this study unsupervised and supervised classification were used to extract forestland cover information from Landsat ETM+ images. After arriving at an acceptable classification result, a 3 x 3 majority filter was applied to eliminate the small areas that occurred through the classified image. In the final part of the study, the results of image classification were compared using standard measures of accuracy and Kappa analysis.

\subsubsection{Unsupervised classification}

Iterative Self - Organization Data Analysis (ISODATA) is a widely used clustering algorithm that makes a large number of passes through an image using a minimum spectral distance formula to form clusters. It begins with either arbitrary cluster means and each time the 
clustering repeats, the means of these clusters are shifted. The new cluster means are used for the next iteration. This iterative process continues until statistically distinct features emerge (Scott G. Bourne, and Mark R. Graves, 2001). According to Lo, C.P. and Jimu Choi, (2004): “ The unsupervised classification using the basis migrating means clustering algorithm, more commonly known as ISODATA was found to be best approach that could achieve $85 \%$ and above in overall, user's and producer's accuracies”. Therefore, in this study, ISODATA clustering algorithm was used to classify on the three dates of Lansat ETM+. To perform ISODATA clustering algorithm, it is necessary to specify the Landsat ETM+ bands to be used for classification. As mentioned above, one visible band (ETM 3), one near infrared band (ETM 4) and one middle infrared band (ETM 5) and Panchromatic band was used. Next step, the maximum numbers of clusters are determined to provide a wide variation of forestland cover types that could be easily identified. On the basis of field knowledge and reference data, we found that 50 classes were sufficient to distinguish different forestland cover which we were looking to identify. The ISODATA clustering algorithm was performed with the fused image of band 453 and PAN, which produced 50 spectral clusters. In order to label the cluster for each image into information classes as accuracy as possible, the following information were used: Field survey in 2005, thematic maps produced in 1998, topographic maps produced in 2000 and the secondary data available in 2003 (see figure 5.3). Using the results of this classification to support for selection of training samples to perform supervised classification.

\subsubsection{Supervised classification}

\subsection{Selection of training samples for image classification}

The training samples for each land cover type under study were selected based on a priority knowledge and field data gathering. All together 335 samples were collected in 2005 and the information collected at each sample:

- Geographical location

- Soil properties.

- Land cover type

- $\mathrm{DBH}$ (diameter breast height).

- Tree height and percentage of canopy cover.

The information was obtained using a Global Position System (GPS) receiver, measuring tape, compass, and clinometer. Additionally field data were available from the forestry faculty, the institute of forest inventory and planning, and all state forest enterprises. 


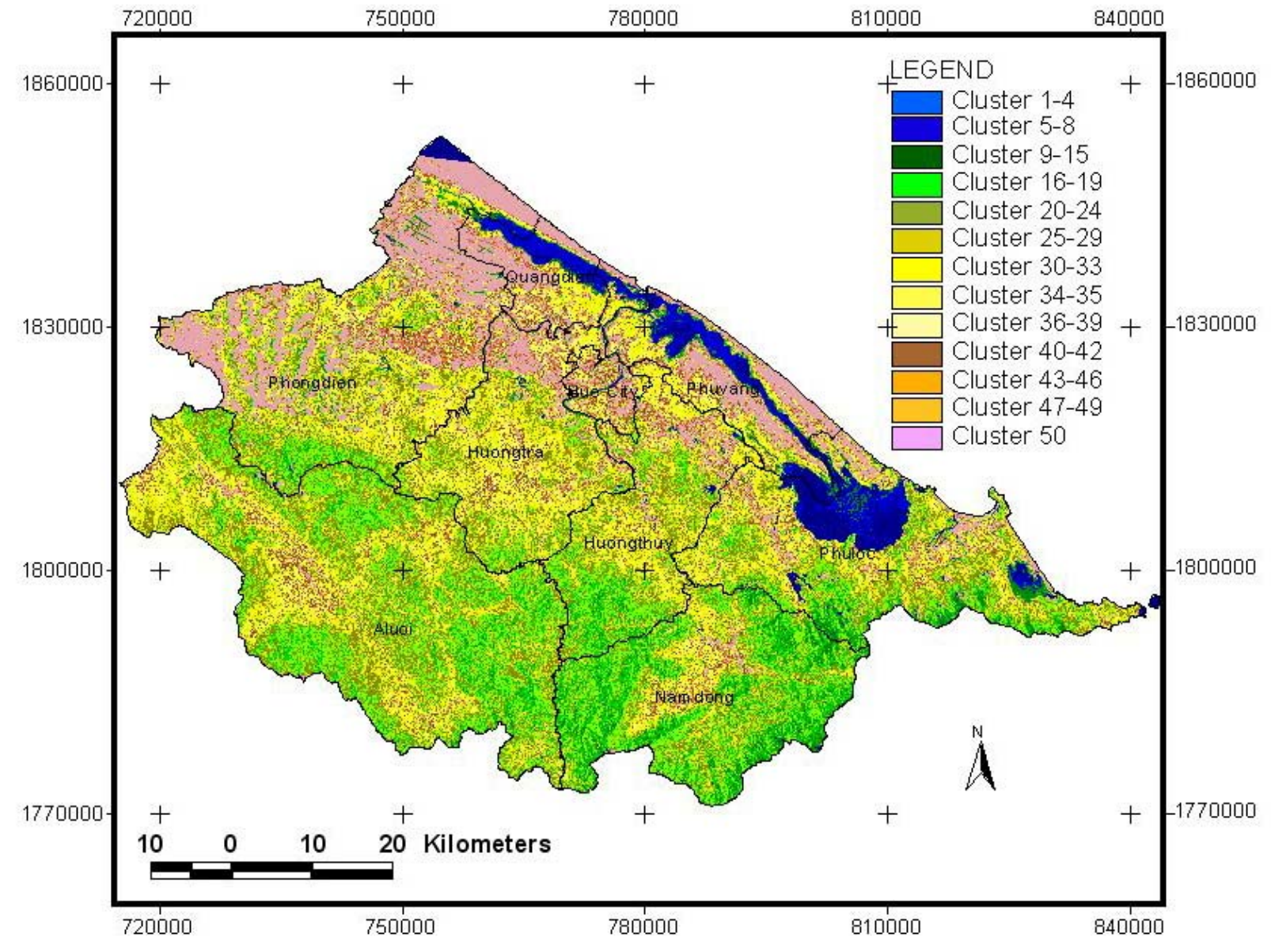

Figure 5.3: ISODATA unsupervised classification of Landsat ETM + of 24 April 2003:

Deep water (cluster 1- 4), shallow water (5-8), dense forest (9-15), degraded forest (16-19), forest plantation (20-24), shrub (25-29), grass and agricultural land (30-39), bare land (40-49) and sandy land, cloud, rock and build up areas (50) 
These data were collected in 2003. One part of these data was used as support to select training samples for the supervised classification process while the other part was used as independent reference data in the accuracy assessment.

In order to select training samples, it was necessary to enhance the image in a way to provide rough information of forestland cover differentiation. The simplest way is to combine different bands like infrared, red and green for false colour composite. The colour composite image was created and displayed on the screen combining the spectral values of the three individual bands (band 3,4 and 5) to enhance the visualization of the vegetation and boundary of each land cover type. They were separately displayed over the images to locate the known land cover classes and define training samples for Landsat ETM + classification. Displaying bands 4, 5 and 3 as infrared colour composite is useful for identification of different forestland cover types during training process (Fig. 5.4).

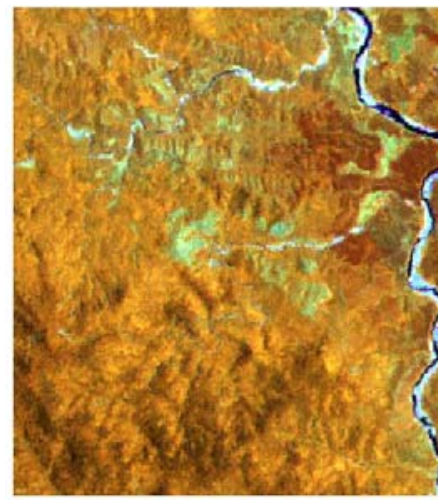

a

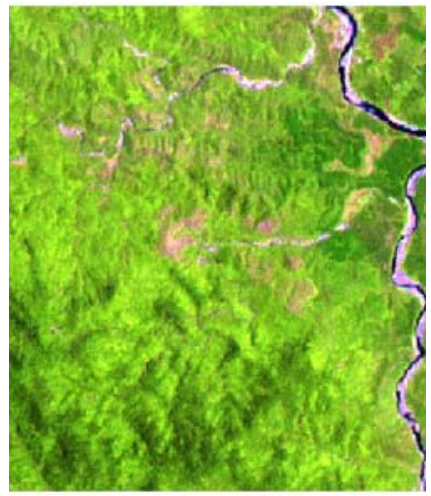

$\mathrm{b}$

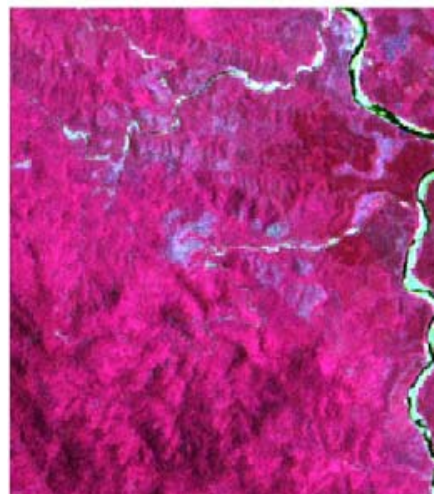

C

Figure 5.4: Three different False Colour Composite (FCC) combinations

In the image (a) the combination was 4,5,3. Image (b) was 5,4,3 and in image (c) the combination 4,3,5

A number of training samples were collected for each type with respect to amount and size of forestland cover type as well as their dispersion throughout the study area. The training samples were selected on the basis of the unsupervised classified image, field survey data and secondary data. These training samples were selected from all cover land found in the study area, at least 3 training areas for each land cover type and a minimum of 30 pixels for each training sample. The training class reparability was investigated using statistical analyses. The statistical analyses were computed based on both the Jeffries-Matusita and Transformed Divergence separability measures. The following classes were defined for Landsat ETM+ image of April 2003: 1) Dense forest (montane closed evergreen sub-tropical monsoon forest and closed evergreen tropical monsoon forest), 2) Degraded forest (secondary forest/ open forest), 3) Shrub, 4) Forest 
plantation (Acacia auriculiformis, A. mangium, A. hybrid and A. crassicapar, Casuarina equisetifolia, Pinus merkussi, P. khasya, P. caribaea and Eucalyptus), 5) grassland, 6) bare land, 7) agricultural land (crops, paddy and plantation of rubber), 8) water, 9) build up areas: The separability of forestland cover types grouped by their physiognomic and structure properties are presented in table 5.2. After completing the training selection for April image of 2003, the same training samples were used to select the training samples for January image of 2003 and April image of 2004. However, the training samples were reedited to reflect any variation in spectral characteristic of altering land cover type.

Table 5.2: Identification and description of training samples for forest and land cover type in Thua Thien Hue province (visual interpretation).

\begin{tabular}{|c|c|c|c|}
\hline $\begin{array}{l}\text { Name of } \\
\text { land cover } \\
\text { type }\end{array}$ & $\begin{array}{l}\text { Training } \\
\text { area class }\end{array}$ & Description & $\begin{array}{l}\text { Appearance in ETM+ } \\
453 \text { (RGB) composite } \\
\text { and histogram of } \\
\text { training samples in } \\
\text { band } 4\end{array}$ \\
\hline \multirow[t]{4}{*}{$\begin{array}{l}\text { 1.Dense } \\
\text { forest }\end{array}$} & $\begin{array}{l}\text { Montane } \\
\text { closed } \\
\text { evergreen } \\
\text { sub-tropical }\end{array}$ & $\begin{array}{l}\text { This kind of forest is characterized by } \\
\text { a canopy closure of more than } 60 \% \\
\text { and the general tree height is from } 15 \\
-30 \mathrm{~m} \text {. The main tree species }\end{array}$ & $\begin{array}{l}\text { Dark brown with } \\
\text { sometimes reddish brown } \\
\text { spots } \\
\text { Rough texture }\end{array}$ \\
\hline & $\begin{array}{l}\text { monsoon } \\
\text { forest }\end{array}$ & $\begin{array}{l}\text { prevailing in this forest are Acer } \\
\text { tonkinensis, Gordonia intricate, Thea } \\
\text { caudate, Adenanthera microsperma, } \\
\text { Quecus bamusaefolia }\end{array}$ & \\
\hline & $\begin{array}{l}\text { Closed } \\
\text { evergreen } \\
\text { tropical } \\
\text { monsoon }\end{array}$ & $\begin{array}{l}\text { Closed canopy closure of more than } \\
60 \% \text { and the general tree height is } \\
\text { from } 18-40 \mathrm{~m} \text {. } \\
\text { The dominant species are Morus alba, }\end{array}$ & $\begin{array}{l}\text { Dark brown with } \\
\text { sometimes reddish brown } \\
\text { spots } \\
\text { Rough texture } \\
\text { Input Histogram }\end{array}$ \\
\hline & & $\begin{array}{l}\text { Cinamomun camphora, Elbern, Melia } \\
\text { azedarach grandiflorus, } \\
\text { Dipterocarpus gasseltii } \\
\text { Dipterocarpus he }\end{array}$ & 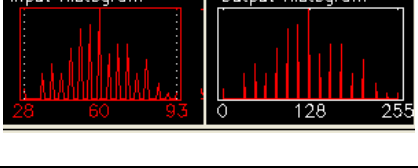 \\
\hline $\begin{array}{l}\text { 2. Degraded } \\
\text { forest }\end{array}$ & $\begin{array}{l}\text { Secondary } \\
\text { forest/ open } \\
\text { forest }\end{array}$ & $\begin{array}{l}\text { Forest this is the results of long term } \\
\text { disturbed by human, the rare and } \\
\text { valuable species and big stands are }\end{array}$ & $\begin{array}{l}\text { Red to reddish brown } \\
\text { Texture varies with } \\
\text { region } \\
\text { Input Histogrom }\end{array}$ \\
\hline & & $\begin{array}{l}\text { rarely found because of illegal logging } \\
\text { and encroachment, crown closure is } \\
\text { approximately } 30-45 \text { percent. } \\
\text { The general height in this class ranges } \\
2 \mathrm{~m} \text { to } 25 \mathrm{~m} \text { tall. The dominant species } \\
\text { includes Elaeocarpus dubius, } \\
\text { Elaeocarpus limatarius, Cratoxylon } \\
\text { formosum and several types bamboo }\end{array}$ & \\
\hline
\end{tabular}




\begin{tabular}{|c|c|c|c|}
\hline & $\begin{array}{l}\text { Young } \\
\text { secondary }\end{array}$ & $\begin{array}{l}\text { The crown coverage is generally } \\
\text { below } 60 \% \text {. }\end{array}$ & $\begin{array}{l}\text { Reddish brown with } \\
\text { smooth texture }\end{array}$ \\
\hline & forest & $\begin{array}{l}\text { Forest growing back in clear-cuts } \\
\text { resulting either from agriculture or } \\
\text { logging. }\end{array}$ & \begin{tabular}{|l|l|} 
Input Histogrom & Output Histogrom \\
\end{tabular} \\
\hline 3. Shrub & & $\begin{array}{l}\text { Mixture of Shrub, grass, and tree } \\
\text { regeneration, medium crown cover } \\
(10-50 \%) \\
\text { Shrub represents small scrub species } \\
\text { and early stage colonizing species. } \\
\text { Shrub areas dominated with }\end{array}$ & $\begin{array}{l}\text { Yellowish green } \\
\text { Smooth texture } \\
\text { If canopy is close appears } \\
\text { in light yellow but in } \\
\text { case of exposed soil it } \\
\text { appears in green }\end{array}$ \\
\hline & & $\begin{array}{l}\text { Rhodomyrtus tomentosa, Cratoxylon } \\
\text { formosum, Mallotus paniculatus), } \\
\text { Melastoma sp. } \\
\text { These areas are often associated with } \\
\text { fallow vegetation. Some taller woody } \\
\text { species might be interspersed }\end{array}$ & \\
\hline $\begin{array}{l}\text { 4.Forest } \\
\text { Plantation }\end{array}$ & Pine forest & $\begin{array}{l}\text { Uniformed forest of Pinus merkussi, } \\
\text { Pinus khasya \& Pinus caribaea }\end{array}$ & $\begin{array}{l}\text { Red brown with rough } \\
\text { texture } \\
\text { Identification between } \\
\text { three species is not } \\
\text { possible without ground } \\
\text { information }\end{array}$ \\
\hline & & & Input Histogram \\
\hline & $\begin{array}{l}\text { Casuarinas } \\
\text { forest }\end{array}$ & $\begin{array}{l}\text { It is hard wood tree species that grows } \\
\text { and develops close to salt water. Can }\end{array}$ & $\begin{array}{l}\text { Light yellow with green } \\
\text { Smooth texture }\end{array}$ \\
\hline & & $\begin{array}{l}\text { grow in poor soil because of its } \\
\text { capacities to fix nitrogen and prevent } \\
\text { moving sand. The main tree species } \\
\text { found in coastal region of Thua thien } \\
\text { Hue is Casuarinas equisetifolia.. }\end{array}$ & \begin{tabular}{|l|l|} 
Input Histogram & Output Histogre \\
\multirow{P}{*}{}
\end{tabular} \\
\hline & $\begin{array}{l}\text { Acacia } \\
\text { forests }\end{array}$ & $\begin{array}{l}\text { Acacias are rapid growth tree species. } \\
\text { They can grow in various soil types. } \\
\text { They found in uniformed forests of } \\
\text { Acacia auriculiformis, Acacia } \\
\text { mangium and Acacia hybrid }\end{array}$ & $\begin{array}{l}\text { Dark red with smooth } \\
\text { texture } \\
\text { Identification between } \\
\text { four species is not } \\
\text { possible without ground } \\
\text { information }\end{array}$ \\
\hline & & & \begin{tabular}{||l|l|l|} 
Input Histogram & Output Histogra \\
\end{tabular} \\
\hline & Eucalyptus & Uniformed forest of Eucalyptus, this & Light, yellowish green \\
\hline & & $\begin{array}{l}\text { tree species is now not suitable for the } \\
\text { purpose of production and protection }\end{array}$ & \\
\hline
\end{tabular}




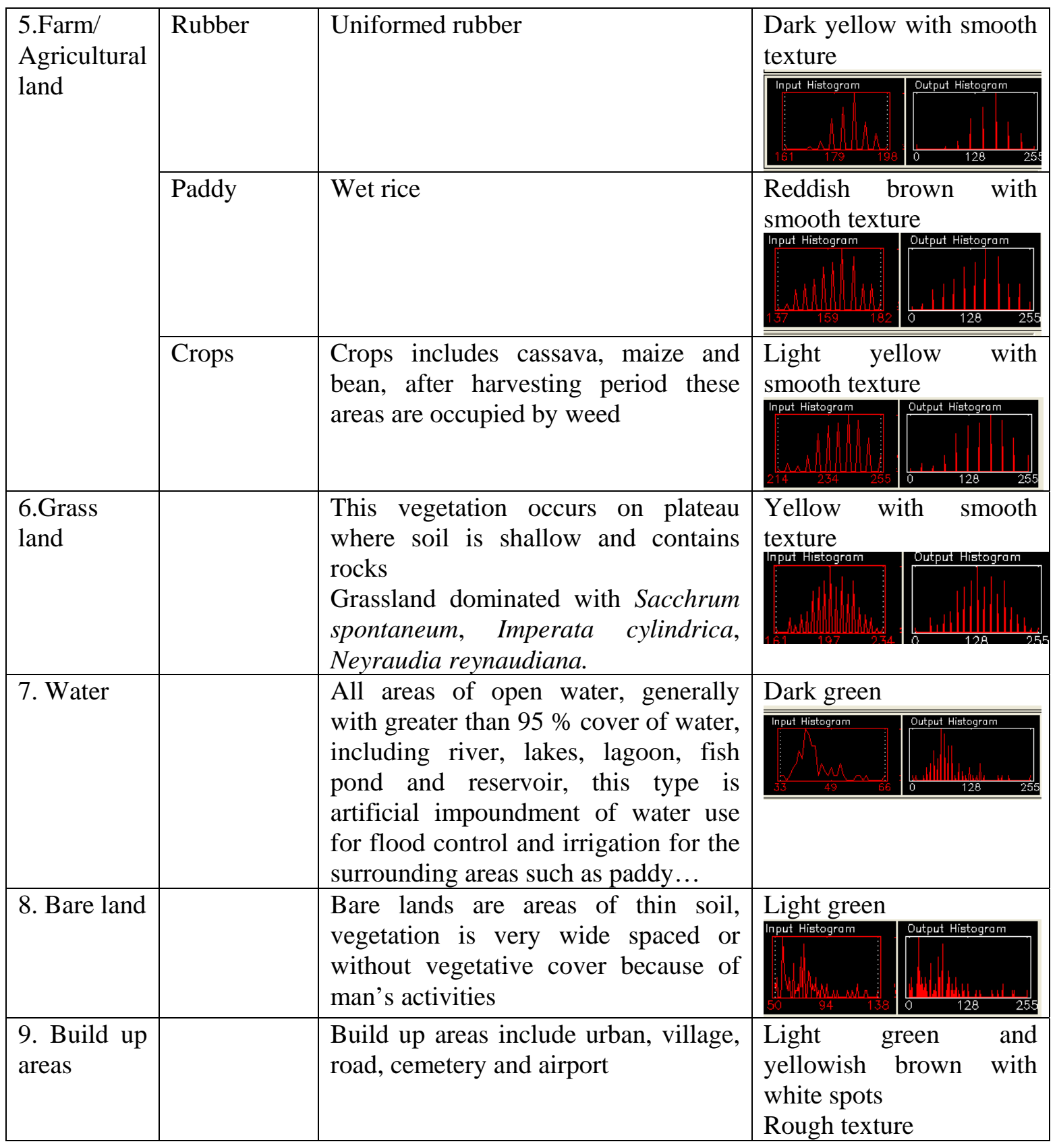

\subsection{Maximum-likelihood classification}

The next step of the classification process involved using supervised classification. The classification type was performed with the maximum-likelihood algorithm, where the pixel sampling took place for homogeneous reflectance areas. The maximum likelihood classifier was chosen, because, it is the one which can obtain some reliable results, since box classifier would introduce problem when overlapping and minimum distance classifier is insensitive to the variances in each class. For each date, maximum-likelihood classifier was also performed to classify the fused image. The results of unsupervised classification, available secondary data 
together with field data to perform the maximum likelihood algorithm were used to produce a land cover map of different forest types.

\subsubsection{Post classification processing}

The forestland cover classification was produced by three Lansdsat ETM + images acquired in January and April of 2003 and 2004. After classification in ENVI, the classification images exported to ARCview/info for further processing. The boundary of different forestland cover types has been separated and combined under broad classes, the boundaries were interactively digitized and forest and land cover categories were labelled using the forest land cover polygons on the Landsat ETM + images. The polygons were digitized in the graphic overlay planes of the colour monitoring using a conventional mouse for location control. The final step is the process of combining the results from interpreting images of Lansdsat ETM+, field survey, available forest land cover map and topographic map to create of a comprehensive map of forest and land cover types. The forest cover land map was prepared with ARC View/ Info.

\subsubsection{Accuracy assessment}

The accuracy assessment of classified image is an important step as it indicates a measure to show how reliable the information extracted from remotely sensed data is. There are many ways to perform accuracy assessment: Qualitative, quantitative, expensive, inexpensive, quick, timeconsuming and so on. Accuracy assessment with the objective of finding out the accuracy of image classification, the results of an accuracy assessment are reported in an error matrix, which compares information from reference sites to information of a map for number of samples areas. Error matrix is a table with the columns representing the reference (observed) data and the row of the classified (mapped) data.

The accuracy assessment (overall accuracy, producer's and user's accuracy) was conducted through a standard method described by Congalton (1991). As for sample size, Congalton emphasized the need for balance between what is statistically sound and what is practically attainable. As a good rule of thumb, he recommended that at least 50 test points per land cover category are necessary to produce an error matrix, the more the better.

In this study, the accuracy assessment is a vital part to analyse the classified image result. The importance of overall accuracy, producer's and user's accuracy indicate the results of the Landsat ETM + classification. After performing the image classification, the classification results were displayed in form of forestland cover map and the confusion matrix was used for quantitative analysis of classification accuracy. The results of image classification were verified 
with a random sampling method, using a total of 585 points, the numbers of samples chosen randomly from each class were proportional to its mapped area and theses samples were collected during fieldwork.

The overall accuracy between Landsat ETM+ classification and the reference data was computed as follows:

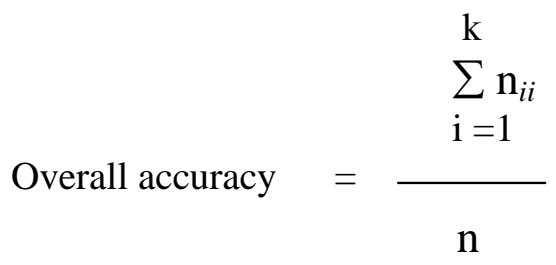

Where: $\mathrm{k}=$ the number of categories

$\mathrm{n} i j=$ total number of samples classified into category $i(\mathrm{i}=1,2, \ldots, \mathrm{k})$ in Landsat ETM + and category $j(\mathrm{j}=1,2, \ldots, \mathrm{k})$ in the reference data set.

$\mathrm{n}=$ total number of observations

The producer's accuracy was computed by

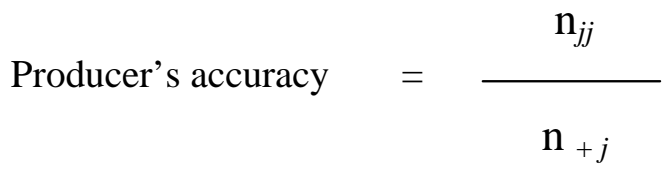

and the user's accuracy was computed by

User’s accuracy $=\frac{\mathrm{n}_{i i}}{\mathrm{n}_{i^{+}}}$

Additionally, measure of classification accuracy that was calculated from the confusion matrix is the Kappa coefficient. The result of performing a Kappa analysis is a Khat statistic (an estimate of Kappa normally coded K), which is another measure of agreement or accuracy (Cohen, 1960). The Kappa index was calculated through a method described by Congalton and Green (1998). The Kappa statistic represents the agreement between the classified forestland cover and the observed forest. A Kappa index is more superior to the other accuracy measures because unlike the overall, producer's and user's accuracies, which make use of the principle diagonal, columns and rows of the matrix, it makes use of all the information in the error matrix in order to take into account the chance allocation of class labels. In other word, the Kappa index incorporates both 
the principle diagonal entries and off- diagonal entries of error matrix consideration (Tso and Mather 2001).

The Kappa statistic is calculated by the following formula:

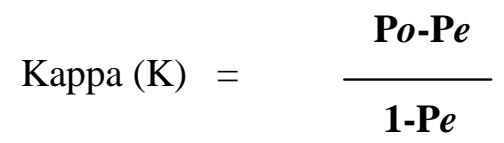

Where:

Po is the observed proportion of agreement (the overall accuracy), the Po value as previously defined above.

$\mathrm{P} e$ is the proportion of agreement that is expected to occur by chance.

The $\mathrm{P} e$ is determined by multiplying the marginal total of row $\mathrm{i}\left(\mathrm{n}_{\mathrm{i}^{+}}\right)$and of column $\mathrm{i}\left(\mathrm{n}_{+i}\right)$ and dividing the sum of the resulting chance value in the agreement diagonal by $\mathrm{N}^{2}$. The Pe value was calculated through formula:

$\mathbf{P e}=\frac{\sum\left(\mathbf{n}_{i^{+}}{ }^{*} \mathbf{n}_{+\mathbf{i}}\right)}{\mathbf{N}^{2}}$

\subsection{Results and discussion}

\subsubsection{Selection of best band}

The following table (Table 5.3) represents the correlation matrix for six bands in the study area. The results of the analysis show that among visible bands (band 1-3) and mid-infrared bands (band 5-7) a high correlation exists. This means that there is a high redundancy of information within those bands in the vegetated areas. Band 4 has the lowest correlation values, so this band brings information independent of the other bands. Band 4(near infrared), one band from the visible region, and one from mid-infrared can be selected for the best separability in the vegetated areas using Landsat ETM +. Therefore band 3, 4 and 5 were selected to fuse panchromatic band for the purpose of interpretation and classification. 
Table 5.3: Correlation matrix of Landat ETM+ for the study area

\begin{tabular}{|c|c|c|c|c|c|c|}
\hline Bands & 1 & 2 & 3 & 4 & 5 & 7 \\
\hline \multicolumn{7}{|c|}{ Landsat of April 21, 2003} \\
\hline 1 & 1.000 & & & & & \\
\hline 2 & 0.899 & 1.000 & & & & \\
\hline 3 & 0.863 & 0.920 & 1.000 & & & \\
\hline 4 & 0.281 & 0.411 & 0.161 & 1.000 & & \\
\hline 5 & 0.686 & 0.765 & 0.642 & 0.674 & 1.000 & \\
\hline 7 & 0.767 & 0.814 & 0.783 & 0.402 & 0.915 & 1.000 \\
\hline \multicolumn{7}{|c|}{ Landsat of January 31, 2003} \\
\hline 1 & 1.000 & & & & & \\
\hline 2 & 0.976 & 1.000 & & & & \\
\hline 3 & 0.959 & 0.984 & 1.000 & & & \\
\hline 4 & 0.225 & 0.297 & 0.275 & 1.000 & & \\
\hline 5 & 0.647 & 0.702 & 0.713 & 0.757 & 1.000 & \\
\hline 7 & 0.832 & 0.864 & 0.883 & 0.522 & 0.926 & 1.000 \\
\hline \multicolumn{7}{|c|}{ Landsat of April 7, 2004} \\
\hline 1 & 1.000 & & & & & \\
\hline 2 & 0.976 & 1.000 & & & & \\
\hline 3 & 0.951 & 0.980 & 1.000 & & & \\
\hline 4 & 0.261 & 0.354 & 0.333 & 1.000 & & \\
\hline 5 & 0.636 & 0.721 & 0.753 & 0.733 & 1.000 & \\
\hline 7 & 0.789 & 0.853 & 0.895 & 0.516 & 0.931 & 1.000 \\
\hline
\end{tabular}

\subsubsection{Maximum Likelihood supervised classification}

\subsubsection{Visual interpretation and training sample}

The two Landsat ETM+ images were displayed at False Colour Composite 4, 5 and 3 and were fused with Panchromatic band in order to perform better visual interpretation as well as to determine the desirable classes of feature for purpose of the image classification and get a better view of land cover types as the areas are dominated by forest types, agricultural land, other land types and river edge. The same band combination was also used for defining the training samples on the images in order to perform Maximum Likelihood supervised classification.

\subsubsection{Classification}

Satellite remote sensing has been successfully implemented on an operational basis for many different fields through standard visual interpretation techniques. Landsat ETM+ is now being used for mapping land cover of different forest types with reliable accuracy through visual as well as digital techniques.

The Maximum Likelihood Algorithm was chosen for digital classification of the image. Working with supervised classification requires a good knowledge of image processing and image 
interpretation and also sufficient familiarity with the real world. Therefore, a skilled operator if supervised classification is to be used. The training samples were examined many times in order to give satisfactory results. The results were used to perform a Maximum Likelihood classification. The selection of training samples requires close interaction between the image analyst and the image data. The training class separability was investigated using statistical analyses. The statistical analyses were computed based on both the Jeffries-Matusita and Transformed Divergence separability measures. Values greater than 1.9 indicate that they have good separability and values lower than 1 indicate that they have very low separability (Richards J.A., 1999). The training classes were grouped according to the forestland cover types in the study area. The distributions of vegetative types are associated with climate, rainfall, aspect and topographic pattern. Based on the results of field survey, the following land cover types were selected as representative classes in a Maximum Likelihood supervised classification: Forest plantation (Resin pine, Acacias, Eucalyptus and Casuarinas), dense forest, degraded forest, grass land, shrub land, bare land, agricultural land (paddy fields and crops), water and build up areas. The results of the classified image were shown in figure 5.5.

\subsubsection{Land cover classification map}

The forestland cover classification was determined based on the results from the interpretation of three Lansdsat ETM + images acquired in January and April of 2003, April of 2004 and ground survey.

After completing image classification in ENVI, the results of classification were exported to ArcView for further processing. The boundary of different forestland cover types were separated and combined together under broad classes. This is due to overlapping in spectral reflectance among some forest classes. For example some degraded forest areas were confused with the forest plantation and shrubs. The boundaries were interactively digitized and forestland cover categories labelled using the forestland cover polygons on the classified images. The polygons were digitized in the graphic overlay planes of the colour monitoring using a conventional mouse for location control to create land cover map of different forest types. In this map, eight land cover categories were recognized namely (1) dense forest, (2) degraded forest, (3) forest plantation, (4) grass land, (5) shrub land, (6) barren land, (7) other land (agricultural land, water and build up areas). Finally, the available land cover map and topographic map were superimposed to get the composite map or the land cover map of different forest types (figure 5.6). 


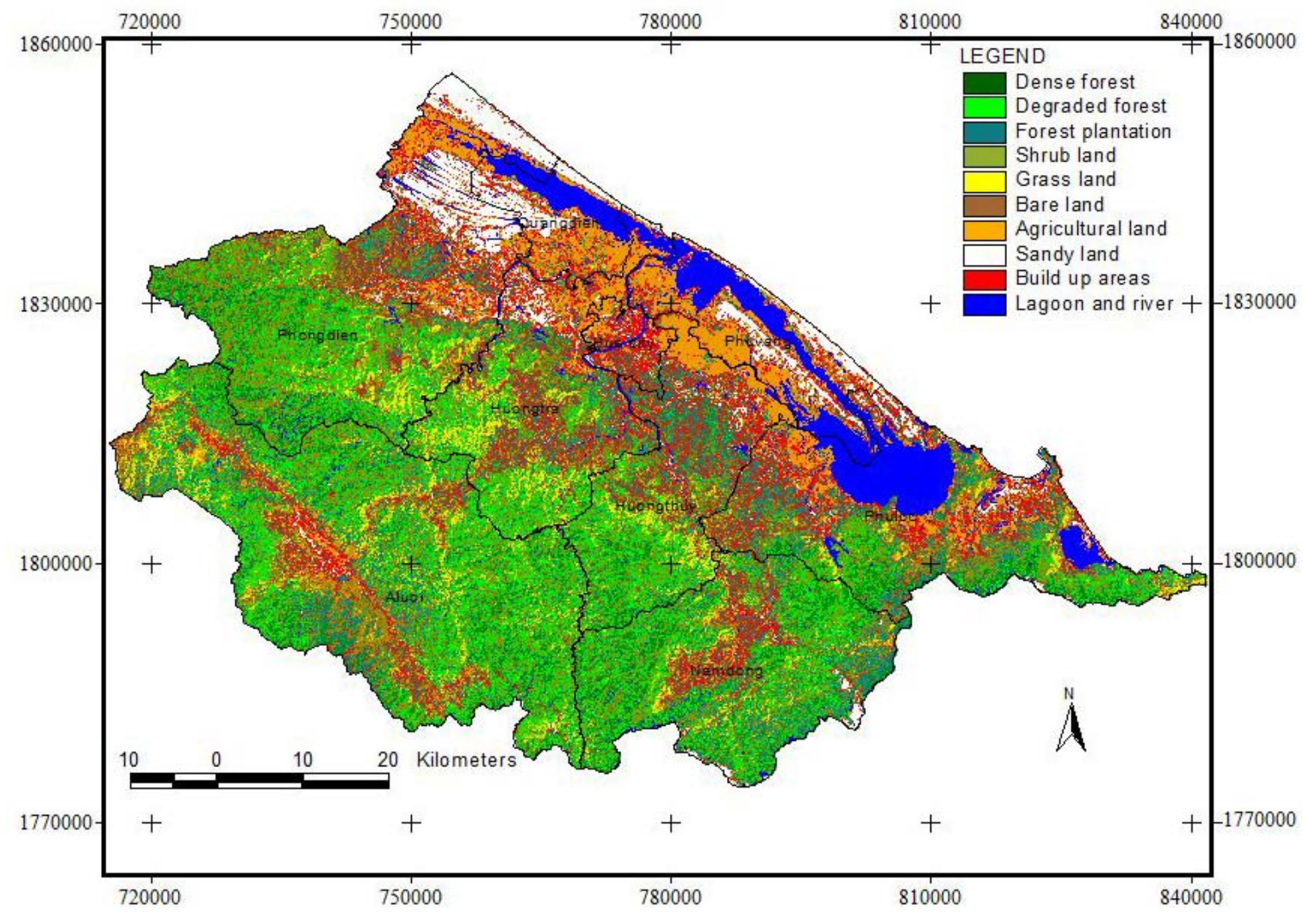

Figure 5.5: Supervised Maximum likelihood classification of Thua Thien Hue province 


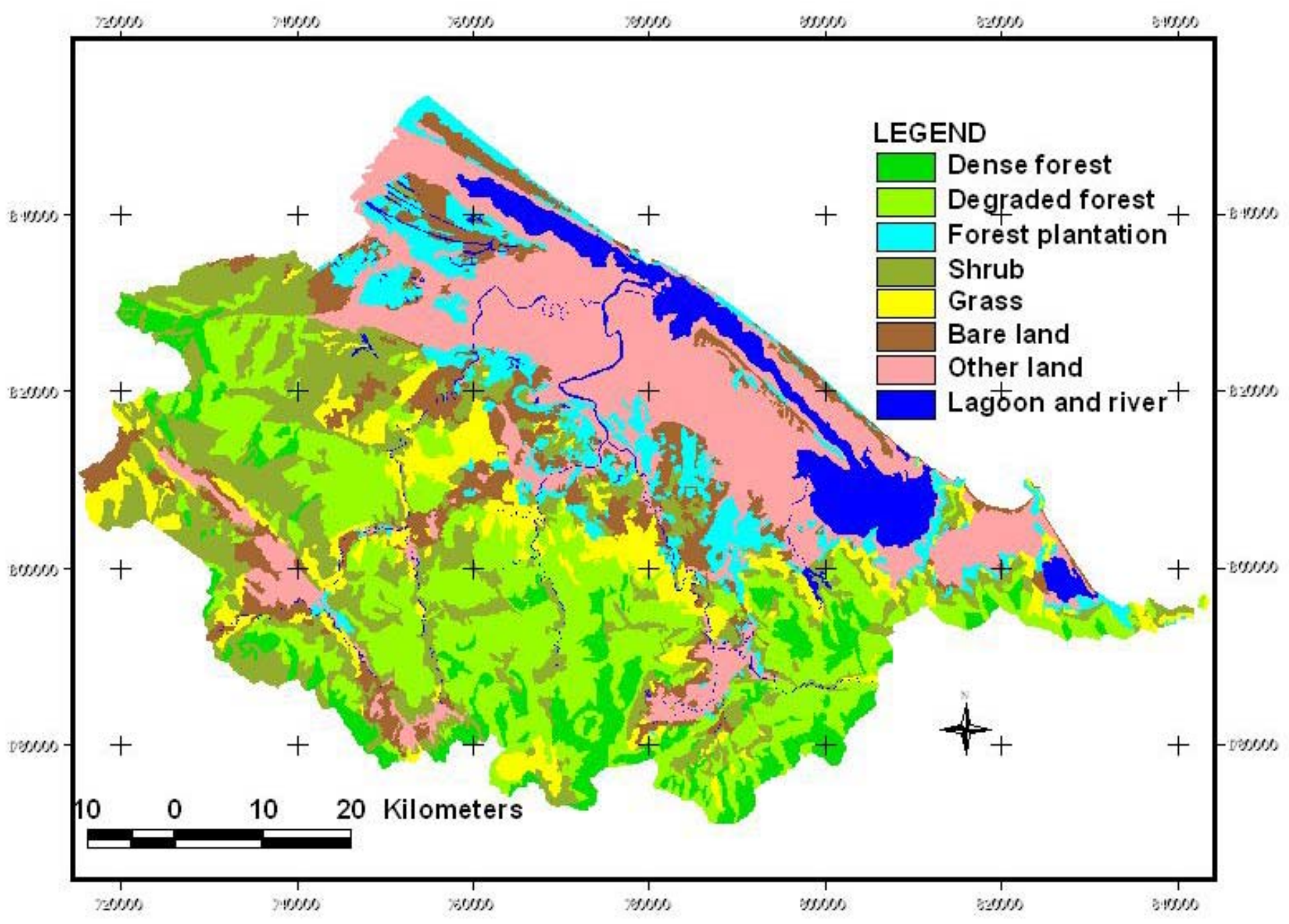

Figure 5.6: Land cover map of different forest types of Thua Thien Hue Province 
The main factors controlling the forest and land cover types and its distributions in the study area are forest physiognomic, and forest structural properties. The vegetation is associated with climate, slope aspect and topography. However based on field survey, it is evident that topography was the main influence on the distribution of forest and land cover in the study area. The examination of the Landsat ETM+ classified image reinforces this observation. The flat land areas are dominated by agriculture, urban, village and coastal sand soil at elevation lower 100 meters above sea level. Hills and low mountains are covered forest plantation, grass, shrub and bare land, and higher areas are dominated by degraded forests and dense forests.

The total area of Thua Thien Hue is 505,339.4 ha, eight land cover categories from classified images are recognized as presented in Table 5.4. The result shows that vegetation occupies 55.1 percent of the entire area, of which 7.1 percent belongs to dense forest, 22.1 percent belongs to degraded forest, 7.5 percent belongs to forest plantation and 18.3 percent belongs to shrub. The image classification also proves that 44.9 percent is under non-forest types, of which 7.9 percent is grassland, 9.5 percent is barren land and 27.6 percent is other land (agriculture, water and build up areas).

Table 5.4: Forest and land cover areas and percentage area of Thua Thien Hue province based on the classified image

\begin{tabular}{|c|c|c|c|c|}
\hline No & $\begin{array}{c}\text { Forest and land cover } \\
\text { types }\end{array}$ & Area in ha & $\begin{array}{l}(\%) \text { of total } \\
\text { natural area }\end{array}$ & $\begin{array}{c}\text { (\%) of total forestry } \\
\text { area }\end{array}$ \\
\hline$I$ & Forestry land & $365,891.4$ & 72.4 & - \\
\hline 1 & Dense forest & $35,800.7$ & $\overline{7.1}$ & 9.8 \\
\hline 2 & Degraded forest & $111,498.6$ & 22.1 & 30.5 \\
\hline 3 & Forest plantation & $37,840.2$ & 7.5 & 10.3 \\
\hline 4 & Grass land & $39,925.8$ & 7.9 & 10.9 \\
\hline 5 & Shrub land & $92,930.2$ & 18.3 & 25.4 \\
\hline 6 & Barren land & $47,896.0$ & 9.5 & 13.1 \\
\hline \multirow[t]{2}{*}{ II } & Other land & $139,448.0$ & $\underline{27.6}$ & - \\
\hline & Total area & $505,339.4$ & 100.0 & 100.0 \\
\hline
\end{tabular}

The forest and land for forestry use is 365,891.4 ha or 72.4 percent of the total entire area. Based on the results of Landsat ETM+, the province has 185,139.5 ha of forests, with $36.7 \%$ forest cover, of which the natural forest (dense forest and degraded forest) is 147,299.3 ha and forest plantation is $37,840.2$ ha. On the other hand, image classification was also observed that a forestry area of 180,752 ha is non forestland, of which 39,925.8 ha is grass land, 47,896.0 ha is barren land and 92,930.2 ha is shrub. This kind of land will be a potential but also a challenge for development of forest plantation in the future, because most of non-forest area is distributed on the slope, degraded and scattered land. 
According to available data of the 1998 map, Thua Thien Hue had 214,183 ha of forests (42.4 \% of the provincial area), of which 170,243 ha is natural forest and 43,940 ha is forest plantations. When comparing between the 1998 map and the Landsat ETM+ classification map, 45,280 ha of dense forest is identified on the 1998 map ( $9 \%$ of the entire area) had been replaced by degraded forest and other land cover types in the image classification, so the degraded forest area in the classification image had increased by 22,337 ha. The results of image classification also show a decrease in the total forest plantation and shrub area and an increase in total area grass and barren area (Fig. 5.7).

In generally, the non-forest area in the Landsat ETM+ classification map has increased and the forest area has decreased by 29,044.5 ha since the 1998 map. The decrease comprised 22,943.7 ha of the natural forest and 6,099.8 ha of forest plantation.

The causes of natural forest changes are complicated and diverse. A lot of commentators agree on the following as main reasons:

- The main human activities with respect to the forest environment are traditional shifting cultivation and farming by settled lowland migrants.

- Poor management capacity of the forest sector and deficient institutional and local framework.

- Fuel wood and timber over-harvesting that are seen both as high-volume commercial logging and low-volume selective logging carried out by state forest enterprises, but illegal logging by individuals or small groups.

- The forest and land cover types in the 1998 map were not reliable anymore because of incorrect mapping and/or the temporal aspect.

The main reasons that have led to decrease forest plantation area can be summarized as follows:

- Survival rates and forest plantation established was very low. Locations of forest plantations were, as a consequence, frequently replanted.

- Some forest plantations were harvested for industrial material such as paper, fibre, and particle board.

- In some location, the forest plantations were destroyed due to change of land use purposes and forest fire.

With these forest resources, the present average in the study area is about 0.16 ha forest/person. Thua Thien Hue belongs to the medium group of provinces, in comparison with the national 
average of 0.15 ha /person and the low group of countries, in comparison with the international average of 0.97 ha /person.

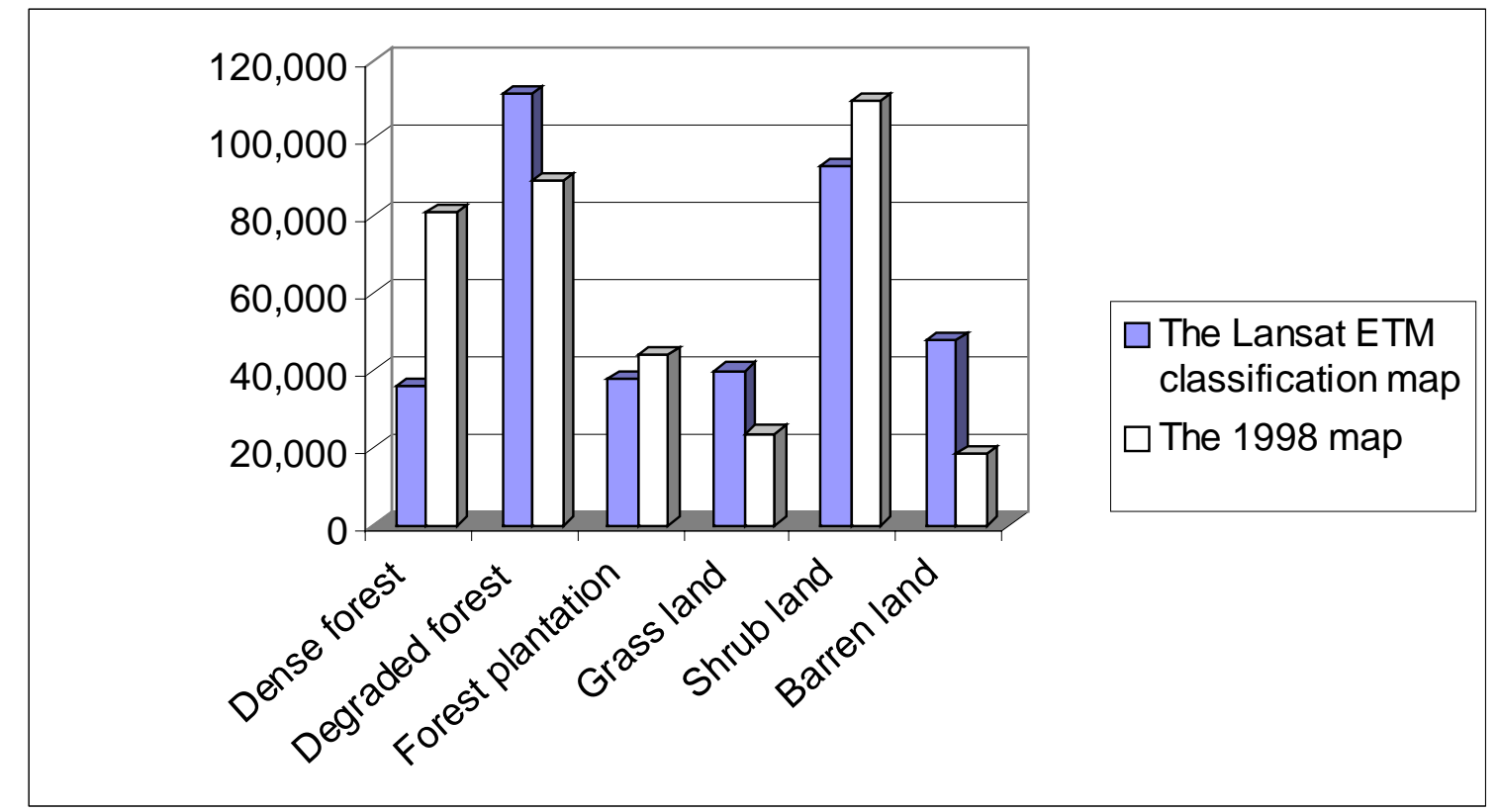

Figure 5.7: Comparison between the 1998 map and the Landsat ETM+ classification

\subsubsection{Dense forest}

Two sub-types of dense forest were found in the study area with an area of 35,800.7 ha or 7.1 percent of total natural area: 1) montane closed evergreen sub-tropical monsoon forest and 2) closed evergreen tropical monsoon forest. These forest types are distributed mainly in the southwest of the province along the border between Thua Thien Hue and Laos (country), and within the south and southwest of the province. Disturbance is minimal, and the forest structure is dense and largely intact, with a very species-rich floral composition. This type includes all forest areas where both evergreen and deciduous are growing with general tree height of $15-40$ $\mathrm{m}$ and the crown coverage of more than $60 \%$.

The montane closed evergreen sub-tropical monsoon forest includes all forest areas where the trees are predominated by those which remain green through out the year. This forest types occupy surrounding high peaks of the mountain, and are occurring at altitudes over $900 \mathrm{~m}$ above sea level where precipitation is high and temperature are cool through out the year. The main tree species prevailing in this forest are some of the families of Acearacae Theaceae, Fabaceae, Ericaceae, Fagaceae, here contains tree species such as: Acer tonkinensis, Cammellia sp, Gordonia intricate, Thea caudate, Adenanthera microsperma, Rhdodendron simsii, Quecus bamusaefolia, Quecus sp, Castanopsis ceratacantha, Castanopsis sp, Lithocarpus balansae, 
Lithocarpus sp and Podocaspus imbricatus. Crown closure is between 60 to 65 percent (canopy cover), and the forest floor is dense (Fig 5.8 a).

The closed evergreen tropical monsoon forest: This forest type includes all forest areas where both evergreen and deciduous are growing and neither predominates. Plant composition and structure are more complex than the montane closed evergreen sub-tropical monsoon. This kind of forest type is located at elevations lower than $900 \mathrm{~m}$ above sea level in which the dominant species are of the families of Leguminoceae, Sapindaceae, Fagaceae, and Lauracae, Flacourtiaceae here it contains species such as: Morus alba, Been, Mango, Cinamomun camphora, Elbern, Melia azedarach, Pometia pinnata, Lepisanthes banaensis, Lagertroemia callyculata and Hydnocarpus annamensis are dominant species on deep moist soil and low slope gradient, Castanopsis $s p$ is also found in this cover type but this stand occupied drier site and higher elevation. Here are many species from the North and South of Vietnam. The species emigrating from the North are Sindora tree, Artocarpus styracifolius, Styrax sp, inside yellow tree and the species from the South as Hopea pierra (Fig. 5.8 b).

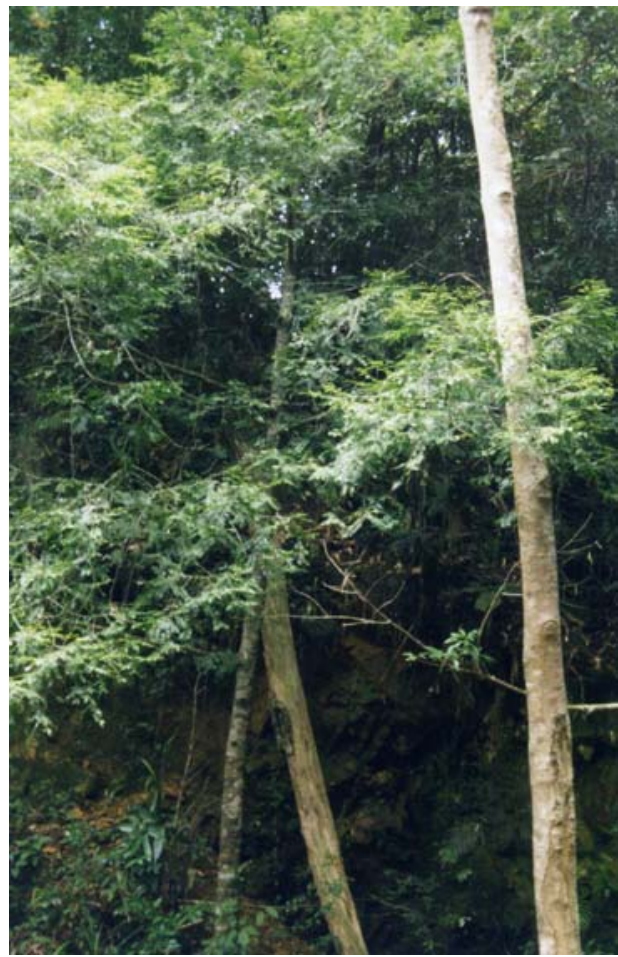

Figure 5.8 a

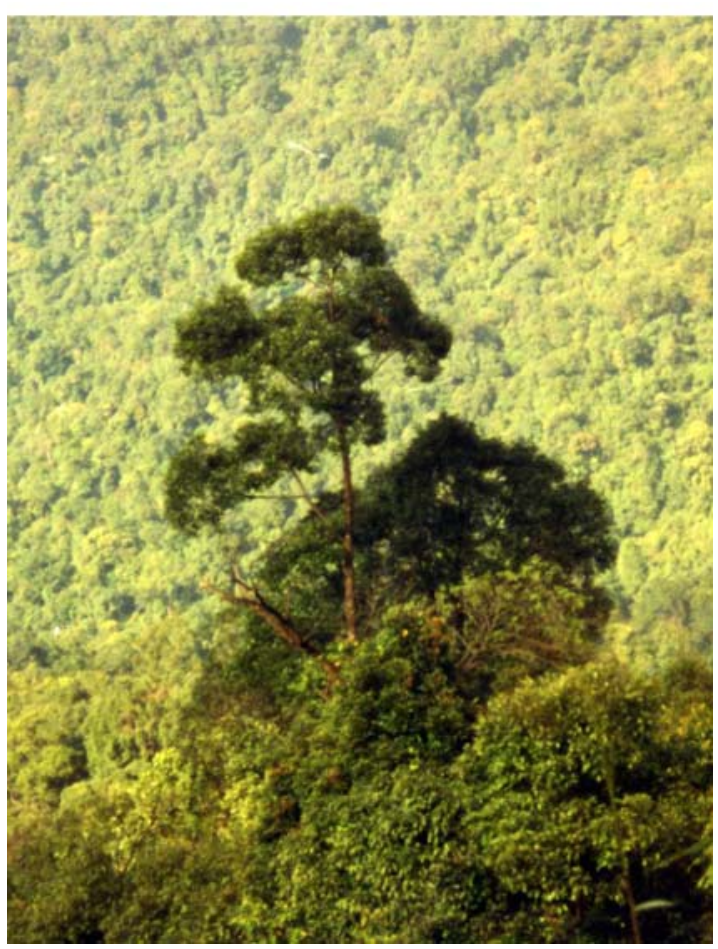

b

The montane closed evergreen sub-tropical The closed evergreen tropical monsoon forest, monsoon forest, $1,250 \mathrm{~m}$ a.s.l 


\subsubsection{Degraded forest}

The degraded forest area covers $111,498.6$ ha or 22.1 percent of the total area of the province, this is the result of long term disturbance by mankind. The rare and valuable species and big stands are rarely found because of illegal logging and encroachment. This forest type occupies at elevation lower than 500 meters above sea level and is classified into two sub classes: (i) secondary forest/ open forest and (ii) young secondary forest.

The secondary forest/ open forest crown: This kind of vegetation occupies at elevation lower than 500 meters above sea level in surrounding of inhabited areas nearly roads. Crown closure is approximately 30- 45 percent and tree height rarely exceeds $20 \mathrm{~m}$. Bamboos and shrubs are found in the openings followed by selective logging. The dominant species include Elaeocarpus dubius, Elaeocarpus limatarius, Molotus annumatious, Sapium discolor, Cratoxylon formosum (Fig.5.9 a).

The young secondary forest: The forest growing in clear cut resulting either from logging or agricultural. Canopy closure exceeds 45 percent but tree height is less than $15 \mathrm{~m}$. This kind of forest was dominated by fast-growing pioneer species, such as Macaranga andersonii, M. denticulata, Trema orientalis, Litsea cubeba and other desiccation-tolerant species (Fig.5.9 b).

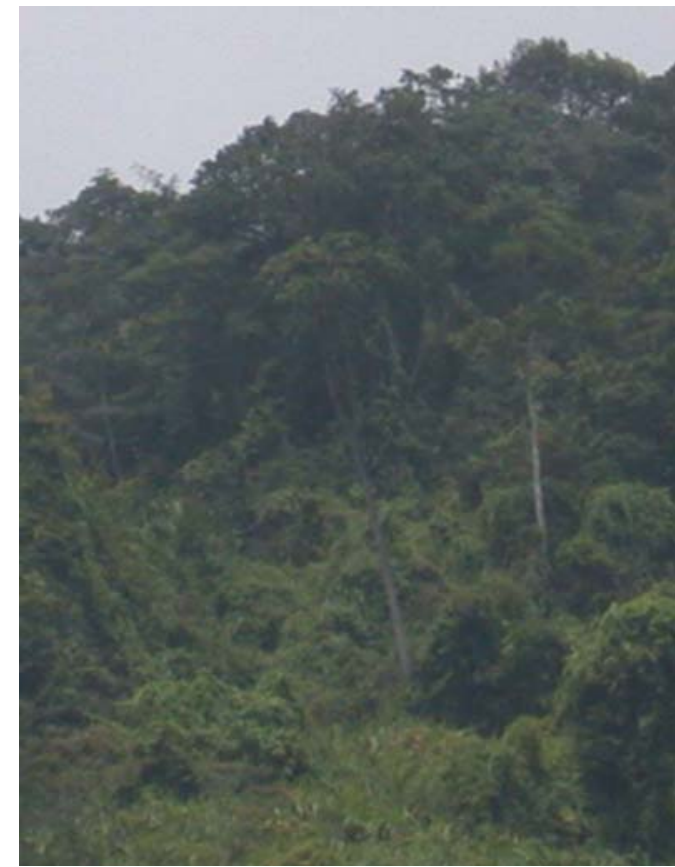

Figure 5.9 a

The secondary forest, $350 \mathrm{~m}$ a.s.l

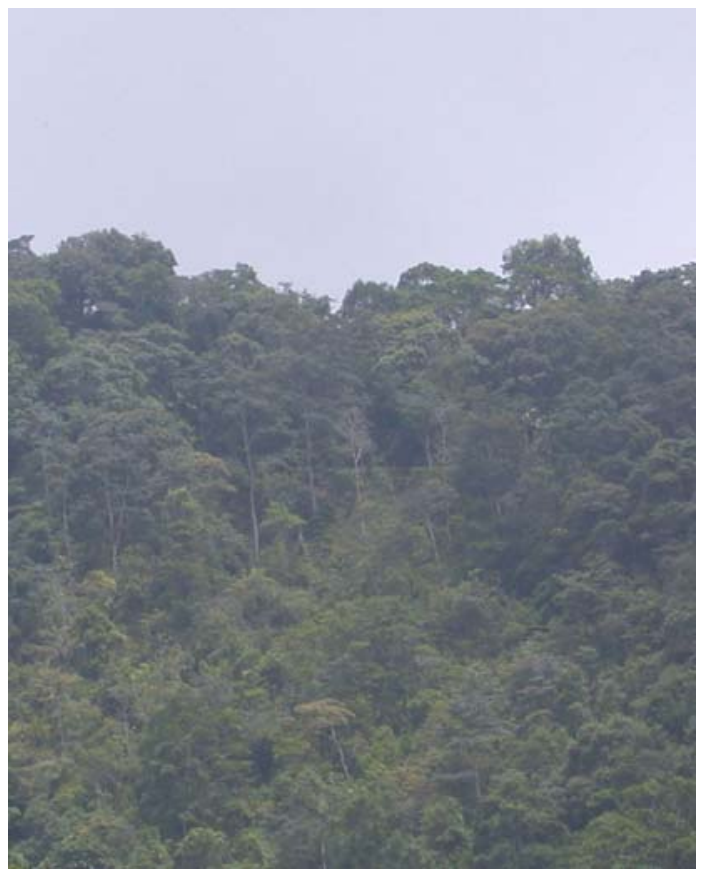

b

The young secondary forest, $300 \mathrm{~m}$ a.s.l 


\subsubsection{Forest plantation}

Land with planted forest accounts for 7.5 percent of the total area. This forest type is the results of past and ongoing reforestation efforts. The main species for plantation establishment such as resin Pine, eucalyptus, casuarinas and Acacia species (Fig.5.10) have been planted by project managers of the national forestry programmes. Most of the forest plantations generally were grown in stands of a uniform height and crown coverage and were found on flat land and lower slopes, where establishment is cheaper and easier. However, the plantation of Eucalyptus suffers from a disease locally named "dry leaf", because the infected leaves of trees grow dry and then die. Effective disease control methods are yet to be found. Therefore this tree species is not suitable for the purpose of soil conservation and forestry production.

At present, pulp industry develops rather fast in the region, especially in the Thua Thien Hue province, which leads to high demand of timber for pulp. Therefore, the forest plantation for pulp industry increased in recent years. However, the forest plantation in the study area is facing many problems. Firstly, is the poor quality of forest plantation. Up to now there is no a collection of suitable forest tree species for each site condition.
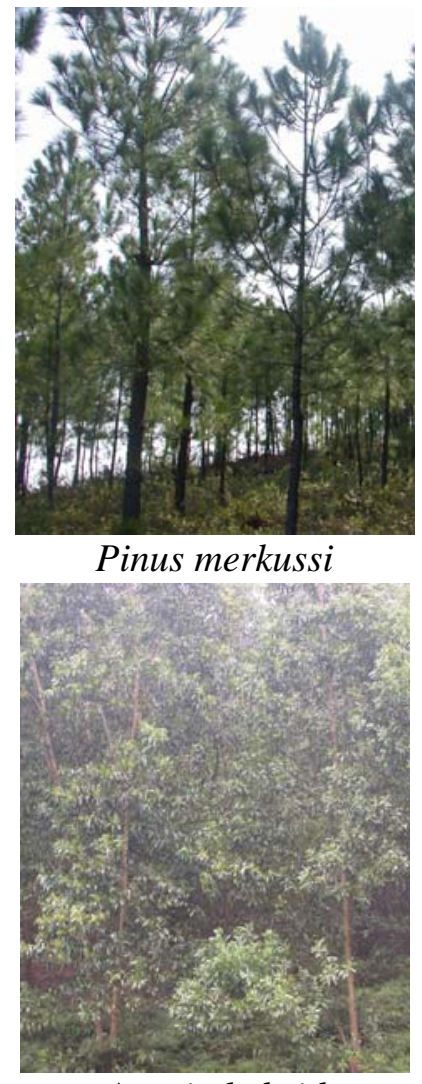

Acacia hybrid

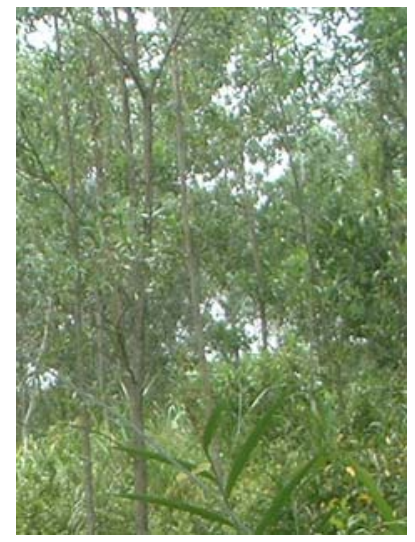

Acacia auriculiformis

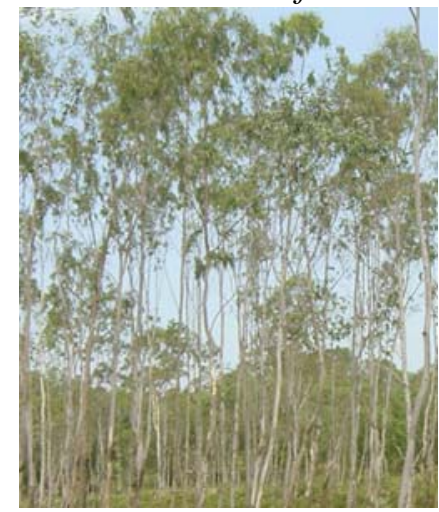

Eucalyptus camaldulensis

Figure 5.10: Different kinds of forest plantation

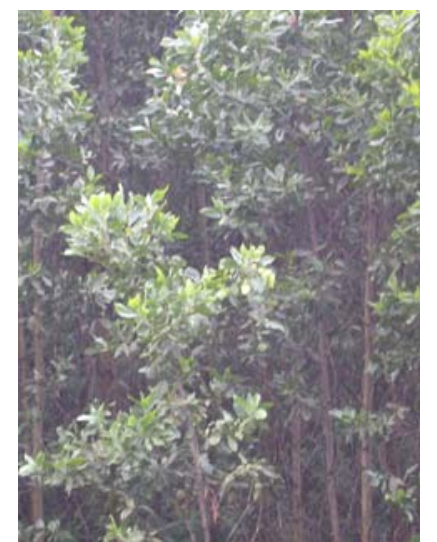

Acacia mangium

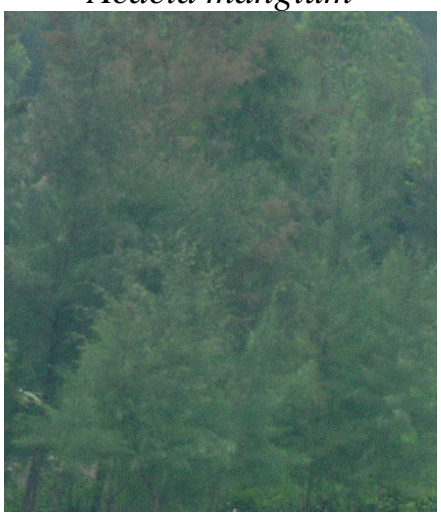

Casuarina equisetifolia 


\subsubsection{Shrub}

With about 92,930.2 ha or 18 percent of the whole area, the shrub is distributed mostly upon flat floodplains contiguous with rivers and streams, although it also occurs on lower hills and some of the shrub areas were even found in the montane evergreen sub-tropical monsoon forest. This forest consists of the various woody bush and bushy thicket, and occurs in dense to opened evergreen and on shallow dry soil. These areas are often associated with fallow vegetation (approximately 2-5 years). The shrub and bushes reach a height between 3 to $7 \mathrm{~m}$. Dominant species include Cataxylon formosum, Mallotus paniculatus, Melastoma spp. and Rhodomyrtus tomentosa (Fig.5.11).
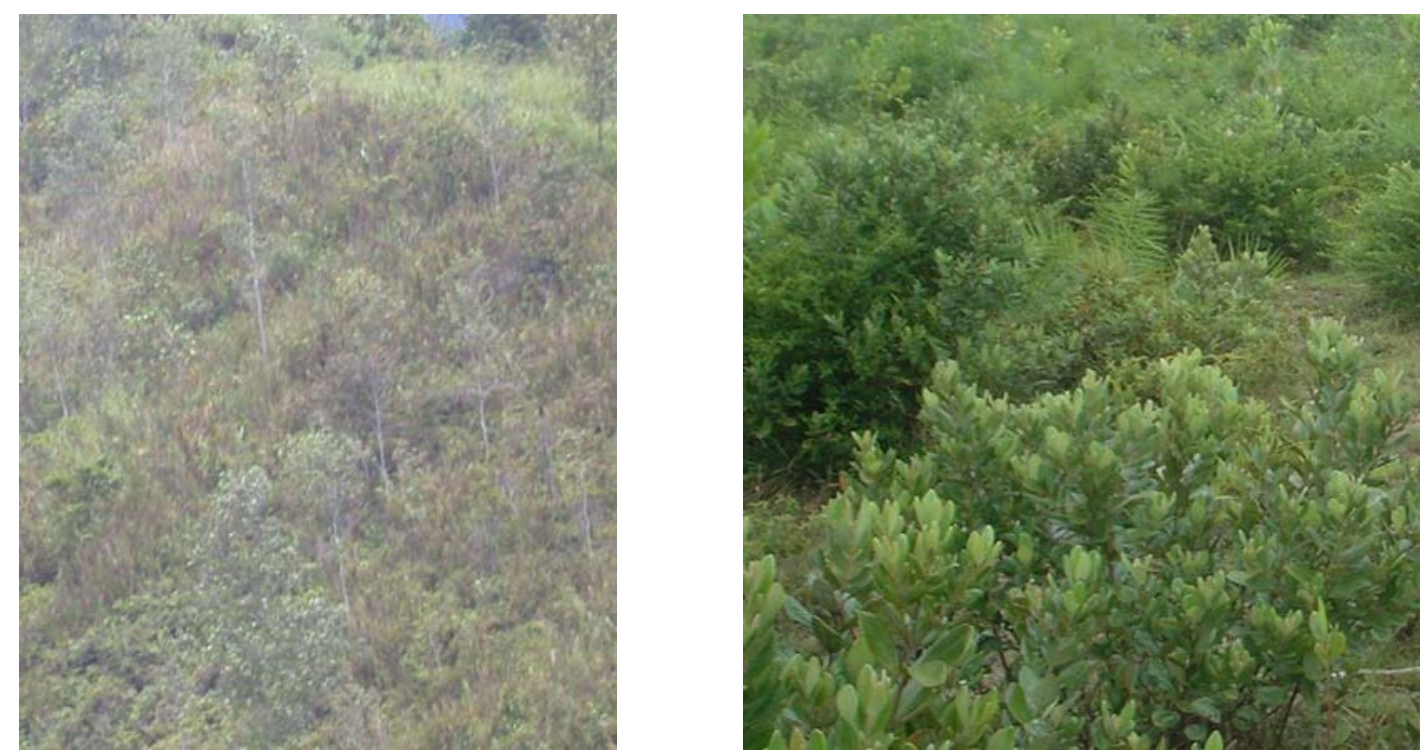

Figure 5.11: Shrub land

\subsubsection{Grassland}

Grassland covers about 39,925.8 ha or 7.9 percent of the total area of the whole area. Most of the grassland at the province was created as a result of either shifting cultivation or wartime spraying of defoliants. This vegetation occurs on plateau where soil is shallow and contains rocks. Ground cover is composed of various grass species such as Cynodon dactylon, Panicum repens, Phragmites communis, Saccharum arundinaceum, Saccharum spontaneum, Thysannolaena maxima, Neyraudia reynaudiana and Imperata cylindrica (Fig.5.12). In some areas, growth is very dense, with grasses reaching a high of $2 \mathrm{~m}$. 


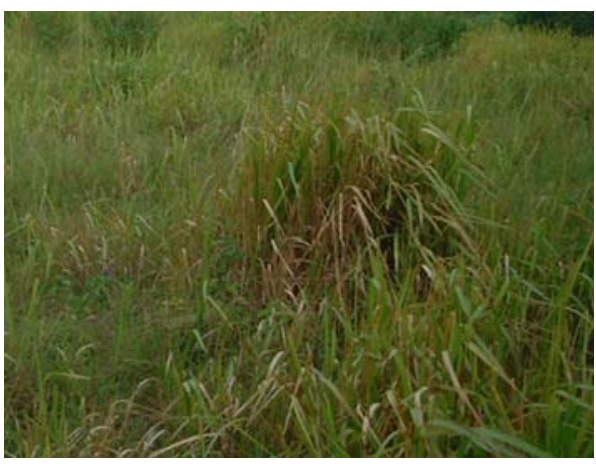

Imperata cylindrica

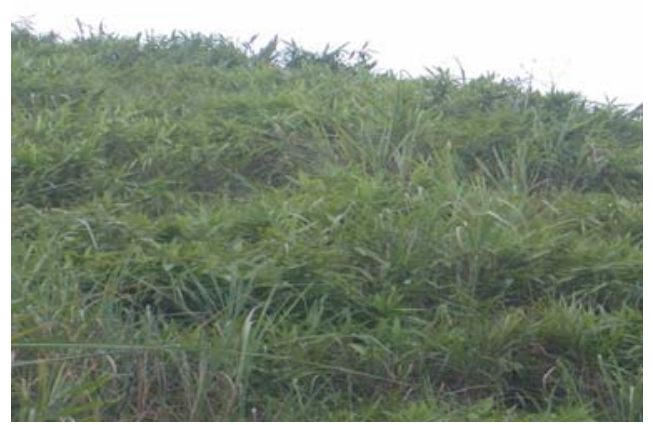

Sacch spontaneum

Figure 5.12: Grass land

\subsubsection{Barren land}

Based on presence or absence of vegetative cover, the areas are delineated into barren land (without vegetative cover). There are about 47,895.8 ha of barren land or 9.4 percent of the total area of the province, of which $42,625.0$ ha or 8.4 percent ha is in the hills and mountains and 5,270.8 or1.0 percent is in coastal sand region. The barren land is located surrounding the inhabited areas. Generally speaking, they are areas of thin soil, vegetation is very wide spaced or without vegetative cover because of man's activities

\subsubsection{Other land}

Other land includes agriculture, water and build up areas, which covers about 139,448.0 ha or 27.6 percent of the whole area located in the North and Northeast of the province where soil is deep and moist as well as in flat area, crops include cassava, wet rice, fruit. After the harvesting period some of these areas are occupied by weed.

\subsubsection{Accuracy assessment}

The accuracy assessment is a vital part to analyse the classified image result. The product of accuracy analysis was an overall classification accuracy, a producer's accuracy, an user's accuracy and a Kappa coefficient of agreement. The importance of the accuracy assessment is indicated by the Landsat ETM + classification results. To assess the accuracy of classification, it is common practice to create an Error (or confusion) matrix. In an error matrix, the classification results are compared information from reference site to information on a map for a number of sample areas. An error matrix analysis provides a natural framework for the convenient display of results that can also be used for analysis. This is an effective tool that presents the overall classification accuracy as well as the producer and user accuracy of each category (Congalton, Oderwald and Mead, 1983). 
The assessment of classification was based on 585 samples using random sampling method, at least 50 per land cover category. The level of agreement or disagreement between the Landsat ETM + classification and reference data is shown in Table 5.5.

Results from the accuracy assessment of classification indicated that the overall classification accuracy is 84.6 percent. This percentage indicates how accurate the classification is with respect to the reference data (Story and Congalton, 1986). The overall accuracy is calculated by summing the main diagonal elements of the error matrix and divided by the total number of samples.

The land cover types of dense forest and forest plantation displayed the highest level of agreement with the reference data with producer’s accuracies of 90 and 95 percent, respectively. The lowest producer's accuracy is found in bare land (73\%)

The land cover classes (dense forest and agriculture) displayed the highest level of agreement with the reference data with user's accuracies of 89 and 88 percent, respectively. The lowest user's accuracy is also found in bare land (75 \%).

The Kappa statistic represents the agreement between the classified forestland cover and the observed forest. A Kappa index is more superior to the other accuracy measures because unlike the overall, producer's and user's accuracies, which make use of the principle diagonal, columns and rows of the matrix, it makes use of all the information in the error matrix in order to take into account the chance allocation of class labels. In other word, the Kappa index incorporates both the principle diagonal entries and off- diagonal entries of error matrix consideration (Tso and Mather 2001). According to Landis and Koch (1977), the values of Kappa greater than 0.80 (80\%) represents strong agreement; a value between 0.40 and 0.80 (40-80\%) represents moderate agreement; and a value below 0.40 (40\%) represents poor agreement. Based on the error matrix, a Kappa index was also computed and Kappa statistic of 0.82 (82\%) has been found, presenting strong agreement. This value indicates that the classification has achieved an accuracy that is 82 percent better than what would be expected from random assignment of samples to forest and land cover types in Thua Thien Hue province. Besides, the figures in table 5.5 are consistent with the above arguments and show that it is statistically significant to apply image of the band ETM 3, ETM 4, ETM 5 and ETM 8 (Panchromatic band) when mapping the forest and land cover. Table 5.5 is the result of Supervised Maximum likelihood classification of Landsat ETM+. It presents the final forest and land cover map of the study area. Note that a number of non- forest classes such as the water and build up areas have been mapped well. 
However, due to lack of independent reference data and that these areas are not forestry land, the classification accuracy of the water and build up areas has not been assessed.

Table 5.5: Error (or confusion) matrix of the Maximum Likelihood clustering method of land cover classification

\begin{tabular}{|c|c|c|c|c|c|c|c|c|c|c|c|}
\hline \multicolumn{12}{|c|}{ Reference data } \\
\hline \multicolumn{2}{|c|}{ Classification } & (1) & (2) & (3) & (4) & (5) & (6) & (7) & (8) & $\begin{array}{l}\text { Row } \\
\text { Total }\end{array}$ & $\begin{array}{l}\text { User's Accuracy } \\
\text { (\%) }\end{array}$ \\
\hline (1) & Dense forest & 47 & 5 & 1 & & & & & & 53 & 89 \\
\hline (2) & $\begin{array}{l}\text { Degraded } \\
\text { forest }\end{array}$ & 2 & 62 & 5 & 2 & & & & & 71 & 87 \\
\hline (3) & Shrub & 3 & 3 & 54 & 5 & & & & & 65 & 83 \\
\hline (4) & $\begin{array}{l}\text { Forest } \\
\text { plantation }\end{array}$ & & 12 & 8 & 143 & & & 3 & & 166 & 86 \\
\hline (5) & Agriculture & & & & & 64 & 6 & 3 & & 73 & 88 \\
\hline (6) & Grass & & & & & 9 & 42 & 1 & & 52 & 80 \\
\hline (7) & Bare land & & & & & 5 & 2 & 40 & 7 & 54 & 75 \\
\hline (8) & Rock / sandy & & & & & & & 8 & 43 & 51 & 84 \\
\hline & Column total & 52 & 82 & 68 & 150 & 78 & 50 & 55 & 50 & 585 & \\
\hline & $\begin{array}{l}\text { Producer's } \\
\text { Accuracy (\%) }\end{array}$ & 90 & 76 & 79 & 95 & 82 & 84 & 73 & 86 & & \\
\hline & $\begin{array}{l}\text { Overall accur } \\
\text { Kappa index }\end{array}$ & $\begin{array}{l}7)= \\
.82\end{array}$ & 4.6 & & & & & & & & \\
\hline
\end{tabular}

\subsection{Conclusion}

Nowadays, monitoring of tropical forests becomes one of the main applications in remote sensing. The objective of this study was to map the forest and land cover distribution and to identify suitable areas in order to assess the forestland potential for forestry using Landsat ETM+. It is essential to select optimal spectral bands and dates of Lansat ETM + data. The limitation of the spatial resolution of Landsat 7 ETM + was overcome by fusing a Panchromatic band with the multi-spectral bands. These are good evidence that forestland cover types could be clearly identified and distinguished using fusion of Panchromatic with ETM+3, ETM+ 4 and $\mathrm{ETM}+5$.

This study showed that the Maximum Likelihood supervised classification using the output of ISODATA clustering, available secondary data together with field data could be used for mapping broad categories of forest and land cover. In addition, the study provided the status of forest resources for the first time with detailed of different forest types along with statistical data on the area of each forest and non-forest category.

The main factors controlling the forest and land cover types and its distributions in the study area are forest physiognomic, forest structural properties and topography and the qualitative analysis of the classified image seems to reinforce this observation. The flat land areas at elevation lower 
than 100 meters above sea level are dominated by farm, urban, village and coastal sand, hilly and low mountain areas are covered by forest plantation, grass, shrub and bare land, and higher areas are dominated by degraded forests and dense forests.

The results of Landsat ETM+ classification indicated that the overall accuracy of mapping forest and land cover is 84.6 percent and the Kappa coefficient for classification is 0.82 or 82 percent. In terms of areas occupied by each forest and land cover type and their class accuracy, degraded forest presents $111,498.6$ ha or 22.1 percent of the entire area with user's accuracy of 87 percent, followed by shrub land, bare land, grass land, forest plantation, dense forest and coastal sand land which represent 92,930.a ha (18.4 \%), 42,625 ha (8.4 \%), 39,925.8 ha (7.9 \%), 37,840.2 ha (7.5 \%), 35,800.7 ha (7.1\%) and 5,270.8 ha (1\%) in terms of area respectively. The respective individual class accuracies are 83 \%, 75\%, 80\%, 86\%, 89\%, and $84 \%$ (user's accuracy), while the producer's accuracy is $76 \%$ for degraded forest, $79 \%$ for shrub land, 73 \% for bare land, 84 $\%$ for grassland, $95 \%$ for forest plantation, $90 \%$ for dense forest and $86 \%$ for coastal sandy land.

These results clearly suggest that the spectral and spatial characteristic of Landsat ETM+ data could be used to identify, classify and map forest and land cover types in tropical forest environments in general and Thua Thien Hue province of Vietnam in particular.

The use of optical sensors in humid regions of Thua Thien Hue is hampered by high occurrence of clouds and thus the acquisition of several cloud free Landsat ETM+ scenes at crucial times within a year can be different. Nevertheless, the success of ETM + and GIS in this application could give an up-to-date synoptic view of the state of the existing forest and forestland in the study area and similar success may be possible in other places of Vietnam.

The forest and land cover map was compiled from Landsat ETM+ images showing the position and classes of the land suitable for development of forest development. This map would play an important role in assessing land potential for forestry use. Better assessment of land potential using digital analysis of Landsat ETM + data can help the forestry managers and planners to develop effective plans for the management of forestry land. In addition, it reduced the number of samples required for forest inventory and also reduced the time and cost to a considerable extent. 


\section{Chapter 6. Land Potential Productivity Assessment for Forestry Use}

\subsection{Introduction}

Land as a resource is finite and scarce. The land use of land is not only determined by the user but also by the land capability. The land capability is governed by the different attributes of land such as the soil types, which is critical for productivity, underlying topography, geology, etc. The soil is an important environment contributing to growth and development of the forests and its vegetation. The land attributes limit the extents of land available for various use purposes. Any land utilization that exceeds its capability will cause degradation and yield reduction in longterm duration. In order to get the maximum benefit out of the forestland both wood production and environmental protection, one way is to increase production per area unit and to utilize the land with respect to its potential in an appropriate way. Hence, it is necessary to have knowledge of potentials and limitations of forestland.

Forestry is a most important economic sector of Thua Thien Hue. Forestry land includes forest and forestland that occupy an area over 70 percent of the entire area. Like many other province of Vietnam, forestry land use planning is not practiced on a regular basis. In many parts, especially in sloping areas, forestlands are converted into agricultural land, this lead to accelerated land erosion and to reduced land productivity. Undoubtedly, a proper land use planning will increase forest yield and decrease soil erosion. A land potential productivity study is a preliminary step when assessing whether land is likely to be practical and successful for sustainable development of an intended venture or not. A site of potential productivity is preliminary for successful forestry production, and the land potential productivity assessment is an important step in the process of land use planning and careful planning of the land resource uses must be based on land potential productivity assessment. A number of studies on land potential have been conducted throughout the country. However, in Thua Thien Hue, like other provinces, most of these studies focused on agricultural production. Moreover these studies used traditional methods to produce maps and the information on the land potential productivity which require time and finance. In recent years, GIS and remote sensing techniques have become very useful tools in land evaluation. The forestry land assessment plays an important role in providing land potential productivity use options to cope with the dynamics and competitive nature of forest production. Assessment of forestry land provides sets of data on potentials and constraints, which can contribute to decisions of the use of sustainable forestry land. Therefore, 
land and its productivity for forestry use is a very important aspect in forest production. The forestlands and their productivities should be assessed not only to better know the land capability, but also to point out the land availability for the purpose of land use.

This study is conducted based on the FAO guideline for land evaluation. Effective implementation of assessment of land potential productivity for forest production at provincial scale relies on spatial modelling inside geographic information system (GIS).

This chapter presents the results of spatial analysis to define potential areas for forestry production using GIS techniques and remote sensing. Data analysis was conducted by using Arcview GIS software, a combination of four factors consisting of nine variables and their impacts are based on Linear Combination Method (Hopkins, 1977) to express land potential productivity for forestry use under forestland management practices in Vietnam.

\subsection{Methodology}

The methodology used is a combination of multi-factor analysis with the help of Remote Sensing to express land potential productivity for forest production based on the FAO approach for land evaluation for forestry (1984) and FAO Framework for land evaluation (1976), modified for particular conditions inside Vietnam. The general process for land potential productivity analysis is shown in figure 6.1 .

\subsubsection{Determination of factors, variables and database development}

The selection and identification of factors and variables should have a very close relationship with soil productivity. It needs to be emphasized that this selection of factor is not exhaustive, only the salient factors for which information is fairly readily obtainable were considered. Based on affecting soil productivity four main factors and nine variables have been selected for land potential assessment, namely (1) soil property factor: Soil type, soil depth, soil texture, soil $\mathrm{pH}$, soil fertility and organic matter, (2) topographic factor: Slope gradient and elevation, (3) climatic factor: Mean annual rainfall and mean annual temperature, (4) vegetation factor. These factors and variables are different in their dependence on land potential productivity. The information was used to develop database using Acrview GIS software.

\subsubsection{Soil property factor}

Soil properties were mapped from a variety of data sources. The soil property map was made based on combining the interpretation of Landsat ETM, soil survey and a topographic and soil 
property map available. The procedure produces soil property map can be divided in to 3 stages as following:

1) Interpretation of Landsat ETM+: Landsat ETM + image provides a synoptic view of study area to determine landscape, land use patterns and geomorphology. In addition, the soil property map and topographic map available at a scale 1: 50,000 were used as base maps.

2) Laboratory of analyses: In this stage, soil samples were grouped by considering texture, then some samples were selected as representatives of soil mapping units for analyses. The aim of analyses is to determine the distribution of soil particle size such as: sand, clay, silt in order to classify high accuracy of soil texture. These results provide information for classifying the soil types.

3) Map compilation: The boundaries of soil types were identified and separated based on interpreting Landsat ETM+. The boundary of soil types were adjusted after checking sample points, soil property maps such as soil types, soil texture, soil $\mathrm{pH}$, soil depth and soil fertility and were extracted from reconnaissance survey maps which were prepared by the Department of Soil science, Hue university of agriculture and forestry and Institute of Geography, Vietnam during the period of 2000 to 2004, available topographic map and laboratory analyses were completed, the final soil property map was prepared by GIS capability.

\section{Soil depth}

Soil depth is an important factor effecting soil productivity. Soils that are deep, well drained, with desirable texture and structure are suitable for forestry production. Deep soils can hold more tree nutrients and water than can shallow soils with similar textures. Soil depth and its capacity for nutrients and water frequently determine the yield from a tree. Trees growing in shallow soils are more easily blown over by wind than are those growing in deep soils. Soil depth was divided into four classes:

1) Very deep: $\geq 100 \mathrm{~cm}$.

2) Deep: $70-100 \mathrm{~cm}$.

3) Moderately deep: $50-70 \mathrm{~cm}$.

4) Shallow: $<50 \mathrm{~cm}$.

\section{Soil texture}

Soil texture is a key variable in the coupled relationship between climate, soil and vegetation, and it can impact the ecological structure. First, by dynamics similar to the inverse texture effect, whereby the optimal soil texture for a given vegetation type changes with rainfall amount, are 
demonstrated for the two most common species at this site. Secondly, it is shown that soil texture plays a major role in the modulation of the impact that inter-annual rainfall fluctuations have on the fitness and coexistence of trees and grasses (Coral Pilar, 2001). At the same time, soil texture plays a key role in belowground $\mathrm{C}$ storage in forest ecosystem and strongly influences nutrient availability and retention. Therefore it plays an important role in helping to assess land potential productivity for forestry use. Soil texture was classified into four classes, these were loamy, clayey, sand, and heavy clay/ coarse sand.

\section{Organic matter content}

Organic matter is one of the most important processes contributing to forest soil degradation. It has a strong impact on forestland productivity and its values vary according to soil and vegetation types and elevation above sea level. Organic matter was divided into four classes:

1) High: $\geq 2.5 \%$

2) Medium: $1.0-2.5 \%$

3) Low: $0.5-1.0 \%$

4) Very low: $<0.5 \%$

\section{Soil reaction (soil pH)}

Soil $\mathrm{pH}$ is an important consideration for forestry production for several reasons, including the fact that many tree species prefer either alkaline or acidic conditions, that some diseases tend to thrive when the soil is alkaline or acidic, and that the soil $\mathrm{pH}$ can affect the availability of nutrients in the soil. It varies depending on soil types, slope, rocks, and vegetation type. Therefore, soil $\mathrm{pH}$ is one of important soil chracteristic in terms of forest production. Soil $\mathrm{pH}$ was divided into following classes:

1) Moderately acid: $5.0-6.0$

2) Very slightly acid: $6.0-7.0$

3) Strongly acid: 4.0-5.0

4) Extremely acid: $<4.0$

\section{Soil fertility}

Soil nutrients are critical elements for tree species growth and development. Total nitrogen, available phosphorus and available potassium were selected to help in assessment of land potential productivity for forest production. Soil fertility was classified into following classes: 
Total nitrogen (\%)

1) High: $\geq 0.2$

2) Medium: $0.1-0.2$

3) Low: $<0.1$

Available phosphorus (ppm/ $\mathrm{kg}$ soil)

1) High: $\geq 25$

2) Medium: $10-25$

3) Moderately low: 6-10

4) Low: $<6$

Available potassium ( $\mathrm{ppm} / \mathrm{kg}$ soil)

1) High: $\geq 90$

2) Medium: $60-90$

3) Low: $30-60$

4) Very low: $<30$

\subsubsection{Topographic factor}

Topography is an important factor for determinant of land potential productivity for forestry use. Absolute height is considered because it is deemed necessary to prohibit development of forestry production above critical contour heights along mountains and hills to protect landscape integrity. Land slope is even more important from an ease of tree planting and construction and an erosion hazard point of view.

\section{Slope gradient}

Slope gradient was considered because it has a very close relationship with soil productivity. First with soil erosion and soil nutrients leaching following different farming practices and systems leading to severe limitations on land uses. Slope gradient was produced from the photographic map of 2000 using 3D Analyst, the Network Analyst and spatial Analyst extensions and slope classification was divided into four classes, namely:

1) Slightly sloping: $<15^{0}(27 \%)$

2) Moderately sloping: $15-25^{0}(27-47 \%)$

3) Steep: 25 - $35^{0}(47-70 \%)$

4) Very steep: $\geq 35^{0}(70 \%)$ 


\section{Elevation}

Elevation is a critical limiting factor due to the effect of temperature and rainfall. In the mountainous areas of Thua Thien Hue province, central Vietnam, elevation is one the most important factors affecting the species composition and structure of forest vegetation. Elevation has a very close relationship with soil productivity and was also produced from topographic map of 2000 and divided into four classes include:

1) Low $<200 \mathrm{~m}$

2) Moderately low: $200-500 \mathrm{~m}$

3) Moderately high: $500-900 \mathrm{~m}$

4) High $\geq 900 \mathrm{~m}$

\subsubsection{Climatic factor}

The climate is an important factor because it affects the growth of vegetation and forest. Climatic factor has both positive and negative effects on forestry production. Climatic constraints may cause direct or indirect losses of biomass increments. These constraints are influenced by conditions as follows:

- Climatic factor which affects the costs of forestry production and the efficiency of forestry operations.

- Constraints indirectly related to climatic conditions such as diseases, pests, and invasion of weeds and unwanted species and forest fire.

Climatic constrains for forestry production are linked to temperature and rainfall regimes. Therefore, mean annual temperature and mean annual rainfall were selected to help in assessing land potential for forestry use and classified into the following classes:

\section{Mean annual temperature}

1) High: $\geq 24{ }^{0} \mathrm{C}$

2) Moderate: $22-24{ }^{0} \mathrm{C}$

3) Low: $20-22{ }^{0} \mathrm{C}$

4) Very low: $<20{ }^{\circ} \mathrm{C}$

\section{Mean annual rainfall}

1) High: $\geq 2,500 \mathrm{~mm}$

2) Moderate: $2,000-2,500 \mathrm{~mm}$

3) Low: $1,000-2,000 \mathrm{~mm}$

4) Very low: $<1,000 \mathrm{~mm}$ 


\subsubsection{Vegetation factor}

Plants and trees provide protective cover on the land and prevent soil erosion. The loss of vegetation through forest fire and deforestation make soil vulnerable to being swept away by water and wind. This causes the soil to lose its structure and cohesion and it becomes more easily eroded. In addition, vegetation plays a role in slope maintenance and reinforcement, the net effect of vegetation is usually beneficial to slope stability. In general, the soil properties are different between the forested and non-forested areas. Therefore, vegetation has a very close relationship with soil productivity and vegetative classification was produced from Landsat $\mathrm{ETM}+$ and divided into four classes include:

1) Dense forest

2) Degraded forest and forest plantation

3) Shrub and grass land

4) Barren land

\subsubsection{Determination of weights of factor and variables}

Each factor and variable in requirement of land potential productivity for forestry production may contribute to its significance differently, hence different weight should be given to each factor and variable. The weights of factors and variables were determined depending on the importance of each factor and variable, the greater the weight, the larger the value and the more important the decision factor and variable. In the procedure of land potential productivity assessment, it is necessary that the factor and variable weights need to be summed up to $100 \%$. In order to decide overlay weighting for each factor and variable (or each map), in this study, the weights were developed from an average based on interviewing the people who have experience and knowledge in this field. At the same time, they were also determined based on ranking four factors and nine variables from most important to least important, using pair-wise comparisons between each of the factor and variable to determine which is the most important, the next most important and so forth, until the least important is reached (e.g. in land potential productivity assessment for forestry, given these ranking for factors from most to least important of soil property, climate, topography and vegetation).

From this methodology, using pair-wise comparison matrix, a relative preference opinion of local experts for all factors and variables can be synthesized into a general weight as follows: 
Table 6.1: Weight for factors and variables

\begin{tabular}{|c|c|c|c|c|}
\hline Main factor & Weight 1 (\%) & Variable & Weight 2 (\%) & Overall Weight (\%) \\
\hline \multirow[t]{5}{*}{ Soil property factor } & \multirow[t]{5}{*}{35} & Soil depth & 25 & 8.8 \\
\hline & & Soil texture & 25 & 8.8 \\
\hline & & Soil pH & 15 & 5.3 \\
\hline & & Soil fertility & 15 & 5.3 \\
\hline & & Organic matter & 20 & 7.0 \\
\hline \multirow[t]{2}{*}{ Climatic factor } & \multirow[t]{2}{*}{25} & Rainfall & 67 & 16.8 \\
\hline & & Temperature & 33 & 8.3 \\
\hline \multirow[t]{2}{*}{ Topographic factor } & \multirow[t]{2}{*}{25} & Slope & 67 & 16.8 \\
\hline & & Elevation & 33 & 8.3 \\
\hline Vegetation & 15 & - & - & 15.0 \\
\hline Total & $100 \%$ & - & - & 100.0 \\
\hline
\end{tabular}

Table 6.2: Score of each variable category for land potential productivity assessment

\begin{tabular}{|c|c|c|c|c|c|}
\hline Variable & Category & Score & Variable & Category & Score \\
\hline \multirow{4}{*}{$\begin{array}{l}\text { Mean annual } \\
\text { temperature } \\
\left({ }^{0} \mathrm{C}\right)\end{array}$} & $\geq 24$ & 4 & \multirow{4}{*}{$\begin{array}{l}\text { Available } \\
\text { phosphorus } \\
\text { (ppm/kg soil) }\end{array}$} & $\geq 25$ & 4 \\
\hline & $22-24$ & 3 & & $10-25$ & 3 \\
\hline & $20-22$ & 2 & & $6-10$ & 2 \\
\hline & $<20$ & 1 & & $<6$ & 1 \\
\hline \multirow{4}{*}{$\begin{array}{l}\text { Average } \\
\text { rainfall } \\
(\mathrm{mm})\end{array}$} & $\geq 2,500$ & 4 & \multirow{4}{*}{$\begin{array}{l}\text { Available } \\
\text { potassium } \\
(\mathrm{ppm} / \mathrm{kg} \text { soil) }\end{array}$} & $\geq 90$ & 4 \\
\hline & $2,000-2,500$ & 3 & & $60-90$ & 3 \\
\hline & $1,000-2,000$ & 2 & & $30-60$ & 2 \\
\hline & $<1,000$ & 1 & & $<30$ & 1 \\
\hline \multirow{4}{*}{$\begin{array}{l}\text { Soil depth } \\
(\mathrm{cm})\end{array}$} & $\geq 100$ & 4 & \multirow{4}{*}{$\begin{array}{l}\text { Soil reaction (soil } \\
\mathrm{pH} \text { ) }\end{array}$} & $6.0-7.0$ & 3 \\
\hline & $70-100$ & 3 & & $5.0-6.0$ & 4 \\
\hline & $50-70$ & 2 & & $4.0-5.0$ & 2 \\
\hline & $<50$ & 1 & & $<4.0$ & 1 \\
\hline \multirow[t]{4}{*}{ Soil texture } & Sand & 2 & \multirow{4}{*}{$\begin{array}{l}\text { Slope angle } \\
\text { (degree) }\end{array}$} & $\geq 35$ & 1 \\
\hline & Loamy & 4 & & $25-35$ & 2 \\
\hline & Clayey & 3 & & $15-25$ & 3 \\
\hline & $\begin{array}{l}\text { Heavy clay and } \\
\text { coarse sand }\end{array}$ & 1 & & $<15$ & 4 \\
\hline \multirow{4}{*}{$\begin{array}{l}\text { Organic matter } \\
(\%)\end{array}$} & $\geq 2.5$ & 4 & \multirow{4}{*}{$\begin{array}{l}\text { Elevation } \\
\text { (m) }\end{array}$} & $\geq 900$ & 1 \\
\hline & $1.0-2.5$ & 3 & & $500-900$ & 2 \\
\hline & $0.5-1.0$ & 2 & & $200-500$ & 3 \\
\hline & $<0.5$ & 1 & & $<200$ & 4 \\
\hline \multirow{5}{*}{$\begin{array}{l}\text { Total nitrogen } \\
(\%)\end{array}$} & $\geq 0.2$ & 4 & \multirow[t]{5}{*}{ Vegetation } & Dense forest & 4 \\
\hline & $0.1-0.2$ & 2 & & Degraded forest & 3 \\
\hline & \multirow[t]{3}{*}{$<0.1$} & \multirow[t]{3}{*}{1} & & Forest plantation & 3 \\
\hline & & & & $\begin{array}{c}\text { Grass and shrub } \\
\text { land }\end{array}$ & 2 \\
\hline & & & & Barren land & 1 \\
\hline
\end{tabular}

The score of each variable category based on requirements of potential productivity levels has been discussed with local officers. According to this method a defined value was given to each class of the variable ranking from 1 to 4 , with 1 being the worst for forestry and 4 the best. These 
were very low potential, low potential, medium potential and high potential as well as assigned the value of each potential productivity level as 1,2,3 and 4, respectively (Table 6.2).

\subsubsection{Land potential productivity model}

The land potential productivity assessment provides information about the supply of land at various suitability levels for forestry production. At present, in Vietnam, there is not a standard model for land potential assessment for forestry use. Therefore, in this study in order to assess and develop a potential productivity map for forestry production in Thua Thien Hue province, central Vietnam, the model was used based on the requirement of forestry production and criteria using fours factors and nine variables as mentioned above. The model was used by Linear Combination Method of ranking and weighting score in order to create land potential productivity map for forestry use (Hopkins, L.D, 1977), the modelling was done using the Acrview GIS software 3.2 because of its ability to accommodate various files formats in common use. Because electronic files were obtained from various sources, they were configured as both raster (cell) and vector format. Consequently, the process of general modelling involved converting the polygons to raster format and using the capability of the Network Analyst and spatial Analyst extensions to undertake cell- based modelling. All scored classes, which restored in vector-based databases, were converted into the raster-based datasets with 30-meter grid cell size, because the raster-based overlay analysis has more advantage in the map algebra technique.

All factors and variables, namely: Climate (mean annual temperature and mean annual rainfall), soil property (soil texture, soil depth, soil $\mathrm{pH}$, organic matter content and soil fertility), topography (slope and elevation) and vegetation were overlaid in one layer, and the multiple overlays were made step by step inside GIS. The land potential productivity levels for forest production were determined by considering the score distribution of each site. The final score of the land potential productivity in each site is given by the formula below:

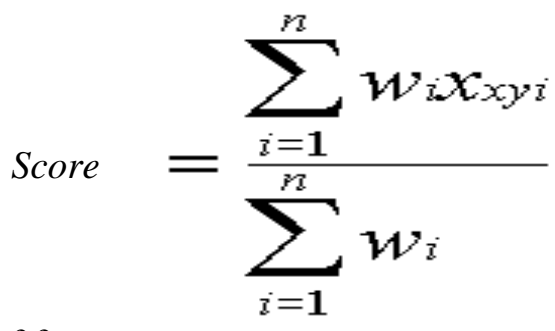

Where: $n$ is the number of factors,

$\mathrm{W}_{i}$ is the weight of factor $i$

$\mathrm{X}_{x y i}$ is the score of category for each variable of each factor $i$. 
This final score was converted to a level of potential productivity, as shown in the following table.

Table 6.3: The level of land potential productivity

\begin{tabular}{|l|l|l|}
\hline Score & $\begin{array}{c}\text { Potential productivity } \\
\text { level }\end{array}$ & \multicolumn{1}{c|}{ Description } \\
\hline 2.5 & High potential & $\begin{array}{l}\text { The land has few limitations for forestry production, its } \\
\text { potential productivity is high. }\end{array}$ \\
\hline $1.5-2.5$ & Low potential & $\begin{array}{l}\text { The land has some limitations for forestry production, its } \\
\text { potential productivity is medium. }\end{array}$ \\
\hline$<1.5$ & Very low potential & $\begin{array}{l}\text { The land has a large number of limitations for forestry } \\
\text { production, its potential productivity is very low }\end{array}$ \\
\hline
\end{tabular}

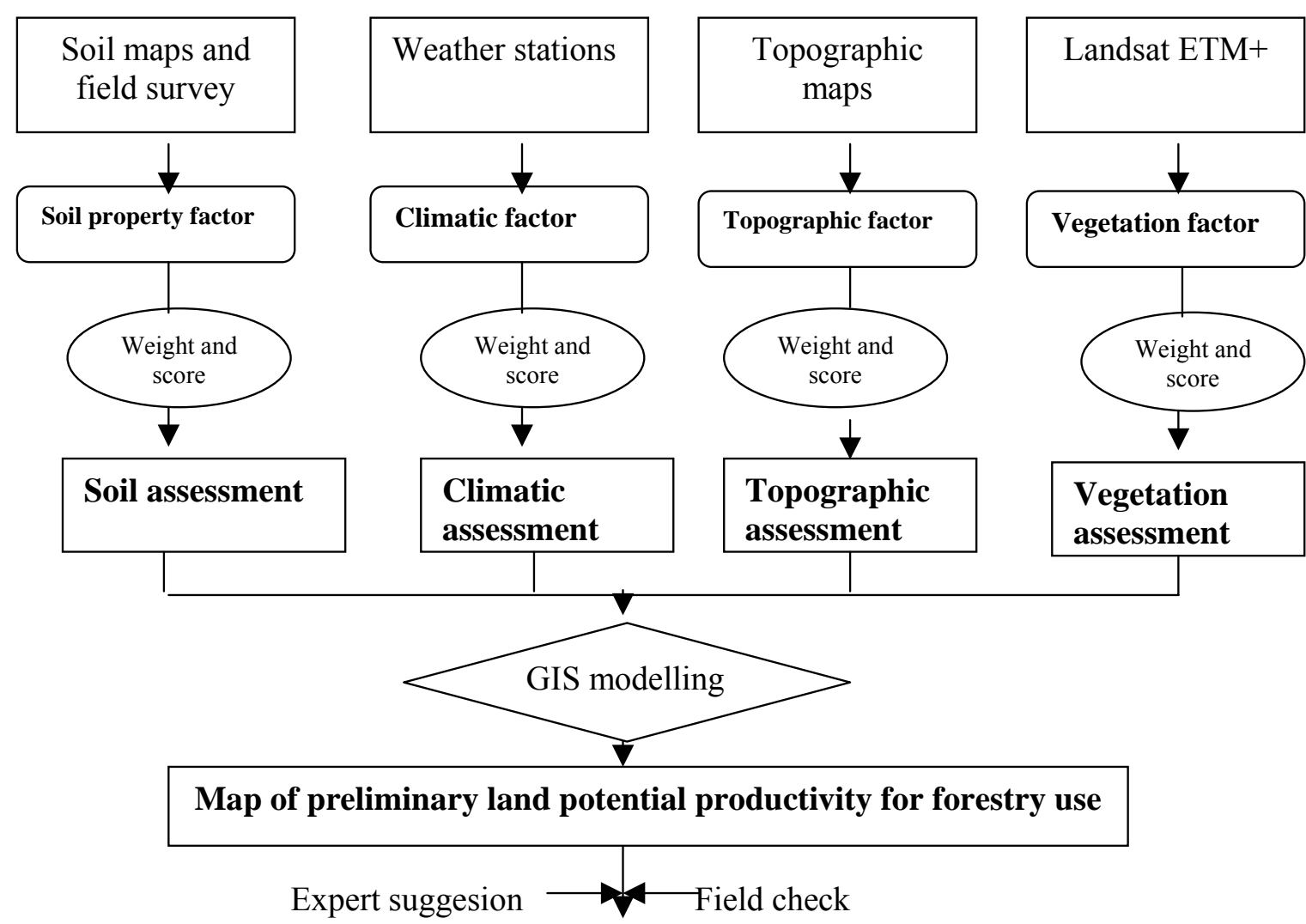

\section{Map of final land potential productivity for forestry use}

Figure 6.1: The general flow of the land potential productivity assessment for forestry use 


\subsection{Results and discussion}

\subsubsection{Provisional land potential productivity assessment}

\subsubsection{Assessment of soil property factor}

The forest soil as a main production factor and its soil properties are an important precondition for forest and downstreamed wood production. The classification of forest soil properties is based on Landsat ETM+ data, field survey, the soil map available as well as on laboratory soil analysis. The forest soils in the study area are classified into four soil groups: 1) Rhodic Ferrasoils, 2) Xanthic Ferrasoils, 3) Lithic Leptosoils and 4) Dystric Fluvisoils. These are the following main soil types: Yellowish brown soils on old alluvia, yellowish red soils on acidic magma rock, yellowish red soils on sandstone, yellowish red soils on metamorphic rock, thin layer soils and alluvial soils on river areas. Chemical analyses have shown that concentration of soil $\mathrm{pH}$, organic matter, total nitrogen, available phosphorus and available potassium are very different between these soil types (chapter IV).

\section{Soil depth}

Soil depth is an important factor in assessment of land potential productivity, in particular on sloping land. The classification of different soil depth classes is described in Table 6.4. The forest soils with depth of more than $100 \mathrm{~cm}$ prevail in the province, about 63.5 percent of the entire area, then next is soil depth of 70-100 cm (5.5\%), other soil depths of 50-70, and less than $50 \mathrm{~cm}$ combined amount to only $3.4 \%$. The forest soils with depth of less than $50 \mathrm{~cm}$ are located on peaks of mountains and hills and are mainly found on thin layer soils (Lithic Leptosoils). The soil depth of more than $100 \mathrm{~cm}$ are mainly found in forested areas, and occupied at elevation lower than $300 \mathrm{~m}$ above sea level. This proves that the beneficial effect of forest trees can play a very important role in controlling the scouring compacts of surface run-off to prevent soil erosion and therefore can keep the depth of forest soil acceptable for land uses in more than the province. Normally soil depth with more than $70 \mathrm{~cm}$ is suitable for cultivation, therefore, some of areas have been converted to agricultural areas under these conditions, the soil depth factor can provide favourable conditions to land use for both forestry and agricultural use. 
Table 6.4: Distribution of forest land with different depth classes

\begin{tabular}{|l|l|c|r|r|r|c|}
\hline No & Purpose of & Soil depth & \multicolumn{3}{|c|}{ Area in ha } & Percentage of the \\
\cline { 3 - 7 } & land use & $(\mathrm{cm})$ & Forested & Non-forested & \multicolumn{1}{c|}{ Total } & total area (\%) \\
\hline 1 & \multirow{2}{*}{ Forestry } & $<50$ & $3,025.0$ & $5,486.9$ & $8,511.9$ & 1.7 \\
\cline { 3 - 7 } & & $50-70$ & $2,938.7$ & $5,611.9$ & $8,550.6$ & 1.7 \\
\cline { 3 - 7 } & & $70-100$ & $7,973.4$ & $20,047.2$ & $28,020.6$ & 5.5 \\
\cline { 3 - 7 } & & $\geq 100$ & $171,202.4$ & $149,605.9$ & $320,808.3$ & 63.5 \\
\hline 2 & Other land & - & - & - & $139,448.0$ & 27.6 \\
\hline & Total area & - & - & - & $\mathbf{5 0 5 , 3 3 9 . 4}$ & $\mathbf{1 0 0 . 0}$ \\
\hline
\end{tabular}

\section{Soil texture}

The forest soils of the study area are mainly loamy and sandy. Lands in mountainous and hilly areas are quite good with loamy texture and is found to be extensive over 55 percent of the entire area or $278,454.6$ ha, of which $148,139.7$ ha lies in forested areas and 130,314.9 ha lies in nonforested areas. Clayey textures do not bound, and in particular here they occupy only 2.1 percent. Sandy texture is found in the yellowish red soils developed on sandstone with an area of 54,895.5 hectares, equivalent to 10.9 percent, of which 24,592.2 ha is forested area and 30,303.3 ha is non-forested area. The lands with coarse sand and heavy clay texture occupy 4.3 percent of the province total or 21,827.0 ha. The distributions of these textures are as follows: Forested area is 9,113.6 ha and non-forested area is $12,713.4$ ha (Table 6.5). Heavy clay texture is found in thin layer soils of all soil types, but coarse sand texture is located in coastal sandy soils. It is found on flat area and on fixed or moving sand dunes at lower elevations of above $2 \mathrm{~m}$ along the coast of the province. The moving sand grains because of dry and loose sand can hit tree and plant leaves, and even destroy young trees by uprooting them and as a result on moving sand dunes, there is no natural vegetation cover. Soil textures of coarse sand and heavy clay create difficult conditions to land development nor only for forestry production but also for agricultural production.

Table 6.5: Distribution of forest land with different soil texture

\begin{tabular}{|c|c|c|c|c|c|c|}
\hline \multirow[t]{2}{*}{ No } & \multirow{2}{*}{$\begin{array}{l}\text { Purpose of } \\
\text { land use }\end{array}$} & \multirow[t]{2}{*}{ Soil texture } & \multicolumn{3}{|c|}{ Area in ha } & \multirow{2}{*}{$\begin{array}{c}\text { Percentage of } \\
\text { the total area } \\
(\%)\end{array}$} \\
\hline & & & Forested & Non-forested & Total & \\
\hline \multirow[t]{4}{*}{1} & \multirow[t]{4}{*}{ Forestry } & Loamy & $148,139.7$ & $130,314.9$ & $278,454.6$ & 55.1 \\
\hline & & Clayey & $3,294.0$ & $7,420.3$ & $10,714.3$ & 2.1 \\
\hline & & Sandy & $24,592.2$ & $30,303.3$ & $54,895.5$ & 10.9 \\
\hline & & $\begin{array}{lr}\text { Coarse } & \text { sand } \\
\text { and } & \text { heavy } \\
\text { clay } & \\
\end{array}$ & $9,113.6$ & $12,713.4$ & $21,827.0$ & 4.3 \\
\hline \multirow[t]{2}{*}{2} & Other land & - & - & - & $139,448.0$ & 27.6 \\
\hline & Total area & - & - & - & $505,339.4$ & 100.0 \\
\hline
\end{tabular}




\section{Organic matter}

Organic mater $(\mathrm{OM})$ is especially important in providing nitrogen, phosphorus, sulphur, and iron. Hence this factor is known to have a strong impact on forestland potential productivity. Under the present climatic and vegetation conditions and prevailing human intervention in Thua Thien Hue province, based on the available data and the results of soil analysis ha shown that the organic matter values varied according to soil and vegetation types and elevation. The content of $\mathrm{OM}$ is also somewhat correlated to land use management, larger values are found in the topsoil of the forested lands. On the other hand, OM values of the non- forested lands tended to be lower than in forested lands.

Soils with rich humus content dominate on dense natural forest, soils medium in humus content of 3-5 \% prevailing on degraded forest, forest plantation, shrub and high grass, soils of poor humus content were found on spars grass land and bare land and soils with very poor humus content were distributed on coastal sandy soil and thin layer soil. In general, forestlands of mountainous and hilly areas of the study area can be rated as rich, medium and poor and coastal area is very poor in humus content.

The detailed analysis of OM content of forestland is shown in Table 6.6, it indicated that four categories of the $\mathrm{OM}$ contents were identified and mapped, namely: very poor humus, poor humus, medium humus and rich humus which occupies 6.1 percent, 26.1 percent, 19.1 percent, and 21.1 percent of the entire area.

Table 6.6: Distribution of forest land with different organic matter

\begin{tabular}{|c|c|c|c|c|c|c|}
\hline \multirow[t]{2}{*}{ No } & \multirow{2}{*}{$\begin{array}{l}\text { Purpose of } \\
\text { land use }\end{array}$} & \multirow{2}{*}{$\begin{array}{c}\text { Organic } \\
\text { matter }(\%)\end{array}$} & \multicolumn{3}{|c|}{ Area in ha } & \multirow{2}{*}{$\begin{array}{c}\text { Percentage of } \\
\text { the total area } \\
(\%)\end{array}$} \\
\hline & & & Forested & Non-forested & Total & \\
\hline \multirow[t]{4}{*}{1} & \multirow[t]{4}{*}{ Forestry } & $<0.5$ & $10,766.60$ & $20,226.10$ & $30,992.7$ & 6.1 \\
\hline & & $0.5-1.0$ & $33,291.20$ & $98,849.70$ & $132,140.9$ & 26.1 \\
\hline & & $1.0-2.5$ & $48,709.80$ & $47,686.90$ & $96,396.7$ & 19.1 \\
\hline & & $\geq 2.5$ & $92,371.9$ & $13,989.2$ & $106,361.1$ & 21.0 \\
\hline \multirow[t]{2}{*}{2} & Other land & - & - & - & $139,448.00$ & 27.6 \\
\hline & Total area & - & - & - & $505,339.4$ & 100.0 \\
\hline
\end{tabular}

\section{Soil pH}

The fourth most important soil characteristic, in terms of forest productivity, is soil $\mathrm{pH}$. The availability of a number of mineral elements, particularly phosphorus and the micronutrients, is directly influenced by soil $\mathrm{pH}$. As a soil becomes more acid, its $\mathrm{pH}$ decreases, as it becomes more alkaline, its $\mathrm{pH}$ increases. Assessment of soil $\mathrm{pH}$, one can say that the forest soils of the study area are acidic, most of soil types are between $\mathrm{pH} 3.7$ and 5.5, soil acidity was generally 
less in coastal sandy area than in mountainous and hilly area. Soil acidity was less in bare land, grassland and shrub than in forest plantation, degraded forest and dense forest. Based on FAO system and behaviour of forest tree species (most forest tree species grow well between soil pH 5 and 6, but many crop plants grow very well in the range of soil $\mathrm{pH} 6$ to 7). Four categories of the soil $\mathrm{pH}$ were identified and mapped: Extremely acid (less than 4 soil $\mathrm{pH}$ ), very strongly acid (4.0 -5.0), moderately acid (5.0-6.0), and very slightly acid (6.0-7.0). Assessment of forest soil $\mathrm{pH}$ categories are given in Table 6.7, the results indicated that 35.5 percent of the province in both forested and non-forested area is assessed to have favourable condition for forestry use, 16.5 percent is found to have limitation, 20.4 percent has minor limitation in forestland use and no land of very slight acid can be found in the study area.

Table 6.7 Distribution of forest land with different soil $\mathrm{pH}$

\begin{tabular}{|c|c|c|c|c|c|c|}
\hline \multirow[t]{2}{*}{ No } & \multirow{2}{*}{$\begin{array}{l}\text { Purpose } \\
\text { of land } \\
\text { use }\end{array}$} & \multirow[t]{2}{*}{ Soil pH } & \multicolumn{3}{|c|}{ Area in ha } & \multirow{2}{*}{$\begin{array}{c}\text { Percentage of } \\
\text { the total area } \\
(\%)\end{array}$} \\
\hline & & & Forested & Non-forested & Total & \\
\hline \multirow[t]{4}{*}{1} & \multirow[t]{4}{*}{ Forestry } & $<4.0$ & $29,739.1$ & $53,773.4$ & $83,512.5$ & 16.5 \\
\hline & & $4.0-5.0$ & $51,731.4$ & $51,368.8$ & $103,100.2$ & 20.4 \\
\hline & & $5.0-6.0$ & $103,669.0$ & $75,609.7$ & $179,278.7$ & 35.5 \\
\hline & & $6.0-7.0$ & 0 & 0 & 0 & 0 \\
\hline 2 & Other land & - & - & - & $139,448.0$ & 27.6 \\
\hline & Total area & - & - & - & $505,339.4$ & 100.0 \\
\hline
\end{tabular}

\section{Soil fertility}

Soil fertility influences the productive potential of forest land. The soil fertility status in the study area was determined by analysis of available nitrogen, phosphorus and potassium concentration. The soil fertility was derived from soil property maps and laboratory analyses. The classification of forest soil fertility was classified into 4 classes, the detailed analysis of forest soil fertility indicated that there is no high potential productivity level, most of forest lands can be noted as of level 3, having low productive potential, this kind of productivity level occupies $304,783.0$ ha or $60.3 \%$ of the entire area. The area for medium potential is only 37,973 ha or $7.5 \%$ and for very low potential is $23,135.4$ ha or $4.6 \%$ (Table 6.8 ).

Table 6.8: Potential productivity level of soil fertility condition for forestry use

\begin{tabular}{|l|l|l|r|r|}
\hline No & Purpose of land use & $\begin{array}{c}\text { Potential productivity } \\
\text { level }\end{array}$ & Area in ha & $\begin{array}{l}\text { Percentage of the total } \\
\text { area (\%) }\end{array}$ \\
\hline 1 & \multirow{2}{*}{ Forestry } & Very low potential & $23,135.4$ & \multicolumn{1}{|c|}{4.6} \\
\cline { 3 - 5 } & & Low potential & $304,783.0$ & 60.3 \\
\cline { 3 - 5 } & & Medium potential & $37,973.0$ & \multicolumn{1}{c|}{7.5} \\
\hline & & High potential & 0 & \multicolumn{1}{c|}{0} \\
\hline 2 & Other land & - & 139,448 & 27.6 \\
\hline & Total area & - & $\mathbf{5 0 5 , 3 3 9 . 4}$ & $\mathbf{1 0 0 . 0}$ \\
\hline
\end{tabular}




\section{Potential productivity assessment of soil property factor}

Soil properties include physical properties (soil texture and soil depth) and chemical property (soil $\mathrm{pH}$, organic matter content and soil fertility) as determinants of forest soil quality, soil quality, like forest productivity or site quality. Therefore, the soil factor plays an important role in predicting potential productivity of forestlands. The results of soil property assessment for forestland potential are given in Fig. 6.2. According to the soil property classification map, $58,999.9$ hectare of forestland is under high potential category, the location of high potential area was distributed in yellowish brown and alluvial soils. The northeast part of the province was assessed as very low potential category with an area of $22,179.8$ hectare or $4.4 \%$ of the entire area, most land areas of this category was found on coastal sand soils and inland sandy soils.

The results were also indicated that the study area was mostly assessed as medium potential category with an area of $183,559.4$ hectare or $36.3 \%$ of the entire area $(50.2 \%$ of the total area of forestry land and 101,152.3 hectare (20\%) belongs to low potential category (Table 6.9). The location of medium potential areas is located on yellowish red soils on acid magma rock, yellowish red soils on sandstone, yellowish red soils on metamorphic rock, while the low potential areas are distributed on thin layer soils.

Table 6.9: Potential productivity level of soil property factor for forestry use

\begin{tabular}{|c|c|c|c|c|c|c|}
\hline \multirow[t]{2}{*}{ No } & \multirow{2}{*}{$\begin{array}{l}\text { Purpose of } \\
\text { land use }\end{array}$} & \multirow{2}{*}{$\begin{array}{l}\text { Potential } \\
\text { productivity level }\end{array}$} & \multicolumn{3}{|c|}{ Area in ha } & \multirow{2}{*}{$\begin{array}{c}\text { Percentage of } \\
\text { the total area } \\
(\%)\end{array}$} \\
\hline & & & Forested & $\begin{array}{c}\text { Non- } \\
\text { forested }\end{array}$ & Total & \\
\hline \multirow[t]{4}{*}{1} & \multirow[t]{4}{*}{ Forestry } & High potential & $34,435.1$ & $24,564.8$ & $58,999.9$ & 11.7 \\
\hline & & Medium potential & $93,695.5$ & $89,863.9$ & $183,559.4$ & 36.3 \\
\hline & & Low potential & $46,714.5$ & $54,437.8$ & $101,152.3$ & 20.0 \\
\hline & & Very low potential & $10,294.4$ & $11,885.4$ & $22,179.8$ & 4.4 \\
\hline \multirow[t]{2}{*}{2} & Other land & - & - & - & $139,448$. & 27.6 \\
\hline & Total area & - & - & - & $505,339.4$ & 100.0 \\
\hline
\end{tabular}




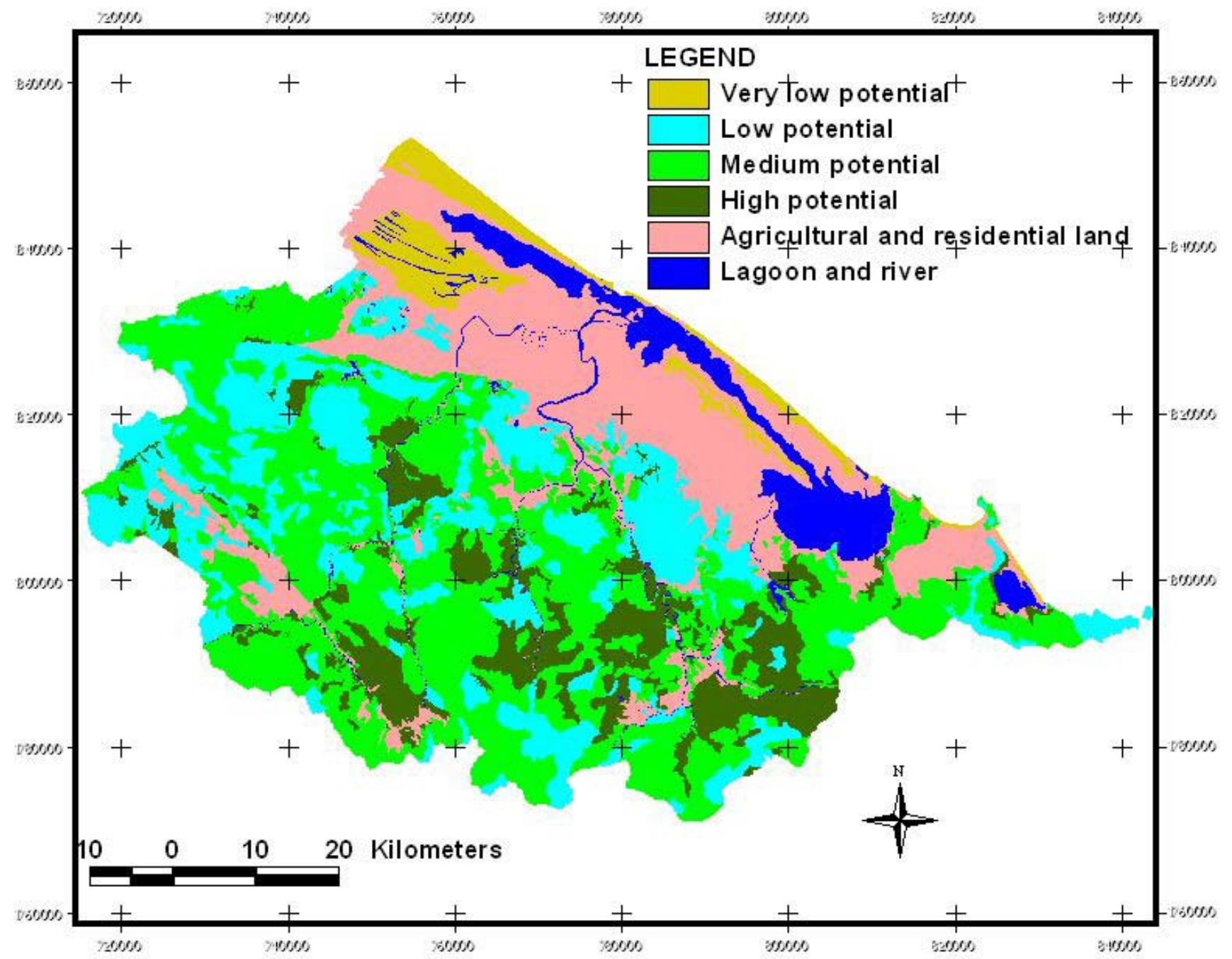

Figure 6.2: Potential productivity classification for soil property factor 


\subsubsection{Assessment of climatic factor}

One of the most important factors for forestry production is the climate. The majority of forestry production is substantially affected by precipitation, temperature, air humidity, and especially the occurrence of these events. The actual climate data of the study area is zoned to define regions with different climate types. The classification of climatic zones and sub- climatic zones is based on analysis of 10 recent year weather records and the natural vegetation types (more detailed see chapter III). The two main climate variables which were used in this study are mean annual temperature and average annual rainfall. Based on the optimum demands concerning climatic requirements of common forest vegetation growth in the study area, four categories of the temperature and rainfall were identified and mapped. The high potential for forestry production or many forest tree species was considered for temperature of more than $24{ }^{\circ} \mathrm{C}$ and rainfall of more than 2,500 mm, medium potential $\left(22-24{ }^{0} \mathrm{C}\right.$ and $\left.2,000-2,500 \mathrm{~mm}\right)$, low potential $\left(20-22{ }^{0} \mathrm{C}\right.$ and 1,000-2,000 $\mathrm{mm}$ ), and less than $20{ }^{\circ} \mathrm{C}$ temperature and 1,000 $\mathrm{mm}$ precipitation are very low potential. Table 6.10 shows that the entire forestry land area of $365,891.4$ ha had the high and medium potential productivity in terms of climatic factor, of which $232,669.3$ ha lies in high potential suitability, 133,222.1 ha lies in medium potential productivity and no level of low potential and very low potential. The location of climatic classification of potential productivity level is shown in figure 6.3.

Table 6.10: Potential productivity level of climatic factor for forestry use

\begin{tabular}{|c|l|r|c|}
\hline No & Potential productivity level & Area in ha & Percentage of the total area (\%) \\
\hline 1 & High potential & $232,669.3$ & 46.0 \\
\hline 2 & Medium potential & $133,222.1$ & 26.4 \\
\hline 3 & Low potential & 0 & - \\
\hline 4 & Very low potential & 0 & - \\
\hline 5 & Other land & $139,448.0$ & 27.6 \\
\hline & Total area & $\mathbf{5 0 5 , 3 3 9 . 4}$ & $\mathbf{1 0 0 . 0}$ \\
\hline
\end{tabular}




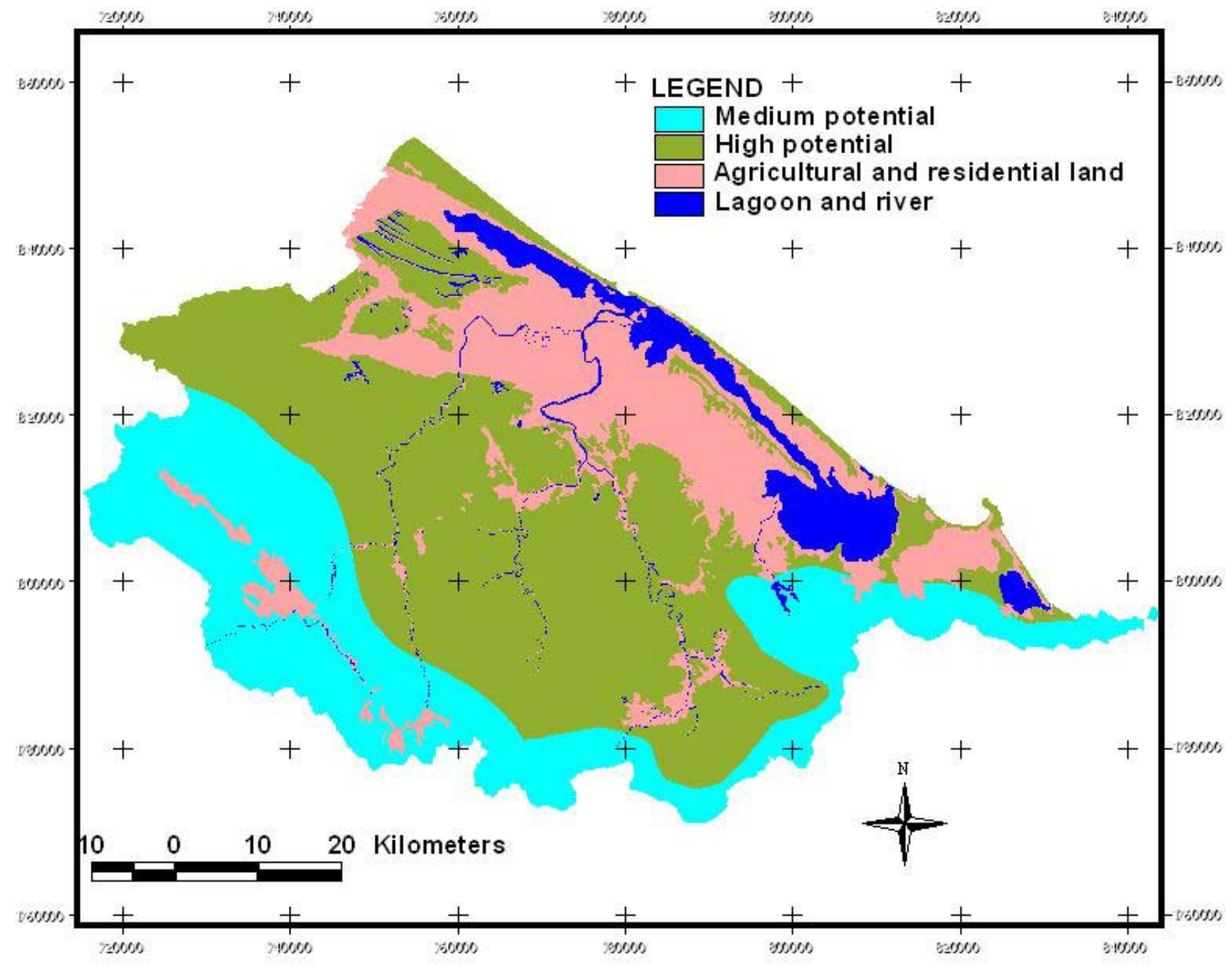

Figure 6.3: Potential productivity classification for climatic factor 


\subsubsection{Assessment of topographic factor}

\section{Land elevation}

The elevation of forest land in the study area varies from $1 \mathrm{~m}$ to $1,774 \mathrm{~m}$. The lowest point lies along coastal land of the province and the highest point lies at Ngai cavern of Aluoi district.

Twenty-meter contour lines from topographic maps are employed to derive a digital elevation model (DEM). Elevation values in the province are extracted from this DEM. Elevation classification of the province was classified into four classes of less than $200 \mathrm{~m}, 200-500 \mathrm{~m}$, $500-900 \mathrm{~m}$, and more than $900 \mathrm{~m}$ based on the distribution of vegetation cover types. Forest land in the study area can be assessed as follows in terms of elevation: forestry land is found mainly at elevation below $200 \mathrm{~m}$ and at elevation between 500 and $900 \mathrm{~m}$ above sea level with percentage of $29.6 \%$ and $22.7 \%$ of the entire area, respectively.

The total forested area is $185,139.5 \mathrm{ha}$, of which $34,104.6$ ha is at elevation above $900 \mathrm{~m}$, $69,935.5$ ha is at elevation between $500-900 \mathrm{~m}, 24,319.6$ ha is at elevation between $200-500 \mathrm{~m}$ and $56,779.8$ ha is at elevation below $200 \mathrm{~m}$ above sea level, while non-forested area is found 21,036.6 ha, 44,841.6 ha, 21,897.9 ha and 92,975.8, respectively (Table 6.11).

Table 6.11: Distribution of forest land with different elevation

\begin{tabular}{|c|c|c|c|c|c|c|}
\hline \multirow[t]{2}{*}{ No } & \multirow{2}{*}{$\begin{array}{l}\text { Purpose } \\
\text { land use }\end{array}$} & \multirow{2}{*}{$\begin{array}{l}\text { Elevation } \\
\text { class }\end{array}$} & \multicolumn{3}{|c|}{ Area in ha } & \multirow{2}{*}{$\begin{array}{l}\text { Percentage of the } \\
\text { total area }(\%)\end{array}$} \\
\hline & & & Forested & Non-forested & Total & \\
\hline \multirow[t]{4}{*}{1} & \multirow[t]{4}{*}{ Forestry } & $\geq 900$ & $34,104.6$ & $21,036.6$ & $55,141.2$ & 10.9 \\
\hline & & $500-900$ & $69,935.5$ & $44,841.6$ & $114,777.1$ & 22.7 \\
\hline & & $200-500$ & $24,319.6$ & $21,897.9$ & $46,217.5$ & 9.1 \\
\hline & & $<200$ & $56,779.8$ & $92,975.8$ & $149,755.6$ & 29.6 \\
\hline \multirow[t]{2}{*}{2} & Other land & - & - & - & $139,448.0$ & 27.6 \\
\hline & Total area & - & - & - & $505,339.4$ & 100.0 \\
\hline
\end{tabular}

\section{Land slope}

Slope can be an important factor in determining and identifying potential productivity location for forestry activities, because it may indicate flat soil and erosion and deposition of soil. Therefore the slope was found to be a fairly precise predictor of limitations on capability imposed by soil type, because limitations of land imposed by soil type are often slope dependent, the different soils in the same slope category often have common characteristics, such as the same drainage of soils on the same slopes.

According to the results of slope classification from DEM model, land slopes range from zero to over $35^{\circ}$, and were found in the study area. This range was divided into the four standard categories as recognized by forestland management practices in Vietnam. Four categories of the 
slope were identified and mapped, slope suitability ranges from $0^{0}$ to $15^{0}$ was considered high potential, slopes from $15^{0}$ to $25^{0}$ medium potential, from $25^{0}$ to $35^{0}$ less potential (low potential), and very steep land $\left(\geq 35^{0}\right)$ very low potential for forestry activities.

Forestry lands with their slopes and the distribution of different slope classes are shown in Table 6.12. Forestry land is found mainly on slopes of high potential accounting for 27.6 percent of the entire area, then next comes land with slope of low potential $(21.1 \%)$, land slopes of medium potential and very low potential are found with percentage of $14.9 \%$ and $8.9 \%$ respectively.

Forestry land area is occupied on slopes of more than $35^{\circ}$ is $44,752.6$ ha, of which forested area is 35,571.8 ha and non- forested area is 9,180.8 ha, while land area is found on slopes of less than $15^{\circ}$ is $139,475.2$ ha, of which $52,711.3$ ha lies in forested area and 86,763.9 ha lies in nonforested area.

Table 6.12: Distribution of forest land with different slope

\begin{tabular}{|l|l|l|r|r|r|c|}
\hline No & Purpose of & $\begin{array}{l}\text { Slope } \\
\text { land use }\end{array}$ & \multicolumn{3}{|c|}{ Area in ha } & Percentage of the \\
class & Forested & Non-forested & Total & area (\%) \\
\hline 1 & Forestry & $\geq 35^{0}$ & $35,571.8$ & $9,180.8$ & $44,752.6$ & 8.9 \\
\hline & & $25^{0}-35^{0}$ & $66,838.4$ & $39,653.5$ & $106,491.9$ & 21.1 \\
\hline & & $15^{0}-25^{0}$ & $30,018.0$ & $45,153.7$ & $75,171.7$ & 14.9 \\
\hline & & $<15^{0}$ & $52,711.3$ & $86,763.9$ & $139,475.2$ & 27.6 \\
\hline 2 & Other land & - & - & - & $139,448.0$ & 27.6 \\
\hline & Total area & - & - & - & $\mathbf{5 0 5 , 3 3 9 . 4}$ & $\mathbf{1 0 0 . 0}$ \\
\hline
\end{tabular}

\section{Potential productivity assessment of topographic factor}

The current potential suitability of topographic condition was created from overlaying all variables within the topographic factor. Table 6.13 shows the potential productivity levels of current environment in topographic condition. This factor of the entire area was assessed as follows: High potential for forestry activities is $120,306.1$ ha or 23.8 percent of the entire area, medium potential is $101,760.8$ ha $(20.1 \%)$, low potential is $107,090.0$ ha $(21.2 \%)$ and very low potential is $36,734.5$ or $7.3(\%)$. The location of climatic potential productivity classification was shown in figure 6.4 .

Table 6.13: Potential productivity level of topographic factor for forestry use

\begin{tabular}{|l|l|l|r|r|r|r|}
\hline \multirow{2}{*}{ No } & Purpose of & Potential & \multicolumn{3}{|c|}{ Area in ha } & Percentage of \\
land use & productivity level & Forested & Non-forested & Total & the total area \\
\hline 1 & Forestry & High potential & $48,099.7$ & $72,206.4$ & $120,306.1$ & 23.8 \\
\hline & & Medium potential & $37,625.1$ & $64,135.7$ & $101,760.8$ & 20.1 \\
\hline & & Low potential & $68,562.7$ & $38,527.3$ & $107,090.0$ & 21.2 \\
\hline & & Very low potential & $30,852.0$ & $5,882.5$ & $36,734.5$ & 7.3 \\
\hline 2 & Other land & - & - & - & $139,448.0$ & 27.6 \\
\hline & Total area & - & - & - & $\mathbf{5 0 5 , 3 3 9 . 4}$ & $\mathbf{1 0 0 . 0}$ \\
\hline
\end{tabular}




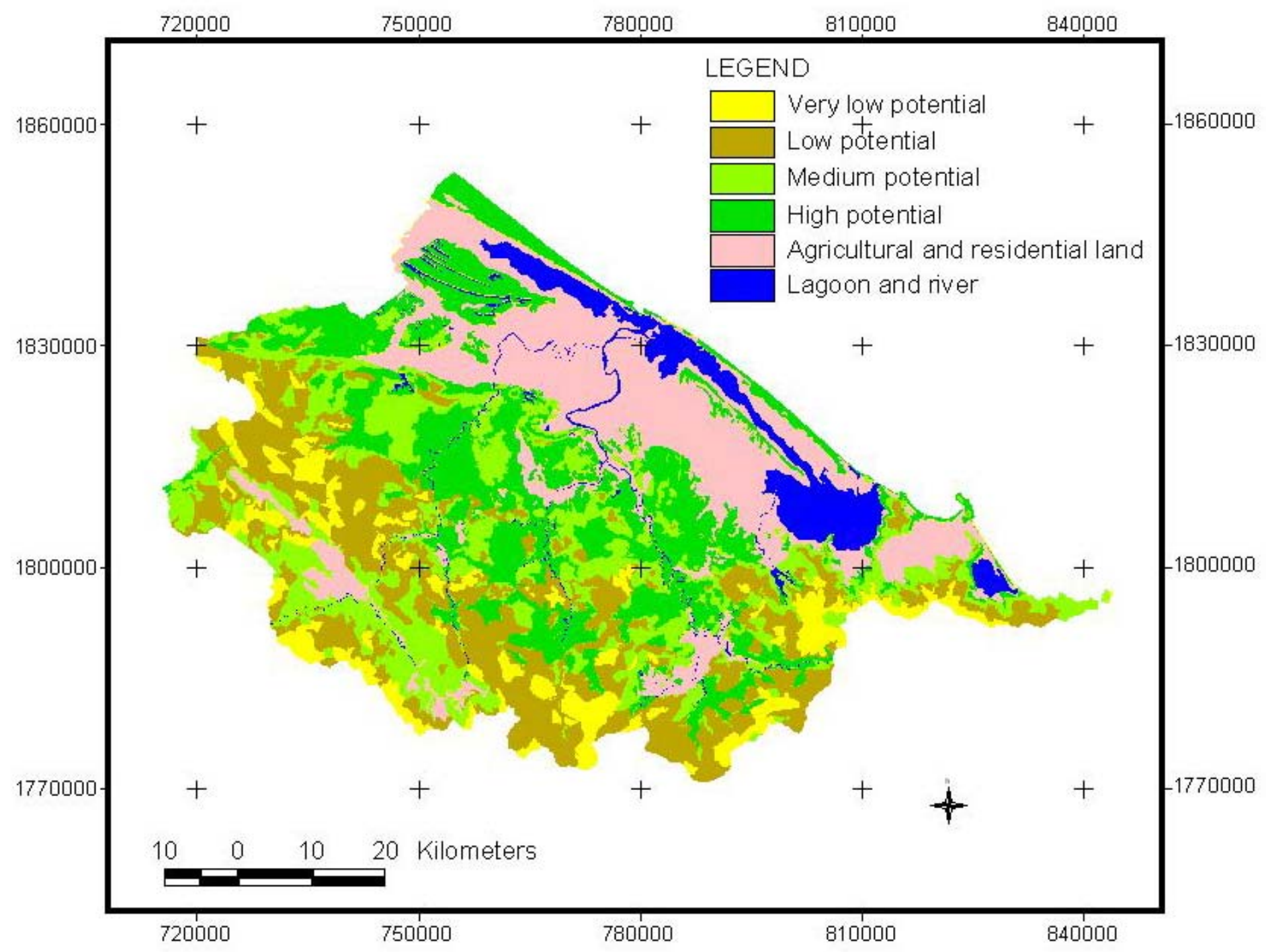

Figure 6.4: Potential productivity classification for topographic factor 


\subsubsection{Assessment of vegetation factor}

As mentioned in chapter $\mathrm{V}$, the vegetation classification was determined basically on the results from interpretation of three Lansdsat ETM + images acquired in January and April of 2003, April of 2004 and ground survey. The results of image classification indicated that the forestland with high potential accounts for a percentage of $9.8 \%$ of total forestland $(7.1 \%$ of the entire area) and is distributed in the dense natural forest. The forestland with medium potential covers $37.4 \%$ (27.1\% of the entire area), of which $30.5 \%$ belongs to degraded natural forest and $6.9 \%$ belongs to forest plantation, and $39.7 \%$ of the forestland area $(28.7 \%$ of the entire area) is found as low potential, of which $3.4 \%$ is forest plantation, $10.9 \%$ is grassland and $25.4 \%$ is shrub. Barren land area account for $13.1 \%$ (9.5\% of the entire area) in very low potential level, most this land cover type is located in coastal sandy region in the study area (Fig. 6.5).

\subsubsection{Final land potential productivity assessment}

Land potential for forest production was assessed through GIS modelling. The model used was a weighted linear combination method which was developed by the author (Lewis. D. Hopkin, 1977) and is derived from dimensionless analysis site selection techniques. Its results as " preference number" or the result of the multiplication of all the score together indicates which site is better for the purpose of forestry use based on the references (the scores and weights) expressed in the model. The weights for the other factors and the scores for its variables were calculated on expert, forester opinion as well as local conditions.

The four factors of current environment (soil property, climate, topography, and vegetation) were overlaid in one layer, the multiple overlays were made step by step inside GIS to create the current land potential, the results present the overall current environmental condition in Thua Thien Hue province, which is mainly classified as medium potential suitability level for forestry use with 51.4 percent of the entire area, while the highly potential productivity level is determined as the smallest areas with 3.7 percent of the entire area (Table 6.14).

Table 6.14: Land potential productivity level for forestry use

\begin{tabular}{|c|c|c|c|c|c|c|}
\hline \multirow[t]{2}{*}{ No } & \multirow{2}{*}{$\begin{array}{l}\text { Purpose of } \\
\text { land use }\end{array}$} & \multirow{2}{*}{$\begin{array}{l}\text { Potential } \\
\text { productivity level }\end{array}$} & \multicolumn{3}{|c|}{ Area in ha } & \multirow{2}{*}{$\begin{array}{c}\text { Percentage of } \\
\text { the total area } \\
(\%)\end{array}$} \\
\hline & & & Forested & $\begin{array}{c}\text { Non- } \\
\text { forested }\end{array}$ & Total & \\
\hline \multirow[t]{4}{*}{1} & \multirow[t]{4}{*}{ Forestry } & High potential & $14,352.7$ & $4,188.8$ & $18,541.5$ & 3.7 \\
\hline & & Medium potential & $133,176.5$ & $126,464.4$ & $259,640.9$ & 51.4 \\
\hline & & Low potential & $27,200.3$ & $37,689.5$ & $64,889.8$ & 12.8 \\
\hline & & Very low potential & $10,410.0$ & $12,409.2$ & $22,819.2$ & 4.5 \\
\hline 2 & Other land & - & - & - & $139,448.0$ & 27.6 \\
\hline & Total area & - & - & - & $505,339.4$ & 100.0 \\
\hline
\end{tabular}


The results of land potential productivity assessment also showed that the highly potential areas for forestry use are mainly located close to dense forests and dominated by low slope gradients and low elevation. The lands are dominated by a gentle slope gradient and degraded forests with deep to very depth soil were identified as medium potential. The results also indicated that the alluvial soils and yellowish brown soils are high potential for forestry use. The soils of medium potential are mainly located in yellowish red soils developed on acid magma and metamorphic rocks, the soils of low potential are the thin layer soil, yellowish red soil developed on sand stones and lands with elevation of more than $900 \mathrm{~m}$ and lands with very low potential were found on sandy and clayey soil (Fig. 6.6). 


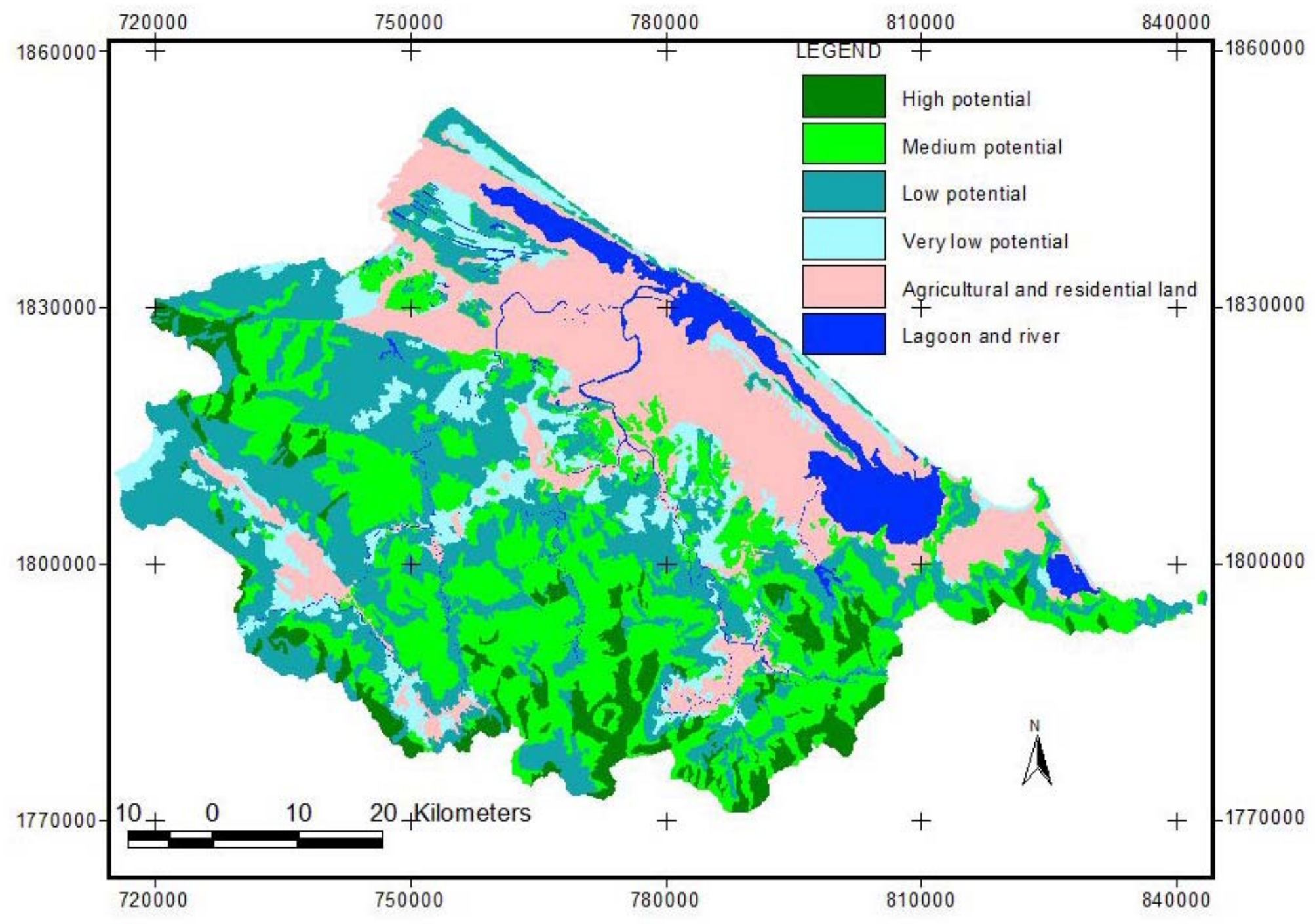

Figure 6.5: Potential productivity classification for vegetation factor 


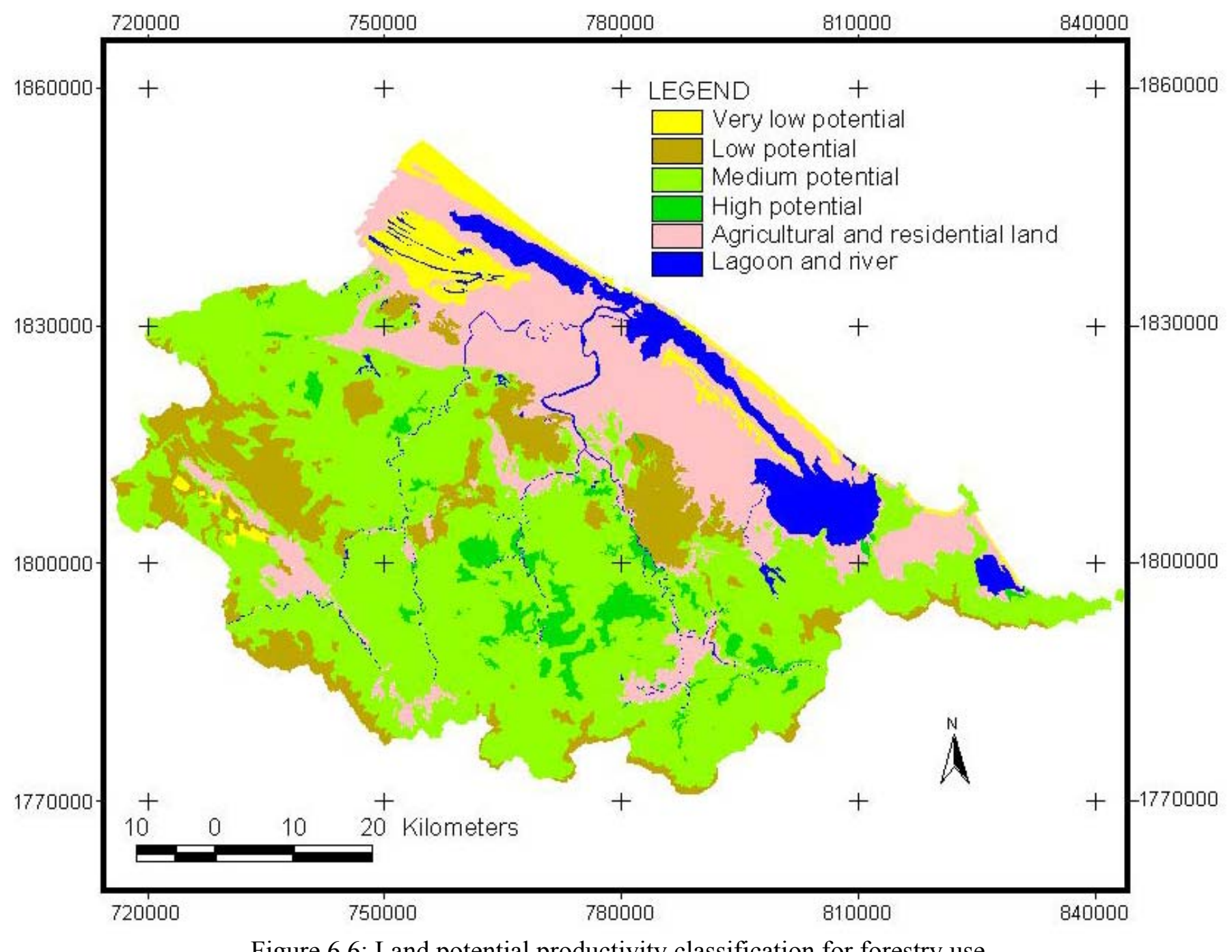

Figure 6.6: Land potential productivity classification for forestry use 


\subsection{Conclusion}

Remote sensing (RS) and GIS with supplemented field survey information are found very useful for assessment of land potential for forest production. A combination of remotely sensed information from Landsat ETM + image and spatial analysis of multi-factors and their impacts with respect to land potential are integrated into a GIS. Inside GIS a weighted linear combination model was used to derive the potential for forest production. This approach delivers a robust tool for forestry land resources assessment and management in Thua Thien Hue province.

According to the study results, it can be concluded that there is very low high potential for forestry use in the study area and most of forestry land areas were assessed as medium potential. The yellowish brown soils and alluvial soils proved to be more productive than yellowish red soils. Among the group of yellowish red soil, the lands developed on sandstones have lowest productivity because of their poor soil structure, fine sand texture low organic matter, phosphorus, potassium and nitrogen content. The group of coastal sand and thin layer soil of all soil types were classified as very low potential for forestry use because of their very low soil fertility and soil depth. Hence perhaps, a different scenario of forestry land use would be better suited for these soil types and further studies need to be formulated to identify the best forestland use options for these soil types. Especially, the study on forestland potential suitability for growing forest tree species in establishment of new forest plantation.

As this study shows the process of illustrating the forestland potential productivity by map and checking their conformity spatially and quantitatively, not only might help the forestry managers to distinguish the problems in the current forestry land use, lead to appropriate investment for forestry production and the useful strategies for planning of optimal forestry land use, but also set up a land-database for use of suitable land resource and sustainable land management in central Vietnam. 


\section{Chapter 7. Land Potential Assessment for Forest Plantation}

\subsection{Introduction}

Knowledge of the forestland is a key component for planning the forestry development of any region. This knowledge is used in assessment of forestland suitability, which determines the land potential for different types of forestry land use. Assessment of forestland suitability is the matching of a species with the local site conditions. Traditionally, assessment of land suitability will match a species with the biophysical growing conditions of the site (physical land suitability). Recently, the land suitability also includes other suitability aspects like environmental and socio-economic potentials (land suitability for economic and environmental forestry) or even local preference.

The land suitability assessment for the development of forest plantation is a prerequisite optimum utilization of the available land resources for sustainable forestry production. In Thua Thien Hue, the need for forest plantation is great, particularly for the production of industrial materials and woodchip exports to Japan and Taiwan. The land used for forest plantation increased rapidly in recent year due to a steadily rising demand of pulp- wood, timber and resin in international markets with high economic returns. However, the expansion of forest plantation in unsuitable land has increasingly grown and has negative impacts on land resources. Moreover, there is an urgent need for an appropriate methodology to help foresters and planners to select and identify land potential suitability sites to develop forest plantation farming. Inappropriate land use of growing tree species without regard to environmental and natural resources, and socio-economic aspect can lead to misuse and degradation of land resources and other social conflicts. To alleviate these problems, assessment of land suitability for expansion of forest plantation can predict land performance based on its attributes using remote sensing and GIS technique.

The target of land potential suitability is to find better and more suitable places for the implementation of planting forest and better and more suitable places were derived from GIS modelling based on the ecological requirements of individual tree species and land characteristics. The land suitability assessment requires consideration of a variety of criteria including not only the physical capacity of land units but also socio-economic and environmental aspects. So it involves analysis of ecological parameters related to soil, climate, topography, economy and environment. 
In this chapter a methodology approach and the application of a method of integration of GIS and Analytic Hierarchy Process (AHP) is presented. Soil property, climate and topography are integrated in GIS in order to assess the land potential suitability of the study area for selected tree species. The forestland cover was derived by Landsat ETM + data analysis. The present forestland cover types are important information for selecting suitable area for reforestation. The results of land potential assessment presented in the form of tables, maps and report are meaningful to local foresters and policy makers in land use planning. Especially, they are to implement the forest plantation programmes of the province so as to reach the ratio of land with forest up to $43 \%$ by the year 2010 and $47 \%$ by 2020 . These results could also be used as a basic soil-database and play an important role for the use of suitable soil resources and sustainable land management in Thua Thien Hue province. Remote sensing and Geographic Information system (GIS) can be effectively applied to complete the study objective. They are determined: (1) to assess land potential suitability for forest tree species, (2) to identify suitable areas for reforestation using Landsat ETM + and (3) to select the possible lands for new forest plantation.

\subsection{Methodology}

This study is based on spatial analysis to assess land suitability for selected tree species using remote sensing and GIS techniques. The methodology used is based on the FAO approach for land evaluation for forestry (1984). The main steps are the following:

- Selection of the forest tree species.

- Determination of ecological parameters.

- Determination of classes for each ecological parameter.

- Determination of weight and score of land suitability for selected tree species.

- Assessment of the land potential suitability for establishing forest plantation.

\subsubsection{Selection of the forest tree species}

The selection of appropriate tree species for the development of forest plantation depends on:

1) The purpose of the forest plantation.

2) Demands of desired product types.

3) Ecological requirement of the tree species.

\section{Purpose of the forest plantation}

According to the purposes of different forest plantations, the priority order will be different. When we choose tree species serving for planting economic forests, the priority order will be: 
Economy-Environment. In contrast, when we choose tree species serving for planting environmental forests, the priority order will be: Environment -Economy.

For the purposes of this assessment, two kinds of forest resources exploitation and management are assumed in the study area. The first type reflects traditional forestry with main management objectives being maximizing the quantity and quality of wood and paper pulp production. This type is referred to as "Economic forestry". Table 7.1 shows attributes of land use type for assessment of tree species suitability for economic forestry.

Table 7.1: Attributes of tree species for economic forestry (production forest)

\begin{tabular}{|l|l|}
\hline Attributes & Function of tree species for economic forestry \\
\hline $\begin{array}{l}\text { Tree } \\
\text { considered }\end{array}$ & $\begin{array}{l}\text { Pinus merkussi P. caribaea, Acacia auriculiformis, A. mangium, A. } \\
\text { hybrid and Casuarina equisetifolia }\end{array}$ \\
\hline Produce & $\begin{array}{l}\text { Main purpose for woodchip and paper pulp production and other uses } \\
\text { include mining poles, furniture wood and non-timber products (resin) }\end{array}$ \\
\hline $\begin{array}{l}\text { Objectives of forest } \\
\text { management }\end{array}$ & $\begin{array}{l}\text { Commercial timber and pulp production: maximization of high quality } \\
\text { timber production, pure equal-aged stands, length of optimal rotation. }\end{array}$ \\
\hline Capital intensity & High \\
\hline Labor intensity & Medium, maintenance and clearing \\
\hline Productivity & High and very high \\
\hline $\begin{array}{l}\text { Benefits of the } \\
\text { environment }\end{array}$ & $\begin{array}{l}\text { Potential for improvement of groundwater quality and carbon dioxide } \\
\text { sequestration in stem-wood, roots and soil }\end{array}$ \\
\hline Scale of operation & Medium and large enterprises and farmers \\
\hline
\end{tabular}

The second type with the management objective is focused on environmental protection and limited selective extraction of individual trees such as improvement of soil, stabilization of steep slopes, dunes, or shifting sand and windbreaks. This type is referred to as "Environmental forestry". The land use type attributes in Table 7.2 form the basis for assessment of tree species suitability for environmental forestry.

Table 7.2: Attributes of tree species for environmental forestry (protection forest)

\begin{tabular}{|l|l|}
\hline Attributes & Function of tree species for environmental forestry \\
\hline $\begin{array}{l}\text { Tree } \\
\text { considered }\end{array}$ & $\begin{array}{l}\text { Pinus merkussi, P. caribaea, Acacia auriculiformis, A. mangium, A. } \\
\text { hybrid, A. crassicarpa and Casuarina equisetifolia. }\end{array}$ \\
\hline Produce & Wood for various purposes. \\
\hline $\begin{array}{l}\text { Objective of forest } \\
\text { management }\end{array}$ & $\begin{array}{l}\text { Conservation of land such as improvement of soil, stabilization of slope } \\
\text { and sand soil, sand dune fixing and soil erosion prevention, windbreak, } \\
\text { dust filters, pest, disease and fire control, watershed protection, and } \\
\text { extraction of limited tree. }\end{array}$ \\
\hline Capital intensity & Low \\
\hline Labor intensity & Low, nature conservation personnel. \\
\hline Productivity & Low \\
\hline $\begin{array}{l}\text { Benefits } \\
\text { environment }\end{array}$ & $\begin{array}{l}\text { Potential for improvement of local environment and groundwater } \\
\text { quality, and carbon dioxide sequestration in stem-wood, roots and soil. }\end{array}$ \\
\hline Scale of operation & Limited operations at small scales. \\
\hline
\end{tabular}




\section{Demands of desired product types}

In the study area, a range of products could be obtained from plantations but the main emphasis of this study is put on production forest and protection forest. If land is assessed as being able to support the purpose of commercial plantation (woodchip and paper pulp production), it is assumed that it could also support forest plantations for other purposes such as environmental protection: Sandy dune fixation, erosion prevent, wind break and soil improvement.

\section{Ecological requirement of the tree species}

The ecological requirements of tree species were presented in three parts, namely:

- Climatic requirement of tree species.

- Edaphic (soil) requirement of tree species.

- And topographic requirement of tree species.

\section{Selected species}

The selection of a tree species for forest plantation depends not only on its adaptability to prevailing environmental conditions, but also on its potential use and acceptance by land users involved. Some trees may even do too well and become invasive and/or annoy people who not directly benefit from them. Cultural and seemingly irrational beliefs should also be considered when promoting tree plantation (Venema, J.H. and Vargas, R., 2007).

A list of tree species to be assessed for forest plantation potential was developed in accordance with the criteria listed above. In this study, the selection is made based on the economic and environmental analysis. We investigate which trees are of most value to the local people to generate some income, to fix the sandy dunes in coastal sandy soil, to improve the soil and to protect cultivated areas. According to these criteria, seven main tree species were chosen for expansion of forest plantation. The land suitability assessment was performed for these tree species actually present within the study area including two pines (Pinus merkussi and P. caribaea), four Acacia species (Acacia auriculiformis, A. mangium, A. hybrid and A. crassicarpa) and one casuarinas species (Casuarina equiselifolia).

To serve the purpose of economic forestry, the preferred plantation species are Pinus caribaea for wood chip and paper pulp production, Acacia auriculiformis and Acacia hybrid for all wood chip, paper pulp and furniture production, Casuarina equisetifolia for firewood production, Pinus merkussi for production of non-timber product (resin). 
For the purpose of environmental forestry, the preferred plantation species are Acacia auriculiformis, A. mangium, A. hybrid and A. crassicarpa for both purpose of soil improvement and erosion prevention and Casuarina equisetifolia for purpose of sand fixation, soil improvement and windbreak (Table 7.3).

Table 7.3: List of selected tree species function for assessment of forest plantation potential

\begin{tabular}{|l|c|c|c|c|c|c|c|}
\hline $\begin{array}{l}\text { Function of selected tree } \\
\text { species }\end{array}$ & $\begin{array}{l}\text { Pinus } \\
\text { merkussi }\end{array}$ & $\begin{array}{l}\text { Pinus } \\
\text { caribaea }\end{array}$ & $\begin{array}{l}\text { Acacia } \\
\text { auriculiformis }\end{array}$ & $\begin{array}{l}\text { Acacia } \\
\text { mangium }\end{array}$ & $\begin{array}{l}\text { Acacia } \\
\text { hybrid }\end{array}$ & $\begin{array}{l}\text { Acacia } \\
\text { crassicarpa }\end{array}$ & $\begin{array}{l}\text { Casuarina } \\
\text { equisetifolia }\end{array}$ \\
\hline $\begin{array}{l}\text { Industrial materials } \\
\text { (paper pulp) }\end{array}$ & - & $\mathrm{xxx}$ & $\mathrm{xxx}$ & $\mathrm{xx}$ & $\mathrm{xxx}$ & $\mathrm{x}$ & - \\
\hline Firewood & - & - & $\mathrm{xx}$ & $\mathrm{xx}$ & $\mathrm{xx}$ & $\mathrm{x}$ & $\mathrm{xxx}$ \\
\hline Furniture product & $\mathrm{xxx}$ & $\mathrm{x}$ & - & - & - & - & - \\
\hline $\begin{array}{l}\text { Non timber } \\
\text { (Resin) }\end{array}$ & $\mathrm{x}$ & $\mathrm{x}$ & $\mathrm{xxx}$ & $\mathrm{xxx}$ & $\mathrm{xxx}$ & $\mathrm{xxx}$ & $\mathrm{xx}$ \\
\hline Soil improvement & $\mathrm{xx}$ & $\mathrm{xx}$ & $\mathrm{xx}$ & $\mathrm{xx}$ & $\mathrm{xx}$ & $\mathrm{xx}$ & - \\
\hline Erosion prevention & - & - & $\mathrm{x}$ & $\mathrm{x}$ & $\mathrm{x}$ & $\mathrm{x}$ & $\mathrm{xxx}$ \\
\hline Sand stabilization & $\mathrm{xx}$ & $\mathrm{xx}$ & $\mathrm{xx}$ & $\mathrm{xx}$ & $\mathrm{xx}$ & $\mathrm{xx}$ & $\mathrm{xxx}$ \\
\hline Wind break & $15-20$ & $15-20$ & 30 & 35 & $40-45$ & $30-40$ & 15 \\
\hline Productivity (m3/ha/ year) & & & & & & - \\
\hline
\end{tabular}

Notes: Very suitable (xxx)

Suitable (xx)

Less suitable (x)

Not suitable (-)

\subsubsection{Determination of ecological parameters}

Determination of ecological parameters was based on the ecological requirement of tree species regarding edaphic and environmental conditions. The ecological characteristics of seven selected tree species are presented as follows:

\section{1) Pinus merkussi}

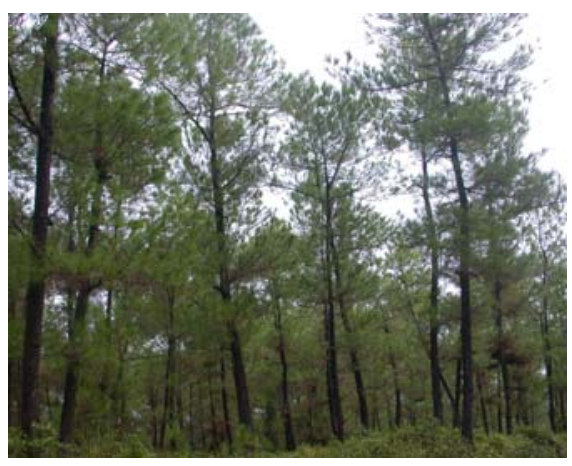

Vietnamese name: Thong nhua

Authority name: J. et De Vries

Family: Pinaceae 
Pinus merkussi is native to Vietnam, Laos, Cambodia, Thailand, Myanmar, Philippines, China and Indonesia. It is cultivated widely in the tropics within an altitude range of $20-900 \mathrm{~m}$ a.s.l. It can grow on acid soil and thin layer soil with $\mathrm{pH}$ ranging from 3.8 to 5.5.

In Vietnam, Pinus merkussi is often found at elevation of less than $900 \mathrm{~m}$ a.s.l in the south and of less than $500 \mathrm{~m}$ a.s.1 in the north of Vietnam on feralite soils developed on mica-schist, acid magma, granite, schist and basalt with mean annual rainfall of $1500 \mathrm{~mm}-2300 \mathrm{~mm}$, mean annual temperature of 20-27 ${ }^{\circ} \mathrm{C}$, mean annual temperature of hottest months of $32-34^{\circ} \mathrm{C}$ and mean annual temperature of coldest months of $14-17^{\circ} \mathrm{C}$. According to Nguyen Xuan Lieu et al., (2003), this species grows best on soils with $\mathrm{pH} 4.0-5.0$, at mean annual temperature of $22-$ $25^{\circ} \mathrm{C}$ and mean annual rainfall of $2,000 \mathrm{~mm}-2,300 \mathrm{~mm}$. This species does not tolerate on soil with heavy clay texture or alkaline and salinity soils and are sensitive to fire.

\section{2) Pinus caribaea}

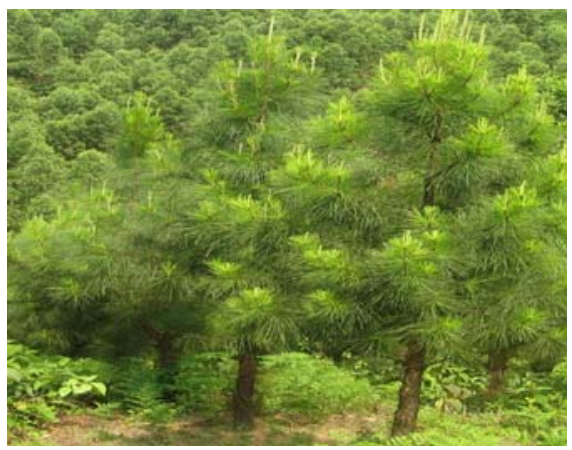

Vietnamese name: Thong caribe

Authority name: Morelet

Family: Pinaceae

Pinus caribaea is native to central America and the Caribbean, widely planted throughout the American, Asian and African tropics and subtropics. It grows best in frost-free areas up to $700 \mathrm{~m}$ altitude on more fertile sites with good drainage, mean annual rainfall of 1,000-3,000 mm and mean annual temperatures of $23-28{ }^{0} \mathrm{C}$.

This tree species is grown between 10 and 1,000 m a.s.l in the southern Vietnam and 200-600 m in the Northern Vietnam where the mean annual temperature of the hottest months is $30-35^{\circ} \mathrm{C}$ and the mean annual temperature of the coldest months is $14-21^{\circ} \mathrm{C}$. It can grow on feralite soils, potzolic soils of hills with $\mathrm{pH}$ ranging from 4.0 to 8 . Grows best in soils with $\mathrm{pH} 4.5-5.5$ and slope of less than $20^{\circ}$ (Le Dinh Kha et al., 2003). 


\title{
3) Acacia auriculiformis
}

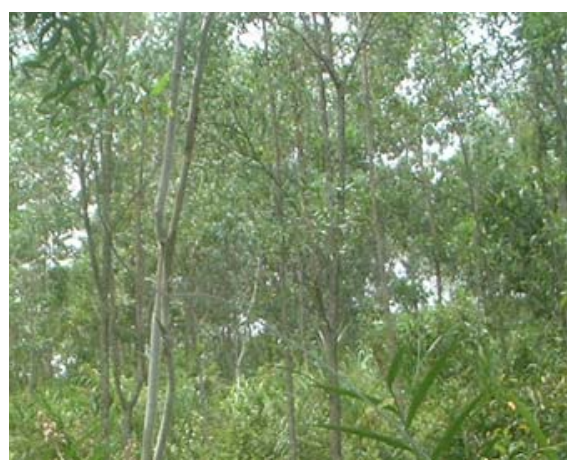

\author{
Vietnamese name: Keo la tram \\ Authority name: A.Cunn. ex Benth \\ Family: Fabaceae (Mimosoideae)
}

Acacia auriculiformis is native to Australia, Papua New Guinea and Indonesia, Java, Malaysia, Niger, Nigeria, Philippines, Tanzania, Thailand, the Soloman Islands, Uganda, and Zanzibar. It has been widely introduced to many tropical countries in South and Southeast Asia, Africa and Latin America.

It occurs from near sea level to $500 \mathrm{~m} \mathrm{n}$ hot humid and sub-humid lowlands with mean annual temperature of 20 to $30^{\circ} \mathrm{C}$, mean annual rainfall of $800-2,500 \mathrm{~mm}$ (Danida Forest Seed Centre, 2000), mean annual temperature of the hottest months of $32-34^{0} \mathrm{C}$ and mean annual temperatures of the coldest months of $16-22^{0} \mathrm{C}$. The tree can grow in a wide range of deep and shallow soils, even on sand dunes and unstable slopes with sand or clay texture and soil with $\mathrm{pH}$ ranging from 3.0 to 9.5. Acacia auriculiformis grows best in humid, deep, medium texture and alluvial soils (John K-Francis- international institute of tropical forestry-USDA forest service 1980) but it does not tolerate strong winds.

This tree species is planted in many provinces from the North to the South of Vietnam, mainly concentrated from Quang Nam to Kien Giang province on a wide variety of soil types with optimal pH of 4.5-6.5 (Nguyen Hoang Nghia et al., 2003).

\section{4) Acacia mangium}

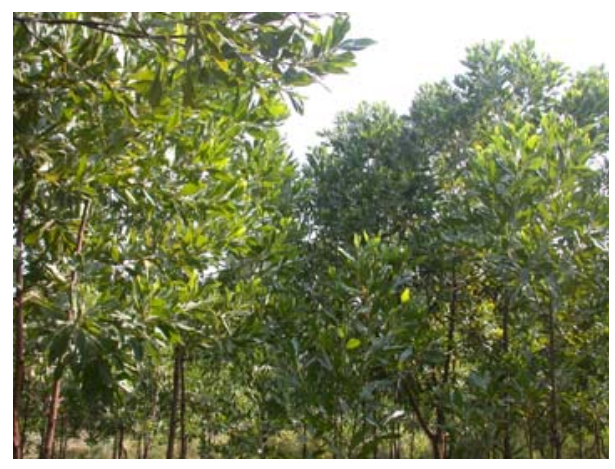

\author{
Vietnamese name: Keo tai tuong \\ Authority name: Wild \\ Family: Fabaceae (Mimosoideae)
}


Acacia mangium is native to northern Queensland, through Papua New Guinea (Western province) to the Indonesia provinces of Irian Jaya and Maluku. It is a fast growing, relatively short lived tree (30-50 years), adapted to a wide range of acidic ( $\mathrm{pH} 4.5-6.5)$ soil in moist tropical lowlands. It does not tolerate frost. It grows better on fertile sites with good drainage but will tolerate soils of low fertility and impeded drainage (Danida Forest Seed center 2000).

It is cultivated widely in the tropics within an altitude range of $5-800 \mathrm{~m}$ a.s.l where the mean annual rainfall in its natural range varies from 1,500-3,000 $\mathrm{mm}$ and the mean annual temperature of 23 to $27^{\circ} \mathrm{C}$

In Vietnam, Acacia mangium is planted between 10 and $700 \mathrm{~m}$ where the mean annual temperature of the hottest months is 32 to $34^{\circ} \mathrm{C}$ and the mean annual temperature of the coldest months is $14-22^{\circ} \mathrm{C}$. It grows on many kinds of soils from coastal sandy soil, feralite soils developed on ancient alluvium to alluvial soil with $\mathrm{pH}$ ranging from 3.8 to 6.5 and where the limited slope is less than $25^{\circ}$. It grows best on the soil with $\mathrm{pH} 4.5-6$ and slope of less than $15^{0}$ (Le Dinh Kha et al., 2003).

\section{5) Acacia hybrid (mangium $\mathbf{x}$ auriculiformis)}

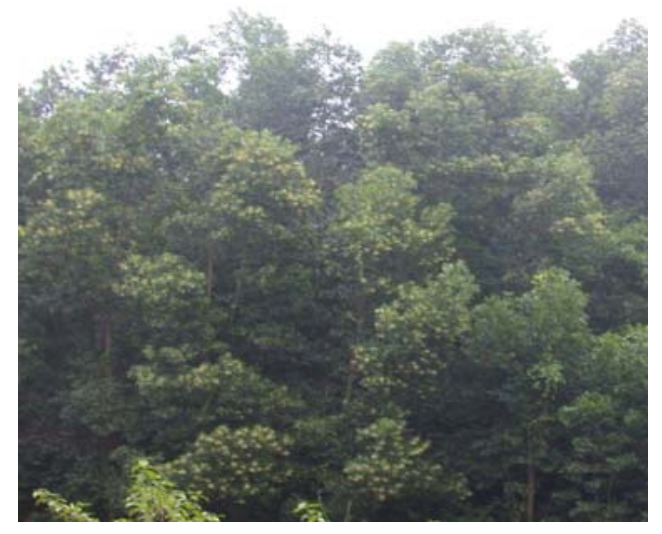

Vietnamese name: Keo lai

Family: Fabaceae (Mimosoideae)

Acacia hybrid, a cross between A. auriculiformis and A. mangium, grows in Vietnam, Thailand, Indonesia, Malaysia, Australia, India and some other countries in Pacific-Asia. This tree species grows faster than A. mangium and A. auriculiformis (Kha 2003, Kijka 1992 and Rufelds 1987).

In Vietnam, Acacia hybrid is planted between seal level and $500 \mathrm{~m}$ where mean annual temperature is 23 to $28^{\circ} \mathrm{C}$, the mean annual temperature of the hottest months is 31 to $34^{\circ} \mathrm{C}$, and the mean annual temperature of the coldest months is 13 to $23^{\circ} \mathrm{C}$ and the mean annual rainfall varies from 1,500 to 2,500 $\mathrm{mm}$ on many kinds of soils such as coastal sandy soil, feralite soils developed on schist, shale, alluvium and ancient alluvium with $\mathrm{pH}$ ranging from 4 to 7 . It grows 
best in humid, deep, medium texture and soil alluvial soil and on more fertile sites with good drainage, soil pH from 5-6 and land slope of less than 15(Nguyen Hong Quan et al., 2003)

\title{
6) Acacia crassicarpa
}

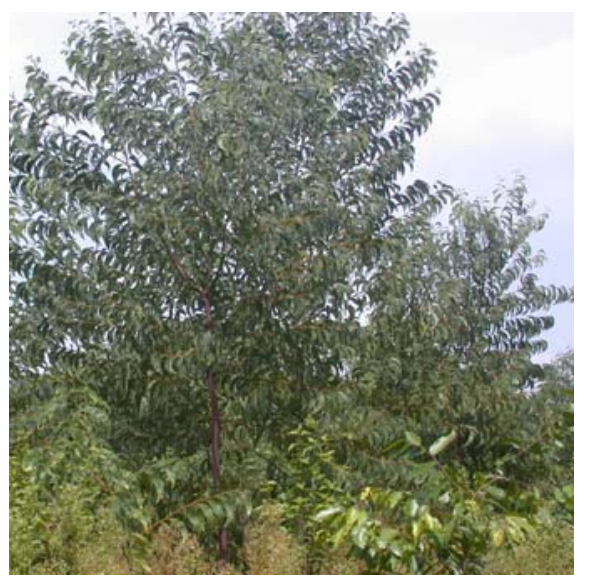

\author{
Vietnamese name: Keo luoi liem \\ Authority name: A.Cunn. ex Benth \\ Family: Fabaceae (Mimosoideae)
}

Acacia crassicarpa is native to Australia (North East of Queensland), South-West Papua New Guinea, Indonesia (South West Irian Jaya) in hot humid and sub-humid lowlands with a mean annual rainfall of $1,000 \mathrm{~mm}-3,500 \mathrm{~mm}$ and a mean annual temperature of $24-28^{\circ} \mathrm{C}$. It can even grow under the most difficult conditions in the tropics. The rapid early growth rate, the ability to fix nitrogen, the tolerance of acid, alkaline and infertile soil and moderately in dry season makes it very suitable for rehabilitation of degraded land.

According to Le Dinh Kha et al., 2003, in Vietnam, this species can be planted between 5 - 450 $\mathrm{m}$ a.s.l where the mean annual temperature of the hottest months is 32 to $34^{0} \mathrm{C}$ and the mean annual temperature of the coldest months is 13 to $23^{\circ} \mathrm{C}$. It tolerates a wide variety of soil types from coastal sandy soil, yellowish red soil, yellowish brown soil to alluvial soil with $\mathrm{pH}$ ranging from 4.0 to 7.0. Acacia crassicarpa grows best on soil with $\mathrm{pH} 5-6$, soil depth of over $70 \mathrm{~cm}$, land slope of less than $15^{\circ}$ and elevation of less than $200 \mathrm{~m}$.

\section{7) Casuarina equisetifolia}

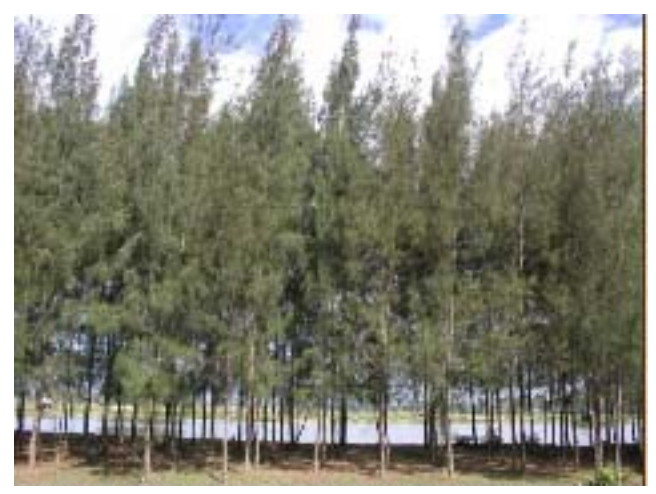

\author{
Vietnamese name: Phi lao/ Duong \\ Authority name: L.ex Adans \\ Family: Casuarinaceae.
}


Casuarina equisetifolia is native to Australia and neighbouring area, and has been introduced into many countries. Casuarinas species occurs natural on subtropical and tropical northern Australia throughout Malaysia, southern Myanmar, Kra Isthmus of Thailand. Casuarina equisetifolia prefers light, sandy soils along the coast, and is relatively fast growing on poor soil and tolerates some salinity and salt laden winds, but it does not tolerate frost and water-logging and is sensitive to fire. Nitrogen fixing, its life span is 40-50 years (Danida Forest Seed center 2000)

Casuarina equisetifolia is found where mean annual temperatures range from 23 to $28^{0} \mathrm{C}$, the mean annual temperature of the hottest months is $30-34^{0} \mathrm{C}$, the mean annual temperature of the coldest months is $6-23^{0} \mathrm{C}$ and the mean annual rainfall is 1,500 to $2,500 \mathrm{~m}$ and elevation is 1 to $300 \mathrm{~m}$. Nowadays this species are mainly planted in coastal areas of Vietnam on a wide variety of soil from alluvial soil, sandy-loamy mixed soil in deltas to sand dunes in coastal areas with $\mathrm{pH}$ $4.0-7.0$ (optimal condition: 6-7) and the limited slope is less than $15^{0}$. The species can be planted on acid and inundated soil (Ha Huy Thinh et al., 2003). However Casuarinas cannot grow well on clayed soils.

Based on behaviour of the tree species as mentioned above, ten criteria have been chosen and grouped into three ecological parameters basing on their specific relationship to the assessment of land suitability for forest plantation, namely: Soil property parameter (soil types, soil texture, soil depth, soil $\mathrm{pH}$, organic matter and soil fertility), topographic parameter (slope and elevation), and climatic parameter (mean annual temperature and mean annual rainfall). Mean annual temperatures of the hottest and coldest months are almost constant and suitable for seven selected tree species in the study area, so they have not been taken into account in this study.

\subsubsection{Determination of classes for each ecological parameter}

The determination of classes for each ecological parameter is also based on the understanding of tree species behaviour regarding edaphic and environmental conditions as described above. The behaviour of the tree species was examined to select classes for ecological parameters. Each class of each ecological parameter was classified with a determined value for each forest tree species. As an example Pinus merkussi tree is widespread in the mountainous areas of central Vietnam, it can tolerate soils of low fertility and shallow soil depth. It prefers acidic soil with good drainage. This tree adapts to a wide range of acidic ( $\mathrm{pH} 4-5.5)$ soils. It avoids heavy clays and poor well drained soils. 


\subsubsection{Procedure of weight and score of land suitability for selected tree species}

Each ecological parameter requires selected forest tree species and will contribute differently to the significance, hence different weight should be given to each parameter. The greater the weight, the larger the value, the more important the decision parameter.

The Analytic Hierarchy Process (AHP) is a widely used method in decision-making. AHP is developed by Saaty (1977), AHP technique is advantageous in the decision making process, where relative importance of the parameter under assessment is to be established consciously. According to Rommelfanger (2003), empirical studies showed that people can not compare more than three parameters at the same time. Therefore, the Analytic Hierarchy Process (AHP) technique was used to define weights of ecological parameters. Fig. 7.1 shows the hierarchical structure used in this study.

At levels of the hierarchy the parameter are required to be assessed to derive the weights. In the procedure for land suitability assessment, it is necessary that the parameter weights need to be summed up to 1 , so the well-established geometric mean method is used and the relative importance weights of parameters were estimated using pair-wise comparison matrix. From this methodology, a general weight ranging was given each ecological parameter as follows:

Table 7.4: Weights of ecological parameters in land suitability assessment

\begin{tabular}{|c|c|c|c|c|c|c|}
\hline \multicolumn{6}{|c|}{ Ecological parameter } & \multirow{2}{*}{$\begin{array}{l}\text { Overall weight } \\
\text { (Wi =W1 X W2 X W 3) }\end{array}$} \\
\hline Level 1 & W1 & Level 2 & $\mathbf{W} 2$ & Level 3 & W3 & \\
\hline \multirow[t]{6}{*}{ Soil property } & \multirow[t]{6}{*}{0.6} & Soil types & 0.546 & - & - & 0.328 \\
\hline & & \multirow[t]{2}{*}{ Physical } & \multirow[t]{2}{*}{0.263} & Soil depth & 0.667 & 0.105 \\
\hline & & & & Soil texture & 0.333 & 0.053 \\
\hline & & \multirow{3}{*}{ Chemical } & \multirow{3}{*}{0.191} & Soil pH & 0.218 & 0.025 \\
\hline & & & & Soil fertility & 0.691 & 0.079 \\
\hline & & & & Organic matter & 0.091 & 0.010 \\
\hline \multirow[t]{2}{*}{ Topography } & \multirow[t]{2}{*}{0.2} & - & - & Slope & 0.667 & 0.133 \\
\hline & & - & - & Elevation & 0.333 & 0.067 \\
\hline \multirow[t]{2}{*}{ Climate } & \multirow[t]{2}{*}{0.2} & - & - & Rainfall & 0.667 & 0.133 \\
\hline & & - & - & Temperature & 0.333 & 0.067 \\
\hline
\end{tabular}

The score of class for each parameter is based on the requirements of selected tree species, the suggestion of experts and technicians as well as local conditions. The ranking score presents the suitability of each class of each parameter for each suitability class. Each ecological parameter on environmental suitability was classified into 4 suitable levels, these were highly suitable (S1), moderately suitable (S2), marginally suitable $(\mathrm{S} 3)$ and not suitable $(\mathrm{N})$ as assigned the value of each suitable level as 4, 3, 2 and 1, respectively (Table 7.5). 


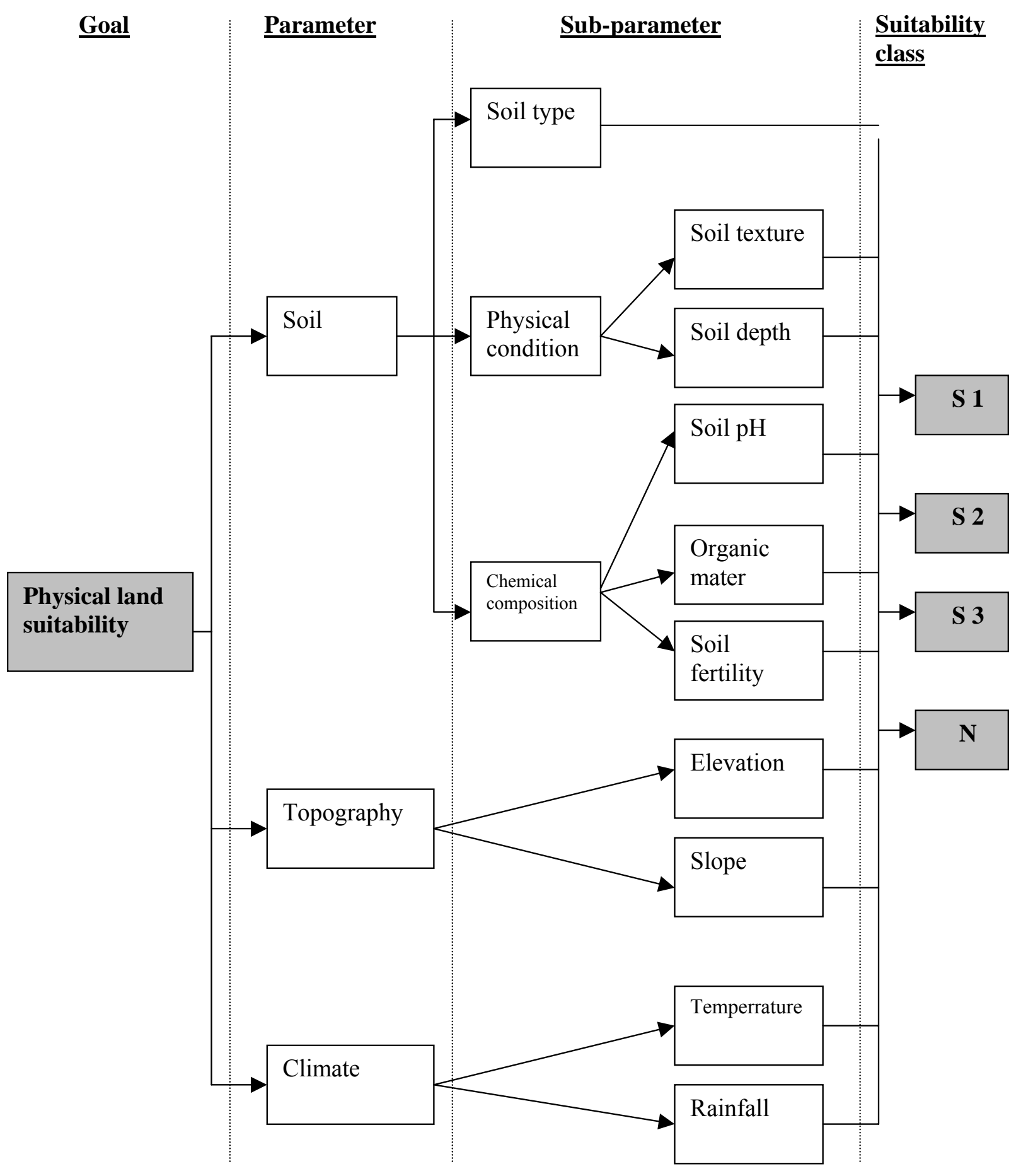

Figure 7.1: Hierarchical organization of the parameter considered for assessing physical land potential suitability for selected tree species. 
Table 7.5: Parameters for determination of suitable classes for growing selected tree species

\begin{tabular}{|c|c|c|c|c|}
\hline \multirow[t]{2}{*}{ Parameter } & \multicolumn{4}{|c|}{ Levels of suitability } \\
\hline & S1 & $\mathrm{S} 2$ & S3 & $\mathbf{N}$ \\
\hline \multicolumn{5}{|l|}{ (1) Pinus merkussi } \\
\hline Mean annual temperature $\left(0^{0} \mathrm{C}^{\prime}\right.$ & $22-24$ & $24-26$ & $26-27$ & $<22, \geq 27$ \\
\hline Average annual rainfall (mm) & $2,000-2,300$ & $1,700-2,000$ & $1,500-1,700$ & $<1,500, \geq 2,300$ \\
\hline Soil types & $\mathrm{Fa}$ and $\mathrm{Fp}$ & $\begin{array}{c}\text { Fs, } \mathrm{Fq}, \mathrm{Pe} \\
\text { and } \mathrm{X}\end{array}$ & $\mathrm{E}$ & $\mathrm{C}$ and $\mathrm{Cc}$ \\
\hline Soil depth $(\mathrm{cm})$ & $\geq 100$ & $70-100$ & $30-70$ & $<30$ \\
\hline Organic matter (\%) & $\geq 2.5$ & $1.5-2.5$ & $0.5-1.5$ & $<0.5$ \\
\hline Soil pH & $4.0-5.5$ & $3.8-4.0$ & $5.0-5.5$ & $<3.8,>5.5$ \\
\hline Soil texture & $1 \mathrm{~s}, \mathrm{sl}, \mathrm{scl}$ & sil, 1, sc & $\mathrm{cl}, \mathrm{si}, \mathrm{sic}, \mathrm{sicl}$ & $\mathrm{c}, \mathrm{s}$ \\
\hline Total nitrogen $(\%)$ & $\geq 0.2$ & $0.1-0.2$ & $0.1-0.05$ & $<0.05$ \\
\hline Available Phosphorus (ppm/kg) & $\geq 25$ & $10-25$ & $6-10$ & $<6$ \\
\hline Available Potassium (ppm/kg) & $\geq 90$ & $60-90$ & $30-60$ & $<30$ \\
\hline Land slope (degree) & $<15$ & $16-25$ & $25-35$ & $\geq 35$ \\
\hline Elevation $(\mathrm{m})$ & $25-100$ & $100-300$ & $300-500$ & $\geq 500$ \\
\hline \multicolumn{5}{|l|}{ (2) P. caribaea } \\
\hline Mean temperature $\left(0^{\mathrm{c}}\right)$ & $23-24$ & $25-26$ & $25-28$ & $<23, \geq 28$ \\
\hline Average annual rainfall $(\mathrm{mm})$ & $1,500-2,000$ & $2,000-3,000$ & $1,000-1,500$ & $\begin{array}{l}<1,000 \\
\geq 3,000\end{array}$ \\
\hline Soil types & Fa and Fp & Fs, Pe and $\mathrm{X}$ & $\mathrm{Fq}$ & $\mathrm{E}, \mathrm{C}$ and $\mathrm{Cc}$ \\
\hline Soil depth $(\mathrm{cm})$ & $\geq 100$ & $70-100$ & $50-70$ & $<50$ \\
\hline Organic matter $(\%)$ & $\geq 2.5$ & $1.5-2.5$ & $0.5-1.5$ & $<0.5$ \\
\hline Soil pH & $4.5-5.5$ & $5.5-6.5$ & $\begin{array}{c}6.5-7 \\
3.5-4.5\end{array}$ & $<3.5$ \\
\hline Soil texture & ls, sl, scl & sil, sc ,cl, 1 & sic, si, sicl & $\mathrm{c}, \mathrm{s}$ \\
\hline Total nitrogen $(\%)$ & $\geq 0.2$ & $0.1-0.2$ & $0.1-0.05$ & $<0.05$ \\
\hline Available Phosphorus (ppm/kg) & $\geq 25$ & $10-25$ & $6-10$ & $<6$ \\
\hline Available Potassium (ppm/kg) & $\geq 90$ & $60-90$ & $30-60$ & $<30$ \\
\hline Land slope (degree) & $<15$ & $15-25$ & $25-35$ & $\geq 35$ \\
\hline Elevation $(\mathrm{m})$ & $<100$ & $100-200$ & $200-300$ & $\geq 300$ \\
\hline \multicolumn{5}{|l|}{ (3) Acacia auriculiformis } \\
\hline Mean temperature $\left(0^{c}\right)$ & $24-26$ & $\begin{array}{l}22-24 \\
26-28\end{array}$ & $\begin{array}{c}20-22 \\
28-30\end{array}$ & $<20, \geq 30$ \\
\hline Average annual rainfall (mm) & $2,000-2,500$ & $1,500-2,000$ & $800-1,500$ & $\leq 800$ \\
\hline Soil types & Pe, Fp and $\mathrm{X}$ & $\mathrm{Fq}, \mathrm{Fa}$ and $\mathrm{Fs}$ & Cc and E & $\mathrm{C}$ \\
\hline Soil depth $(\mathrm{cm})$ & $\geq 70$ & $50-70$ & $30-50$ & $<30$ \\
\hline Organic matter (\%) & $\geq 2.5$ & $1.5-2.5$ & $0.5-1.5$ & $<0.5$ \\
\hline Soil $\mathrm{pH}$ & $4.5-6.5$ & $6.5-7.0$ & $\begin{array}{c}3.0-4.5 \\
7-9.5\end{array}$ & $<3,>9.5$ \\
\hline Soil texture & $\mathrm{sl}, \mathrm{scl}, \mathrm{l}$ & $\begin{array}{c}\text { ls, sil, sc, cl, } \\
\text { si, sic, sicl }\end{array}$ & $\mathrm{c}, \mathrm{s}$ & Heavy clay \\
\hline Total nitrogen $(\%)$ & $\geq 0.2$ & $0.1-0.2$ & $0.1-0.05$ & $<0.05$ \\
\hline Available Phosphorus (ppm/kg) & $\geq 25$ & $10-25$ & $6-10$ & $<6$ \\
\hline Available Potassium (ppm/kg) & $\geq 90$ & $60-90$ & $30-60$ & $<30$ \\
\hline Land slope (degree) & $<8$ & $8-15$ & $15-35$ & $\geq 35$ \\
\hline Elevation $(\mathrm{m})$ & $<100$ & $100-300$ & $300-500$ & $\geq 500$ \\
\hline
\end{tabular}




\begin{tabular}{|c|c|c|c|c|}
\hline (4) A. mangium & & & & \\
\hline Mean temperature $\left(0^{\mathrm{c})}\right.$ & $23-24$ & $24-25$ & $25-27$ & $<23, \geq 27$ \\
\hline Average annual rainfall $(\mathrm{mm})$ & $2,000-2,500$ & $2,500-3,000$ & $1,500-2,000$ & $\begin{array}{l}<15,00 \\
\geq 3,000\end{array}$ \\
\hline Soil types & $\mathrm{Pe}, \mathrm{Fp}$ and $\mathrm{X}$ & $\mathrm{Fq}, \mathrm{Fa}$ and $\mathrm{Fs}$ & $\mathrm{Cc}$ & $\mathrm{E}$ and $\mathrm{C}$ \\
\hline Soil depth $(\mathrm{cm})$ & $\geq 100$ & $70-100$ & $50-70$ & $<50$ \\
\hline Organic matter $(\%)$ & $\geq 2.5$ & $1.5-2.5$ & $0.5-1.5$ & $<0.5$ \\
\hline Soil pH & $4.5-6.0$ & $5.5-6.5$ & $3.8-4.5$ & $<3.8,>6.5$ \\
\hline Soil texture & $\mathrm{sl}, \mathrm{scl}, 1$ & $\begin{array}{c}\text { ls, sil, sc ,cl, } \\
\text { si, sic, sicl }\end{array}$ & $\mathrm{c}, \mathrm{s}$ & Heavy clay \\
\hline Total nitrogen $(\%)$ & $\geq 0.2$ & $0.1-0.2$ & $0.1-0.05$ & $<0.05$ \\
\hline Available Phosphorus (ppm/kg) & $\geq 25$ & $10-25$ & $6-10$ & $<6$ \\
\hline Available Potassium (ppm/kg) & $\geq 90$ & $60-90$ & $30-60$ & $<30$ \\
\hline Land slope (degree) & $<8$ & $8-15$ & $15-25$ & $\geq 25$ \\
\hline Elevation $(\mathrm{m})$ & $<200$ & $200-400$ & $400-700$ & $\geq 700$ \\
\hline (5) A. hybrid & & & & \\
\hline Mean temperature $\left(0^{\mathrm{c}}\right)$ & $23-24$ & $24-25$ & $25-28$ & $<23, \geq 28$ \\
\hline Average annual rainfall $(\mathrm{mm})$ & $2,000-2,500$ & $1,700-2,000$ & $1,500-1,700$ & $\begin{array}{l}<1,500 \\
\geq 2,500\end{array}$ \\
\hline Soil types & Pe, Fp and $X$ & $\mathrm{Fq}, \mathrm{Fa}$ and $\mathrm{Fs}$ & $\mathrm{Cc}$ & $\mathrm{E}$ and $\mathrm{C}$ \\
\hline Soil depth $(\mathrm{cm})$ & $\geq 100$ & $70-100$ & $50-70$ & $<50$ \\
\hline Organic matter $(\%)$ & $\geq 2.5$ & $1.5-2.5$ & $0.5-1.5$ & $<0.5$ \\
\hline Soil pH & $5.0-6.0$ & $6.0-7.0$ & $4.0-5.0$ & $<4.0,>7.0$ \\
\hline Soil texture & sl, scl, 1 & $\begin{array}{c}\text { ls, sil, sc ,cl, } \\
\text { si, sic, sicl }\end{array}$ & $\mathrm{c}, \mathrm{s}$ & Heavy clay \\
\hline Total nitrogen $(\%)$ & $\geq 0.2$ & $0.1-0.2$ & $0.1-0.05$ & $<0.05$ \\
\hline Available Phosphorus (ppm/kg) & $\geq 25$ & $10-25$ & $6-10$ & $<6$ \\
\hline Available Potassium (ppm/kg) & $\geq 90$ & $60-90$ & $30-60$ & $<30$ \\
\hline Slope (degree) & $<8$ & $8-15$ & $15-25$ & $\geq 25$ \\
\hline Elevation $(\mathrm{m})$ & $<100$ & $100-300$ & $300-500$ & $\geq 500$ \\
\hline (6) A. crassicarpa & & & & \\
\hline Mean temperature $\left(0^{\mathrm{c}}\right)$ & 24-25 & $25-26$ & $26-28$ & $<24, \geq 28$ \\
\hline Average annual rainfall $(\mathrm{mm})$ & $1,500-2,500$ & $2,500-3,000$ & $\begin{array}{l}1,000-1,500 \\
3,000-3,500\end{array}$ & $\begin{array}{l}<1,000 \\
\geq 3,500\end{array}$ \\
\hline Soil types & Pe, Fp and $\mathrm{X}$ & $\mathrm{Fs}, \mathrm{Fq}$ and $\mathrm{Fa}$ & $\mathrm{Cc}$ and $\mathrm{C}$ & $\mathrm{E}$ \\
\hline Soil depth $(\mathrm{cm})$ & $\geq 70$ & $50-70$ & $30-50$ & $<30$ \\
\hline Organic matter $(\%)$ & $\geq 2.5$ & $1.5-2.5$ & $0.5-1.5$ & $<0.5$ \\
\hline Soil $\mathrm{pH}$ & $5.0-6.0$ & 6.0-7.0 & $4.0-5.0$ & $<4.0,>7.0$ \\
\hline Soil texture & $\mathrm{sl}, \mathrm{scl}, 1$ & $\begin{array}{l}\text { ls, sil, sc ,cl, } \\
\text { si, sic, sicl }\end{array}$ & $\mathrm{c}, \mathrm{s}$ & Heavy clay \\
\hline Total nitrogen $(\%)$ & $\geq 0.2$ & $0.1-0.2$ & $0.1-0.05$ & $<0.05$ \\
\hline Available Phosphorus (ppm/kg) & $\geq 25$ & $10-25$ & $6-10$ & $<6$ \\
\hline Available Potassium (ppm/kg) & $\geq 90$ & $60-90$ & $30-60$ & $<30$ \\
\hline Land slope (degree) & $<8$ & $8-15$ & $15-25$ & $\geq 25$ \\
\hline Elevation $(\mathrm{m})$ & $<200$ & $200-300$ & $300-450$ & $\geq 450$ \\
\hline
\end{tabular}




\begin{tabular}{|c|c|c|c|c|}
\hline \multicolumn{5}{|l|}{ (7) Casuarina equisetifolia } \\
\hline Mean temperature $\left(0^{\mathrm{c}}\right)$ & $23-24$ & $24-25$ & $25-28$ & $<23, \geq 28$ \\
\hline Average annual rainfall (mm) & $2,000-2,500$ & $1,700-2,000$ & $1,500-1,700$ & $\begin{array}{l}<1,500, \\
\geq 2,500\end{array}$ \\
\hline Soil types & $\mathrm{C}$ and $\mathrm{Fe}$ & $\mathrm{X}$ and $\mathrm{Fp}$ & $\begin{array}{c}\text { Fs, Fq and } \\
F a\end{array}$ & $\mathrm{E}$ and $\mathrm{Cc}$ \\
\hline Soil depth $(\mathrm{cm})$ & $\geq 100$ & $70-100$ & $50-70$ & $<50$ \\
\hline Organic matter $(\%)$ & $\geq 2.5$ & $1.5-2.5$ & $0.5-1.5$ & $<0.5$ \\
\hline Soil pH & $6.0-7.0$ & $5.0-6.0$ & $4.0-5.0$ & $<4.0,>7.0$ \\
\hline Soil texture & $\mathrm{sl}, \mathrm{scl}, \mathrm{ls}, \mathrm{sc}$ & $1, \mathrm{~s}, \mathrm{sil}, \mathrm{sicl}, \mathrm{cl}$ & si, sic, c & Heavy clay \\
\hline Total nitrogen $(\%)$ & $\geq 0.2$ & $0.1-0.2$ & $0.1-0.05$ & $<0.05$ \\
\hline Available Phosphorus (ppm/kg) & $\geq 25$ & $10-25$ & $6-10$ & $<6$ \\
\hline Available Potassium (ppm/kg) & $\geq 90$ & $60-90$ & $30-60$ & $<30$ \\
\hline Land slope (degree) & $<5$ & $5-8$ & $8-15$ & $\geq 15$ \\
\hline Elevation $(\mathrm{m})$ & $<100$ & $100-200$ & $200-300$ & $\geq 300$ \\
\hline
\end{tabular}

Notes: Is: Loamy sand, sl: Sandy loam, scl: Sandy clay loam, sil: Silt loam, sic: Silty clay, sicl: Silty clay loam, l: Loam, cl: Clay loam, si: Silt, c: Clay, s: Sand, sc: Sandy clay.

Pe: Alluvial soil, Fp: Yellowish brown soil on old alluvia, X: Grey soil, Fs: Yellowish red soil on metamorphic rock, Fq: Yellowish red soil on sandstone rock, Fa: Yellowish red soil on acid magma, E: Thin layer soil, C: Coastal sandy soil, Cc: Inland sandy soil.

S1: Highly suitable, S2: Moderately suitable, S3: Marginally suitable and N: Not suitable. 


\subsubsection{Land suitability assessment}

The physical land suitability analysis is based on the comparison of tree species requirements and ecological condition (soil, climatic and topographic condition) and has been done for each tree species. According to Hopkins (1977), the most prevalent procedure for integrating multicriteria evaluation in GIS for land suitability assessment is using a weighted linear combination (WLC) approach. The WLC procedure was also developed by Eastman et al (1995) and achieves the simultaneous constraint satisfaction by modifying the suitability measure and is used by many scholars. The suitable areas for each tree species were determined by considering the score distribution of each site. The final score of the land suitability in each site is given by the formula below.

$$
\mathrm{S}=\left(\sum W i \times X i\right) \times \Pi C_{j}
$$

S: Suitability index/final score

$W i$ : weight of parameter i

$X i$ : Score of class i

$C_{j}$ : Boolean value of limited parameter

П: Product

In this study $C_{j}$ took value 0 . This value was applied for land unit and is not suitable on other lands such as residential areas, water body and paddy fields. The above formula was applied in 30 meters grid cell size. The higher the value in the cell, the more suitable it is for forest tree species.

The final score/ suitability index was converted to a suitability class, as shown in the following table.

Table 7.6: Land suitability classes

\begin{tabular}{|c|c|}
\hline Score & Suitable classes \\
\hline$\geq 3.5$ & Highly suitable (S1) \\
\hline $2.5-3.5$ & Moderately suitable (S2) \\
\hline $1.5-3.5$ & Marginally suitable (S3) \\
\hline$<1.5$ & Not suitable (N) \\
\hline
\end{tabular}

The next step is to develop the map of preliminary land suitability for forest plantation. All physical land suitability maps of seven selected tree species were superimposed in order to get the final suggestion based on priority matrix. In the priority matrix, the two criteria to revise tree species boundaries consist of suitable class, and priority. The highest suitability will be selected first. If sites have the same suitable class, the priority was derived from environmental (soil conservation) and economic analysis of the behaviour of the tree species (Table 7.7). 
Table 7.7: Scenarios for the land suitability classification

\begin{tabular}{|c|c|c|c|}
\hline \multirow{2}{*}{$\begin{array}{c}\text { Selected tree } \\
\text { species }\end{array}$} & \multicolumn{2}{|c|}{ Hilly and mountainous region } & $\begin{array}{c}\text { Inland } \\
\text { coastal sandy region }\end{array}$ \\
\cline { 2 - 4 } & $\begin{array}{c}\text { Environmental forestry } \\
\text { (protection forest) }\end{array}$ & $\begin{array}{c}\text { Economic forestry } \\
\text { (production forest) }\end{array}$ & $\begin{array}{c}\text { Environmental forestry } \\
\text { (protection forest) }\end{array}$ \\
\hline $\begin{array}{c}\text { Pinus } \\
\text { merkusii }\end{array}$ & 40 & 60 & 0 \\
\hline $\begin{array}{c}\text { Pinus } \\
\text { caribaea }\end{array}$ & 50 & 75 & 0 \\
\hline $\begin{array}{c}\text { Acacia } \\
\text { auriculiformis }\end{array}$ & 80 & 80 & 70 \\
\hline $\begin{array}{c}\text { Acacia } \\
\text { mangium }\end{array}$ & 75 & 70 & 60 \\
\hline $\begin{array}{c}\text { Acacia } \\
\text { hybrid }\end{array}$ & 85 & 85 & 65 \\
\hline $\begin{array}{c}\text { Acacia } \\
\text { crassicarpa }\end{array}$ & 83 & 30 & 80 \\
\hline $\begin{array}{c}\text { Casuarina } \\
\text { equisetifolia }\end{array}$ & 70 & 65 & \\
\hline
\end{tabular}

The value represented the importance of each tree species according to the scenario chosen. This value was also converted to a suitability class in order to calculate preliminary land suitability and is shown in Table 7.8 .

Table 7.8: Conversion of the land suitability classes

\begin{tabular}{|c|c|c|}
\hline $\begin{array}{c}\text { Land suitability classes of } \\
\text { environment and economy }\end{array}$ & Score & Conversion \\
\hline S1 & $75-100$ & 3 \\
\hline S2 & $50-75$ & 2 \\
\hline S3 & $25-50$ & 1 \\
\hline N & $<25$ & 0 \\
\hline
\end{tabular}

In order to produce a final land suitability map for forest plantation, the preliminary land suitability map will be simplified based on expert and planner suggestions as well as on field checks.

The final step is to match the present forestland cover with land suitability levels to present possible land for new forest plantation. The general process for the land suitability assessment for development of forest plantation is shown in Fig. 7.2. 


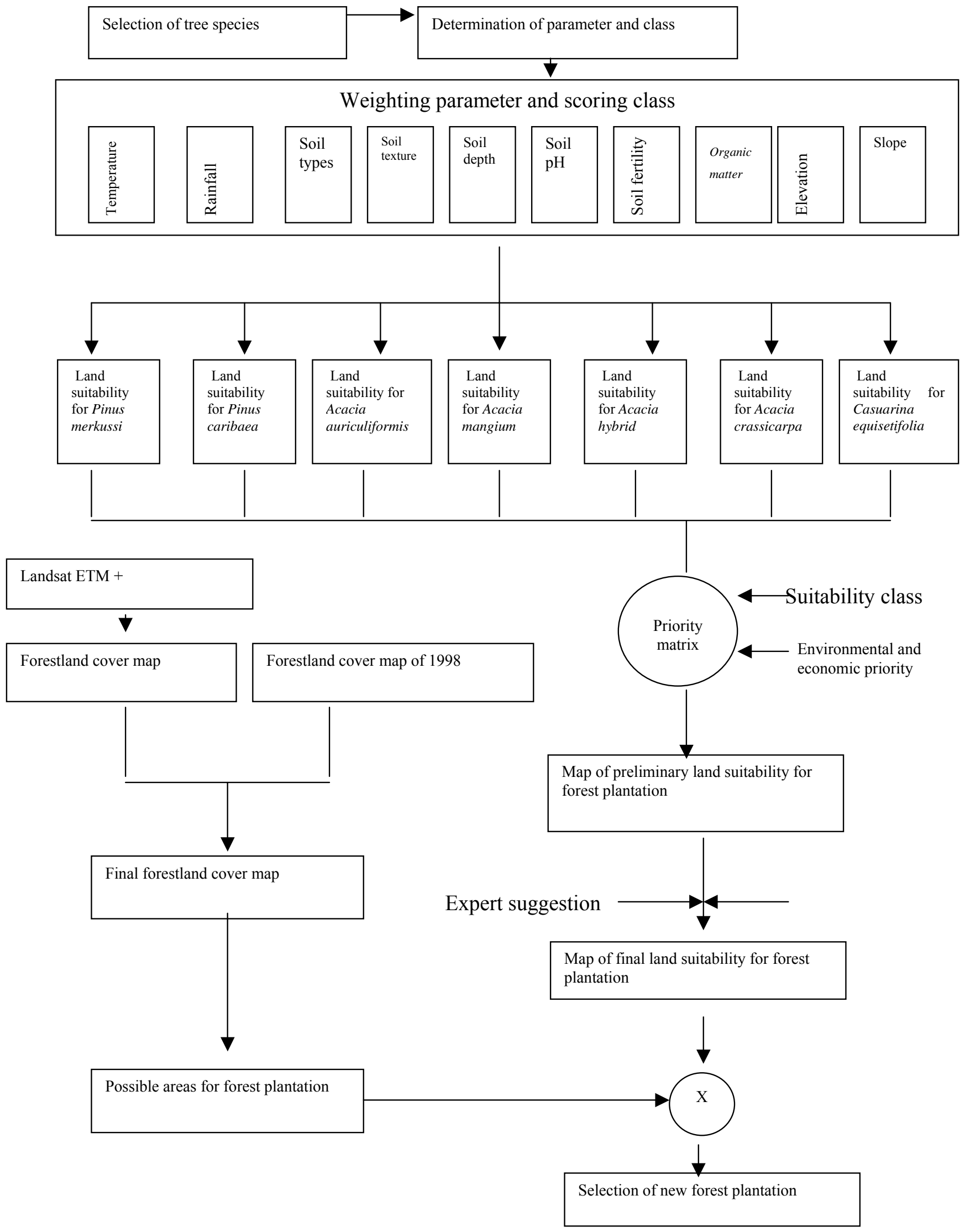

Figure 7.2: Process steps of land suitability analysis for forest plantation 


\subsection{Results and discussion}

\subsubsection{Provisional land suitability assessment}

\subsubsection{Physical land suitability assessment}

In consideration of current environmental conditions, it is necessary to use information for physical land suitability assessment at first. This assessment provides the overall current condition of forestland, which is related to the limitation and requirements of the forest plantation. The land suitability assessment was done for each tree species based on comparison of tree requirements with the current ecological environment.

\subsection{Assessment of land suitability for two Pine species}

The current ecological environment expresses the potential physical productivity of forestland. The suitability class was created from Weighted Linear Combination method based on climatic condition (mean annual temperature, mean annual rainfall), topographic condition (elevation and slope) and soil properties (soil types, soil depth, soil texture, soil $\mathrm{pH}$, organic matter and soil fertility). Table 7.9 below shows the physical land suitability of the study area for two forestry species, namely resin pine (Pinus merkussi) and caribe pine (P. caribaea). The suitability for Pinus merkussi and P. caribaea are also presented in Fig. 7.3 and 7.4, respectively. The study area was mostly assessed as the moderately suitable class (S2) with an area of 296,706.0 ha (58.7 \%) for Pinus merkussi and 235,512.2 ha (46.6\%) for P. caribaea, while the highly suitable class (S1) is determined as the smallest area for two pines. Pinus merkussi is found only on $3.8 \%$ and P. caribaea on $8.5 \%$ of the entire area

Table 7.9: Land suitability class for two selected pine species

\begin{tabular}{|l|c|c|c|c|}
\hline \multirow{2}{*}{ Suitability class } & \multicolumn{2}{|c|}{$\begin{array}{c}\text { Pinus } \\
\text { merkussi }\end{array}$} & \multicolumn{2}{c|}{$\begin{array}{c}\text { Pinus } \\
\text { caribaea }\end{array}$} \\
\cline { 2 - 5 } & Area (ha) & \% & Area (ha) & \% \\
\hline Highly suitable (S1) & $19,100.3$ & 3.8 & $42,991.3$ & 8.5 \\
\hline Moderately suitable (S2) & $296,706.0$ & 58.7 & $235,512.2$ & 46.6 \\
\hline Marginally suitable (S3) & $27,052.0$ & 5.3 & $64,281.8$ & 12.7 \\
\hline Not suitable (N) & $23,033.1$ & 4.6 & $23,106.1$ & 4.6 \\
\hline Other land & $139,448.0$ & 27.6 & $139,448.0$ & 27.6 \\
\hline Total area & $\mathbf{5 0 5 , 3 3 9 . 4}$ & $\mathbf{1 0 0 . 0}$ & $\mathbf{5 0 5 , 3 3 9 . 4}$ & $\mathbf{1 0 0 . 0}$ \\
\hline
\end{tabular}

The highly suitable location for Pinus merkussi plantation was mainly located close to the open shrub. Soil characteristic of highly suitable class was mostly sandy loam on soil reaction was acidic ( $\mathrm{pH} 4$ to 5.5). The highly suitable location for Pinus caribaea plantation was mainly found close to the gentle slope and soil depth. Soil characteristic of highly suitable class was mostly sandy clay loam with deep to very deep soil depth and soil reaction was acidic (pH 4.5 to 5.5). 
The northeast part of the study area with most of inland sandy soil and coastal sandy soil was assessed as not suitable (N) for both Pinus merkussi and P. caribaea because of its coarse sandy texture and moving sandy dunes. 


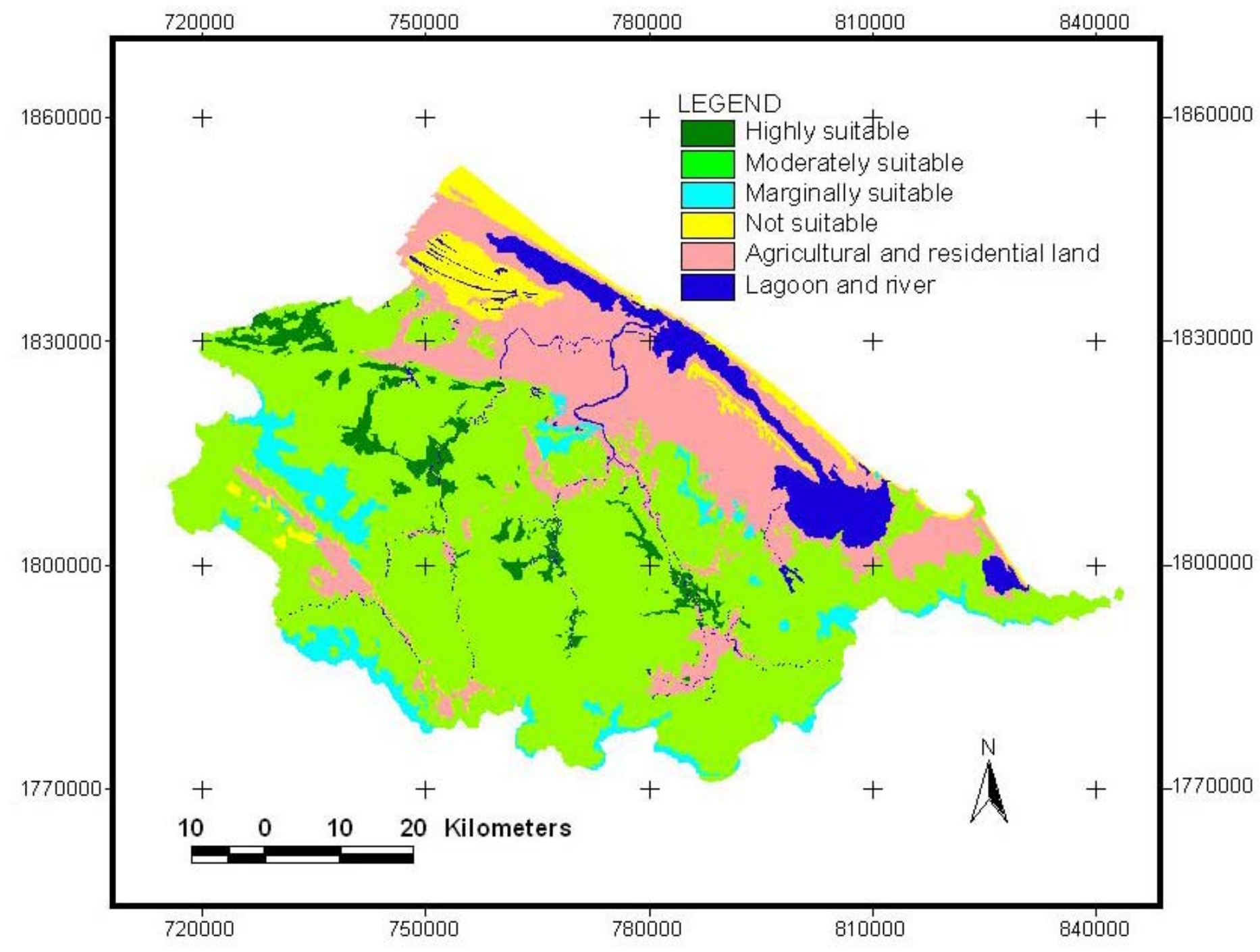

Figure 7.3: Physical land suitability for growing Pinus merkussi 


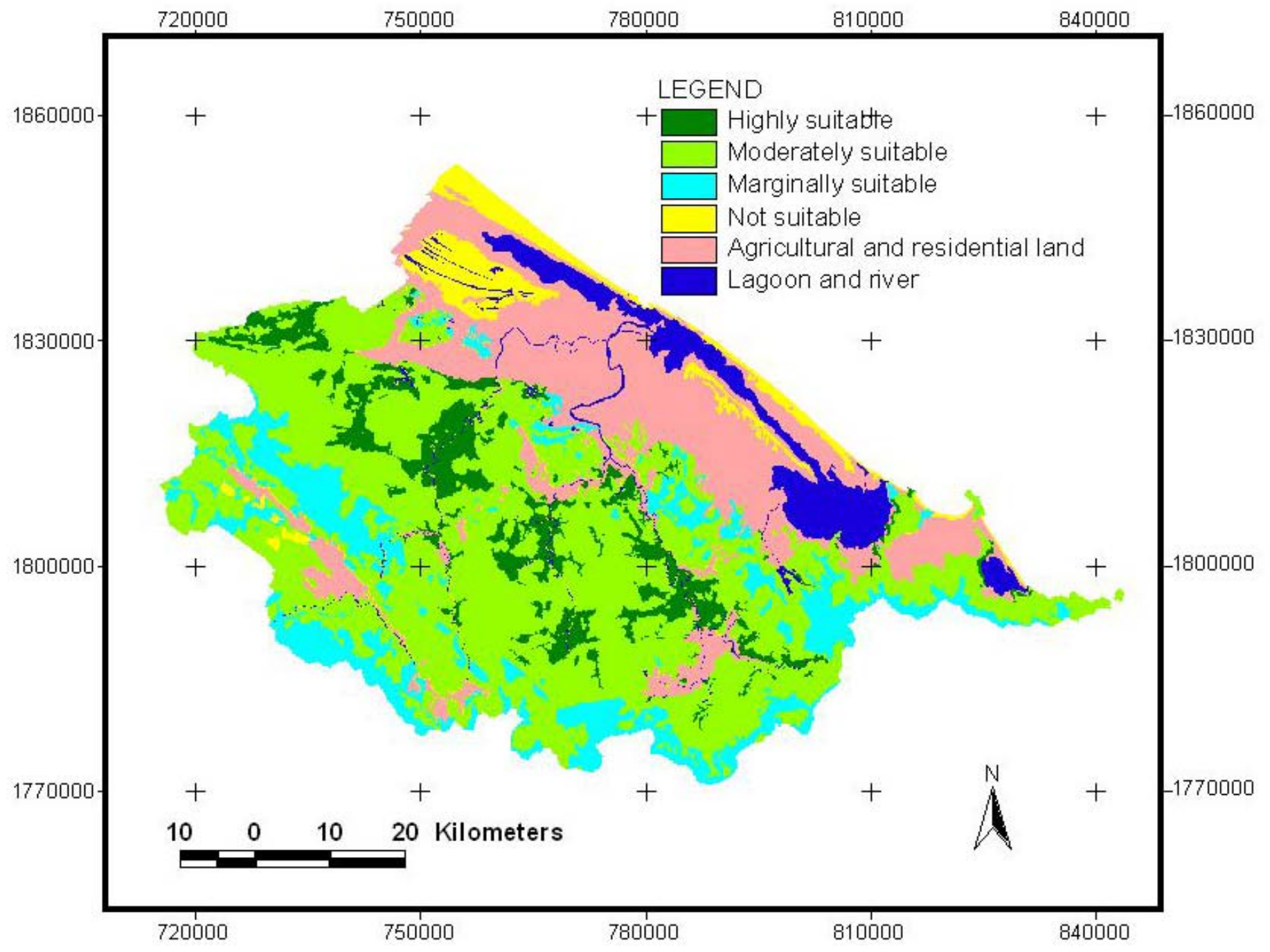

Figure 7.4: Physical land suitability for growing Pinus caribaea 


\subsection{Assessment of land suitability for four Acacia species}

Table 7.10 and Fig 7.5, 7.6, 7.7 and 7.8 show the physical land suitability of the study area for four selected Acacia species. Table 7.10 shows that there is not much difference between the suitability of the four Acacia species varieties studied. This can be explained by the fact that large parts of the study area have some limitations for forest plantation, notably very shallow layer, steep and very steep soils in the mountains and acid sandy soils and very poor soil fertility in the coastal zone. Also remarkable is the fact that there is not much difference the overall suitability for Acacia auriculiformis and A. hybrid.

From Table 7.10, it was found that Acacia crassicarpa is mostly suitability tree crop where 65.3 $\%$ of the entire area is highly suitable and moderately suitable, followed by A. auriculiformis and A. hybrid with $64.6 \%$ highly suitable and moderately suitable, while $6.7 \%$ of the area is highly suitable and $53.2 \%$ is moderately suitable for A. mangium. It is shown that there is very little land which has been classified as not suitable (about $0.2 \%$ of the whole province) for four Acacia species because of very shallow and stony soils.

The area of marginally suitable land is about $7.6 \%$ of the total for both Acacia auriculiformis and A. hybrid, $12.2 \%$ for Acacia mangium and $6.9 \%$ for Acacia crassicarpa. The main reason why most of inland sandy soil and coastal sandy soil have been classified as only marginally suitable is because the soils are acid, coarse texture and very poor in nutrient.

Table 7.10: Land suitability class for four selected Acacia species

\begin{tabular}{|l|r|c|c|c|c|c|c|c|}
\hline \multirow{2}{*}{$\begin{array}{l}\text { Suitability } \\
\text { class }\end{array}$} & \multicolumn{2}{|c|}{$\begin{array}{c}\text { Acacia } \\
\text { auriculiformis }\end{array}$} & \multicolumn{2}{c|}{$\begin{array}{c}\text { Acacia } \\
\text { mangium }\end{array}$} & \multicolumn{2}{c|}{$\begin{array}{c}\text { Acacia } \\
\text { hybrid }\end{array}$} & \multicolumn{2}{c|}{$\begin{array}{c}\text { Acacia } \\
\text { crassicarpa }\end{array}$} \\
\cline { 2 - 9 } & Area (ha) & $\mathbf{\%}$ & Area (ha) & $\mathbf{\%}$ & Area (ha) & $\mathbf{\%}$ & Area (ha) & \% \\
\hline $\begin{array}{l}\text { Highly } \\
\text { suitable }\end{array}$ & $27,098.2$ & 5.4 & $33,981.7$ & 6.7 & $27,098.2$ & 5.4 & $21,390.0$ & 4.2 \\
\hline $\begin{array}{l}\text { Moderately } \\
\text { suitable }\end{array}$ & $299,425.6$ & 59.2 & $268,812.2$ & 53.2 & $299,417.1$ & 59.2 & $308,641.1$ & 61.1 \\
\hline $\begin{array}{l}\text { Marginally } \\
\text { suitable }\end{array}$ & $38,165.1$ & 7.6 & $61,895.0$ & 12.2 & $38,165.1$ & 7.6 & $34,645.5$ & 6.9 \\
\hline Not suitable & $1,202.5$ & 0.2 & $1,202.5$ & 0.2 & $1,211.0$ & 0.2 & $1,214.8$ & 0.2 \\
\hline Other land & $139,448.0$ & 27.6 & $139,448.0$ & 27.6 & $139,448.0$ & 27.6 & $139,448.0$ & 27.6 \\
\hline Total area & $\mathbf{5 0 5 , 3 3 9 . 4}$ & $\mathbf{1 0 0 . 0}$ & $\mathbf{5 0 5 , 3 3 9 . 4}$ & $\mathbf{1 0 0 . 0}$ & $\mathbf{5 0 5 , 3 3 9 . 4}$ & $\mathbf{1 0 0 . 0}$ & $\mathbf{5 0 5 , 3 3 9 . 4}$ & $\mathbf{1 0 0 . 0}$ \\
\hline
\end{tabular}

The location of highly suitable and not suitable areas for the four Acacia species practically overlapped in the hilly southern part of the province. Most of the highly suitable lands are located in the Namdong district and not suitable lands are situated in the Aluoi district. The moderately suitable for A. crassicarpa was distributed in the marginally suitable land for three Acacias of A. auriculiformis, A. mangium and A. hybrid. For instance, the low lands in inland sandy soils were assessed as moderately suitable for A. crassicarpa. 


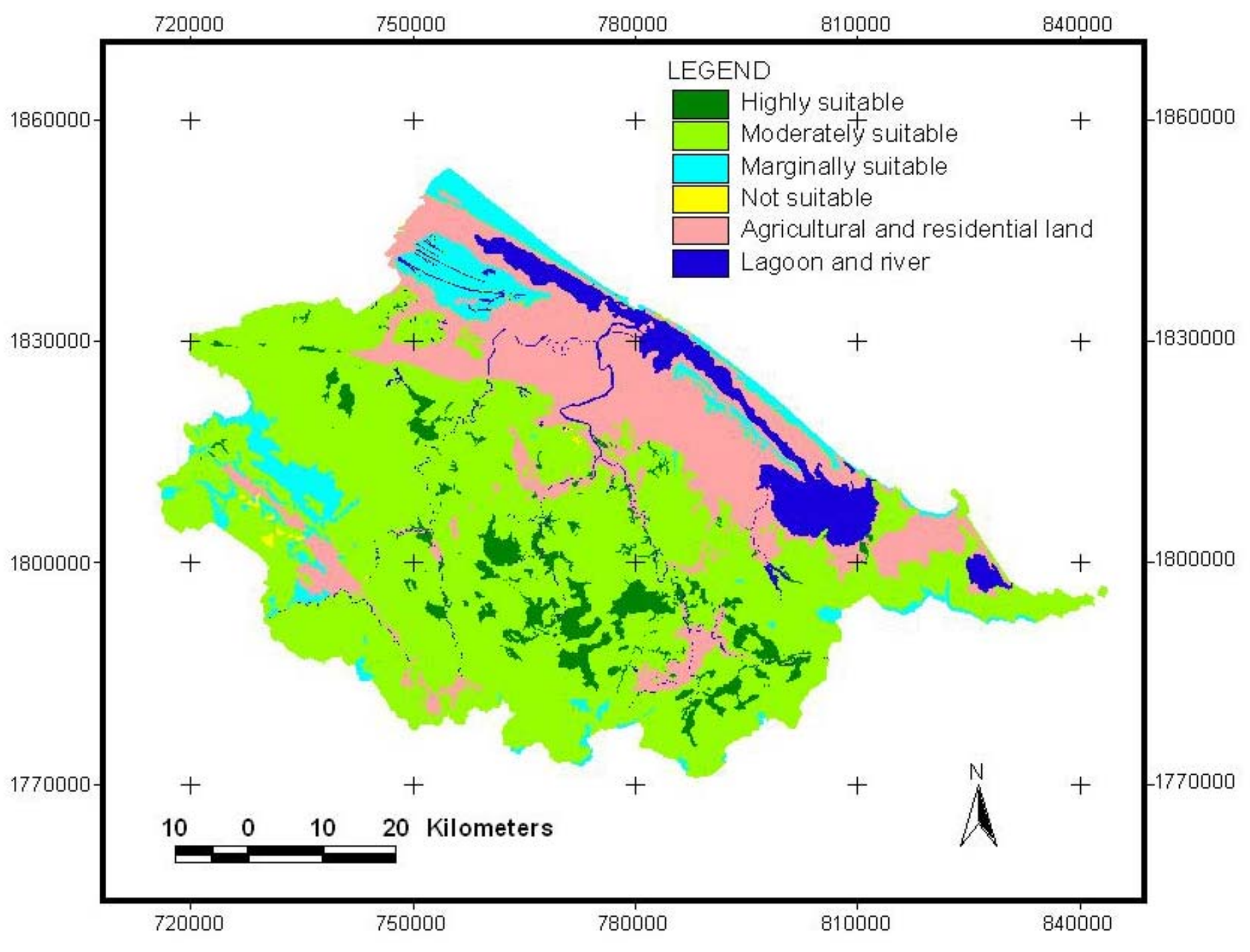

Figure 7.5: Physical land suitability for growing Acacia auriculiformis 


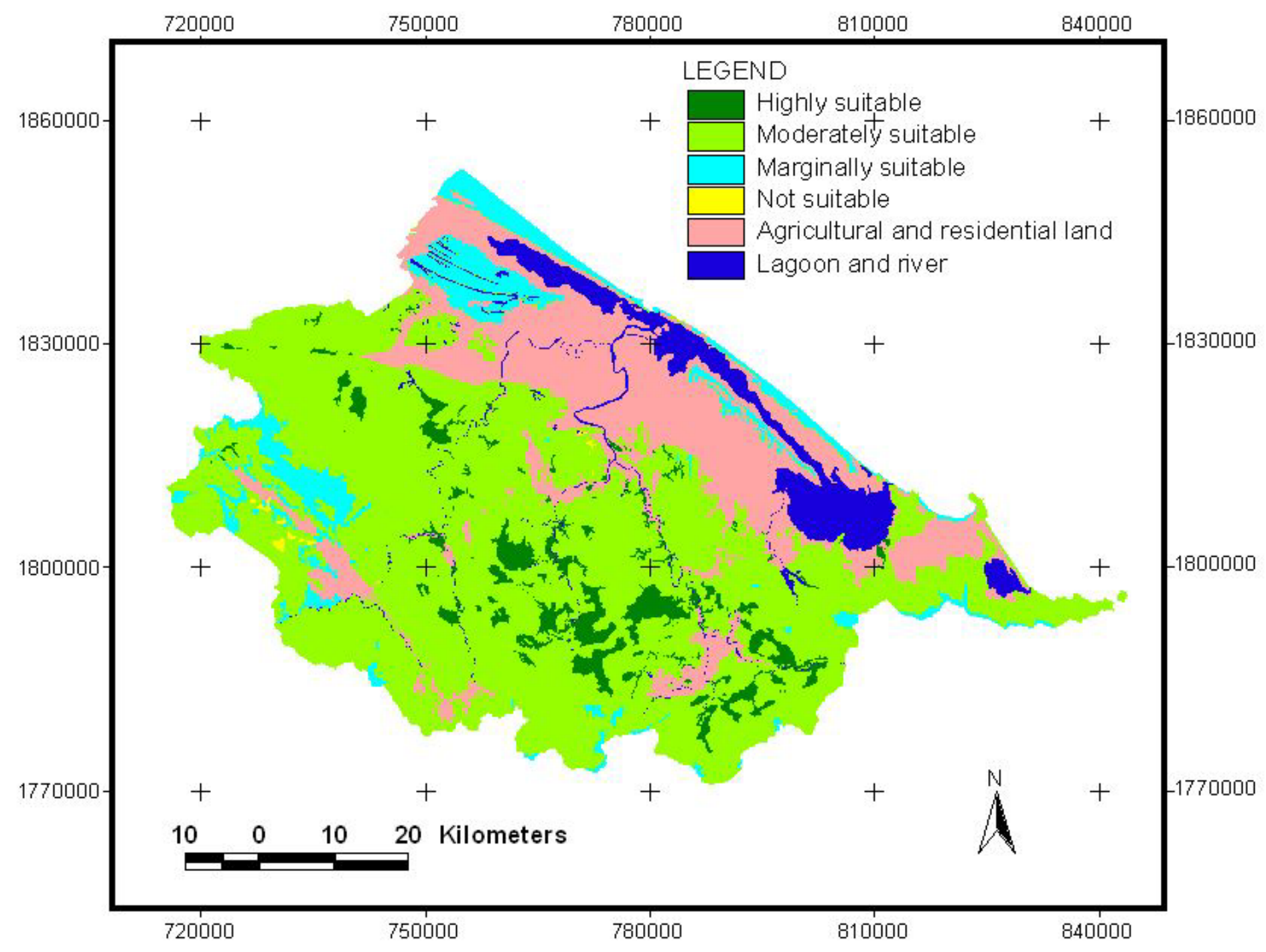

Figure 7.6: Physical land suitability for growing Acacia mangium 


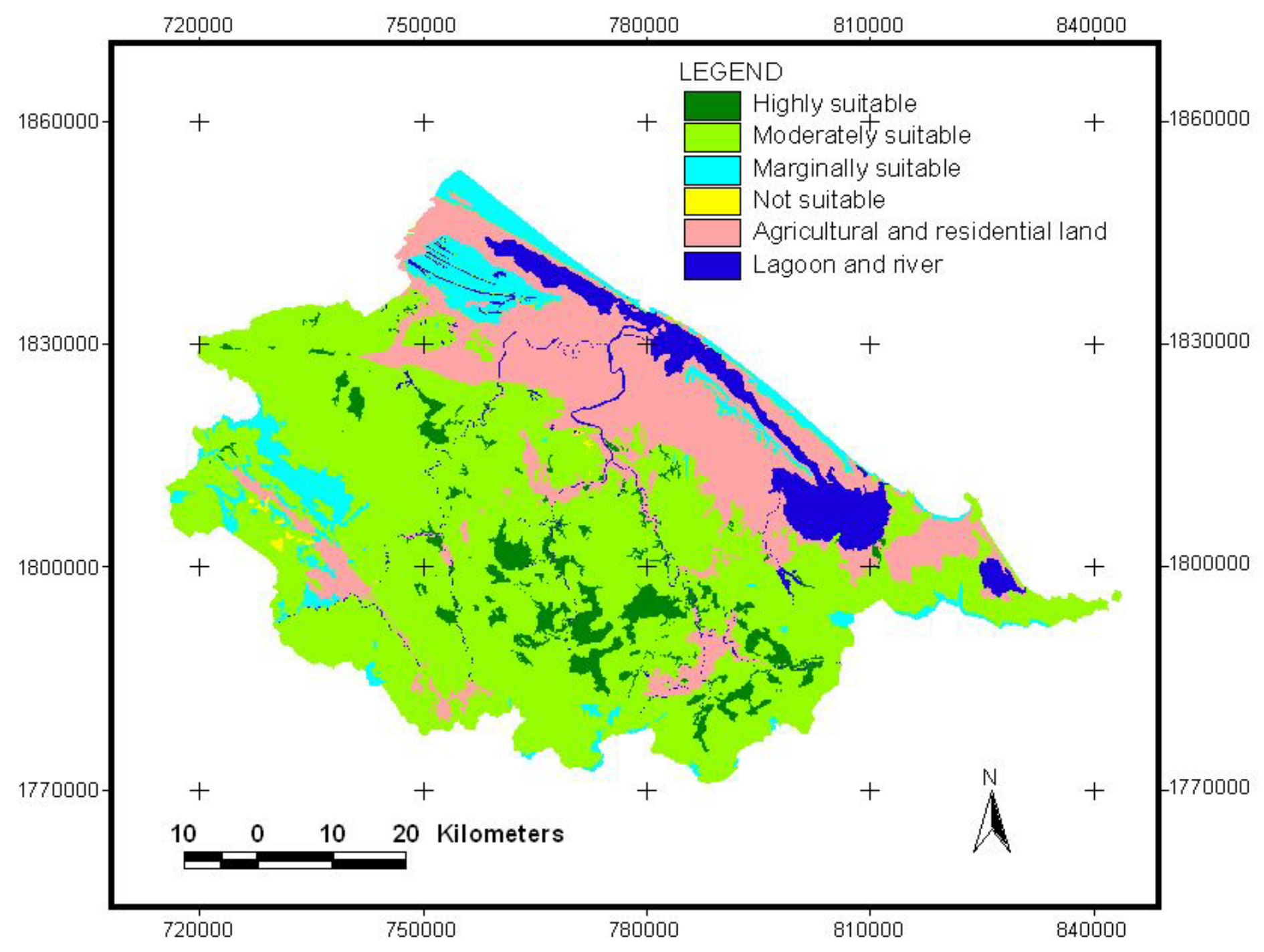

Figure 7.7: Physical land suitability for growing Acacia hybrid 


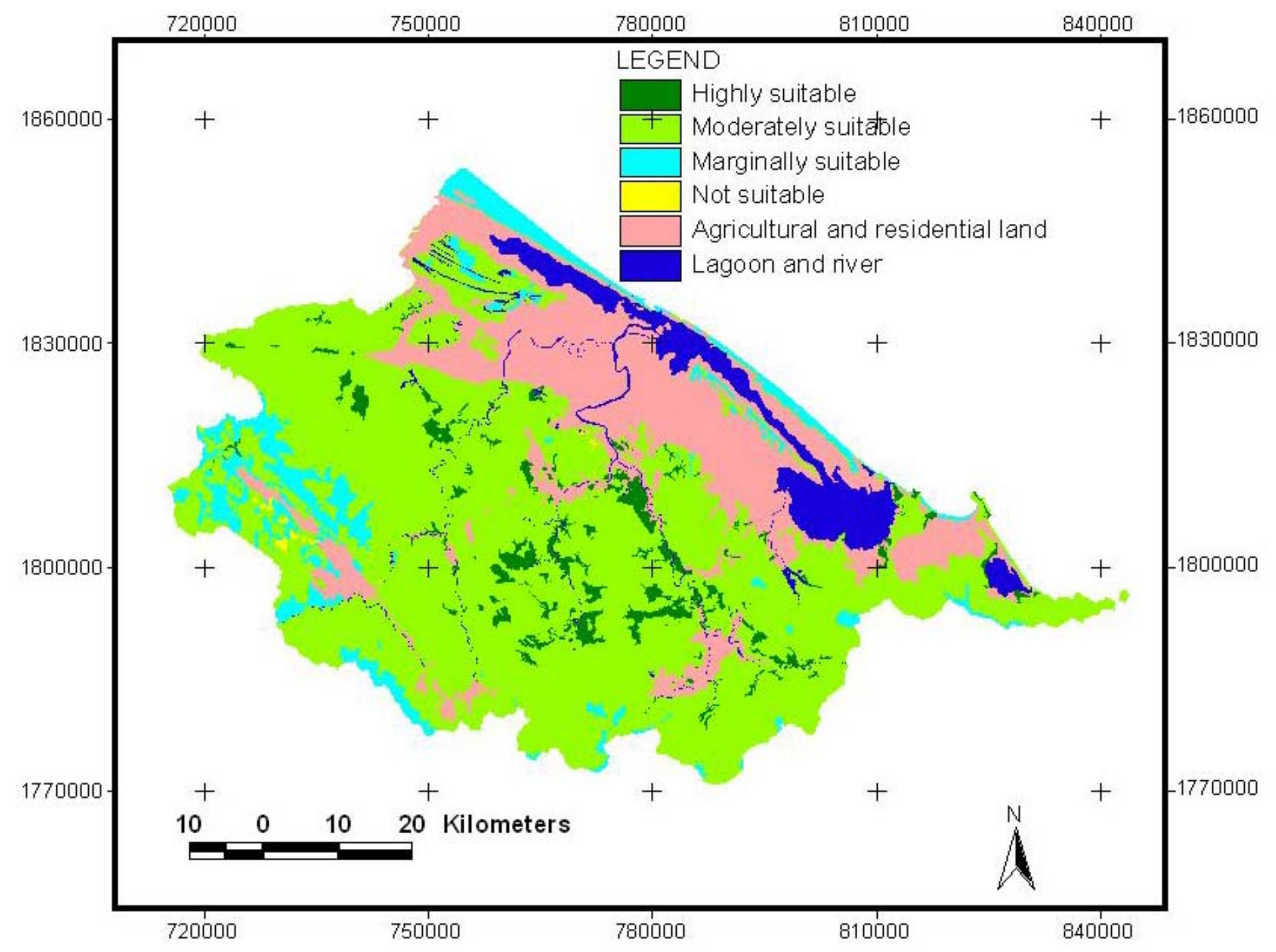

Figure 7.8: Physical land suitability for growing Acacia crassicarpa 


\subsection{Assessment of land suitability for Casuarinas species}

As discussed earlier, the weighted linear combination method has also been used to assess physical land suitability for Casuarina equisetifolia. The result showed that about $72.2 \%$ of the entire area is potentially suitable to grow Casuarina equisetifolia, whereas $0.2 \%$ is not. The land potential suitability is distributed as follows: $1.6 \%$ is highly suitable, $54.3 \%$ is moderately suitable and $16.3 \%$ is marginally suitable (Table 7.11).

Table 7.11: Land suitability class for Casuarinas species

\begin{tabular}{|l|r|c|}
\hline Suitability class & \multicolumn{1}{|c|}{ Area in ha } & Percentage of total area \\
\hline Highly suitable (S1) & $8,086.5$ & 1.6 \\
\hline Moderately suitable (S2) & $274,309.9$ & 54.3 \\
\hline Marginally suitable (S3) & $82,285.4$ & 16.3 \\
\hline Not suitable (N) & $1,209.6$ & 0.2 \\
\hline Other land & $139,448.0$ & 27.6 \\
\hline \multicolumn{1}{|c|}{ Total area } & $\mathbf{5 0 5 , 3 3 9 . 4}$ & $\mathbf{1 0 0 . 0}$ \\
\hline
\end{tabular}

The most suitable location for Casuarinas trees is in flat areas with elevation lower than $200 \mathrm{~m}$ above sea level. The high adaptability of this tree is related to the low requirement of the species. The soil characteristics of highly suitable class were mostly loamy sand and the soil $\mathrm{pH}$ was also slightly acid.

In coastal sandy soil the predominant lands are not suitable for almost all tree crops, but having medium value for Casuarinas. The coastal and the low hill lands of the study area are assessed as moderately suitable. Most of the highly mountainous and inland sandy areas were ranked as marginally suitable because of high topographical location, steep slopes and very low soil $\mathrm{pH}$. The land with very thin layer and rocky mountains were considered as not potentially suitable to grow Casuarina equisetifolia because of problems with soil depth of less than $30 \mathrm{~cm}$ (Fig.7.9). 


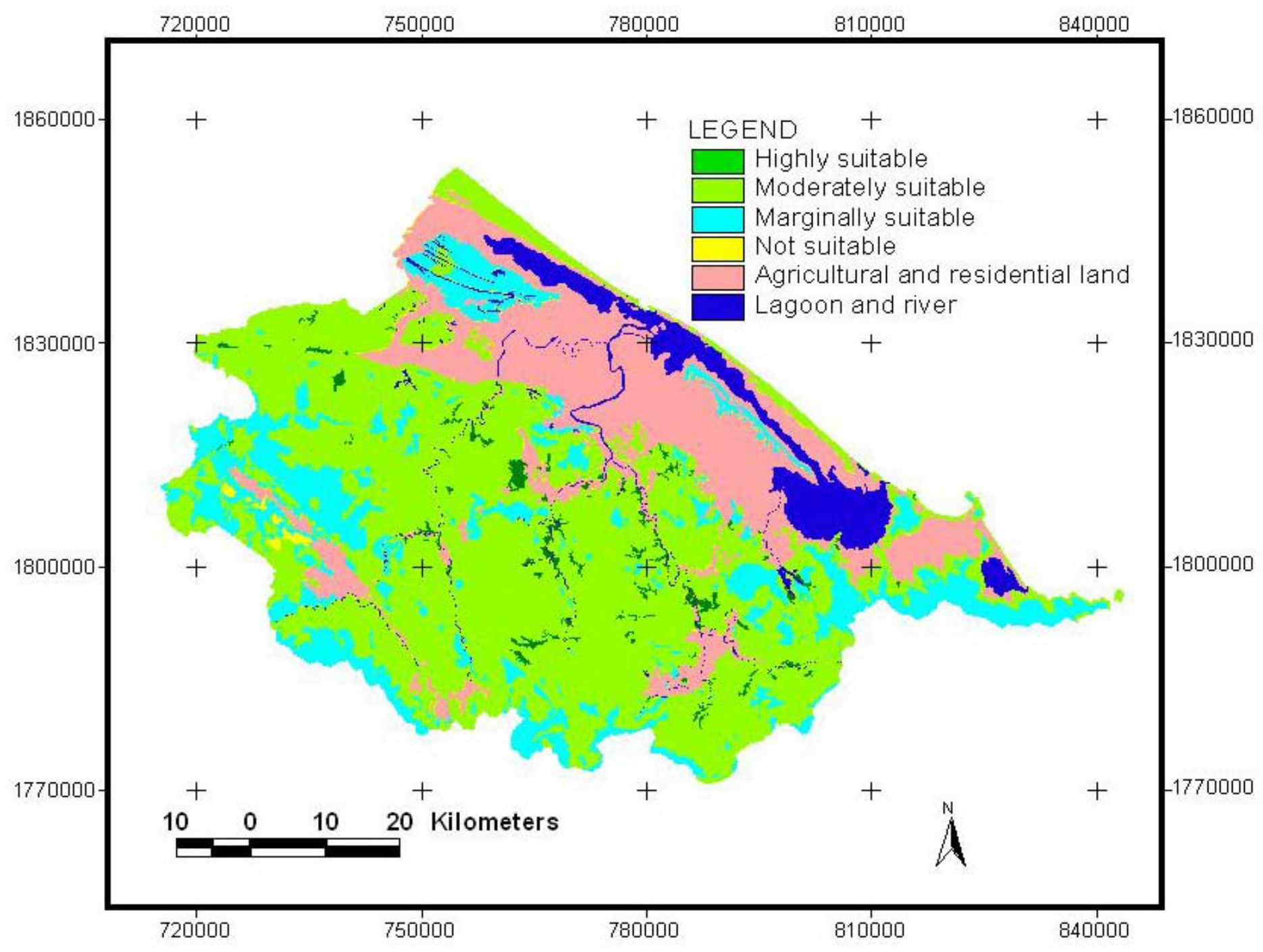

Figure 7.9: Physical land suitability for growing Casuarina equisetifolia 


\subsubsection{Assessment of land suitability for economic forestry (production forest)}

The land suitability classes for economic forestry were determined by considering the score distribution based on economic analysis. The score is ranked from 1 to 100 (points), the higher the score is the more significant it is. In order to decide the score of each class for each selected tree species, we also considered an averaging of different decision makers ranking from interviewing the local people: Highly suitable (75-100), moderately suitable (50-75), marginally suitable (25-50) and not suitable $(<25)$. The location of land suitability classes was shown in Fig. 7.10 .

We have selected four Acacia species for the development of forest plantation. Acacia hybrid, A. auriculiformis and A. mangium have been considered a more important economic value and they are assessed as highly suitable for this purpose because they are fast growing trees and are the most appreciated species in wood production. A. hybrid often grows faster than its parent species (A. auriculiformis and A. mangium) and it often produces wood with high utility value, making it economically more feasible. Acacia hybrid has a growth rate that is almost double of those of its parent species. In Thua Thien Hue province, the yielded differentials vary across different site condition but on average, A. hybrid produces an additional 9-12 cubic metres of wood per hectare each year. A. auriculiformis and A. mangium have a mean annual increment (MAI) of 11 - $14 \mathrm{~m}^{3} /$ ha/year respectively while $A$. hybrid achieves $23 \mathrm{~m}^{3} /$ ha/year under similar growing conditions. In the southern Vietnam, the growth rate of A. hybrid has achieved over 30 $\mathrm{m}^{3} /$ ha/year. A faster growth rate means that $A$. hybrid can be harvested 2 years earlier than its parent species. The optimal rotation of $A$. hybrid for wood production is 5 years and 6-7 years for A. auriculiformis and A. mangium. In addition, according to Le Dinh Kha 2001, Acacia hybrid produces wood of good quality for making paper. A. hybrid generally outperform their parent species in terms of pulping quality. The pulp yield of $A$. hybrid is also superior to that of its parent species. Acacia hybrid has an average pulp productivity of $232 \mathrm{~kg} / \mathrm{m}^{3}$ of wood, while the productivity of $A$. mangium is $195 \mathrm{~kg} / \mathrm{m}^{3}$ and $A$. auriculiformis is $223 \mathrm{~kg} / \mathrm{m}^{3}$. Moreover, on average, production costs and returns of Acacia hybrid are almost twice as profitable as its parent species. The hybrid is estimated to return a net present value of USD 894 per hectare over 5 years, while the parent acacias return USD 460 per hectare over 7 years (Martin van Bueren, 2004). Therefore, the local people have selected three of these acacia trees for production forest, of which A. A. hybrid played a most important role in economic forestry, followed by $A$. auriculiformis and A. mangium. Although A. crassicarpa also grows very fast, this tree species is assessed as marginally suitable for the purpose of economy because of its bad wood quality. 
P. caribaea also played an important role in economic forestry and is classified as highly suitable. Pinus merkussi and Casuarina equisetifolia are the next in importance for economic aim, as they are assessed as moderately suitable for economic forestry. Pinus merkussi and P.caribaea are used for both the production of paper and resin. The resin can be harvested from 15 years onward. The resin constitutes of one of the principle sources of income. Casuarina equisetifolia is used for fuel wood. This tree as a fast -growing evergreen timber cannot produce durable timbers but is highly appreciated by local farmers because its wood has a high heat content and burns slowly. Casuarinas fuel wood in great demand on local markets along the coast. Moreover, this tree is suitable for most of the coastal sandy areas of the study area. It should be an important source for generating the incomes of the local people.

Based on economic and physical land suitability analysis, the land potential suitability for economic purpose is shown (wood chip, pulp wood, fuel wood, timber and resin). Table 7.12 and Fig. 7.10 present the economic land suitability of the study area for seven selected tree species. As results it can be noticed that two Acacia species of Acacia hybrid and A. auriculiformis and one pine of $P$. caribaea were assessed as highly suitable for economic forestry with an area of $315,977.5$ ha or $62.5 \%$ of the entire area, of which $256,743.0$ ha (50.8\%) belongs Acacia hybrid, 49,606.4 ha (9.8\%) belongs to A. auriculiformis and 9,628.1 ha (1.9\%) belongs to Pinus caribaea.

Aacia mangium, Pinus merkussi, and Casuarina equisetifolia are assessed as moderately suitable for $7.1 \%$ of the entire area, of which Aacia mangium is $2 \%$; P. merkussi is $2.8 \%$ P. caribaea and $2.3 \%$ is Casuarina equisetifolia, while Acacia crassicarpa is considered as marginally suitable with an area of 13,353.4 ha $(2.7 \%)$. The unsuitable area for economic purpose for seven selected tree species occupies about $0.1 \%$ of the entire area and is distributed in stony soil because soil depth is very shallow (less than $30 \mathrm{~cm}$ ) here.

Table 7.12: Land suitability for economic forestry (production forest)

\begin{tabular}{|l|r|c|}
\hline \multicolumn{1}{|c|}{ Name } & Area in ha & Percentage of total area \\
\hline Pinus merkussi & $14,371.6$ & 2.8 \\
\hline Pinus caribaea & $9,628.1$ & 1.9 \\
\hline Acacia auriculiformis & $49,606.4$ & 9.8 \\
\hline Aacia mangium & $9,966.7$ & 2.0 \\
\hline Acacia hybrid & $256,743.0$ & 50.8 \\
\hline Acacia crassicarpa & $13,353.4$ & 2.7 \\
\hline Casuarina equisetifolia & $11,573.1$ & 2.3 \\
\hline Not suitable & 649.1 & 0.1 \\
\hline Other land & $139,448.0$ & 27.6 \\
\hline Total area & $\mathbf{5 0 5 , 3 3 9 . 4}$ & $\mathbf{1 0 0 . 0}$ \\
\hline
\end{tabular}




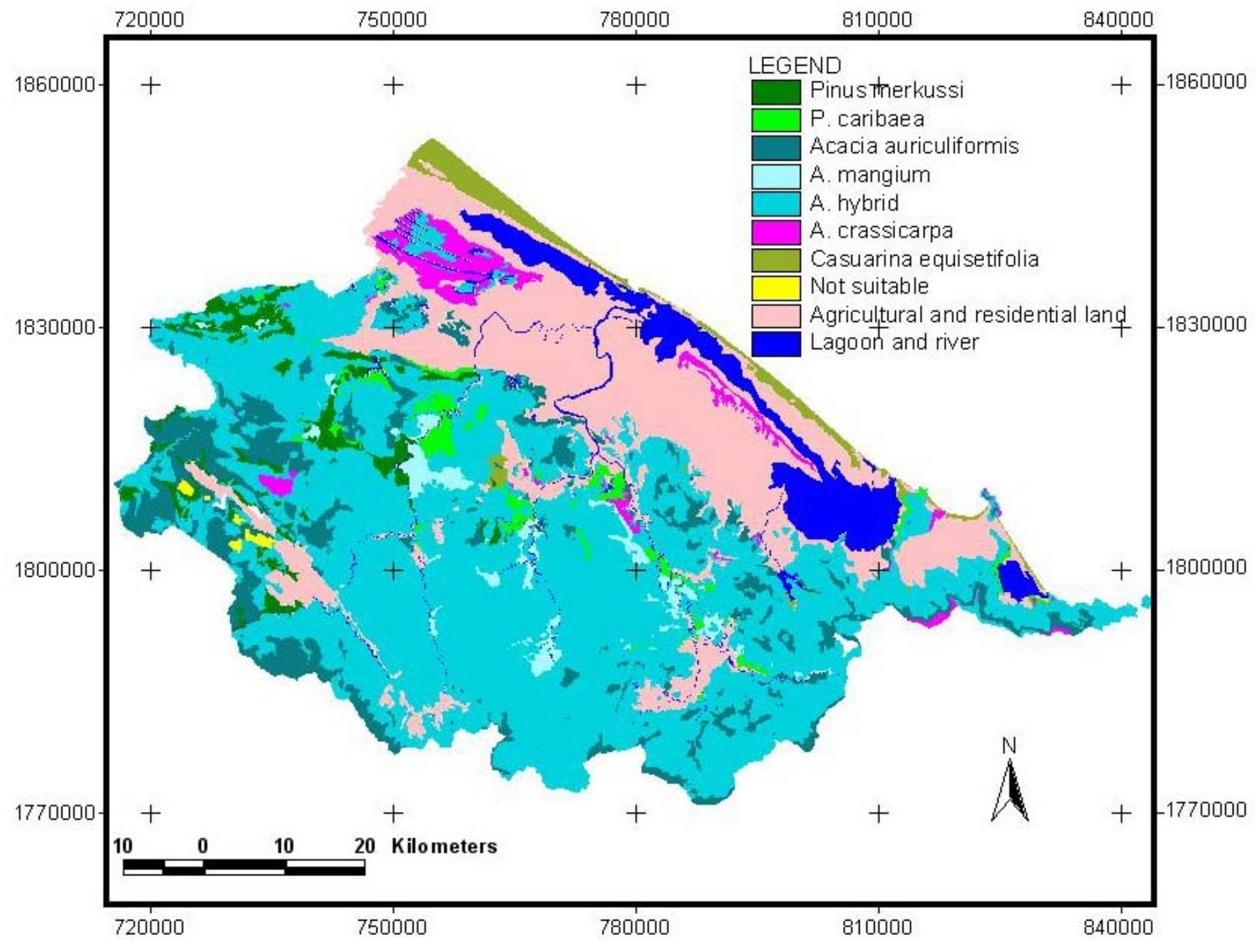

Figure 7.10: Land suitability for economic forestry (production forest) 


\subsubsection{Assessment of land suitability for environmental forestry (protection forest)}

Because of central Vietnam's geography, Thua Thien Hue is particularly prone to natural calamities and therefore needs to pay attention to environment protection, especially in coastal sandy, inland sandy and watershed area. Storms, flood, soil erosion, droughts and intrusion are frequent events in Thua Thien Hue province. Deforestation and forest degradation in the last decade have changed the climate of central Vietnam and have caused negative impacts such as heavy floods in 1991, 1999 and 2007 killed hundreds of people and caused an estimated USD hundreds of million worth of damage in central provinces of Vietnam. So the Ministry of Agriculture and Rural Development (2001) stated that "Environmental protection is the most important function of forests, especially to mitigate natural disaster". The link between forest cover and downstream flooding is questioned by FAO (2005). Therefore the land suitability for selected tree species should not only be based on physical land suitability (growth potential) and economic suitability but also on environmental concerns.

The land suitability classes for environmental forestry were also determined by considering the score distribution based on environmental analysis, which is similar to the land suitability assessment for economic forestry.

Four Acacia species of Acacia hybrid, A. auriculiformis, A. mangium and A. crassicarpa are native to Australia and Papua New Guine. These tree species can be considered for reclamation work, they can grow under the most difficult condition, especially eroded soil. They grow fast, have a large root system and the ability to fix nitrogen and they are adapted to rehabilitate degraded land. The site condition often is dry with friable soil that washes away during heavy thunder storms which are common in the tropics. In Vietnam they were planted to meet both the demands of fuel wood, pulpwood and improvement of soil conditions. Among them Acacia hybrid also has markedly better fixing ability than its parent species. According to Le Dinh Kha 2001, Acacia hybrid creates a more favourable environment for many other soil microorganisms, and thus improves the physical and chemical soil properties. In addition, the Acacia species plantations have the potential to provide several other environmental benefits. They have been used to allow agro-forestry to be practiced on steep land where previously cultivation would have caused excessive soil erosion and to stabilize hill slopes. The Acacia species plantations also play an important role in reducing greenhouse gases and are also expected to reduce the pressure on native forests as a source of industrial raw material. This will help to preserve the environmental integrity of native forests. However, they are not suitable as windbreaks because 
of the tendency of trees to snap in high winds. As discussed before, A. crassicarpa seems to be well adapted to conditions prevailing on poor and acid sandy soil, in particular on inland sandy soil of Thua Thien Hue, A. crassicarpa has scored a survival percentage of over $95 \%$ and thrived very well, at a rate two times better than other Acacias, while Acacia hybrid, and A. mangium grow best on more fertile sites with good drainage and very deep soil depth.

Pinus merkussi as a drought-tolerant tree, this species is one of the principal tree species planted on bare or bushy hills in Thua thien Hue province, having the function of protecting against erosion and land-deformation. Young trees are slowly growing during the first five years, later they are rather fast-growing. Compared to other tree species such as Acacia and Casuarinas species, Pinus merkussi has several physiological and morphological characteristics that may contribute to its ability to adapt to environment of acid, shallow and poor soil, in particular on thin layer soil of the study area. Pinus caribaea is native to central America and the Caribbean, and in comparison with $P$. merkussi, this species has better capacities of windbreak and prefers more fertile sites with good drainage. However, disadvantages of these two pine plantations are that burn easily in dry seasons.

Casuarina equisetifolia is suitable in the areas closed to the beach, as windbreaks and sandy dune fixation. In this situation it can protect the cultivated areas located in the small depression against the wind effects and prevent moving sandy dunes in coastal sandy soil. It is tolerant of very saline conditions, allowing good growth in slightly acid sandy soil. C. equisetifolia is important as a source of nitrogen, the fallen bark and leaves are important source of humus. It is a good species to use in the protective belt along the coast to help improving the local environment: it has strong impacts on maintaining the water table high enough to provide water for uses in agricultural production, and on keeping warmer temperature during the night in winter and on the lowering air temperature during hot day in summer. It is also a very good species to use in agro-forestry for its ability to improve the soil, in particular on coastal sandy soil. All Acacia species grow faster than Casuarinas, but under the moving sandy conditions they are easy to destroy by moving sand grain and their root system are not strong and not as well spread as those of Casuarinas. Therefore, different Acacia species are unsuitable for the purpose fixation of moving sandy dunes and crop protection in the windiest zones.

As mentioned above, from a environmental point of view, in hilly and mountainous areas, we considered the seven tree species in this order of importance: Acacia hybrid, A. crassicarpa, A. auriculiformis, and A. mangium have been considered as more importance for purpose of soil 
improvement, erosion prevention and other environmental purpose, followed by Casuarina equisetifolia, then Pinus caribaea, and P. merkussi.

In contrast, in inland sandy areas, four Acacia tree species have been considered in order of importance as follows: A. crassicarpa has been considered as most important for the purpose of soil improvement, erosion prevention, A. auriculiformis is next important, then Acacia hybrid and A. mangium. In the coastal sandy area, Casuarina equisetifolia has been assessed as most important for the purpose of sandy soil fixation and windbreaks.

Table 7.13 and Fig.7.11 below show the land suitability of selected tree species for environmental forestry. The results of land suitability assessment for environmental forestry showed four Acacia species of Acacia auriculiformis, A. hybrid, A. mangium, and A. crassicarpa were assessed as highly suitable class. Among Acacias, A. hybrid is the most suitable species with an area of $254,872.3$ ha or $50.5 \%$ of the total area, followed by A. crassicarpa with $11 \%$, while only $2.1 \%$ and $2.3 \%$ for A. auriculiformis and A. mangium.

Casuarina equisetifolia was considered as moderately suitable for $2 \%$ of the entire area, about $3.8 \%$ is marginally suitable for $P$. caribaea, and only $0.6 \%$ is for $P$. merkussi. The unsuitable area for environmental purpose for seven selected tree species is similar to the economic unsuitable area, about $0.1 \%$ of the entire area and was also distributed in Aluoi district.

Table 7.13: Land suitability for environmental forestry (protection forest)

\begin{tabular}{|l|r|c|}
\hline \multicolumn{1}{|c|}{ Name } & Area in ha & Percentage of total area \\
\hline Pinus merkussi & $2,880.7$ & 0.6 \\
\hline Pinus caribaea & $19,279.0$ & 3.8 \\
\hline Acacia auriculiformis & $10,662.0$ & 2.1 \\
\hline Aacia mangium & $11,650.6$ & 2.3 \\
\hline Acacia hybrid & $254,872.3$ & 50.5 \\
\hline Acacia crassicarpa & $55,823.6$ & 11.0 \\
\hline Casuarina equisetifolia & $10,074.1$ & 2.0 \\
\hline Not suitable & 649.1 & 0.1 \\
\hline Other land Total area & $139,448.0$ & 27.6 \\
\hline \multicolumn{2}{|c|}{$\quad \mathbf{5 0 5 , 3 3 9 . 4}$} & $\mathbf{1 0 0 . 0}$ \\
\hline
\end{tabular}




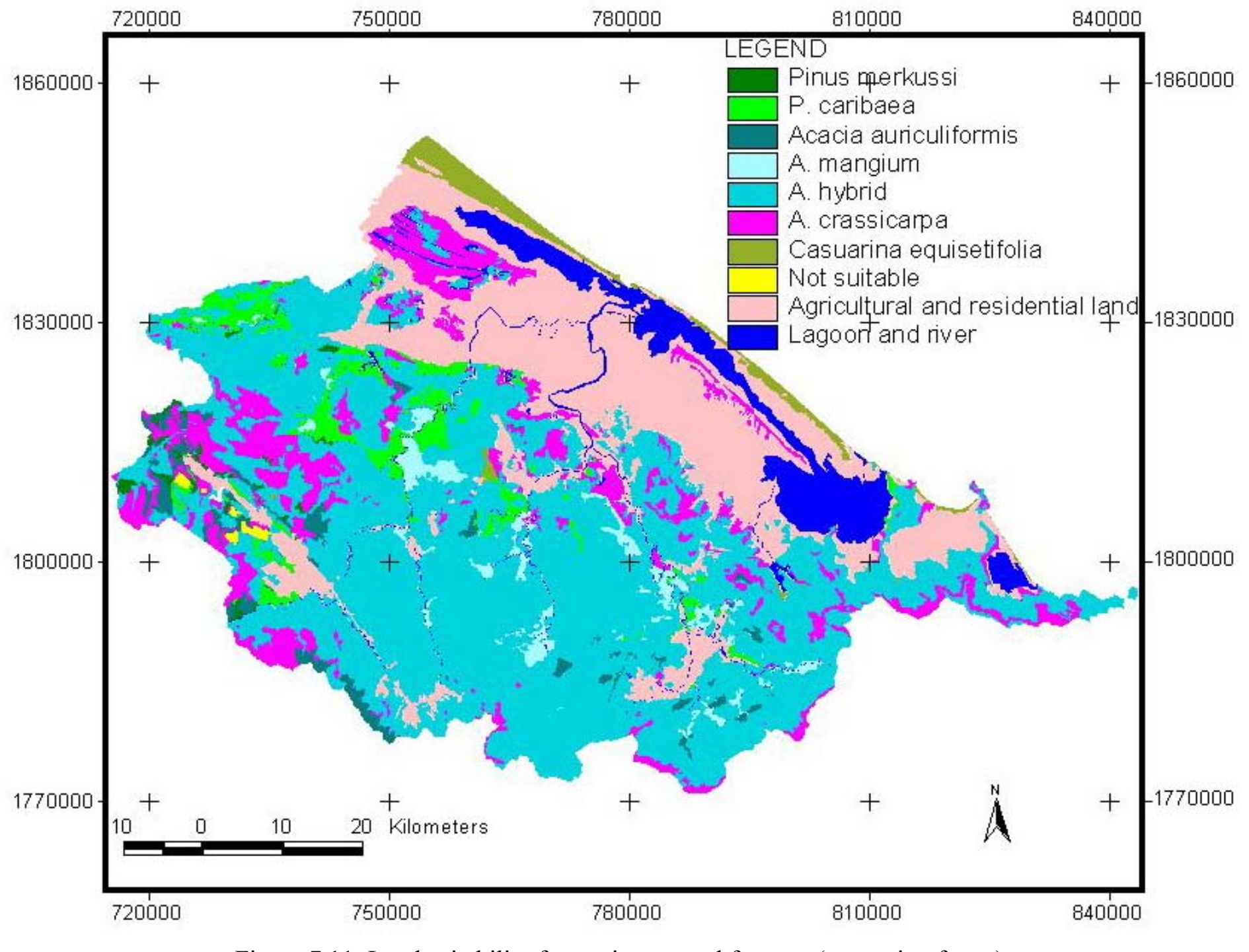

Figure 7.11: Land suitability for environmental forestry (protection forest) 


\subsubsection{Final land suitability classification}

To develop the final land suitability map for forest plantation, seven physical land suitability maps of selected tree species as mentioned above were created by a weighted linear combination method. The environmental land suitability map and the economic land suitability map were superimposed to derive a composite map (Fig.7.12). The boundaries of each tree species were determined based on the suitability class of the seven species, this means the highest suitability class will be the first priority. The environmental and economic suitability will be considered the next priority according to forest goals and management objective.

Table 7.14 below shows the final land suitability of the study area for development of forest plantation. About 649.1 ha or $0.1 \%$ of the entire area is not suitable for all seven tree crop varieties analyzed. On the other hand, analyzing the results for seven selected tree species, it can be noticed that Aacia hybrid is one of the most suitable species for the study area. It occupies $257,305.5$ ha or $50.9 \%$ of the total area, of which $13,224.9$ ha $(2.6 \%)$ is highly suitable, $172,799.7$ ha $(34.2 \%)$ is moderately suitable and 71,280.9 ha (14.1\%) is marginally suitable.

Acacia auriculiformis is the most plastic tree species. It can grow in a wide variety of soil including soils with sand or clay texture, salty soil and soils with $\mathrm{pH}$ ranging from 3 to 9.5 . It grows best in humid deep, medium texture and alluvial soil. About 49,782.2 ha or $9.9 \%$ of the total area was located in suitable areas, of which $42,099.3$ ha $(8.4 \%)$ belongs to moderately suitable and 7,682.9 ha (1.5\%) belongs to marginally suitable.

An area of 10,334.5 ha or $2.0 \%$ is suitable for Acacia mangium, most of the land areas are located in marginal suitability $(10,004.0$ ha or $1.9 \%)$, while only 330.5 ha $(0.1 \%)$ are moderately suitable.

Acacia crassicarpa is an important species for soil reclamation. This tree performs well, even on marginal and inland sandy lands where most other Acacia and forest tree either fail to grow or give poor performance. About $14,473.5$ ha or $2.9 \%$ of the total area is suitable for $A$. crassicarpa, of which most of the area $(10,376.1$ ha or $2.1 \%)$ is moderately suitable, $4,097.4$ ha $(0.8 \%)$ are distributed in marginal suitability. 


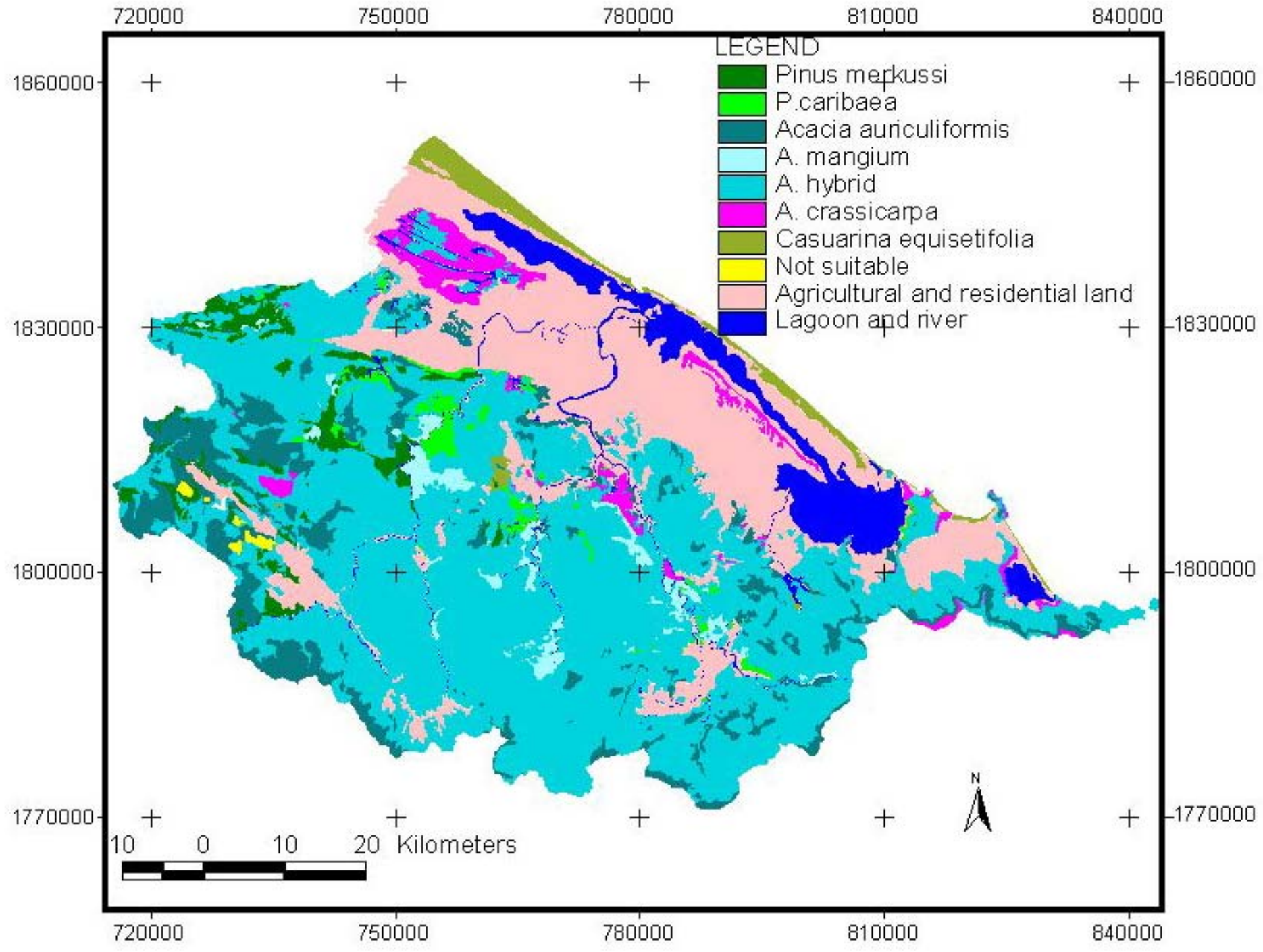

Figure 7.12: Final land suitability for forest plantation 
An area of $14,576.3$ or $2.9 \%$ of the total area belongs to Pinus merkussi, of which 5,011 ha (1 $\%)$ lies in moderately suitable areas and 9,565.3 ha (1.9\%) in marginally suitable areas.

An area of $7,818.6$ or $1.5 \%$ of the total area belongs to Pinus caribaea, most of land is located in marginally suitable areas and there is no area with in high and moderate suitability.

In the case of Casuarina equisetifolia, the suitable areas is $10,951.8$ ha or $2.2 \%$ of the total area. The land suitability is distributed as follows: Moderate suitability is 9,824.9 ha (1.9\%) and marginal suitability is $1,126.9$ ha $(0.3 \%)$.

Table 7.14: land suitability classification for selected forest tree species

\begin{tabular}{|c|c|c|}
\hline Name & Area in ha & Percentage of total area \\
\hline Pinus merkussi & $14,576.3$ & 2.9 \\
\hline Pinus caribaea & $7,818.6$ & 1.5 \\
\hline Acacia auriculiformis & $49,782.2$ & 9.9 \\
\hline Acacia mangium & $10,334.5$ & 2.0 \\
\hline Acacia hybrid & $257,305.5$ & 50.9 \\
\hline Acacia crassicarpa & $14,473.5$ & 2.9 \\
\hline Casuarina equisetifolia & $10,951.8$ & 2.2 \\
\hline Not suitable & 649.1 & 0.1 \\
\hline Other land & $139,448.0$ & 27.6 \\
\hline Total area & $505,339.4$ & 100.0 \\
\hline
\end{tabular}

\subsubsection{Selection of possible potential lands for new forest plantation (reforestation)}

The matching of current forestry land use with the land suitability map can support information for selecting sites of new forest plantation. Although, the distribution of seven selected tree species covers $72.3 \%$ of the entire area, most of them have already been occupied by forested areas, with $29.2 \%$ and $7.5 \%$ of the area of natural forest and forest plantation, respectively. These forested lands may not be changed easily in the future. The alternative way of changing land cover type for new forest plantation area might probably be in the area of non- forestlands and in a part of the unsuitable area of existing forest plantations. These types of land use consist of grasslands, bare lands, shrub lands and existing plantations of Eucalyptus.

To develop the land suitability map for new forest plantation, the final land suitability map of seven selected tree species was created basing on a combination of assessment of physical land suitability, environmental suitability and economic suitability, and existing forest and land cover map were superimposed to select the final sites of new forest plantation.

Figure 7.13 and Table 7.15 show the possible areas for expansion of new forest plantation including areas of natural forests, existing forest plantation and other land based on the forest 
and land cover in the year 2004 in which it was produced from Landsat ETM +. The results can be noticed that Acacia hybrid species occupy most of land area for development of new forest plantation. This species is suitable from moderate to high in low undulating hilly surface, while is marginally suitable in the flat area in inland sand area where the soil texture condition, one of the limiting factors, in addition to soil fertility is very poor and soil $\mathrm{pH}$ is very acid. The same results are also found for two Acacia species of A. mangium and A. auriculiformis.

Acacia crassicarpa is marginally suitable in most of the wet inland sandy area. This species presents moderate suitability on shrub land of the Huongthuy and the Aluoi district and a part of the dry inland sandy area.

Pinus merkussi and P. caribaea show suitability on non-forest area of Huongtra and Phongdien district. P. merkussi is found to be moderately suitable, while P. caribaea is marginally suitable. In inland sandy areas of the study area, soil types and its poor soil properties, probably are the main cause of these two pine species absence.

As previously stated, Casuarina equisetifolia is found to be from marginally to moderately suitable along coastal sandy soil, but it is not suitable in mountainous areas because of high elevation.

The total area of possible land for expansion of new forest plantation is $180,102.8$ ha $(35.6 \%$ of the total area), of which Pinus merkussi is $11,329.9$ ha $(2.2 \%)$, P. caribaea is 5,178.4 ha (1\%), Acacia auriculiformis is $24,893.5$ ha (4.9\%), A. mangium is $8,677.4$ ha (1.7\%), A. hybrid is $117,953.8$ ha $(23.3 \%)$, A. crassicarpa is 5,620.2 ha (1.1\%) and Casuarina equisetifolia is $6,449.6$ ha $(1.3 \%)$.

Table 7.15: The possible area for establishment of new forest plantation

\begin{tabular}{|l|l|r|c|}
\hline No & \multicolumn{1}{|c|}{ Name } & Area in ha & Percentage of total area \\
\hline \multirow{4}{*}{1} & New forest plantation & $180,102.8$ & 35.6 \\
\cline { 2 - 4 } & Pinus merkussi & $11,329.9$ & - \\
\cline { 2 - 4 } & Pinus caribaea & $5,178.4$ & - \\
\cline { 2 - 4 } & Acacia auriculiformis & $24,893.5$ & - \\
\cline { 2 - 4 } & Acacia mangium & $8,677.4$ & - \\
\cline { 2 - 4 } & Acacia hybrid & $117,953.8$ & - \\
\cline { 2 - 4 } & Acacia crassicarpa & $5,620.2$ & - \\
\cline { 2 - 4 } & Casuarina equisetifolia & $6,449.6$ & - \\
\hline 2 & Rocky land & $\underline{649.0}$ & 0.1 \\
\hline 3 & Dense natural forest & $\underline{11,800.7}$ & 7.1 \\
\hline 4 & Degraded natural forest & $\underline{37,840.2}$ & 22.1 \\
\hline 5 & Existing forest plantation & $\underline{139,448.0}$ & 7.5 \\
\hline 6 & Other land & $\mathbf{5 0 5 , 3 3 9 . 4}$ & $\mathbf{1 0 0 . 0}$ \\
\hline & Total area & & \\
\hline
\end{tabular}




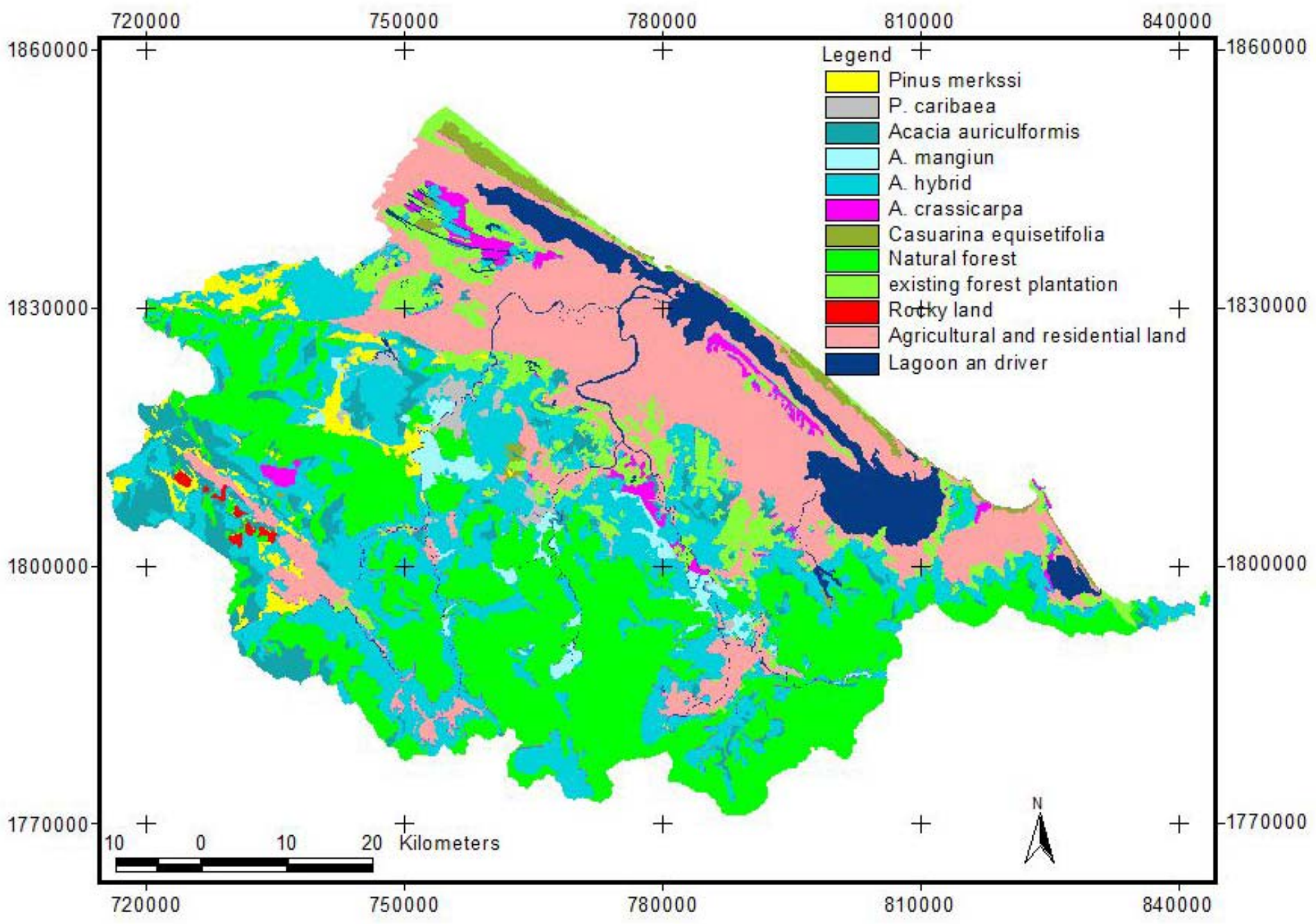

Figure 7.13: Possible potential land suitability for new forest plantation 


\subsection{Conclusion}

The Analytic Hierarchy Process (AHP) method was found to be a useful method to determine the weights. The method is also endowed with visualisation of the outcomes of the standardization process. It is known that comparative evaluation of the elements under consideration is very effective and easy as an element is being evaluated in comparison to its contenders. Compared with other methods determining the weights, the AHP method is superior because it can deal with inconsistent judgement for determining the weights. So, this method looks more effective to standardize the values of the ecological parameters involved.

The study area in the present investigation is relatively large, covering the whole area of the province. Several important parameters such as soil erosion and soil drainage are not considered in the present study. These parameters may be useful for land suitability in small areas.

The present study demonstrates the combination of Analytic Hierarchy Process (AHP) method and ecological parameter analysis with the help of Remote Sensing being integrated into a GIS to assess the physical land suitability for the selected tree species. The approach is also found to be advantageous to determine the tree crops of highest suitability for a given area, so that decisions could be made to grow appropriate tree species and derive optimum production.

For the economic forestry, three Acacia species of Acacia auriculiformis, A. mangium and A. hybrid and one pine species of $P$. caribaea were assessed as highly suitable, of which $A$. hybrid is the most suitable tree crop, followed by A. auriculiformis and A. mangium.

For the environmental forestry, all four Acacia species were considered as highly suitable in hilly and mountainous areas. However, only one Acacia of Acacia crassicarpa and Casuarina equisetifolia are classified as highly suitable in inland sandy area and coastal sandy areas, respectively.

Incorporating environmental and economic aspect into land suitability assessment for main tree species will allow forestry planners to develop better land use pattern and make reasonable decisions for forestland use. This study shows that the land suitability assessment model developed here is useful to identify suitable areas for forest plantation in terms of effective conservation, efficient income generation and sustainable forestland management in Thua Thien Hue province of central Vietnam. 


\section{Chapter 8. General Conclusions and Recommendations}

\subsection{Conclusions}

The key objectives of this research is to develop GIS modelling in order to assess the forestry's land potential and to determine factors/parameters that differentiate the forestry land area into different suitability levels for forest production, including assessment of land potential productivity for forestry use and assessment of land suitability for expansion of forest plantation. Remote sensing (RS) and GIS with supplemented the field survey information were found very useful for assessment of forestland. Remote sensing can provide valuable information for assessment of land suitability, especially in remote area in the absence of detailed forest and land cover map. The forest and land cover map was produced through the supervised classification. The discrimination of the forestland cover classes in the study area was carried out using variations in spectral responses throughout growing season. The use of bands 4,5 and 3 of Landsat ETM+ could be optimal interpretation of vegetation. The limitation of the spatial resolution of Landsat 7 ETM + was overcome through fusing Panchromatic band with ETM+3, ETM+ 4 and ETM+ 5. The proposed classification methodology is to use the output of ISODATA clustering, available secondary data together with field data in order to perform the Maximum Likelihood supervised classification. The classified map from this technique showed Kappa value of $82 \%$, thus strong agreement. The accuracy of the final classification data with the overall accuracy of $84.6 \%$, and individual forest and land cover types were mapped with a producer's accuracy above $73 \%$ and a user's accuracy above $75 \%$.

This study showed that the digital classification with limited ground truth work could be use for mapping broad categories of forest and land cover. The study provided the status of the study's area forest resources as of 2004 for the first time with detailed of different forest types along with statistical data on the area of each forest and non-forest category. The study highlighted the usefulness of remote sensing techniques in extracting information about the location and extent of different forest types and non- forest category. In addition, it reduced the number of samples require forest inventory and volume estimation and also reduced the time and cost to a consideration extent.

According to the results of Landsat ETM+ classification, it was found that an area of 185,139.5 ha or 36.7 percent of the provincial area is under the forest, of which 7.1 percent lies in the dense 
forest, 22.1 percent in degraded forest, 7.5 percent in forest plantation. An area of 320,199.9 ha or 63.3 percent of the provincial area is under non-forest, of which the distribution of area in grass land, shrub land, barren land and other land are 7.9; 18.3; 9.5 and 27.6 percent, respectively.

The Analytic Hierarchy Process (AHP) method was found to be a useful method to determine the weights. The method also endowed with visualisation of the outcomes of the standardization process. It is known that comparative evaluation of the elements under consideration is very effective and easy as an element is being evaluated in comparison to its contenders. Compared with other methods determining the weights, the AHP method is superior because it can deal with inconsistent judgement for determining the weights. So, this method looks more effective in the standardization of the values of factors/ ecological parameters involved. The combination of AHP method and GIS proves a powerful combination to apply for assessment of forestland potential suitability for forestry use and land suitability for the expansion of forest plantation.

The entire work was structured in a way that permitted full participation of foresters, technician, farmers and other local experts. They participated in the decision of diagnostic factors/parameters and forest planting types. Through our field survey and interviews with them, the weights and scores of factors/parameters were determined, including: climate, soil property, topography and vegetation. Seven main tree species in the study area also were chosen for the expansion of forest plantation: Pinus merkussi, P. caribaea, Acacia auriculiformis, A. mangium, A. hybrid, A. crassicarpa and Casuarina equisetifolia.

The criteria and indicators developed for forestry land evaluation can improve the methodology for forestry land assessment for potential productivity.

The entire area of forestland had high potential and medium potential level in term of the climatic factor, while most of forestland fell into low potential to high potential level considering the topographic factor. The study area was mostly assessed as medium potential and low potential in terms of soil property and vegetation factor.

Model of forestland potential productivity assessment used Weighted Linear Combination Method of ranking and weighting score. Rating assigned was high potential, medium potential, low potential and very low potential obtained from calculating based on experts, forest farmer opinion as well as local conditions. The forestland potential productivity assessment Model offers considerable promised for sitting four forestland potential productivity levels in the province. It has been applied successfully for assessing, identifying and choosing the potential 
productivity site for forestry production in the future, and could be used as well to guide the selection of the most approximate boundaries for each forestland potential productivity level. The forestland potential productivity classification map was produced through GIS modelling based on the four factors: soil property, climate, topography and vegetation, it can be concluded that:

- $\quad$ Land of level 1 (few limitations and highly potential productivity for forestry use) is 3.7 percent of the entire area.

- Land of level 2 (medium potential productivity with some limitations for forestry use) covers 51.4 percent.

- Land of level 3 (serious limitations and lowly potential productivity for forestry use) occupies 12.8 percent.

- Land of level 4 (very lowly potential productivity with a large number of limitations for forestry use) is 4.5 percent.

For the purpose of the forest plantation expansion in term of physical land suitability assessment, seven selected tree species were moderately suitable in most of forestland, the location of suitable area for seven selected species practically overlapped in the hilly and mountainous zone. The unsuitable area for Pinus merkussi and $P$. caribaea was distributed in marginal area for three Acacias: Acacia auriculiformis, A. mangium and A. hybrid and Casuarinas. The Acacia crassicarpa species is moderately suitable in the inland sandy soil, while other species were classified as marginally suitable and not suitable. Casuarina equisetifolia was assessed as moderately suitable in the coastal sandy soil, but this kind of soil was marginally suitable for 4 Acacia species and not suitable for two Pine species.

For the purpose of the forest plantation expansion in term of environmental forestry, A. hybrid was the most suitable tree crop with an area of $254,872.3$ ha or 50.5 percent of the entire area, followed by A. carassicarpa with $11 \%$, while only $3.8 \%$ for $P$. caribaea, $2.3 \%$ for A. mangium, $2.1 \%$ for A. auriculiformis, $2.0 \%$ for Casuarina equisetifolia and $0.6 \%$ for $P$. merkussi.

For the purpose of the forest plantation expansion in term of economic forestry, about half of the entire area (50.8\%) is high suitable for Acacia hybrid, while only $9.8 \%$ for A. auriculiformis and $1.9 \%$ for P. caribaea. About $7.1 \%$ of the entire area was assessed as moderately suitable for one Pine, Acacia and Casuarinas, of which $2.0 \%$ for A. mangium, $2.8 \%$ for Pinus merkussi, and $2.3 \%$ for Casuarina equisetifolia. Acacia crassicarpa was considered as marginally suitable with $2.7 \%$ of the entire area. 
For the purpose of the final land suitability classification for seven selected species. Based on analyses of the environmental and economic aspects and physical land suitability, the overall assessment showed the estimated areas of the forestland with soil types having a high suitability for growing A. hybrid are 13,224.9 ha (2.6 \% of the entire area). The areas of the forestland with soil types having a moderate suitability for growing Pinus merkussi, Acacia auriculiformis, A. mangium, A. hybrid, A. crassicarpa, and Casuarina equisetifolia are 5,011 ha (1 \%); 42,099.3 (8.3\%); 330.5 (0.1\%); $172,799.7$ (34.2\%); 10,376.1 (2.1\%) and 9,824.9 ha (1.9\%), respectively. The areas of the forestland with soil types having a marginal suitability for growing Pinus merkussi, P. caribaea, Acacia auriculiformis, A. mangium, A. hybrid, A. crassicarpa, and Casuarina equisetifolia were estimated as 9,565.7 ha (1.9 \%); 7,818.6 (1.5 \%); 7,682.9 (1.5 \%); 10,004.0 (1.9 \%); 71,280.9 (14.1\%); 4,097.4 (0.8 \%) and 1,126.9 ha (0.3 \%), respectively. The locations of suitable areas for three Acacia species of Acacia auriculiformis, A. mangium, and A. hybrid were found in the low undulating hilly surface. A. crassicarpa was assessed as more suitable species in the inland sandy soil, Casuarina equisetifolia was considered as most suitable species in the coastal sandy soil. The suitable areas for Pinus merkussi, and P. caribaea were distributed on the yellowish red soils developed on sandstone at the Huongtra and the Phongdien district of Thua Thien Hue province.

For the purpose of the new forest plantation expansion, the implication of these results are that $180,102.8$ ha (35.6 \% of the entire area) is suitable and potentially available for the expansion of new forest plantation, of which Pinus merkussi is 11,329.9 ha (2.2 \%), P. caribaea is 5,178.4 ha (1 \%), Acacia auriculiformis is 24,893.5 ha (4.9\%), A. mangium is 8,677.4 ha (1.7 \%), A. hybrid is $117,953.8$ ha (23.3 \%), A. crassicarpa is 5,620.2 (1.1\%) ha and Casuarina equisetifolia is 6,449.6 ha (1.3\%).

The land areas have relatively high potential for forestry use and highly suitable for the expansion of forest plantation:

- The flat lands of the lower sites are located at the Phuloc, NamDong and Huongtra district.

The land areas with limited potential for forestry use and marginally suitable for development of forest plantation include as follows:

- Most of the coastal dunes and inland plain in Eastern and the Northeast part of the study area

- Erosion surfaces at the Huongthuy, Huongtra and Phongdien district. 
- Most of the high mountain land in the Western and Southwest part of the study area.

- The land areas which are not suitable for two species of Pinus merkussi and P. caribaea but have a marginally to moderately suitable for all four Acacia species and Casuarinas:

- The inland sandy and coastal sandy zone of the PhongDien, QuangDien, HuongTra, PhuVang and Phuloc district.

\subsection{Recommendations for further research}

In this research, topographic map, thematic maps such as soil property map, climatic map, existing forest and land cover map and Landsat ETM + imageries were used for various spatial analyses. However, many problems were encountered in data co-registration, regarding the precision of various maps. We recommend a further research aiming to identify these problems that can arise when attempting to integrate multi-data from various data sources in development of geographic database for assessment of forestland resources in Thua Thien Hue province.

Nowadays, remotely sensed data have become essentially in mapping forest and land cover. However, the tropical areas do not benefit from this technology because of the problems of frequently cloud cover. Chapter 5 has provided a mapping method that gives better accuracy only after selection of imageries and optimal bands. Further research should implement on what types of remote sensing data are better to use in tropical environment to identify and discriminate better all the forest and land cover types, and what is the temporal resolution that may best exploit to overcome some of the problems of frequently cloud cover in the study area.

The selection of suitability ranks and identification of factors discussed in this research work have significant influence on forestland suitability. Several important factors/parameters such as soil erosion and soil drainage and other soil properties are not considered in this research. These factors/parameters may be useful for assessment of forestland. Future research should aim at quantifying soil loss and its effects to forest land potential suitability analysis.

The Weighted Linear Combination model was applied to identify and demarcate forestland potential productivity for forestry use as well as land potential suitability for main tree species in the study area. The same model need further testing to another places and can be applied considering more tree crops for study area. The methods and models presented in this research provides a reference point for other research, but the problems and demands are specific for Thua Thien Hue province and should be identified and adapted for other conditions. These may lead to choose different methods and models. 


\section{References}

ACHARD, F., H.D. EVA, H.-J. STIBIG, P. MAYAUX, J. GALLEGO, T. RICHARDS and J.-P. MALINGREAU (2002): Determination of deforestation rates of the world's humid tropical forests. Science 297: 999-1002.

ACHARD, F., C. ESTREGUIL (1995): Forest classification of Southeast Asia using NOAA AVHRR data. In: Remote Sensing of Environment 54 (3): 198-208.

ACHARD, F., H. EVA and P. MAYAUX (2001): Tropical forest mapping from coarse spatial resolution satellite data: production and accuracy assessment issues. In: International Journal of Remote Sensing 22: 2741-62.

AHERN, F., A. C. JANETOS, and E. LANGHAM (1998): Global observation of forest cover: EEOS integrated observing strategy, proceedings of 27th International Symposium on Remote Sensing of Environment, Tromso, Norway 8-12:103-105.

AHERN, F., R. DAVIS, T. LOVELAND, D. SKOLE, A. BELWARD, A. JANETOS, J-P. MALINGREAU, V. TAYLOR, Z. ZHU, P. CHURCHILL, C. JUSTICE, M. MADEN, and Y. YASUOKA (1999): A strategy for Global Observation of Forest Cover, GOFC Design Team report.

ALLEN, J.C. and D.F. BARNES (1985): The causes of deforestation in developing countries. Annals of the Association of American Geographers 75: 163-184.

ALLEN, R. B., A. E. HEWITT and T. R. PARTRIDGE (1995): Predicting land use suitability from vegetation and landform in depleted semiarid grassland, New Zealand. In: Landscape and Urban Planning 32: 31-42.

AMARSAIKHAN, D. and DOUGHLAS (2004): Data fusion and multi-source image classification. In: International Journal of Remote Sensing 17: 3529-3539.

AMERICAN SOCIETY OF PHOTOGRAMMETRY (1983): Manual of remote sensing. $2^{\text {nd }}$ ed. Vol. 1. Theory, instruments and techniques; 2. Interpretation and applications. Falls Church, VA: ASP\&RS. 2440 pp. +G70.4 .M29 1983 Engineering.

ANDERSON, J.R., E.E. HARDY, J.T. ROACH, and R.E. WITMER (1976): A land use and land cover classification system for use with remote sensor data. US Geological Survey Professional Paper 964, Washington, DC: US Government Printing Office. QE75 .P96 No. 964 Engineering.

ANDERSON, L.T. (1987): Seven methods for calculating land capability/suitability. Planning advisory service (PAS) report No. 402. American Planning Association, Chicago: 20 PP.

ANDREW T. HUDAK, MICHAEL A. LEFSKY, WARREN B. COHEN, MERCEDES BERTERRETCHE (2002): Integration of lidar and Landsat ETM+ data for estimating and mapping forest canopy height. In: Remote Sensing of Environment 82: 397-416.

ANKE GLEITSMANN (2005): Exploiting the spatial information in high resolution satellite data and utilizing multi-source data for tropical mountain forest and land cover mapping. PhD thesis, Goettingen University, 253 pp. 
APAN, A.A. (1997): Land cover mapping for tropical forest rehabilitation planning using remotely-sensed data. International Journal of Remote Sensing 18(5): 1029- 1049.

ARCVIEW 3.X AND ARCGIS 9.X (2005): Land Suitability Analysis User Guide.

ARONOFF, S. (1982): Classification accuracy: a user approach. Photogrammetric Engineering and Remote Sensing 48: 1299-1307.

ARONOFF, S. (1985): The minimum accuracy value as an index of classification accuracy. In: Photogrammetric Engineering and Remote Sensing 51(1): 99-111.

BACIC, I.L.Z., D.G. ROSSITER and A.K. BREGT (2003): The use of land evaluation information by land use planners and decision-makers: a case study in Santa Catarina, Brazil. Soil Use and Management 19: 12-18.

BALZTER, H., E. TALMON, W. WAGNER, D. GAVEAU, S. PLUMMER, J.J. YU, S. QUEGAN, M. DAVIDSON, T. LE TOAN, M. GLUCK, A. SHVIDENKO, S. NILSSON, K. TANSEY, A. LUCKMAN and C. SCHMULLIUS (2002): Accuracy assessment of a large-scale forest cover map of central Siberia from synthetic aperture radar. In: Canadian Journal of Remote Sensing 28: 719-37.

BERRY, B.J.L., AND A.M. BAKER (1968): Spatial analysis: a reader in statistical geography, In B.J.L. Berry and D.F. Marble (Eds.), Geographic sampling. Prentice Hall, Englewood Cliffs, NJ, pp. 91-100.

BERRY, J.K. (1993): Cartographic modeling: The analytical capabilities of GIS. In Environmental Modeling with GIS, edited by M. F. Goodchild, B. O. Parks and L. T. Steyaert (New York: Oxford University Press), pp. 58- 74.

BIOT, Y., J. DEBAVEYE, W. BOUCKAERT and C. SYS (1984): A contribution towards the development of a methodology for the application of the FAO framework for land evaluation in peninsular Malaysia. Chair of tropical soil science, State University Gent, Gent, Belgium. 63 p.

BOOTH, T.H. (1998): A broad scale land evaluation program to assess the potential for growing particular trees in Africa. Agro-forestry Systems 40: 125-138.

BOUMA, J., R.J. WAGENET, M.R. HOOSBEEK and J.L. HUTSON (1993): Using expert systems and simulation modeling for land evaluation at farm level. A case study from New York State. In: Soil Use and Management 9: 131-139.

BOYD, D.S., and F.M. DANSON (2005): Satellite remote sensing of forest resources: three decades of research development. In: Progress in Physical Geography 29(1): 1-26.

BOYD, D.S. (2001): Vegetation indices. In Mathews, J.A., editor, the encyclopaedic dictionary of environmental change. London: Edward Arnold.

BRAMMER, H., J. ANTOINE, A.H. KASSAM, \& H.T. VAN VELTHUIZEN (1988): Land resources appraisal of Bangladesh for agricultural development. Technical Reports 1-7, FAO/ UNDP Agricultural Development Advice project BGD/81/035, Dhaka, Bangladesh.

BRONSVELD, K. H. HUIZING and M. OMAKUPT (1994): Improving land evaluation and land use planning. In: ITC journal 4: 359-365.

BURROUGH, P.A. (1986): Principles of geographical information systems for land resources assessment. Oxford University press, New York. 
BURROUGH, P.A. (1987): Mapping and map analysis: new tools for land evaluation. In: Soil Use and Management 3: 20-25.

BURROUGH, P.A. (1989a): Fuzzy mathematical methods for soil survey and land evaluation. In: Journal of Soil Science 40: 477-492.

BURROUGH, P.A. (1989b): Matching spatial databases and quantitative models in land resource assessment. In: Soil Use \& Management 5: 3-8.

BURROUGH, P.A., and R.A. MCDONNELL (1998): Principles of Geographical Information Systems .Oxford University Press.

BYDEKERKE, L., E. VAN RANST, L. VAN MECHELEN and R. GROENEMANS (1998) Land suitability assessment for cherimoya in southern Ecuador using expert knowledge and GIS. In: Agriculture, Ecosystems and Environment 69: 89-98.

CAMPBELL, J. (1987): Introduction to remote sensing, Guilford Press, New York, 551 pp.

CAMPBELL, J.B. (1996): An introduction to remote sensing. $2^{\text {nd }}$ edition. Guiford Press, New York.

CAMPBELL, J.C., J. RADTKE, J.T. GLESS, and R.M. WIRTSHAFTER (1992): An application of linear programming and geographic information systems: Cropland allocation in Antigua. In: Environment and Planning 24: 535-49.

CAMPBELL, J.B. (2002): Introduction to Remote Sensing, 3rd edition (New York: Guiford Press).

CARVER, S.J. (1991): Integrating multi-criteria evaluation with geographical information systems. International Journal of Geographical Information Systems 5: 321-39.

CASTEL, T., F. GUERRA, Y. CARAGLIO and F. HOLLIER (2002): Retrieval biomass of a large Venezuelan pine plantation using JERS-1 SAR data. Analysis of forest structure impact on radar signature. In: Remote Sensing of Environment 79: 30-41.

CHUVIECO, E. (1993): Integration of linear programming and GIS in land use planning. International Journal of Geographical Information Systems 7(1):71-83.

CIHLAR, J. (2000): Land cover mapping of large areas from satellites: status and research priorities. International Journal of Remote Sensing 21(6): 1093-1114.

CLARK, D.B., C.S. CASTRO, L.D.A. ALVARADO and J.M. READ (2004a): Quantifying mortality of tropical rain forest trees using high-spatial-resolution satellite data. In: Ecology Letters 7: 52-59.

CLARK, D.B., J.M. READ, M.L. CLARK, A. MURILLO CRUZ, M. FALLAS DOTTI and D.A. CLARK (2004): Application of 1-m and 4-m resolution satellite data to ecological studies of tropical rain forest. In: Ecological Applications 14 (1): 61-74.

CLIFF, A.D. and J.K. ORD. (1973): Spatial autocorrelation. Pion, London.

COCHRAN, W.G. (1977): Sampling techniques (3rd ed.). New York: Wiley.

COHEN, J. (1960): A coefficient of agreement for nominal scales. - Educational and Psychological Measurement 20:37-46.

COLLINS, M.G., F.R. STEINER, M.J. RUSHMAN (2001): Land-use suitability analysis in the United States: historical development and promising technological achievements. In: Environmental Management 28 (5): 611-621. 
COLWELL, R.N., (EDITOR) (1960): Manual for photographic interpretation (Washington, D.C.: The American Society of Photogrammetry).

CONGALTON, R.G. (1988 a): Using spatial autocorrelation analysis to explore error in maps generated from remotely sensed data. Photogrammetric Engineering and Remote Sensing 54 (5): 587-592.

CONGALTON, R.G. (1991): A review of assessing the accuracy of classifications of remotely sensed data. Remote Sensing of Environment 37: 35-46.

CONGALTON, R.G., K. GREEN and J. TEPLY (1993): Mapping old growth forests on National Forest and Park Lands in the Pacific Northwest from remotely sensed data. In: Photogrammetric Engineering and Remote Sensing 59: 529- 535.

CONGALTON, R.G. (1996): Accuracy assessment: a critical component of land cover mapping. In Gap Analysis: A Landscape Approach to Biodiversity Planning, edited by J. M. Scott, T. H. Tear and F. Davis (Bethesda, Maryland: American Society for Photogrammetry and Remote Sensing): 119-131.

CONGALTON, R.G., and K. GREEN (1999): Assessing the accuracy of remotely sensed data: principles and practices. Boca Raton: Lewis Publishers.

CONGALTON, R.G. (1988): A comparison of sampling schemes used in generating error matrices for assessing the accuracy of maps generated from remotely sensed data. In: Photogrammetric Engineering and Remote Sensing 54(5): 593-600.

CONGALTON, R.G. (2001): Accuracy assessment and validation of Remote Sensed \& other spatial information. In: International Journal of Wild land Fire. 10: 321-328.

CONGALTON, R.G. and R.A. MEAD (1983): A quantitative method to test for consistency and correctness in photo-interpretation. In: Photogrammetric Engineering and Remote Sensing 49(1): 69-74.

CURRAN, P.J. (1983): Multi-spectral remote sensing of vegetation amount. In: Progress in Physical Geography 4: 315-41.

CZAPLEWSKI, R.L. (1991): Strategies for global monitoring of tropical forests. Remote sensing for tropical forest assessment. Proceedings of a Workshop held in San Juan Puerto Rico, New Orleans: Southern Forest Experiment Station, pp. 10-19.

DAR A. ROBERTS, MICHAEL KELLERC, JOAO VIANEI SOARES (2003): Studies of landcover, land-use, and biophysical properties of vegetation in the Large Scale Biosphere Atmosphere experiment in Amazonia. In: Remote Sensing of Environment 87: 377388.

DAVIS, F. W. and S. GOETZ (1990): Modeling vegetation-pattern using digital terrain data. In: Landscape Ecology 4:69-80.

DE GROOF, H.D., J.P. MALINGREAU, A. SOKELAND and F. ACHARD (1992): A first look at ERS-1 data over the tropical forest of West Africa. World Forest Watch Conference on Global Forest Monitoring. Sao Paulo: INPE.

DE LA ROSA, D. (2000): MICROLEIS: Conceptual Framework, Instituto de Recursos Naturales y Agrobiologia, CSIC, Avda. Reina Mercedes 10, 41010 Sevilla, Spain.

DE LA ROSA, D., J.A. MORENO, J. BARROS, F. MAYOL and A. ROSALES (2001): MicroLEIS 4.1:exploring the agro-ecological limits of sustainability. Manual. Consejo Superior de Investigaciones Científicas, Instituto de Recursos Naturales y Agrobiología, Sevilla. 
DEES, M., B. KOCH (1997): Integrating satellite and GIS data into a large scale sample based forest inventory - the classical sample based approach: Expert meeting on data fusion techniques. Univiversity of Freiburg, Dept. of RS and LIS: 66-76.

DEFRIES, R. S., M. HANSEN and J. R. G. TOWNSHEND (1995): Global discrimination of land cover types from metrics derived from AVHRR Pathfinder data. In: Remote Sensing of Environment 54: 209-222.

DEFRIES, R. S., M. HANSEN, J. R. G. TOWNSHEND and R. SOHLBERG (1998): Global land cover classification at $8 \mathrm{~km}$ spatial resolution: the use of training data derived from Landsat imagery in decision tree classifiers. In: International Journal of Remote Sensing 19: 3141-3168.

DEFRIES, R.S. and J. R. G. TOWNSHEND (1994): NDVI-derived land cover classification at global scales. In: International Journal of Remote Sensing 15: 3567-3586.

DENT, D. and A. YOUNG (1981): Soil survey and land evaluation. George Allen \& Unwin London, England.

DENT, D.L. and R.B. RIDGWAY (1986): A land use planning handbook for Sri Lanka. FD 2, SRL 79/058. Land Use Policy Planning Division, Ministry of Lands and Land Development, Colombo. 389 p.

DEPARTMENT OF AGRICULTURE AND RURAL DEVELOPMENT (2004): Forestry Development strategy period 2001-2010, Thua Thien Hue.

DIAO, Y. and W. N. XIANG (2007): How complex can a land suitability map be? In: International Journal of Geographical Information Science 21(7): 747-755.

DOMAÇ, A. and M. L. (2006): Integration of environmental variables with satellite images in regional scale vegetation classification. International Journal of Remote Sensing 27(7): 1329-1350.

DORREN, L.K.A., B. MAIER and A.C. SEIJMONSBERGEN (2003): Improved Landsat-based forest mapping in steep mountainous terrain using object-based classification. In: Forest Ecology and Management 183: 31-46.

DORTHE JØKER (2000): Casuarina equisetifolia L. Danida Forest Seed Centre, DK-3050 Humlebaek, Denmark.

DOUGLAS O. FULLER (2006): Tropical forest monitoring and remote sensing: A new era of transparency in forest goverenment. In: Sinapore Journal of Tropical Geograpy 27: 1529.

DOWNTON, M.A. (1995): Measuring tropical deforestation: development of the methods. Environmental Conservation 22: 229-240.

EASTMAN, J.R., P.A.K. KYEM, J. TOLEDANO and W. JIN (1993): GIS and decision making Geneve, Unitar.

EASTMAN, J.R., P.A.K. KYEM, J. TOLEDANO and W. JIN (1995): Raster procedure for multi-criteria/multi-objective decisions. In: Photogrammetric Engineering and Remote sensing 61: 539-547.

EASTMAN, R.J. (2001): Guide to GIS and Image processing. Clark University, USA 2: 144.

EMMANUAL, B. and H. MICHAEL (1999): Integrated of Image Analysis and GIS. In: International Arhives of Photogrammetry and Remote Sensing, 32, part 7-4-3 W6.

ENVI (2002): ENVI version 4.2. National Space Science data center. 
ESRI (1998): Arcview GIS Version 3.2. 1992-1998. Environmental Systems Research

ESRI (2000): Using Model Buldere for ArcView Spatial Analyst, ESRI, Redlands, CA.

ESRI (2003), ESRI Data and Maps (2002): Available online at: http://www.esri.com/data/ datacd02.html (accessed 20 December 2004).

EHRLICH, D., J. E. ESTES and A. SINGH (1994): Applications of NOAAAVHRR 1km data for environmental monitoring. In: International Journal of Remote Sensing 15: 145161.

EVA, H. and E.F. LAMBIN (2000): Fires and land-cover change in the tropics: A remote sensing analysis at the landscape scale. In: Journal of Biogeography 27: 765-76.

EZCURRA and EXEQUIEL (2001): GIS-based approach for participatory decision making and land suitability assessment. In: International Journal of Geographical Information Science 15(2): 129-151.

FAHSI, A., T. TSEGAYE., W. TADESSE and T. COLEMAN (2000): Incorporation of digital elevation models with Landsat-TM data to improve land cover classification accuracy. In: Forest Ecology and Management 128: 57-64.

FAO (1973): A framework for land evaluation. Draft edition. FAO, Rome. 65 p.

FAO (1976): A framework for land evaluation. Soils bulletin 32. Food and Agriculture Organization of the United Nations, Rome, Italy.

FAO (1978a): Report on the agro-ecological zones project. Methodology and results for Africa. World Soil Resources Report 48, Volume 1. FAO, Rome.

FAO (1978b): Report on the agro-ecological zones project. Results for Southwest Asia. World Soil Resources Report 48, Volume 2. FAO, Rome.

FAO (1980): Report on the agro-ecological zones project. Results for Southeast Asia. World Soil Resources Report 48, Volume 4. FAO, Rome.

FAO (1981): Report on the agro-ecological zones project. Results for South and Central America. World Soil Resources Report 48, Volume 3. FAO, Rome.

FAO (1983): Guidelines: land evaluation for rainfed agriculture. Soils Bulletin 52. Food and Agriculture Organization of the United Nations, Rome, Italy.

FAO (1984): Land evaluation for forestry. Forestry paper 48. Food and Agriculture Organization of the United Nations, Rome, Italy.

FAO (1985): Guidelines: land evaluation for irrigated agriculture. Soils Bulletin 55. Food and Agriculture Organization of the United Nations, Rome, Italy.

FAO (1991): Guidelines: land evaluation for extensive grazing. Soils Bulletin 58. Food and Agriculture Organization of the United Nations, Rome, Italy.

FAO (1993): Guidelines for land-use planning. FAO Development Series 1. Food and Agriculture Organization of the United Nations, Rome, Italy.

FAO \& UNEP (1994): A suggested national soils policy for Jamaica. Project FP/6101-91-02. FAO, Rome. 77 p. Executive Summary, 10 p.

FAO (1995a): Sustainability issues in agricultural and rural development policies.

FAO (1995b): Our land, our future - A new approach to land use planning and management. FAO, Rome. 48 p. ISBN 9251039062. 
FAO (1997a): Africa cover land cover classification. Remote Sensing Centre Series 70. FAO, Rome.

FAO (1997b): Negotiating a sustainable future for land - Structural and institutional guidelines for land resources management in the 21st century. FAO, Rome. $61 \mathrm{p}$.

FAO (1998b): Integrated coastal area management and agriculture, forestry and fisheries .FAO Guidelines. FAO, Rome.

FAO (1999): Terminology for integrated resources planning and management. Rome.

FAO (1999a): The future of our land - Facing the challenge. Guidelines for integrated planning for sustainable management of land resources. FAO, Rome. XIII + 71 p. ISBN 925 104366 3. Also CD-ROM incl. related documents: Land and Water Digital Media Series 8.

FAO /UNEP (1999): The future of our land-facing the challenge. Guidelines for integrated planning for sustainable management of land resources. FAO. 71p.

FAO (2000): Land cover classification system (LCCS): Classification concepts and user manuals. Retrieved 26, January, 2005, from http://www.fao.org/documents/show_cdr.asp?url_file=/DOCREP/003/X0596E/X0596e 00.htm.

FAO (2001): Global forest resources Assessment 2000 Main Report. FAO Forestry Paper 140. Rome.(URL: (02.02.2004): http://www.fao.org/forestry/foris/webview/forestry2/index.jsp?siteId=2921\&sitetreeId7 9 47\&langId=1\&geoId=0)

FAO (2003): State of the world’s forests 2003. Rome: FAO.

FAO (2007): Land evaluation. Towards a revised framework. Land and Water discussion Paper 6. FAO, Rome.

FAO-UNEP (1981): Tropical forest resource assessment project. FAO, Rome, Italy.

FENSTERMAKER, L. (1991): A proposed approach for national to global scale error assessments. In: Proceedings GIS/LIS '91, ASPRS, ACSM, AAG, AM/FM International and URISA 1: 293-300.

FERAS, M. ZIADAT (2007): Land suitability classification using different sources of information: Soil maps and predicted soil attributes in Jordan. Geoderma 140: 73-80.

FISCHER, G.W. and J. ANTOINE (1994): Agro-ecological land resources assessment for agricultural development planning. A case study of Kenya. Making land use choices for districtplanning. Land and Water Development Division, FAO and IIASA, Rome.

FOODY, G. (1992): On the compensation of chance agreement in image classification accuracy assessment. In: Photogrammetric Engineering and Remote Sensing 58(10): 1459-1460.

FOODY, G.M. and P.M. ATKINSON (2002): Current status of uncertainty issues in remote sensing and GIS. In: Foody G.M. and Atkinson P.M. Uncertainty in Remote Sensing and GIS. John Wiley \& Sons, New York.

FOODY, G., and P. J. CURRAN (1994): Estimation of tropical forest extent and regenerative stage using remotely sensed data. J. Biogeogr 21: 223-244.

FOODY, G.M., D.S. BOYD and M.E.J. CUTLER (2003): Predictive relations of tropical forest biomass from Landsat TM data and their transferability between regions. In: Remote Sensing of Environment 85:463-474. 
FOODY, G.M., CUTLER MEJ (2003): Tree diversity in protected and logged Bornean tropical rain forests and its measurement by satellite remote sensing. In: Journal of Biogeography 30: 1053-1066.

FOREST PROTECTION DEPARTMENT and FOREST INVENTORY and PLANNING INSTITUTE (2001): Results of national forest resource inventory, Hanoi, Vietnam, 31 pp.

FORESTRY HISTORY 1945-2000 (2001), Agriculture Pulbishing House, Hanoi, Vietnam.

FORESTRY LEGAL PAPERS (2000), Agriculture Pulbishing House, Hanoi, Vietnam.

FRANKLIN, J. (1993): Discrimination of tropical vegetation using SPOT multi-spectral data. In: Geo-cartographical International 8: 57-63.

FRANKLIN, S.E. (2001): Remote sensing for sustainable forest management. Boca Raton, FL: Lewis.

FRANKLIN, S.E., M.A. WULDER and G.R. GERYLO (2001): Texture analysis of IKONOS panchromatic data for Douglas-fir forest age class separability in British Columbia. In: International Journal of Remote Sensing 22: 2627-2632.

FRORENT, J., T. MARIUS and M. ANDREE (2001): Using GIS and outranking multi-criteria analysis for land use suitability assessment. In: International Journal of Geographical information science 15:153-174.

FUKUNAGA, K. (1990): Introduction to Statistical Pattern Recognition, Second Edition, Academic Press, New York, pp 445-455.

FULLER.D.O. and M. FULK (2001): Burned area in Kalimantan Indonesia with mapped NOAA AVHRR and Landsat TM imagery. In: International Journal of Remote Sensing 22: 691-697.

GILES M. FOODY (2002): Status of land cover classification accuracy assessment. Remote Sensing of Environment 80: 185-201.

GOVERNMENT OF VIETNAM (Gov, 2005): National report to the fifth session of the United Nation Forum on forest. http://www.un.org/esa/forests/natural-report/Vietnam.

GOWARD, C.J., TUCKER and D.G. DYE (1985): North American vegetation patterns observed with the NOAA-7 advanced very high-resolution radiometer, Vegetation 64: 3-14.

GOWARD, S.N., P.E. DAVIS, D. FLEMING, L. MILLER and J.R. TOWNSHEND (2003): Empirical comparison of Landsat 7 and IKONOS multispectral measurements for selected Earth Observation System validation sites. In: Remote Sensing of Environment 88: 80-99.

GRACE NANGENDO, ANDREW K. SKIDMORE, HENK VAN OOSTEN (2007): Mapping East African tropical forests and woodlands: A comparison of classifiers. In: Journal of Photogrammetry and Remote Sensing 61: 393-404.

GRAINGER, A. (1993): Rates of deforestation in the humid tropics, estimates and measurements. In: The Geographical Journal 159: 33-44.

GRAINGER, A. (1993): Controlling tropical deforestation, Earthscan Publications, London, UK.

GREEN, G. M. and R. SUSSMAN (1990): Deforestation history of the eastern rainforests of Madagascar from satellite images. Science 248: 212-215. 
GUILLERMO A. MENDOZA., ALAN B. ANDERSON., GEORGE Z. GERTNER (2002): Integrating multi-criteria analysis and GIS for land condition assessment: Part IIAllocation of military training areas. In: Journal of Geographic information and Decision Analysis 2: 17-30.

HA CHU CHU, LE DINH KHA (1996): Planting and uses of Casuarina equisetifolia in Vietnam. In: inyopusarerk K, Turnbull JW, Midgley SJ, eds. Recent Casuarina research and development. Proc. 3rd Int. Casuarina Workshop. Canberra, Australia: CSIRO Forestry and Forest Products, 223-225.

HAN, S.-Y., T.J. KIM, (1988): ESSAS: expert system for site analysis and selection. Computers, Environment and Urban Systems 12 (4): 239-252.

HANSAN OZCAN, MAHMUT CETIN and KENAN DIKER (2003): Monitoring and assessment of land use status by GIS. In: Environmental Monitoring and Assessment 87: 33-45.

HANSEN, M. C., R. S. DEFRIES, J. R. G. TOWNSHEND and R. SOHLBERG (2000): Global land cover classification at $1 \mathrm{~km}$ spatial resolution using a classification tree approach. In: International Journal of Remote Sensing 21: 1331-1364.

HELLDEN, U. (1980): A test of Landsat-2 imagery and digital data for thematic mapping illustrated by an environmental study in northern Kenya. Sweden, Lund University, Natural Geography Institute Report No. 47.

HELMER, E.H., S. BROWN and W.B. COHEN (2000): Mapping montane tropical forest successional stage and land use with multi-date Landsat Imagery. In: International Journal of Remote Sensing, 21: 2163-2183.

HELMER, E.H., O. RAMOS and T.D.M. LOPES (2002): Mapping forest types and land cover of Puerto Rico, a component of Caribbean biological hotpot. In: Caribbean Journal of Science 38 (3-4) 165-183).

HEUVELINK, G.B. and P.A. BURROUGH (1993): Error propagation in cartographic modelling using Boolean logic and continuous classification. In: International Journal of Geographical Information Science, 7 (3): 231-246.

HOBBS, B.F. (1980): A comparison of weighting methods in power plant sitting. Decision Sciences 11: 725-737.

HOPKINS, L. (1977): Methods for generating land suitability maps: a comparative evaluation. In: Journal for American Institute of Planners 43 (4): 386-400.

HILL, I.D. (ED.) (1979): Land resources of central Nigeria. Agricultural development possibilities. Land Resources Development Center, Overseas Development Administration, Surbiton, UK.

HILL, R.A. and G.M. FOODY (1994): Separability of tropical rain-forest types in the Tambopata-Candamo reserved zone, Peru. In: International Journal of Remote Sensing 15: 2687-2693

HOERSCH, B., G. BRAUN and U. SCHMIDT (2002): Relation between landform and vegetation in alpine regions of Wallis, Switzerland. A multi-scale remote sensing and GIS approach. Computers, Environment and Urban Systems 26:113-139.

HOUGHTON, R.A., J.L. HACKLER and K.T. LAWRENCE (2000): Changes in terrestrial carbon storage in the United States. 2: the role of fire and fire management. In: Global Ecology and Biogeography 9: 145-170. 
HOUNTONDJI, Y.C., N. SOKPON and P. OZER (2005): Analysis of the vegetation trends using low resolution remote sensing data in Burkina Faso (1982-1999) for the monitoring of desertification. In: International Journal of Remote Sensing 27(5): 871884.

HUIZING, H., A. FARSHAD and C. DEBIE (1995): Land evaluation. Enschede, the Netherlands.

HURTT, G., X. XIAO, M. KELLER, M. PALACE, G.P. ASNER, R. BRASWELL (2003): IKONOS imagery for the large scale biosphere atmosphere experiment in Amazonia (LBA). In: Remote Sensing and Environment.

HUSSIN, Y. A., and S. R. SHAKER (1996): Optical and radar satellite image fusion techniques and their applications in monitoring natural resources and land use change. Synthetic Aperture Radar, Proceedings European Conference (EUSAR '96), Königswinter, Germany, 26- 28 March, 1996 (Berlin: VDE): 451- 456.

HYYPPÄ, J., M. INKINEN, M. ENGDAHL, S. LINKO and Y.H. ZHU (2000): Accuracy comparison of various remote sensing data sources in the retrieval of forest stand attributes. In: Forest Ecology and Management 128: 109-120.

IMA CELIA G. VIEIRA, ARLETE SILVA DE ALMEIDA, ERIC A. DAVIDSON, THOMAS A. STONE, CLAUDIO J. REIS DE CARVALHO, JOSE BENITO GUERRERO (2003): Classifying successional forests using Landsat spectral properties and ecological characteristics in eastern Amazonia. In: Remote Sensing of Environment 87: 470-481.

INSTITUTE OF FOREST INVENTORY and PLANNING (1998): Digital forest and land cover map of Thua Thien Hue province. Vietnam.

JACEK MALCZEWSKI (2000): On the use of weighted linear combination method in GIS: Common and best practice approaches. Transactions in GIS 4: 5-12.

JACEK MALCZEWSKI (2004): GIS-based land-use suitability analysis: a critical overview. In: Progress in Planning 62: 3-65.

JACK BAYNES (2007): A GIS based assessment of land suitable for growing Hoop Pine in the Atherton, Eacham and Herberton Shires of North Queensland. Annals of tropical research 29(1): 67-82.

JANKOWSKI, P. and T. NYERGES (2001): Geographic Information Systems for Group Decision Making, Taylor \&Francis, London.

JANKOWSKI, P. and L. RICHARD (1994): Integration of GIS-based suitability analysis and multi-criteria evaluation in a spatial decision support system for route selection. In: Environment and Planning B 21 (3): 326-339.

JANSEEN, L.L.F., M.N. JAARSMA and E.T.M. VAN DER LINDEN (1990): Integrating topographic data with remote sensing for land-cover classification. In: Photogrammetric Engineering \& Remote Sensing 56: 1503-1506.

JANSSEN, L.L.F., and F.J.M. VAN DER WEL (1994): Accuracy assessment of satellite derived land-cover data: a review. in Photogrammetric Engineering and Remote Sensing 60: 419-426.

JENSEN, J. R. (1996): Introductory digital image processing. A Remote Sensing Perspective. upper Saddle River, New Jersey: Prentice Hall. 
JIAO LIMIN LIU YAOLIN (2007): Model of land luitability evaluation based on computational intelligence. In: Geo-spatial information science 10(2):151-156.

JOERIN, F., M. THE'RIAULT and A. MUSY (2001: Using GIS and outranking multi-criteria analysis for land-use suitability assessment. In: International Journal of Geographical Information Science 15 (2): 153-174.

JOERIN, FLORENT, THERIAULT, MARIUS and MUSY, ANDRE (2001): Using GIS and outranking multi-criteria analysis for land-use suitability assessment. In: International Journal of Geographical Information Science 15(2): 153-174.

KALOGIROU, S., (2002): Expert systems and GIS: an application of land suitability evaluation. Computers, Environment and Urban Systems 26 (2-3): 89-112.

KANGAS, J. (1993): A multi-attribute preference model for evaluating the reforestation alternatives of a forest stand. In: Forest Ecology and Management 59: 271-288.

KIJKAR S. (1992): Vegetative propagation of Acacia mangium x Acacia auriculiformis. ASEAN-Canada Forest Tree Seed Centre, Muak- Lek, Saraburi, Thailand.

LANDIS, J.R. and G.G. KOCH (1977): The measurement of observer agreement for categorical data. Bioometrics 33(1): 159-174.

LE DINH KHA (2001): Studies on the use of natural hybrids between A. mangium and A. auriculiformis in Vietnam. Hanoi, Agriculture Publishing House.

LE DINH KHA, NGUYEN XUAN LIEU, NGUYEN HOANG NGHIA, HA HUY THINH, HOANG SY DONG, NGUYEN HONG QUAN, VU VAN ME (2003): Forest tree species selection for forest planting programme in Vietnam, Hanoi.

LEGAL PAPERS ON FOREST PROTECTION, MANAGEMENT (2001). Agriculture Pulbishing House. Hanoi, Vietnam

LI, Z.Q., J. CIHLAR, L. MOREAU, F.T. HUANG and B. LEE (1997): Monitoring fire activities in the boreal ecosystem. In: Journal of Geophysical Research-Atmospheres 102(D24): 29611-29624.

LILLESAND, T.M. and R.W. KIEFER (2000): Remote sensing and image interpretation (4 ${ }^{\text {th }}$ edition). John Wiley \& Sons, New York.

LILLO, M -SAAVERDRA, C.GONZALO, A.ARQUERO and E. MARTINES (2005): Fusion of multi-spectral and panchromatic satellite sensor imagery based o tailored filtering in the Fourier domain. In: International Journal of Remote Sensing 26: 1263- 1268.

LO, C.P. and JINMU CHOI (2004): A hybrid approach to urban land use/cover mapping using Landsat 7 Enhanced Thematic Mapper Plus (ETM+) images. In: International Journal of Remote Sensing 25: 2687-2700.

LOI, N. VAN, M. KAPPAS and S. ERASMI (2007): GIS-based assessment of land potential for forestry in Thua Thien Hue province, Central Vietnam. In: Proceedings of the $2^{\text {nd }}$ Göttingen GIS and Remote sensing, Gemany.

LOVELAND, T. R., B. C. REED, J. F. BROWN, D. O. OHLEN, Z. ZHU, L. YANG and J. W. MERCHANT (2000): Development of a global land cover characteristics database and IGBP discover from 1-km AVHRR data. In: International Journal of Remote Sensing 21: 1303-1330. 
LOWRY .J.H, H. MILLER and G.F. HEPNER (1995): A GIS- Based on sensitivity analysis of community vulnerability to hazardous contaminations on the Mexico/U.S. Border. In: Photogrammetric Engineering and Remote Sensing 61: 1347-1359.

LUIS A.B., SALOMON.D. and EXEQUIEL EZCURRA (2001): GIS- Based approach for participatory decision making and land suitability assessment. In: International Journal of Geographical Information Science 15: 129-151.

MALCZEWSKI, J., (1996): A GIS-based approach to multiple criteria group decision making. In: International Journal of Geographical Information Systems 10 (8): 955-971.

MALCZEWSKI, J., (1999): GIS and multi-criteria decision analysis, John Wiley \& Sons, New York.

MALCZEWSKI, J., (2000): On the use of weighted liner combination method in raster GIS: common and best practice approaches. In: Transactions in GIS 4 (1): 5-22.

MALINGREAU, J. P., C. J. TUCKER and N. LAPORTE (1989): AVHRR for monitoring global tropical deforestation. In: International Journal of Remote Sensing 10: 855-867.

MALINGREAU, J.P., M.M. VERSTRAETE and F. ACHARD (1992): Monitoring global deforestation: a challenge for remote sensing. In Mather, P., editor, TERRA-1: understanding the terrestrial environment. London: Taylor and Francis 203-209.

MARD (Ministry for Agriculture and Rural Development) (1998): Five million ha reforestation projects (1998-2010), Hanoi.

MARD (1995): Roles and functions of forest protection guard. In forest administrative system in Vietnam. (In Vietnamese). Agricultural publishing house, Hanoi, Vietnam, 126 pp.

MARD (2001): National forest development strategy for 2001-2010, Hanoi.

MARD (2006): The national forest strategy for the period 2006-2020. Ministry for Agriculture and Rural Development, Hanoi.

MARTIN VAN BEUREN (2004): Acacia hybrid in Vietnam, centre for international economics, Canberra \& Sydney, Australia, 44 pp.

MARY PAX-LENNEY, CURTIS E. WOODCOCK, SCOTT A. MACOMBER, SUCHARITA GOPAL, CONGHE SONG (2001): Forest mapping with a generalized classifier and Landsat TM data. In: Remote Sensing of Environment 77: 241-250.

MASSAM, B.H. (1988): Multi-criteria decision making (MCDM) techniques in planning. In: Progress in Planning 30 (1): 1-84.

MAYAUX, P. and E. F. LAMBIN (1995): Estimation of tropical forest area from coarse spatial resolution data: a two step correction function for proportional errors due to spatial aggregation. In: Remote Sensing of Environment 53: 1-15.

MICHALAK, W. Z. (1993): GIS in land use change analysis: Integration of remotely sensed data inside GIS. In: Applied geography 13: 28-44.

MOORE, I.D., GRAYSON, R.B. and LADSON, A.R. (1991): Digital terrain modelling: A review of hydrological and biological applications. Hydrological Processes 5: 3-30.

MORISETTE, J.T., J.E. NICKESON, P. DAVIS, Y. WANG, Y. TIAN, C.E. WOODCOCK, N. SHABANOV, M. HANSEN, W.B. COHEN, D.R. OETTER \& R.E. KENNEDY (2003): High spatial resolution satellite observations for validation of MODIS land products: IKONOS observations acquired under the NASA Scientific Data Purchase. Remote Sensing of Environment 88 (1): 100-110. 
MUMBY, P.J. and A.J. EDWARDS (2002): Mapping marine environments with IKONOS imagery: enhanced spatial resolution can deliver greater thematic accuracy. In: Remote Sensing of Environment 82: 248-257.

MYINT, S.W. (2001): A robust texture analysis and classification approach for urban land-use and land-cover feature discrimination. In: Geocarto International 16 (4): 27-38.

MYINT, S. (1996): Site selection and growth prediction in Myanmar. Matching Trees and Sites. Proceedings of an International Workshop, Bangkok, 27-30 March 1995 (ACIAR Proceedings No. 63). ACIAR, Canberra.

NAGENDRA, H. (2001): Using remote sensing to assess biodiversity. In: International Journal of Remote Sensing 22: 2377- 2400.

NASA (1998): Landsat 7 Science Data Users Handbook, vol. 2001, http://ltpwww.gsfc.nasa.gov/IAS/handbook/handbook_toc.html.

NATIONAL INSTITUTE FOR AGRICULTURAL PLANNING and PROJECTION (2000): Digital Soil Map. Hanoi, Vietnam.

NEWTON, W., C. GURNEY, D. SLOGGETT, I. DOWMAN (1994): An approach to automated identification of forests and forest change in remotely sensed images. IAPRS, Munich, Germany 30 (3/2): 607-614.

NGUYEN VAN DE, LE HA, LUU VAN PHAI, TRUONG DINH CHIEN, TRAN QUANG TUAN AND NGUYEN THIEN TU (2005): Build of sand soil map at scale of 25,000 in inland sandy area, Thua Thien Hue province. Department of Science and Technology.

PATRICIA A. BERGE (2006): Generating agricultural landscapes for alternative future analysis: A multiple attribute decision-making model. In: Transaction in GIS 2006, 10: 103-120.

PEREIRA, J.M.C. and L. DUCKSTEIN (1993): A multiple criteria decision-making approach to GIS-based land suitability evaluation. In: International Journal of Geographical Information Systems 7 (5): 407-424.

PFEFFER, K., E.J. PEBESMA and P.A. BURROUGH (2003): Mapping alpine vegetation using vegetation observations and topographic attributes. In: Landscape Ecology 18: 759776.

PINDER, J.E., G.C. KROH, J.D. WHITE and A.M. BASHAM MAY (1997): The relationship between vegetation type and topography in Lassen Volcanic National Park. In: Plant Ecology 131: 1729.

POHL, C. and J.L. VAN GENDEREN (1998): Multi-sensor Image fusion in remote sensing: Concept, methods and applications. In: International Journal of Remote Sensing 19: 823 - 854.

POLICY ON SHIFTING OF AGRICULTURE, RURAL ECONOMIC PATTERNS (20012010): Agriculture Pulbishing House in 2001.

QUEGAN, S., T. LE TOAN, J.J. YU, F. RIBBES and N. FLOURY (2000): Multitemporal ERS SAR analysis applied to forest mapping. In: Transactions on Geoscience and Remote Sensing 38: 741-753.

RANSON, K.J. and G. SUN (1994): Mapping biomass of a northern forest using multifrequency data. IEEE TGRS 32: 388-396. 
RICHARD J.A. and X. JIA (1999): Remote sensing digital image analysis: An introduction. 3rd Edition. Springer, Berlin.

RICHARDS, J.A. (1993): Remote sensing digital image analysis: An introduction, 2nd edn (Berlin: Springer-Verlag).

ROBERTS, M.C., J.C. RANDOLPH, J.R. CHIESA (1979): Land suitability model for the evaluation of land-use change. In: Environmetal Management 3 (4): 339-352.

ROMMELFANGER, .T. (2003): A fuzzy logic Approach to multi-criteria decision making: http//www.wiw.unifrankfurt.de/professionen/rommelfanger/index/document/IFSA99p2.doc

ROSEBERRY, J.L. (1994): Assessing the potential impact of conservation reserve program lands on bobwhite habitat using remote sensing, GIS, and habitat modelling. In: Photogrammetric Engineering \& Remote Sensing, 60(9): 1139-1143.

ROSENFIELD, G.H. and K. FITZPATRICK-LINS (1986): A coefficient of agreement as a measure of thematic accuracy. In: Photogrammetric Engineering and Remote Sensing 52(2): 223-227.

ROSSITER .D.G., (1996): A theoretical framework for land evaluation (with discussion). Geoderma 72: 165-202.

ROSSITER, D.G. and A.R. VAN WAMBEKE (1997): Automated Land Evaluation System: ALES Version 4.65 User's Manual. Cornell University, Department of Soil, Crop \& Atmospheric Sciences.

ROSSITER, D.G. (1995): Economic land evaluation: why and how. Soil-use management, Oxford: CAB International 11 (3): 132-140.

RUFELD, C.W. (1988): Acacia mangium, A. auriculiformis and hybrid A. auriculiformis seedling morphology study. Forest research centre publication No. 41. Sabah: Forest Research Centre.

SAATY, T.L. (1977): A Scaling Method for Priorities in Hierarchical Structure. In: Journal of Mathematical Psychology.

SAATY, T.L. (1980): The Analytic Hierarchy Process. New York, McGraw-Hill.

SCHRIEVER, J.R., and R.G. CONGALTON (1993): Mapping forest cover types in New Hampshire using multi-temporal Landsat Thematic Mapper data. ASPRS/ACSM Annual Convention \& Exposition, 15-19 February (New Orleans Louisiana) 3: 333342.

SCHULTINK, G. (1987): The cries resource information system: Computer-aided land resource evaluation for development planning and policy analysis. Soil Survey, Land Evaluation 7: 47-62.

SCOTT G. BROURNE, MARK, R. GRAVES (2001): Classification of Land cover types for the Fort Benning Ecoregion using Enhanced Thematic Mapper data. Strategic Environmental Research and Development Program.

SERWAN M.J. BABAN (2001): Mapping land use/land cover distribution on a mountainous tropical island using remote sensing and GIS. In: International Journal of Remote Sensing 21: 1909-1918.

SHRESTHA, R.P., A. EIUMNOH and E.O. BOX (1995): Towards sustainable land use through land evaluation: a case study of Muaklek, Thailand. In: Proceedings, 16th Asian 
Conference on Remote Sensing, 20-24 November 1995. http://www.gisdevelopment.net/aars/acrs/1995/ts2/ts2002.shtml.

SIDERIUS, W. (ED.) (1986): Land evaluation for land-use planning and conservation in sloping areas. ILRI Publication 40 International Institute for Land Reclamation and Improvement (ILRI), Wageningen.

SOME GUIDELINES, POLICIES ON AGRICULTURE, FORESTRY, AQUACULTURE, IRRIGATION AND RURAL DEVELOPMENT. Rural Publishing House in 2000.

SOUTHWORTH, J. (2004): An assessment of Landsat TM band 6 thermal data for analyzing land cover in tropical dry forest regions. In: International Journal of Remote Sensing 25(4): 689-706.

STEHMAN, S.V. (2000): Practical implications of deign-based sampling for thematic map accuracy assessment. In: Remote Sensing of Environment 72: 35-45.

STEHMAN, S.V. and R.L. CZAPLEWSKI (1998): Design and analysis for thematic map accuracy assessment: fundamental principles. In: Remote Sensing of Environment 64: 331-344.

STEININGER, M.K. (2000): Satellite estimation of tropical secondary forest above-ground biomass: data from Brazil and Bolivia. In International Journal of Remote Sensing 21(6): 1139-1157.

STOMS, D.M. and J.E. ESTES (1993): A remote sensing research agenda for mapping and monitoring bio-diversity. In: International journal of remote sensing 14 (10): 1839-860.

STORE, R., and J. KANGAS (2001): Integrating spatial multi-criteria evaluation and expert knowledge for GIS-based habitat suitability modelling. In: Landscape and Urban Planning 55 (2): 79-93.

STORY, M. and R.G. CONGALTON (1986): Accuracy assessment: a users perspective. In: Photogrammetric Engineering and Remote Sensing 52(3): 397-399.

SYS, C., E. VAN RANST, J. DEBAVEYE (1991a): Land Evaluation Part I: Principles in land evaluation and crop production calculations. Agric. Publ. GADC, Brussels, Belgium 7: 274.

SYS, C., E. VAN RANST, J. DEBAVEYE (1991b): Land Evaluation Part II: Methods in land evaluation. Agric. Publ. GADC, Brussels, Belgium 7: 248.

SUZUKI, T. and M. SHIMADA (1992): Japanese Earth Observation satellite program and application of JERS-1 sensors data to forest monitoring.World Forest Watch Conference on Global Forest Monitoring, Sao Paulo: INPE: 47.

TAKYU, M., S.I. ABIA and K. KITAYAMA (2002): Effects of topography on tropical lower montane forest under different geological conditions on Mount Kinabalu, Borneo. In: Plant Ecology 159: 35-49.

THAI VAN TRUNG (1963, 1978): Tham Thuc Vat rung Vietnam, Hanoi, Vietnam

THE SOCIALIST REPUBLIC OF VIETNAM (2002): Vietnam forestry development strategy 2006-2020. Socialist Republic of Vietnam (Approved by the Prime Minister), Hanoi.

THENKABAIL, P.S. (2004): Inter-sensor relationships between IKONOS and Landsat-7 ETM+ NDVI data in three eco-regions of Africa. International Journal of Remote Sensing, 25: 389-408. 
THENKABAIL, P.S., E.A. ENCLONA, M.S. ASHTON, C. LEGG and M.J. DE DIEU (2004): Hyperion, IKONOS, ALI and ETM plus sensors in the study of African rainforests. In: Remote Sensing of Environment 90: 23-43.

THOMAS SIKOR AND ULRICH APEL (1998): The possibilities for community forestry in Vietnam. Asian forest network working paper series, volume:1. http://www.Asiaforestnetwork.org.

TOMLIN, C.D. (1990): Geographical Information Systems and Cartographic Modeling (Englewood Cliffs, NJ: Prentice Hall Publishers).

TOWNSHEND, J. R. G. (1992): Land cover. In: International Journal of Remote Sensing, 13: 1319-1328.

TOWNSHEND, J. R. G., V. BELL, A. C. DESCH, C. HAVLICEK, C. O. JUSTICE, W. E. LAWRENCE, D. SKOLE, W.W. CHOMENTOWSKI (1995): T he NASA Landsat Path. under humid tropical deforestation project and satellite information in the next decade (yson's Corner, Virginia. In: American society of photogrammetry and remote sensing), pp. IV76-IV87.

TOWNSHEND, J., C. JUSTICE, W. LI, C. GURNEY and J. MCMANUS (1991): Global land cover classification by remote sensing: present capabilities and future possibilities. In: Remote Sensing of Environment 35: 243-255.

TRIANTAFILIS, J., W.T. WARD, and A.B. MCBRATNEY (2001): Land suitability assessment in the Namoi Valley of Australia, using a continuous model. In: Australian Journal of Soil Research 39: 273-290.

TRIGG S.N, L.M CURRAN, and A.K. MCDONALD (2006): Testing the utility of Landsat 7 satellite data for continued monitoring of forest cover in protected areas of Southeast Asia. In: Singapore Journal of Tropical Geography 27 (1): 59-79.

TSO, B. and M.P. MATHER (2001): Classification Methods for Remotely Sensed Data. Taylor and Francis, London.

TUCKER, C.J. and J. R.G. TOWNSHEND (2000): Strategies for monitoring tropical deforestation using satellite data. In: International Journal of Remote Sensing 21(6): 1461-1471.

VAN DIEPEN CA VAN KEULEN H WOLF J and BERKHOUT JAA (1991): Land evaluation: from intuition to quantification. In: Advances in Soil Science, BA Stewart, Springer, New York, pp 139-204.

VAN DIEPEN, C. A., C. RAPPOLDT, J. WOLF and H. VAN KEULEN (1988): CWFS crop growth simulation model WOFOST, documentation version 4.1, Wageningen, the Netherlands, centre for world food studies.

VAN LANEN, H.A.J., HACK-TEN BROEKE, J. BOUMA and W.J.M. DE GROOT (1992a): A mixed qualitative/quantitative physical land evaluation methodology. Geoderma 55: 37-54.

VAN LANEN, H.A.J., C.A. VAN DIEPEN, G.J. REINDS and G.H.J. DE KONING (1992b): A comparison of qualitative and quantitative physical land evaluations, using an assessment of the potential for sugar beet growth in the European Community. In: Soil Use and Management 8: 80-89.

VENEMA, J.H. and R.R. VARGAS (2007): Land suitability assessment of a selected study area in Somaliland. FAO-SWALIM Technical Project Report L-06. Nairobi, Kenya. 
WALTER, V., D. FRITSCH (1998): Automatic verification of GIS data using high resolution multi-spectral data. IAPRS, Vol. 32, Part 3/1, Columbus, USA: 485-490.

WANG, L., W.P SOUSA, P. GONG and G.S. BIGING (2004b): Comparison of IKONOS and QuickBird images for mapping mangrove species on the Caribbean coast of Panama. In: Remote Sensing of Environment 91: 432-440.

WANG, Q., M. WATANABE, S. HYASHI and S. MURAKAMI (2003): Using NOAA AVHRR data to assess flood damage in China. In: Environmental monitoring and assessment 82: 119-148.

WEI NING XIANG (2001): Weighting by chosen: a weigh elicitation methods for map overlays. In: Landscape and Urban Planning, USA 56: 61-73.

WILKINSON .G.G. (1996): A review of current issues in the integration of GIS and remote sensing. In: International Journal of Geographic Information Science 10(1): 85-101.

WOODWELL, G.M., R.A. HOUGHTON, T.A. STONE, R.F. NELSON and W. KOVALICK (1987): Deforestation in the tropics: new measurements in the Amazon basin using Landsat and NOAA/AVHRR imagery. In: Journal of Geophysical Research 92: 21572163.

XIAOJIUN YANG and ZHI LIU (2005): Using satellite imagery and GIS for land use and land cover change mapping in an estuarine watershed. In: International Journal of Remote Sensing, 26: 5275- 5296.

YIZENGAW, T. and W. VERHEYE (1995): Application of computer captured knowledge in land evaluation, using ALES in Central Ethiopia. Geoderma 66: 297-311.

ZUHDI, M. (1999): Using neural network and GIS to model and perform land evaluation for Olive plantation in Alora Spain. http://cgi.gir.wageningen.ur.nl/cgi. 


\section{Appendix 1}

Plates: The forest and land cover types of the study area

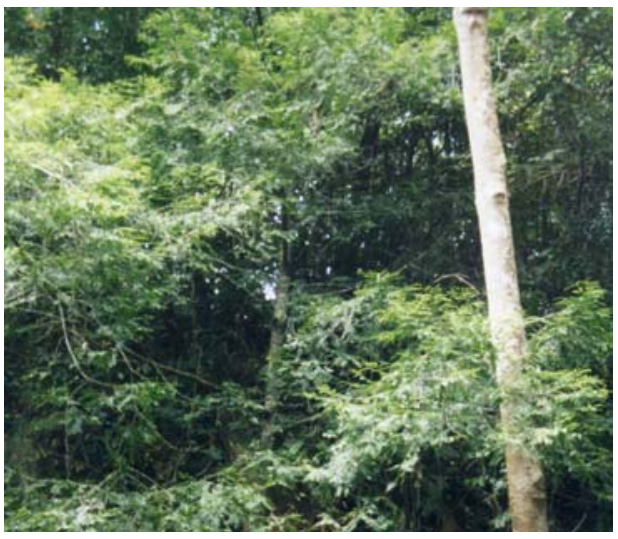

Plate 1: Montane closed evergreen subtropical monsoon forest with Podocarpus imbricatus species, $1250 \mathrm{~m}$ a.s.l., Phuloc district

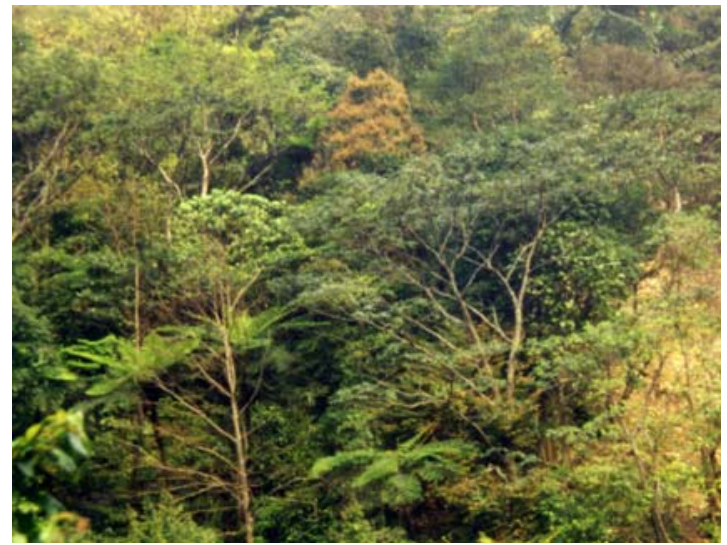

Plate 3: Closed evergreen tropical monsoon forest, $600 \mathrm{~m}$ a.s.l., Aluoi district

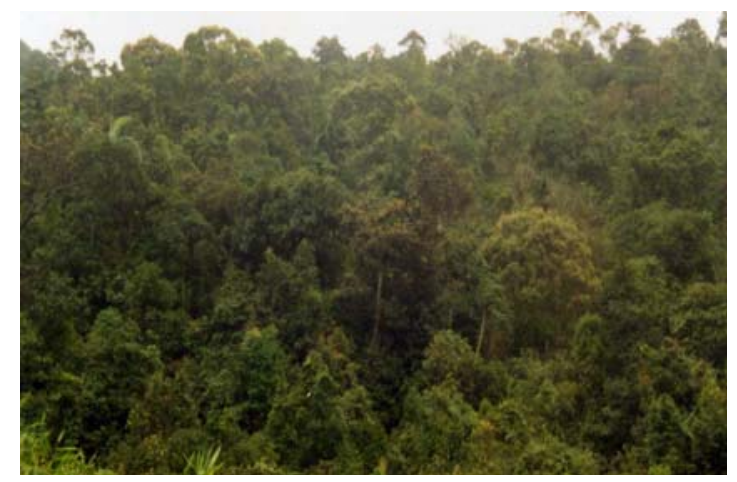

Plate 5: Closed evergreen tropical monsoon forest, $400 \mathrm{~m}$ a.s.l., Phongdien district

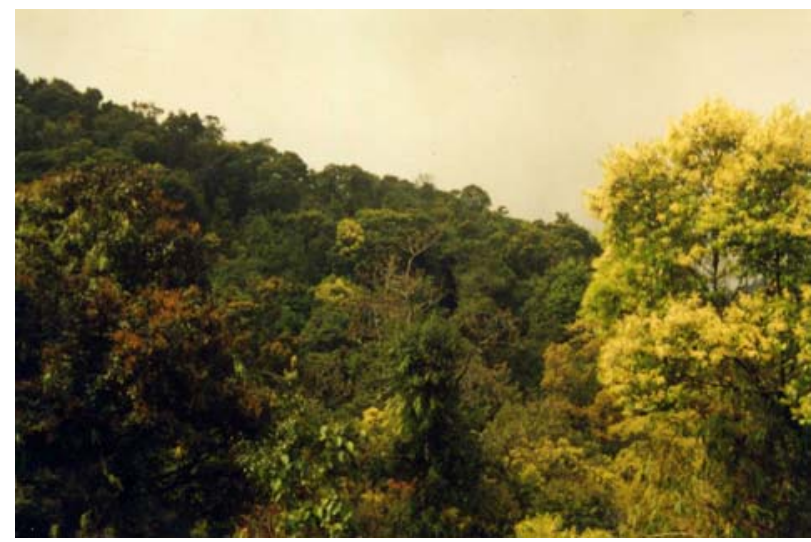

Plate 2: Montain closed evergreen sub-tropical monsoon forest, $1115 \mathrm{~m}$ a.s.l., Namdong district

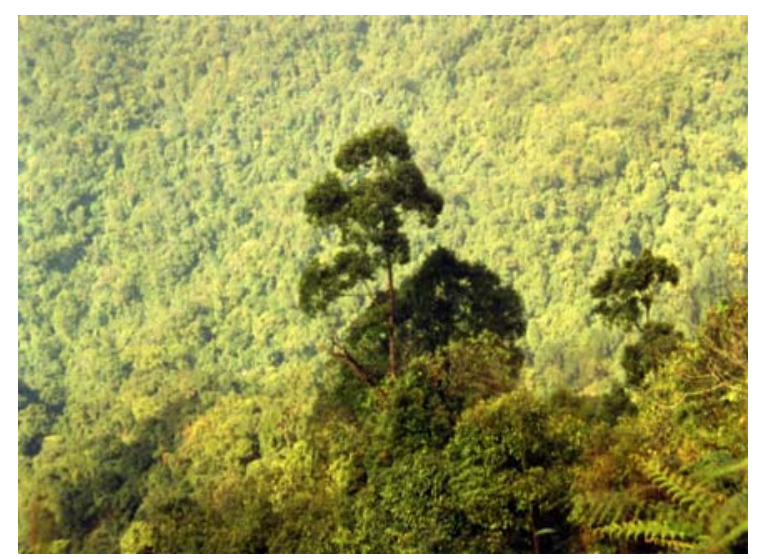

Plate 4: Closed evergreen tropical monsoon forest, $750 \mathrm{~m}$ a.s.l., Phuloc district

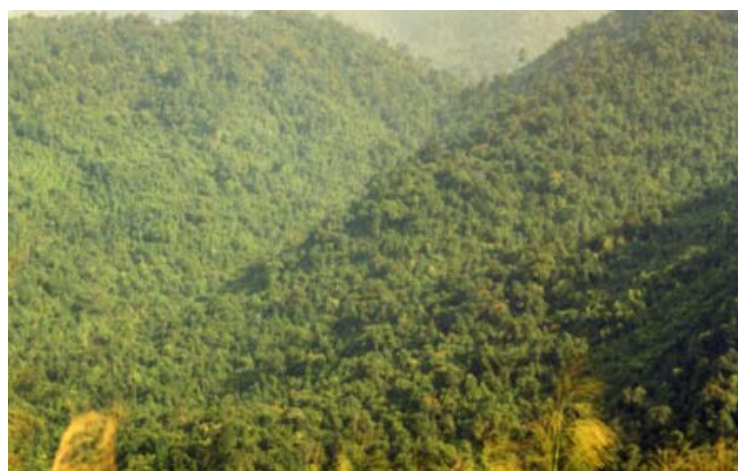

Plate 6: Closed evergreen tropical monsoon forest, $430 \mathrm{~m}$ a.s.l., Huongthuy district 


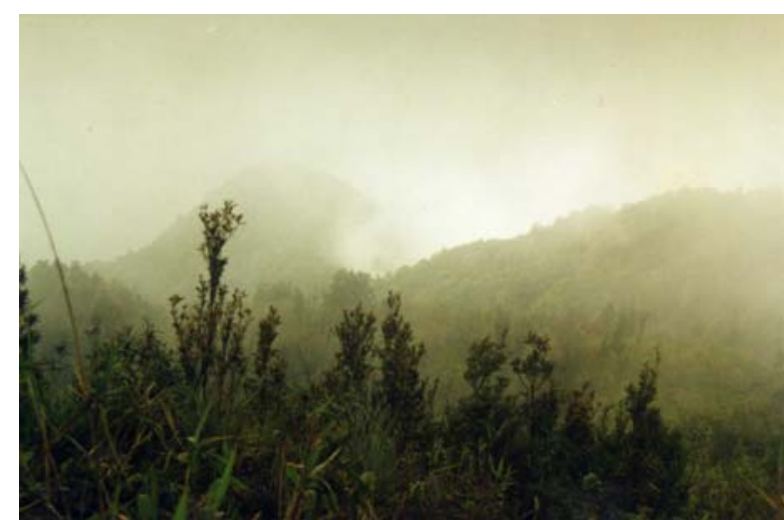

Plate 7:Young secondary forest, $1350 \mathrm{~m}$ a.s.l., Phuloc district

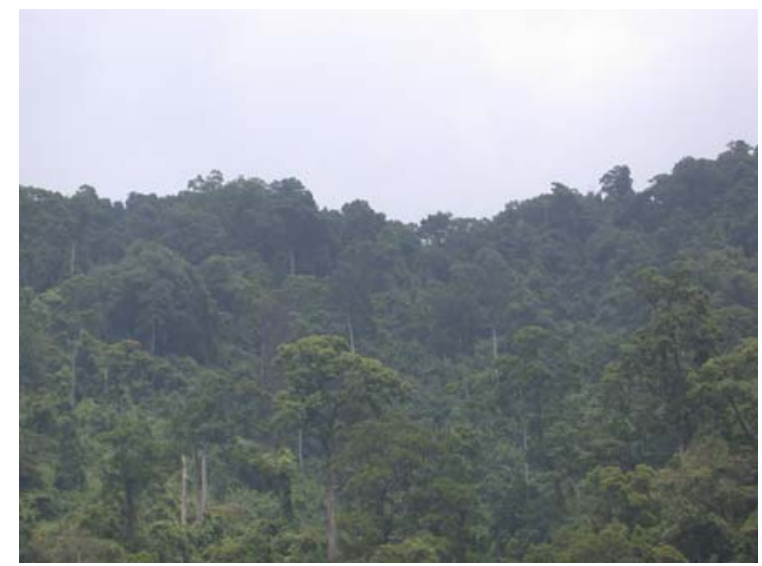

Plate 9: Secondary forest, $400 \mathrm{~m}$ a.s.l., Namdong district

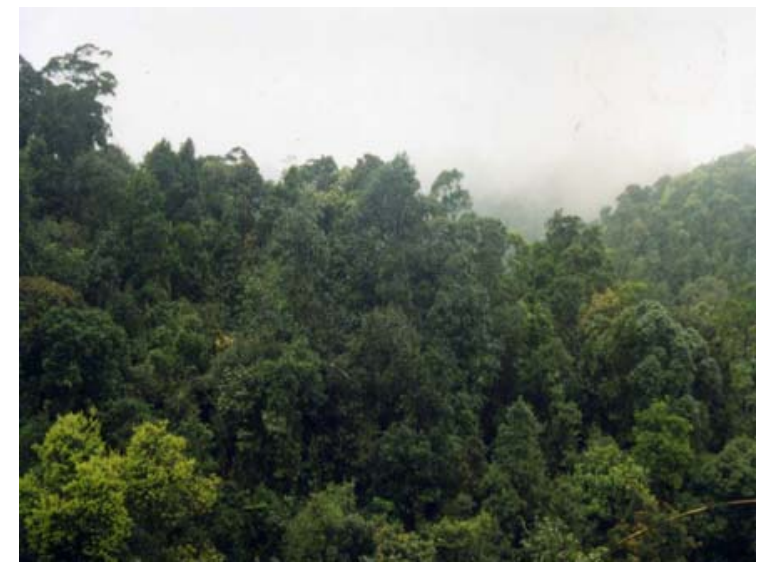

Plate 11: Young secondary forest, $200 \mathrm{~m}$ a.s.l., Namdong district

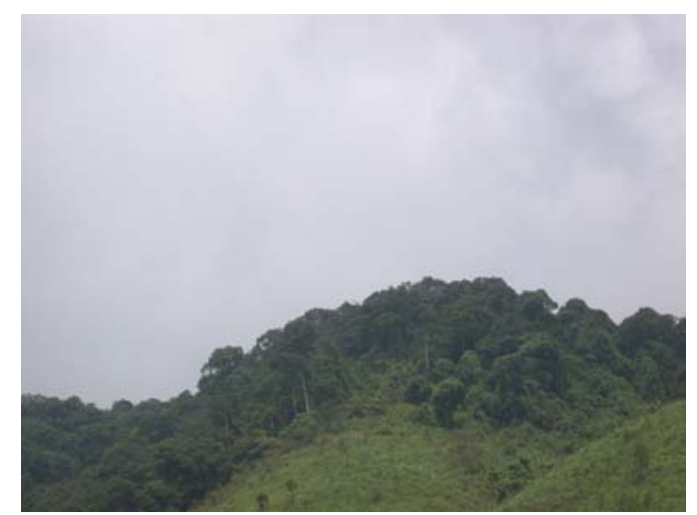

Plate 8: Secondary forest, approximately 300 $\mathrm{m}$ a.s.l., Aluoi district

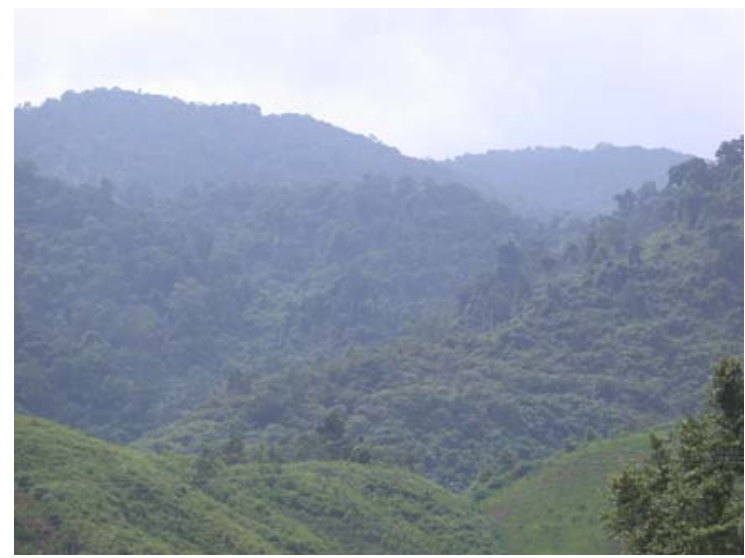

Plate 10: Secondary forest, 300 - 400 m a.s.l., Huongthuy district

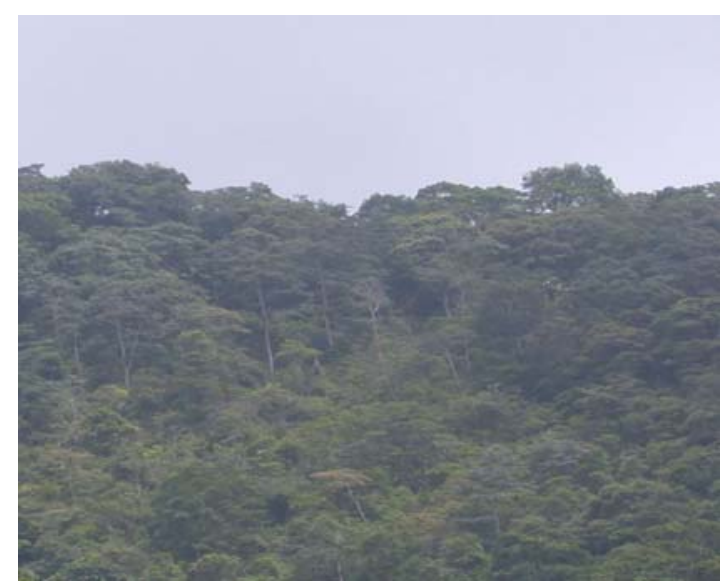

Plate 12: Young secondary forest with older stands in the background, $300 \mathrm{~m}$ a.s.l., Phongdien district 


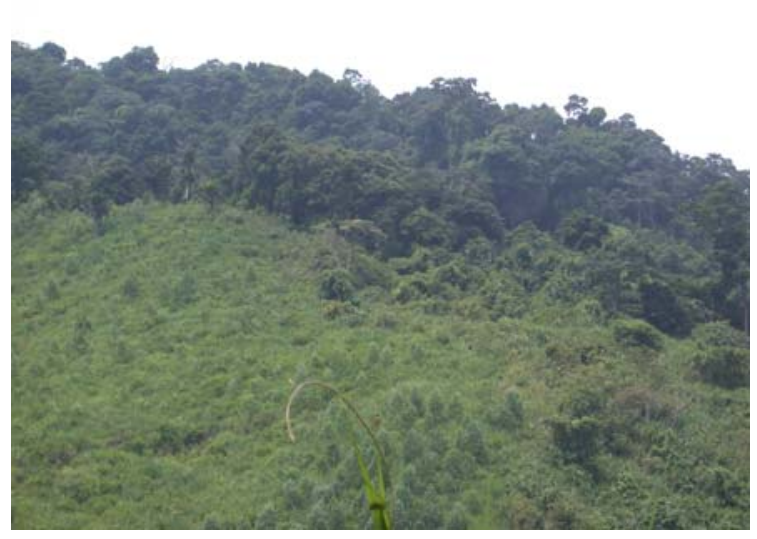

Plate 13: Secondary forest bordered by grass and shrub, $250 \mathrm{~m}$ a.s.l., Phongdien district

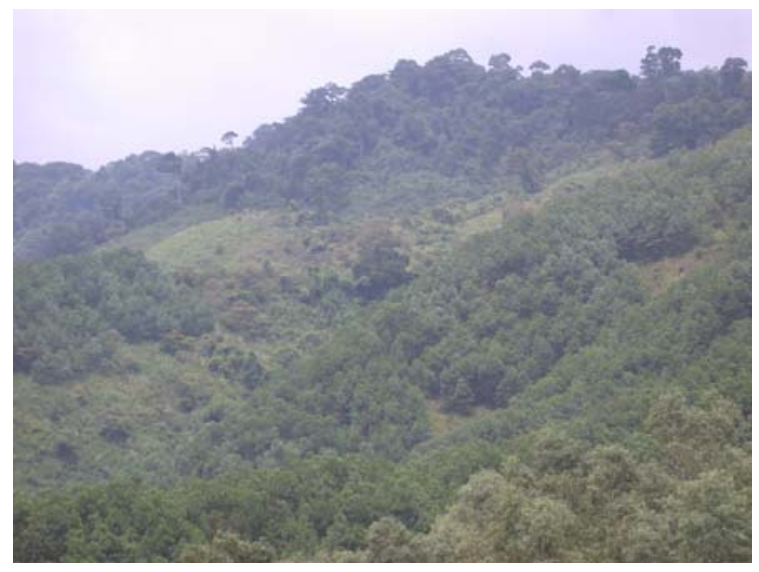

Plate 14: Secondary forest bordered Acacia mangium plantation, $250 \mathrm{~m}$ a.s.l., Aluoi district
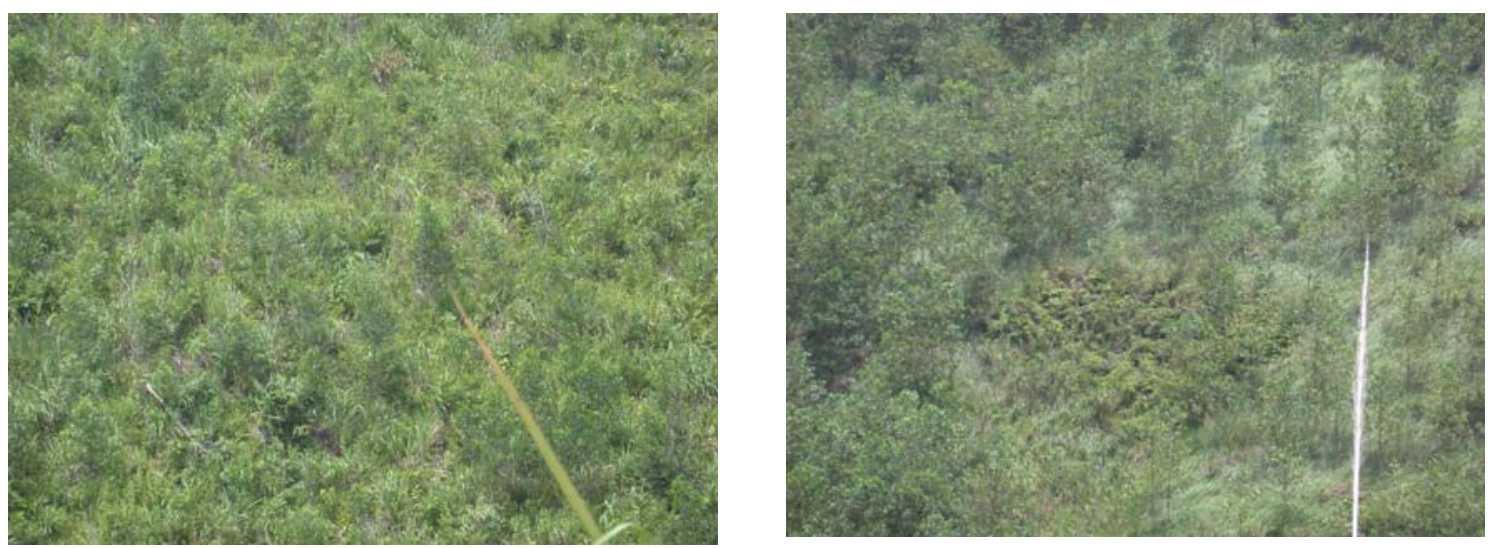

Plate 15: Two views of transition from grass land to short shrub
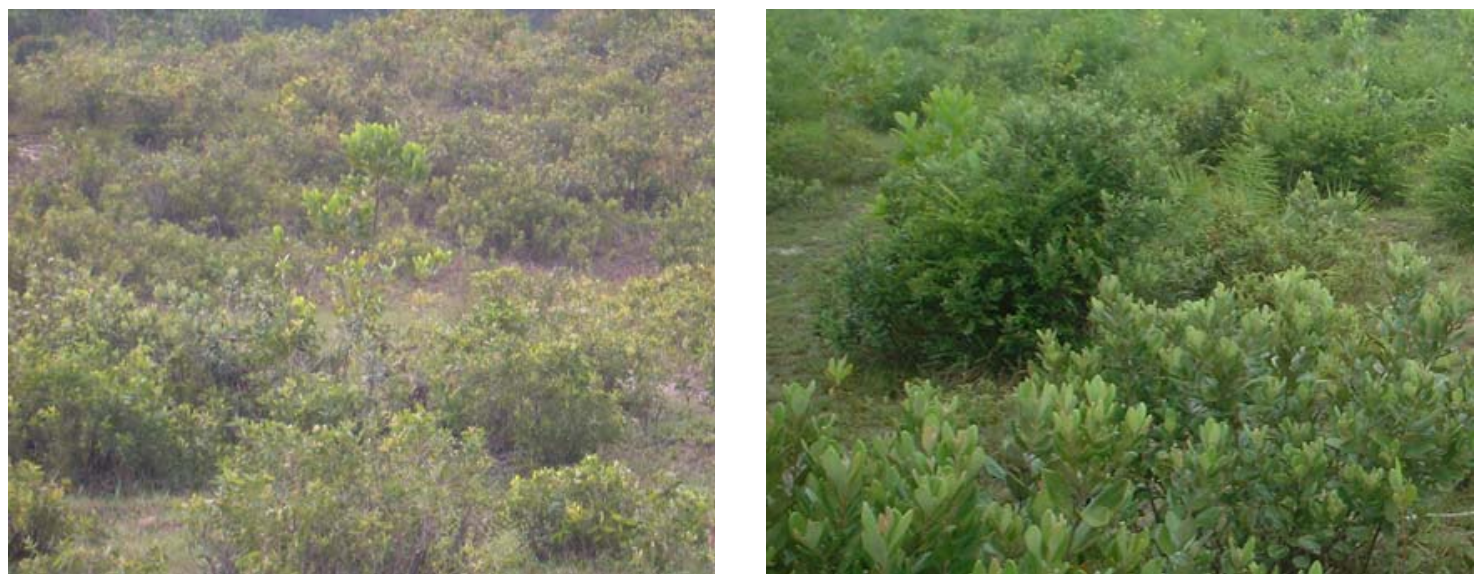

Plate 16: Two views of short shrub (Rhodomyrtus tomentosa and Melastoma spp.) 


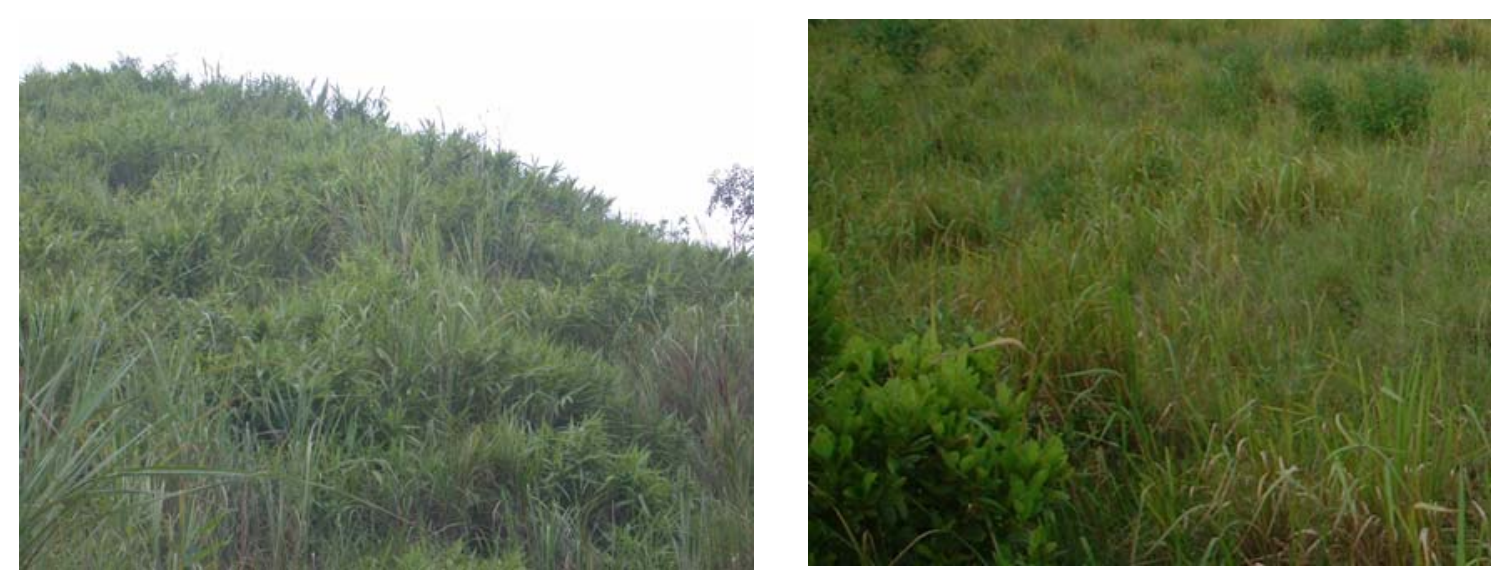

Plate 17: Two views of grass land (Sacch spontaneum and Imperata cylindrical)
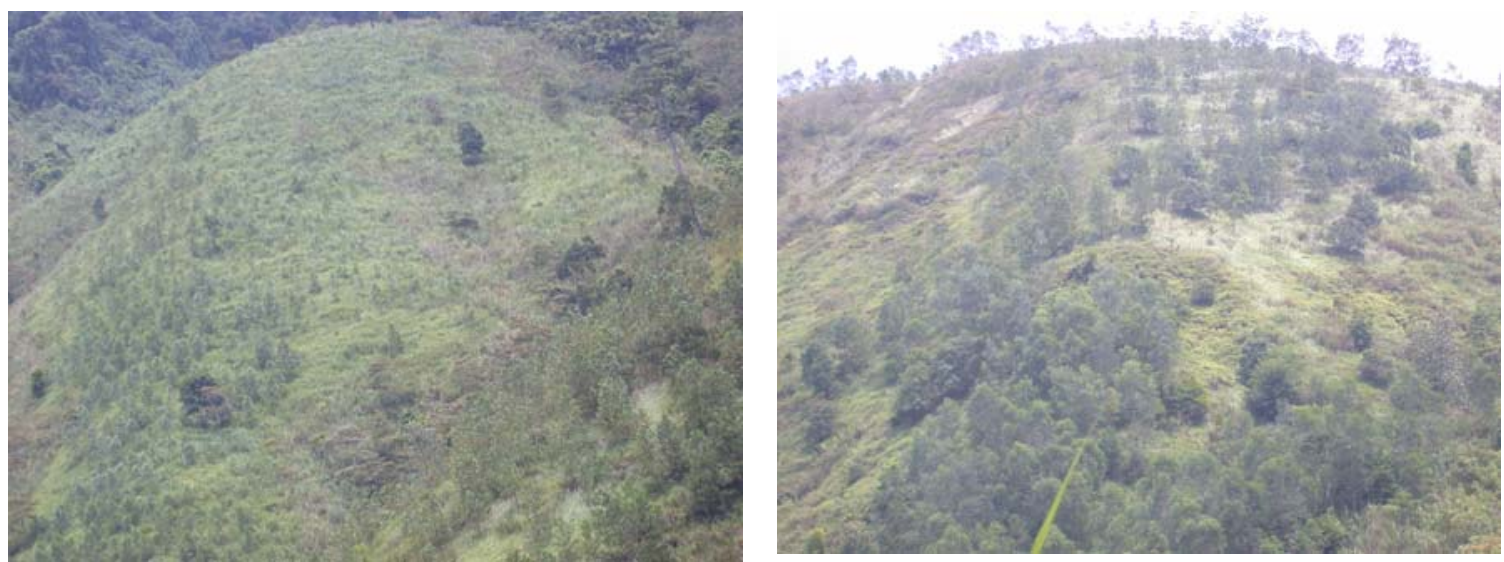

Plate 18: Two views of land cover mix of grass land and (sparse) Acacia auriculiformis plantation between 100 and $250 \mathrm{~m}$ a.s.l., Huongtra district

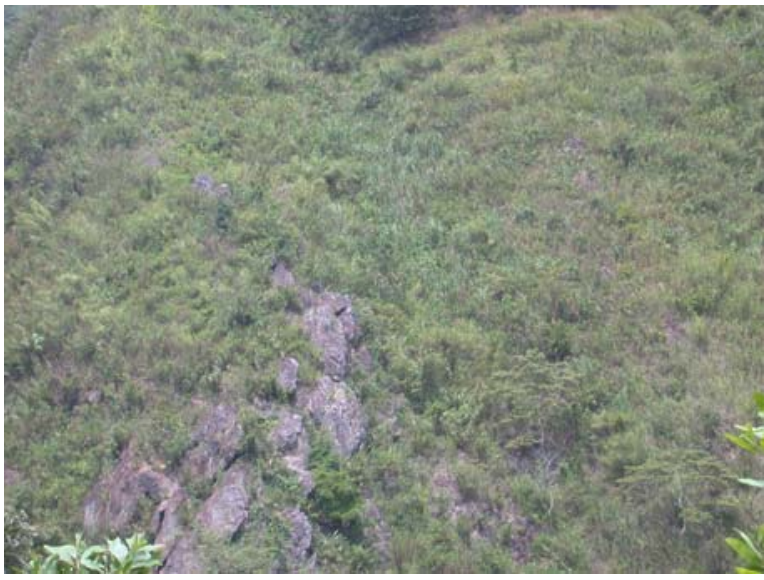

Plate 19: Rocky land with short shrub, Aluoi district

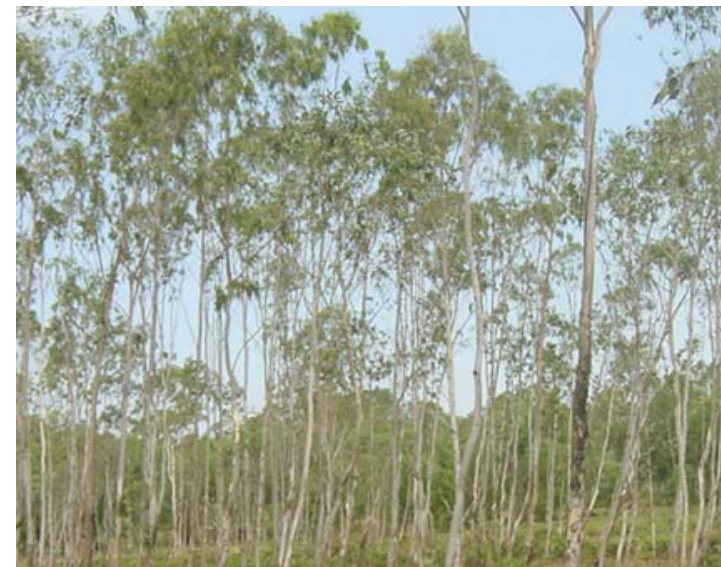

Plate 20: Eucalyptus camaldulensis plantation, Huongtra district 


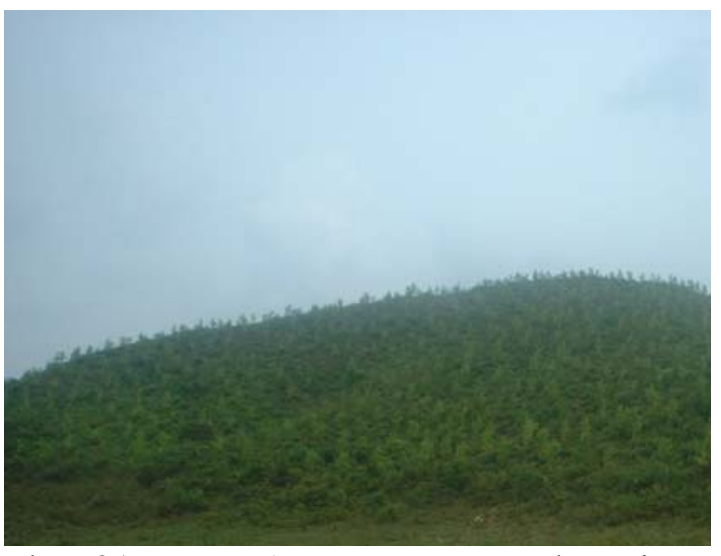

Plate 21:Young Acacia mangium plantation, Huongthuy district

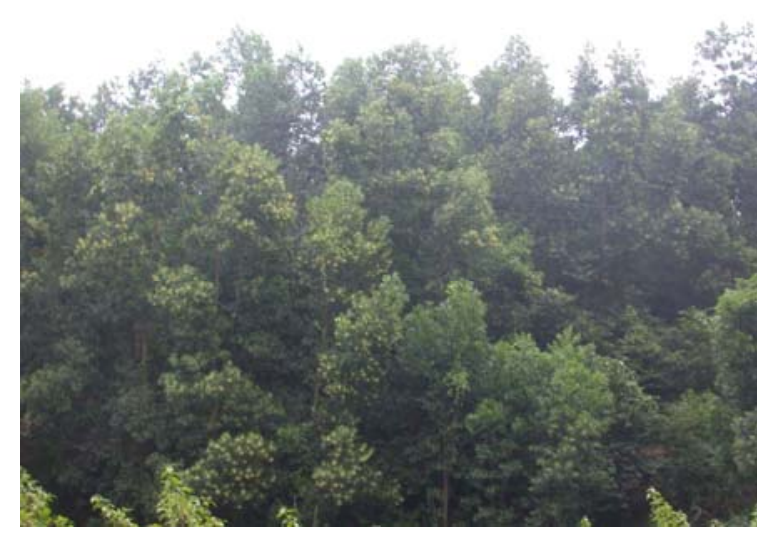

Plate 23: Acacia hybrid plantation, Huongthuy district

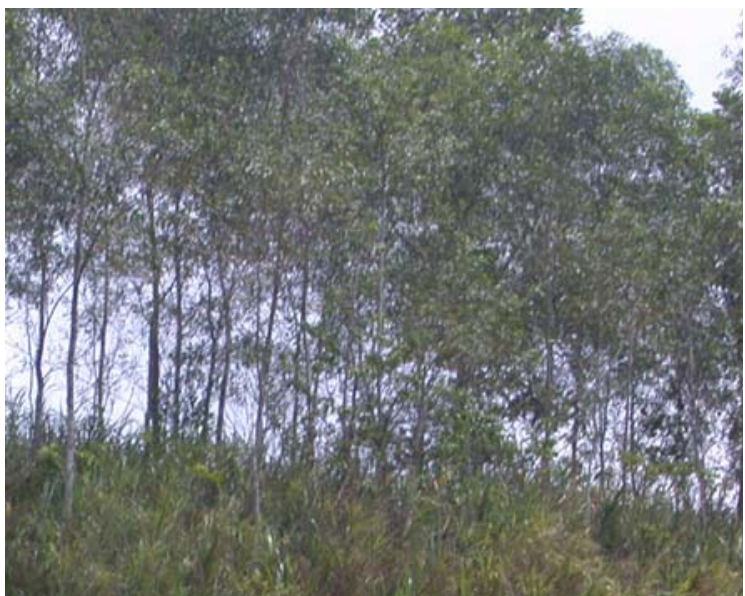

Plate 25: Acacia auriculiformis plantation, Aluoi district

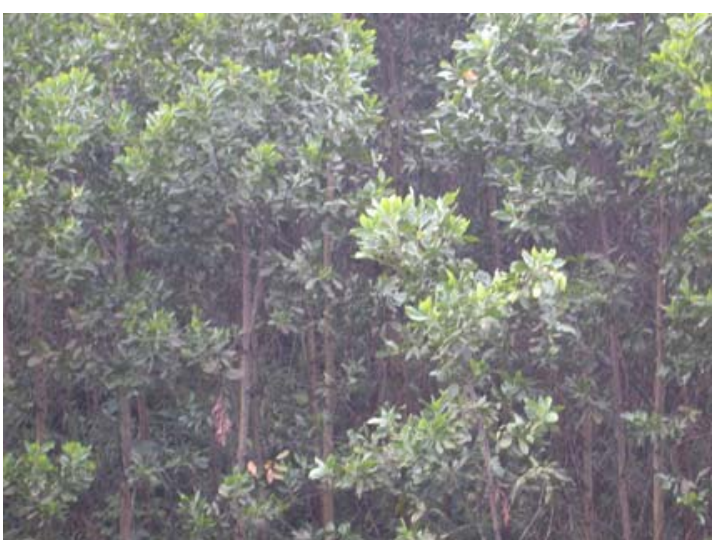

Plate 22: Acacia mangium plantation, Huongtra district

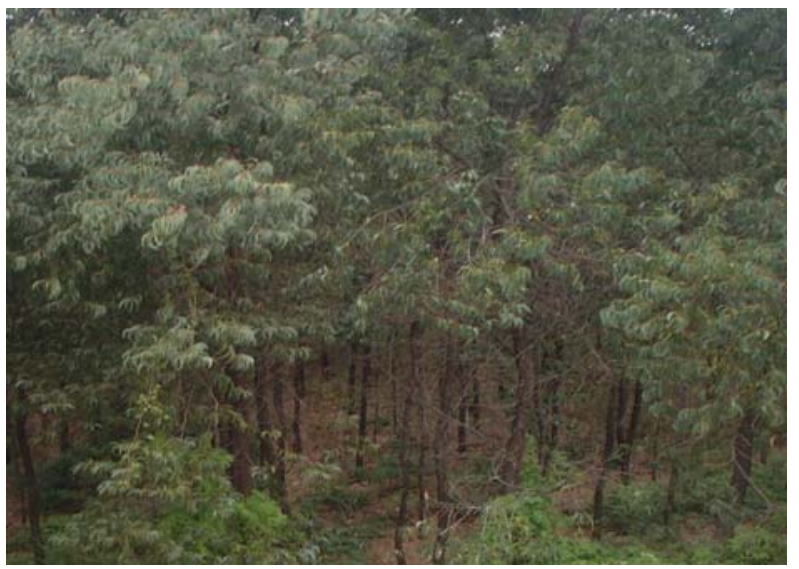

Plate 24: Acacia crassicarpa plantation, Huongtra district

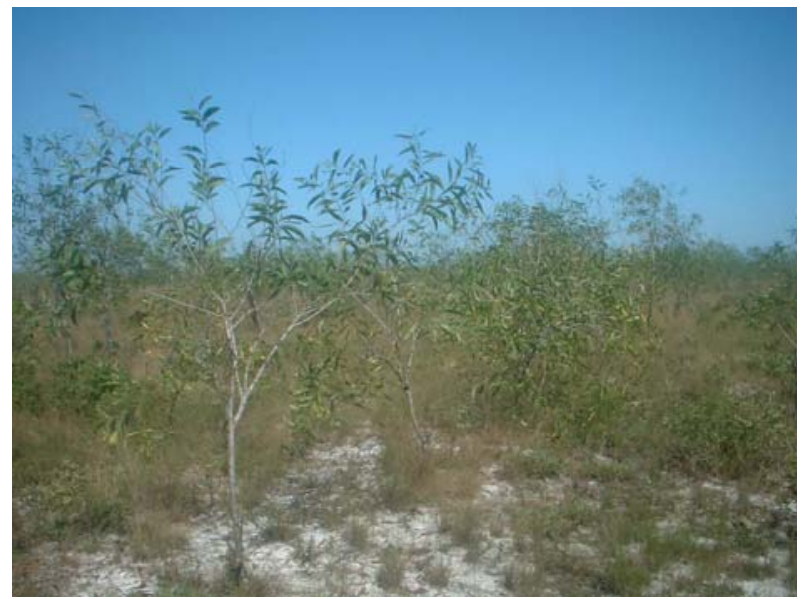

Plate 26: Acacia auriculiformis plantation grows in inland sandy soil, Quangdien district 


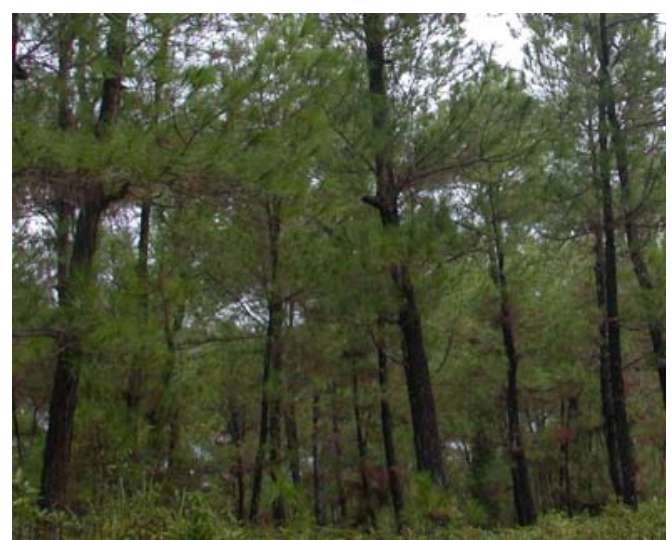

Plate 27: Pinus merkusii plantation, Phongdien district

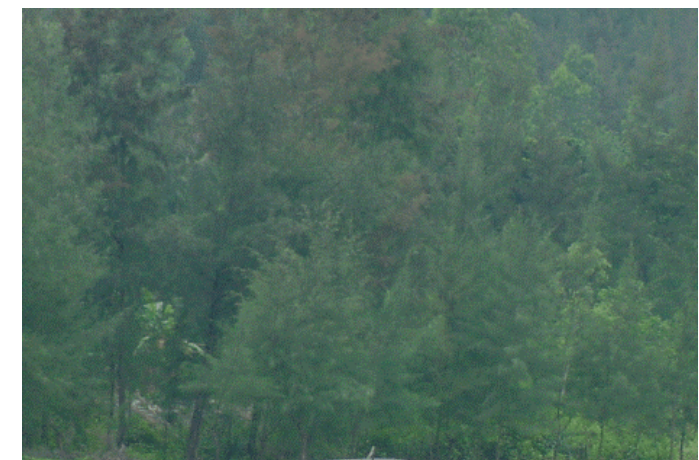

Plate 29: Casuarina equisetifolia plantation grows in coastal sandy soil, Phuvang district

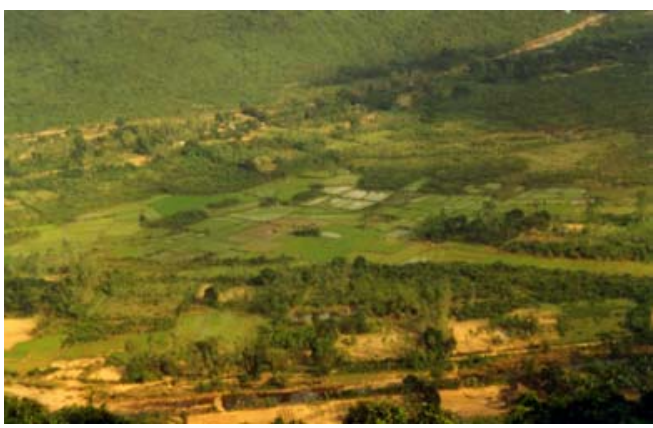

Plate 31: Wet rice field

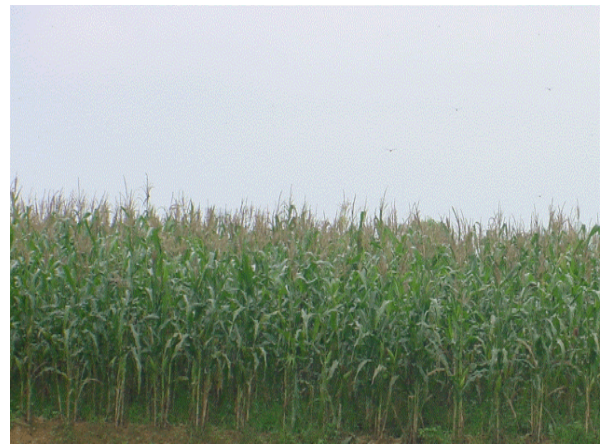

Plate 32: Maize field

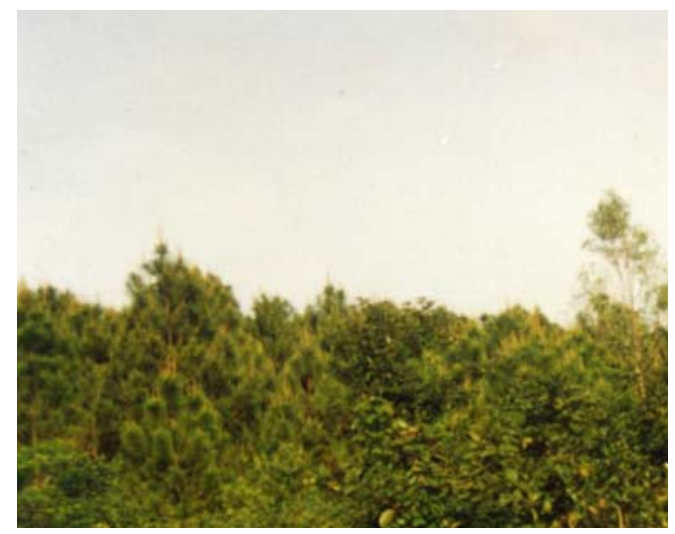

Plate 28: Pinus caribaea plantation, Phuloc district

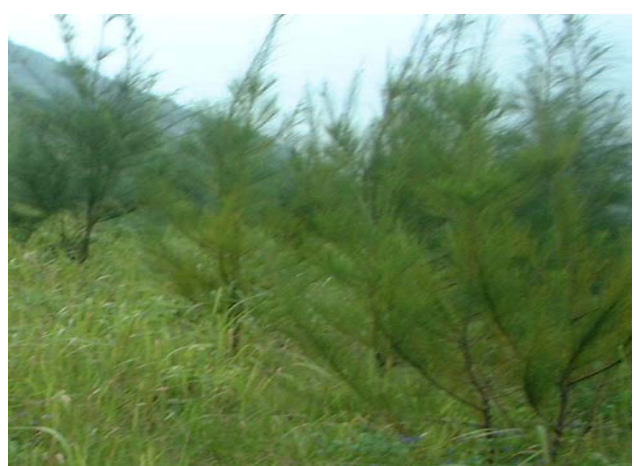

Plate 30: Young Casuarina equisetifolia plantation grows in low hills, Huongtra district
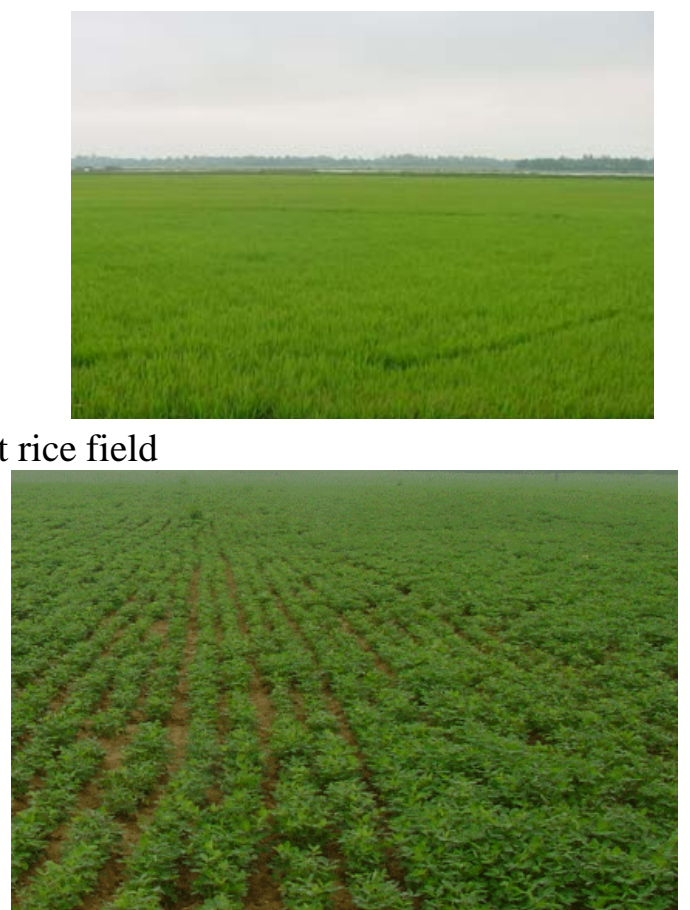

Plate 33: Peanut field 


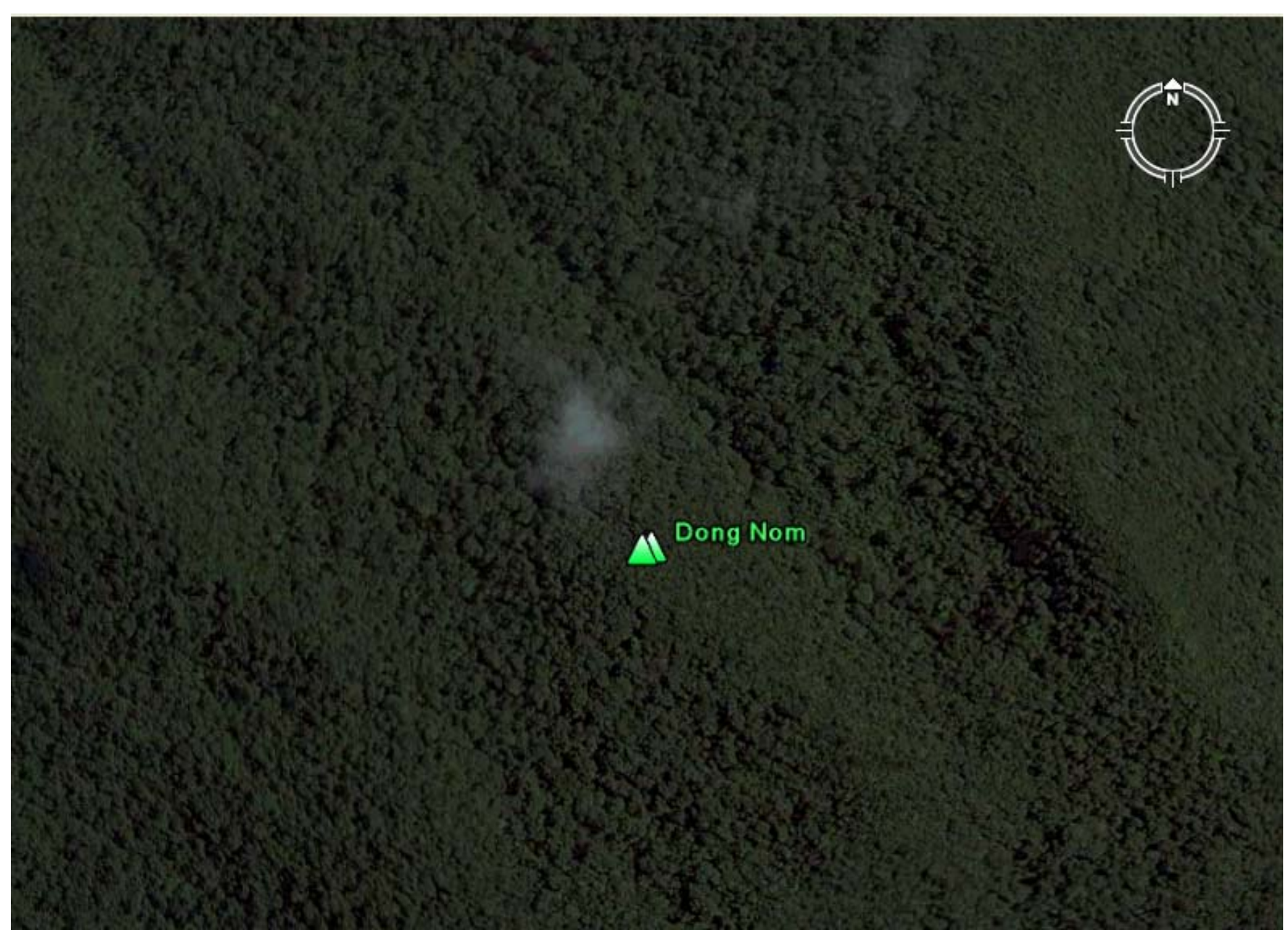

Plate 34: Google earth view of dense forest in forest surroundings, Nom cavern (Dong Nom), 1,186 m a.s.l, X= 797455, Y= 1791881, Namdong district 


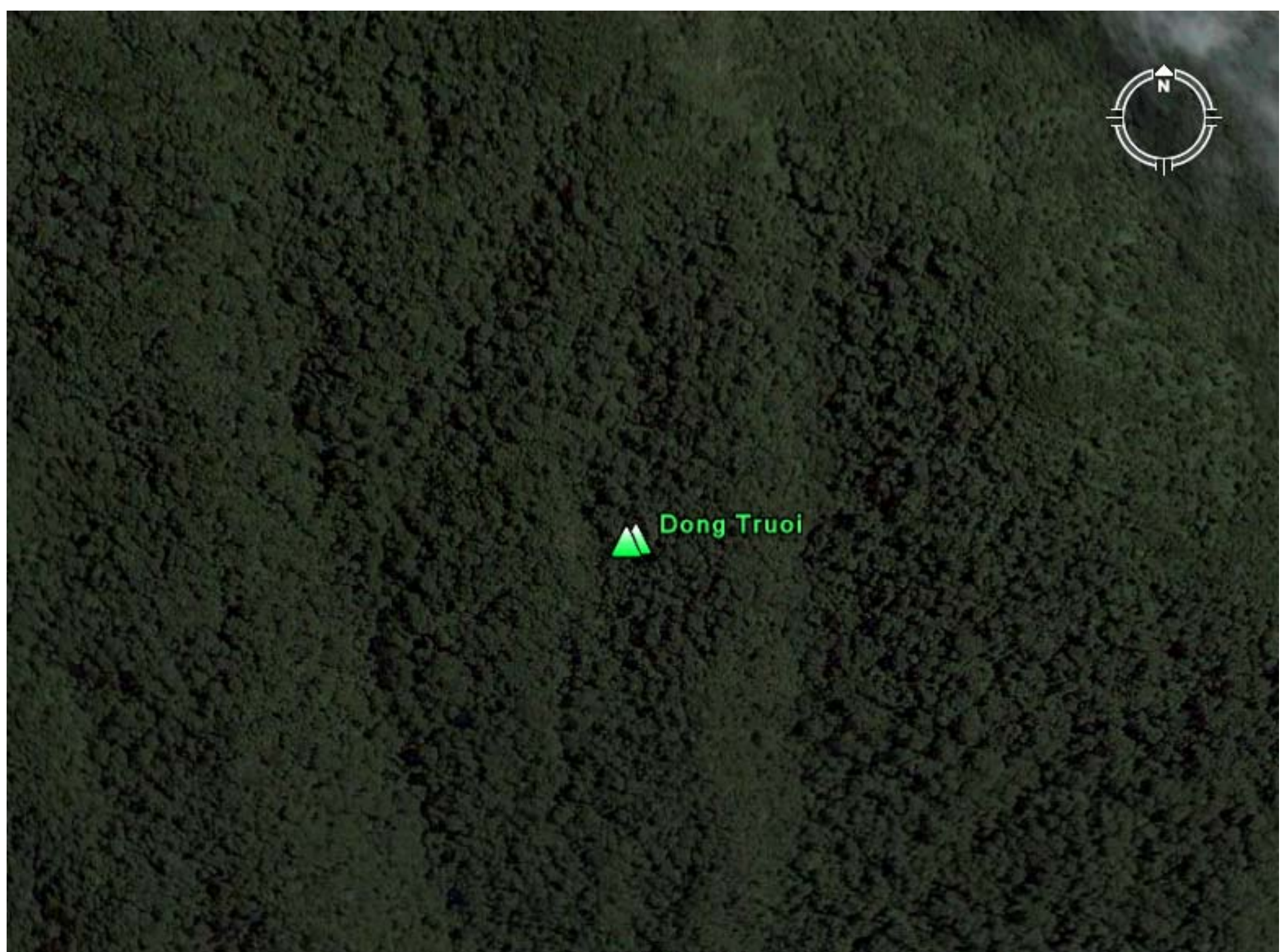

Plate 35: Google earth view of dense forest in forest surroundings, Truoi cavern (Dong truoi), 1,154 m a.s.l, X =792449, Y= 1797879, Phuloc district 


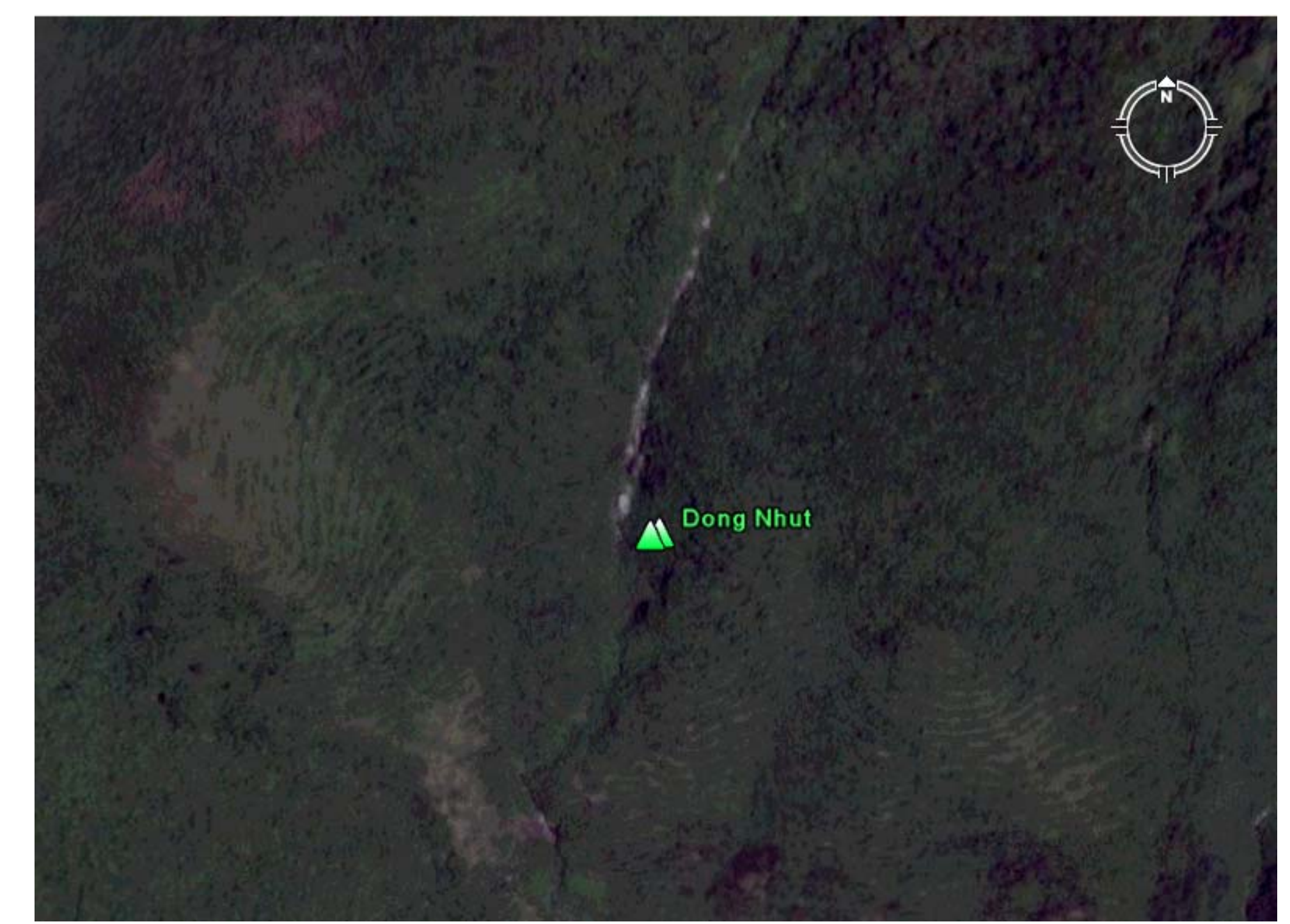

Plate 36: Google earth view of barren land and shrub in surroundings of Nhut cavern (Dong Nhut), $597 \mathrm{~m}$ a.s.l, $\mathrm{X}=814000$, Y= 1806000, Phuloc district 


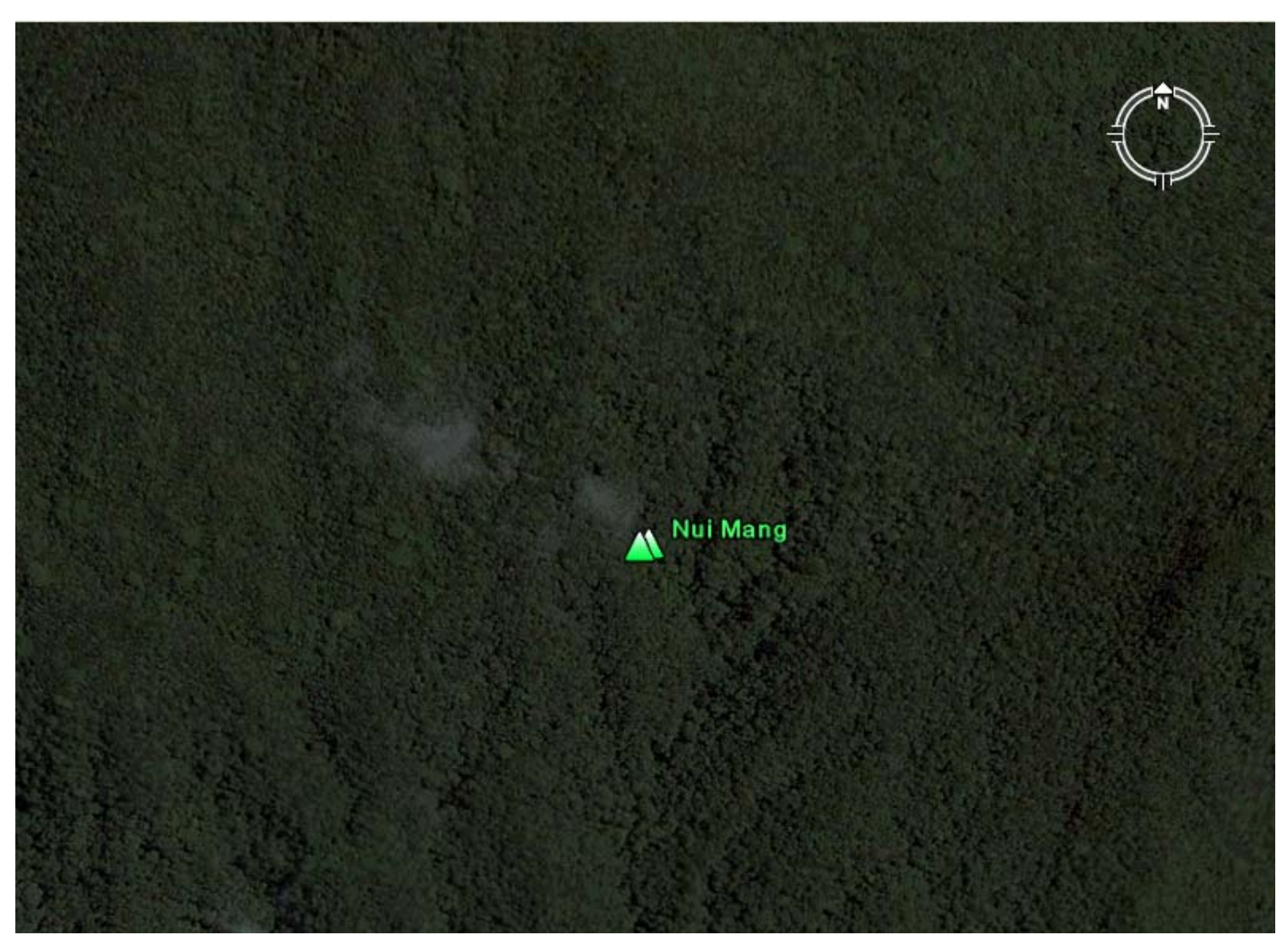

Plate 37: Google earth view of degraded forest in forest surroundings, Mang mount (Nui Mang), 1,712 m a.s.l., X= 801457, Y=1777704 Namdong district 


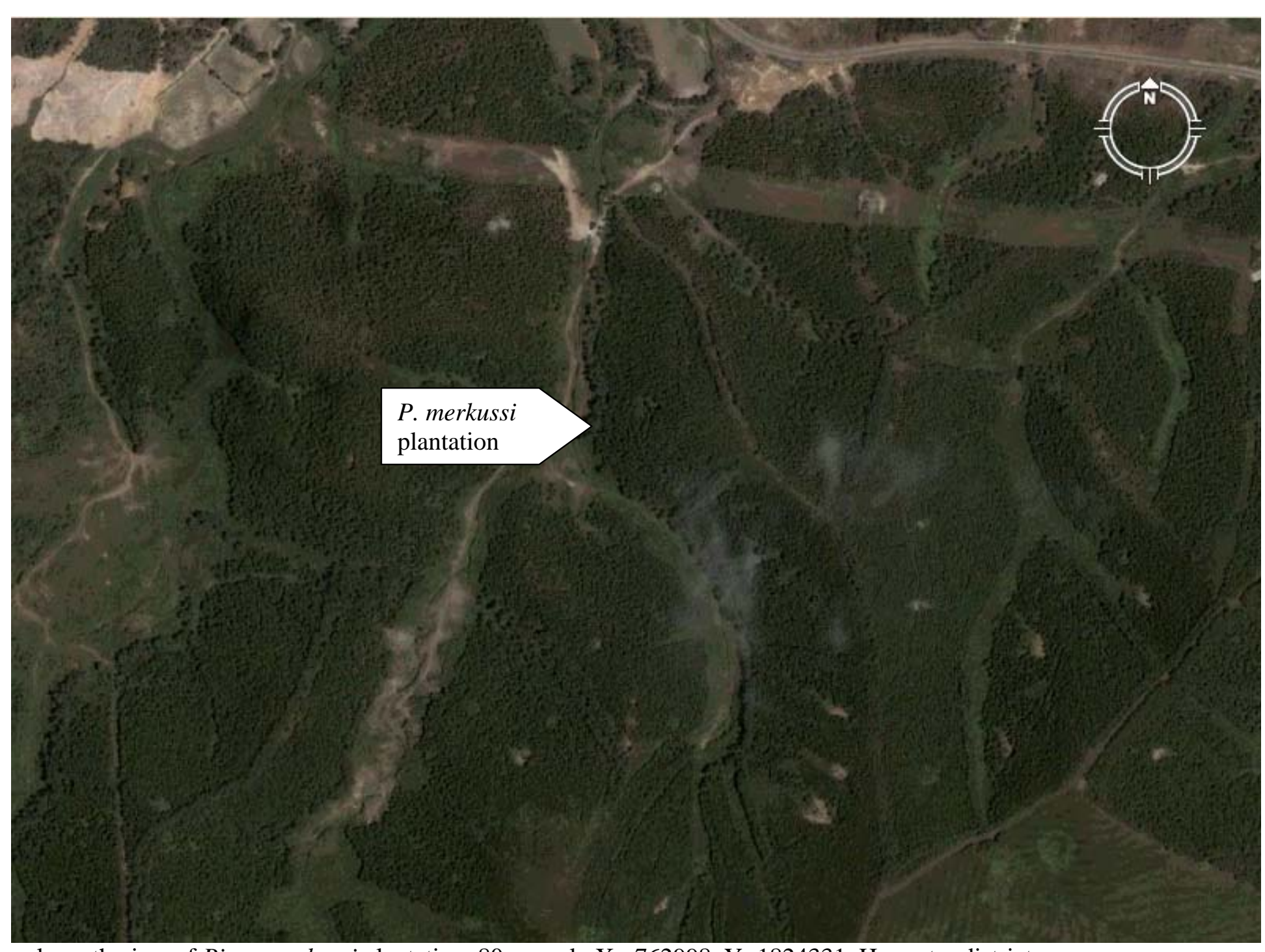

Plate 38: Google earth view of Pinus merkussi plantation, 80 m a.s.l., $X=762998, Y=1824331$, Huongtra district 


\section{Appendix 2: Thematic maps}

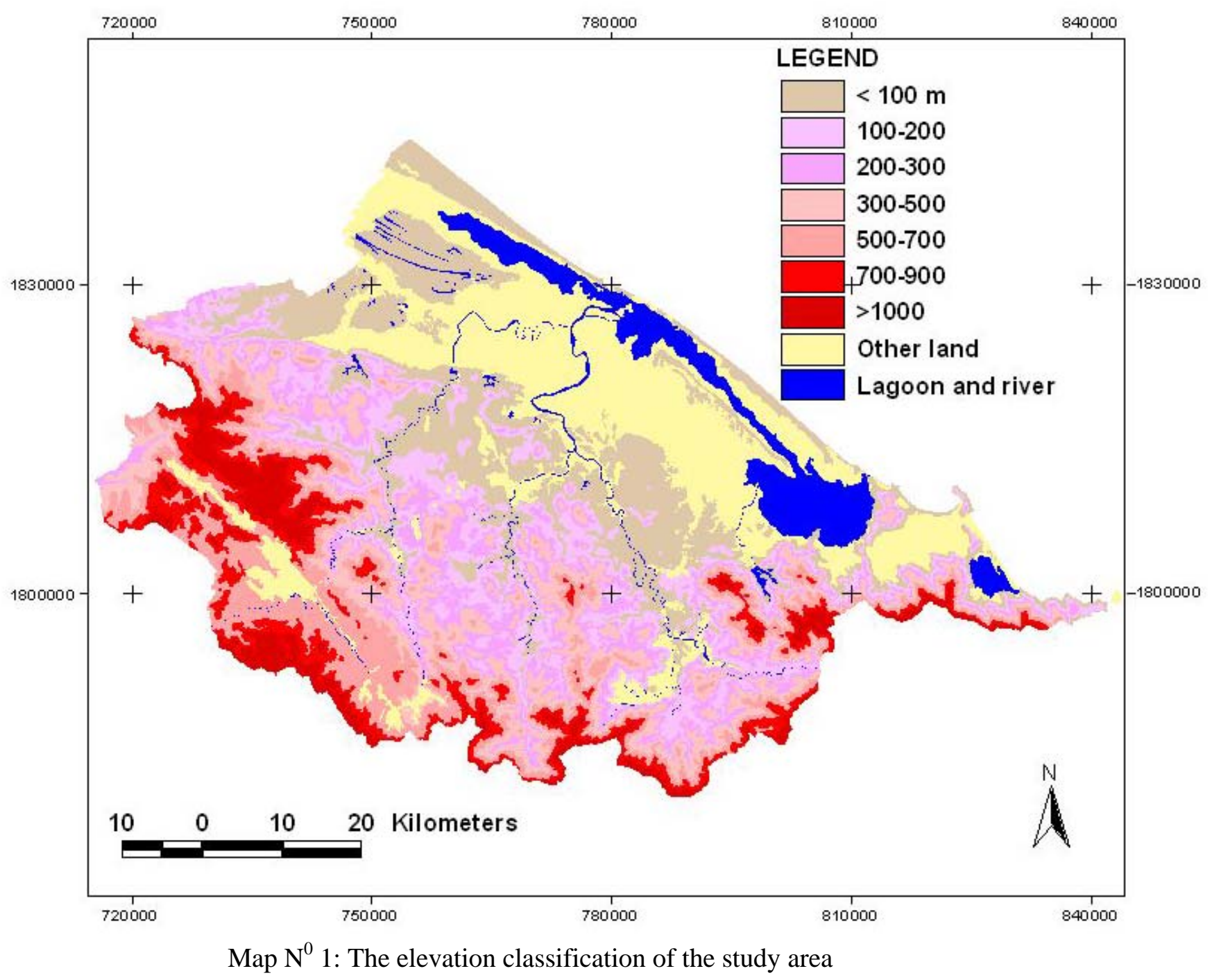




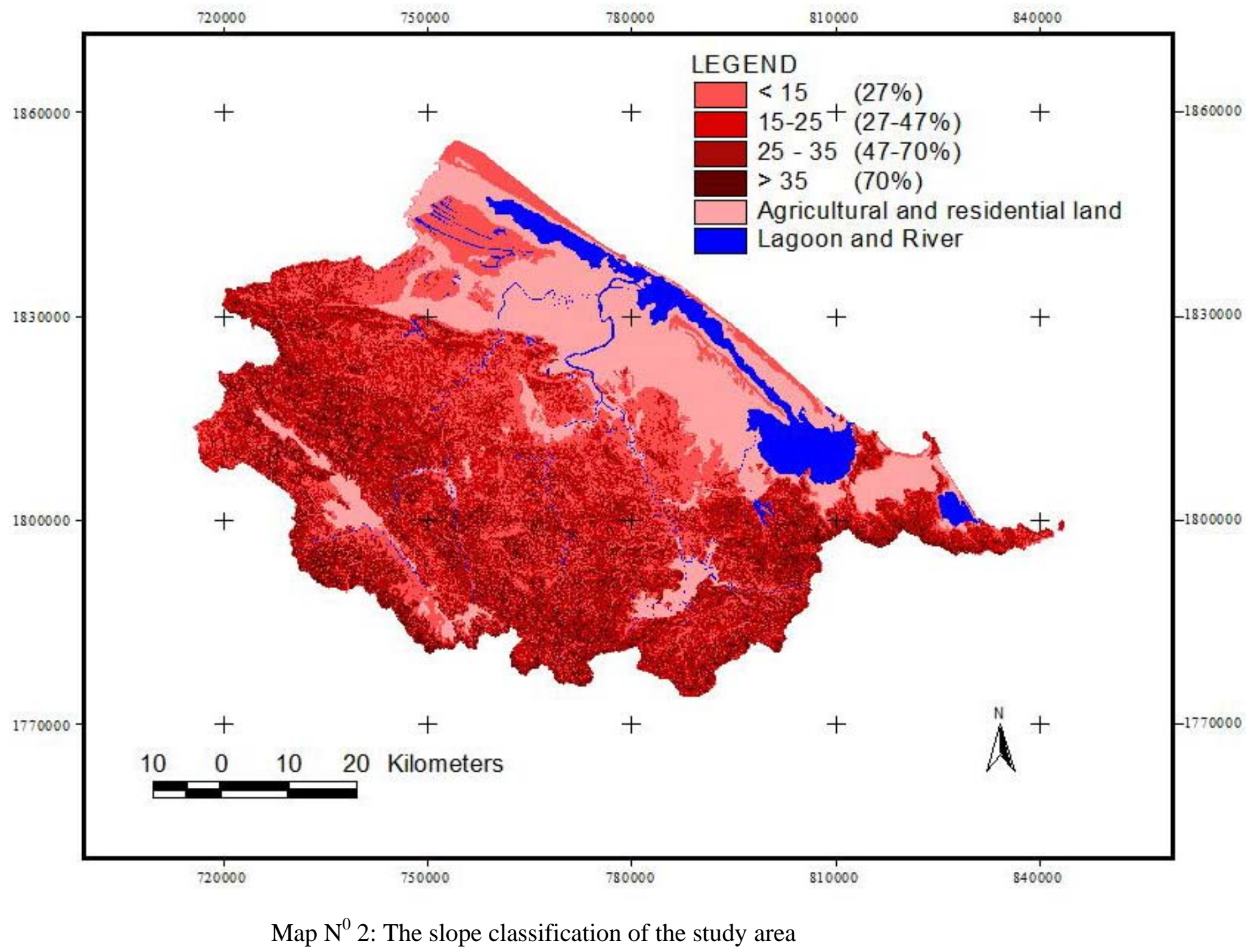




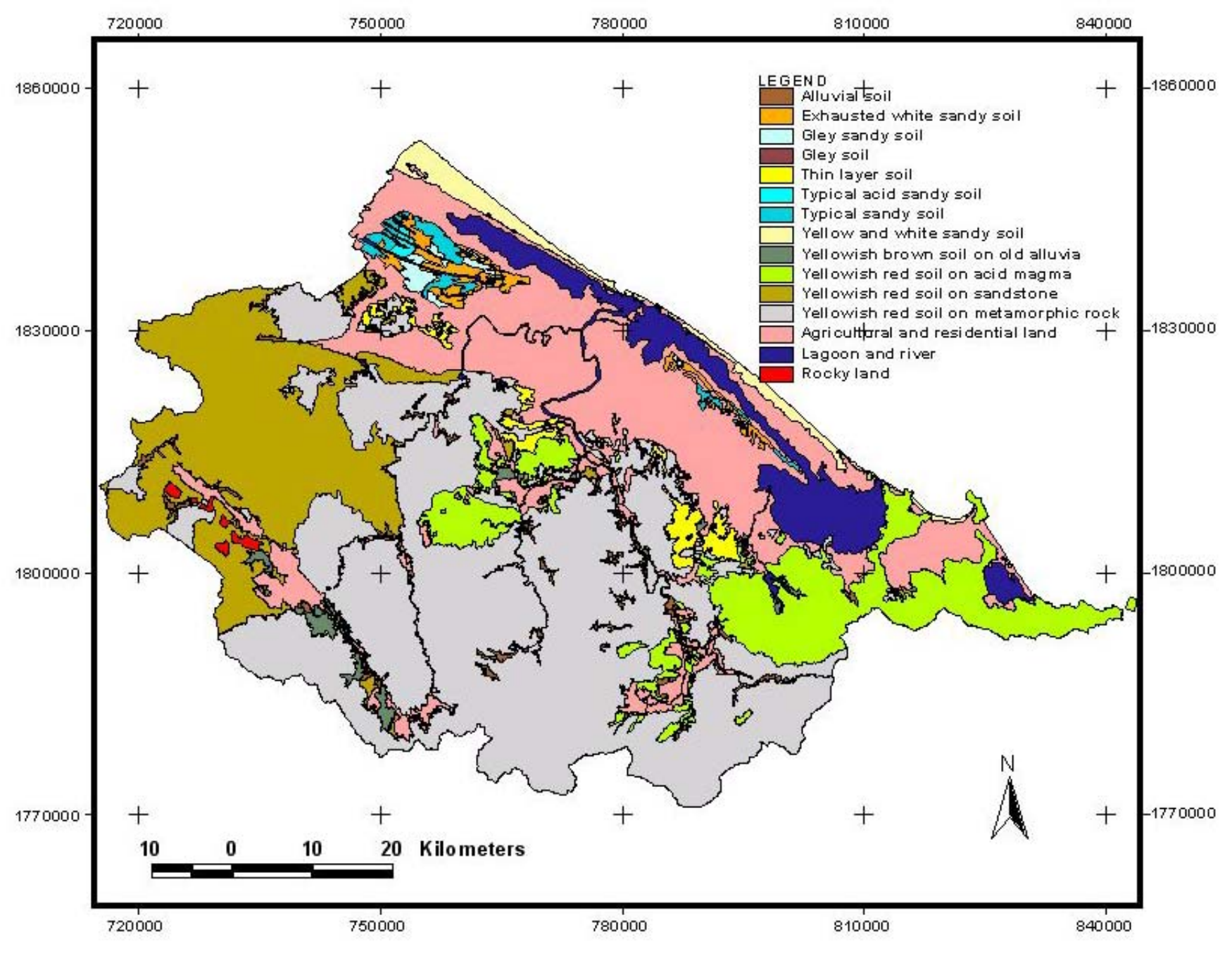

Map $\mathrm{N}^{0}$ 3: The different soil types of the study area 


\section{Appendix 3}

Pair-wise comparison matrix of all parameters over complete hierarchy

\begin{tabular}{|l|c|c|c|c|}
\hline Forest tree crops & Soil & Climate & Topography & Weight \\
\hline Soil & 1 & 3 & 3 & 0.600 \\
\hline Climate & $1 / 3$ & 1 & 2 & 0.200 \\
\hline Topography & $1 / 3$ & $1 / 2$ & 1 & 0.200 \\
\hline
\end{tabular}

a. Soil property parameter

\begin{tabular}{|l|c|c|c|c|}
\hline \multicolumn{1}{|c|}{ Soil types } & Soil types & Physical & Chemical & Weight \\
\hline Soil types & 1 & 2 & 3 & 0.546 \\
\hline Physical & $1 / 2$ & 1 & $4 / 3$ & 0.263 \\
\hline Chemical & $1 / 3$ & $3 / 4$ & 1 & 0.191 \\
\hline
\end{tabular}

\begin{tabular}{|l|c|c|c|}
\hline \multicolumn{1}{|c|}{ Physical } & Soil depth & Soil texture & Weight \\
\hline Soil depth & 1 & 2 & 0.667 \\
\hline Soil texture & $1 / 2$ & 1 & 0.333 \\
\hline
\end{tabular}

\begin{tabular}{|l|c|c|c|c|}
\hline \multicolumn{1}{|c|}{ Chemical } & pH soil & Soil fertility & Organic matter & Weight \\
\hline pH soil & 1 & $1 / 4$ & 3 & 0.218 \\
\hline Soil fertility & 4 & 1 & 6 & 0.691 \\
\hline Organic matter & $1 / 3$ & $1 / 6$ & 1 & 0.091 \\
\hline
\end{tabular}

b. Topographic parameter

\begin{tabular}{|l|c|c|c|}
\hline \multicolumn{1}{|c|}{ Topographic } & Slope & Elevation & Weight \\
\hline Slope & 1 & 2 & 0.667 \\
\hline Elevation & $1 / 2$ & 1 & 0.333 \\
\hline
\end{tabular}

c. Climatic parameter

\begin{tabular}{|l|c|c|c|}
\hline \multicolumn{1}{|c|}{ Climatic } & Rainfall & Temperature & Weight \\
\hline Rainfall & 1 & 2 & 0.667 \\
\hline Temperature & $1 / 2$ & 1 & 0.333 \\
\hline
\end{tabular}

d. Overall weights of parameters in land suitability assessment for forest tree species

\begin{tabular}{|c|c|c|c|c|c|c|}
\hline \multicolumn{6}{|c|}{ Parameter } & \multirow{2}{*}{$\begin{array}{l}\text { Overall weight } \\
\text { Wi =W1 X W2 X } \\
\text { W 3) }\end{array}$} \\
\hline Level 1 & W1 & Level 2 & $\mathrm{~W} 2$ & Level 3 & W3 & \\
\hline \multirow[t]{6}{*}{ Soil property } & \multirow{6}{*}{0.6} & Soil types & 0.546 & $\begin{array}{l}\text { Different soil } \\
\text { types }\end{array}$ & - & 0.328 \\
\hline & & \multirow[t]{2}{*}{ Physical } & \multirow[t]{2}{*}{0.263} & Soil depth & 0.667 & 0.105 \\
\hline & & & & Soil texture & 0.333 & 0.053 \\
\hline & & \multirow{3}{*}{ Chemical } & \multirow[b]{3}{*}{0.191} & pH soil & 0.218 & 0.025 \\
\hline & & & & Soil fertility & 0.691 & 0.079 \\
\hline & & & & Organic matter & 0.091 & 0.010 \\
\hline \multirow[t]{2}{*}{ Topography } & \multirow[t]{2}{*}{0.2} & - & - & Slope & 0.667 & 0.133 \\
\hline & & - & - & Elevation & 0.333 & 0.067 \\
\hline Climate & 0.2 & - & - & Rainfall & 0.667 & 0.133 \\
\hline
\end{tabular}


Name: $\quad$ Nguyen Van Loi

Date of birth: July 13, 1966

Place of birth: Namdinh province, Vietnam

Nationality: Vietnamese

Marital status: Married

Email: $\quad$ loanloi2003@yahoo.com/lnguyen@uni-goettigen.de

\section{Academic qualification:}

1983 -1988 Study of forestry in Vietnam forestry college (BSc.)

1998-2000 Study of Remote sensing and GIS in Asian Institute of Technology (AIT,Thailand), Master thesis: GIS modelling in evaluation of the Bachma national park zone system in central Vietnam

2005-2008 PhD student in Cartography, GIS \& Remote Sensing Sect. Institute of Geography, Georg-August University, Göttingen, Germany

\section{Short course attended:}

9/1995 Trainee, project monitoring and evaluation in Los Banos, Philippnes

10/2/2003 Trainee, agricultural extension and rural development in Chiangmai, Thailand

8/1996 Trainee, PRA and rural development in Hue University of Agriculture and Forestry, Vietnam

2001 Trainee, community development and sub-project planning based on community in Hue University of Agriculture and Forestry, Vietnam

5/2001 Trainee, community development and management in HEVELTAS, Hanoi, Vietnam

\section{Employment experience:}

1988 - now Lecturer and researcher of forestry faculty of Hue University of Agriculture and Forestry, Vietnam

1996-2003 Consultant for CRD (Centre for Rural Development) in central Vietnam, technical assistance for rural development project, training job for project cadres, project development and capacity building 